\author{
UNIVERSIDADE DE SÃO PAULO \\ ESCOLA DE ENGENHARIA DE SÃO CARLOS \\ INSTITUTO DE FÍSICA DE SÃO CARLOS \\ INSTITUTO DE QUÍMICA DE SÃO CARLOS
}

\title{
Estudo das propriedades eletrônicas e ópticas de filmes e dispositivos poliméricos
}

\section{RODRIGO FERNANDO BIANCHI}

Tese apresentada à Área de Interunidades em Ciências e Engenharia de Materiais, da Universidade de São Paulo, como parte dos requisitos para a obtenção do Título de Doutor em Ciência e Engenharia de Materiais.

Orientador: Prof. Dr. ROBERTO MENDONÇA FARIA

\section{São Carlos}

2002 
Bianchi, Rodrigo Fernando

B577e Estudo das propriedades eletrônicas e ópticas de filmes e dispositivos poliméricos / Rodrigo F. Bianchi. - São Carlos, 2002.

Tese (Doutorado) -- Escola de Engenharia de São Carlos/Instituto de Física de São Carlos/Instituto de Química de São Carlos - Universidade de São Paulo, 2002

Área: Ciência e Engenharia de Materiais. 
Dedico essa tese à minha esposa Andrea e aos meus pais Luiz e Marylanda pelo apoio e compreensão em todos os momentos desse trabalho. 


\section{AGRADECIMENTOS}

Com certeza, esse trabalho não teria sido o mesmo sem o apoio da Fapesp e de algumas pessoas que tornaram esses últimos 4 anos menos difíceis. Gostaria de agradecer:

- Ao Prof. Roberto M. Faria pela orientação e confiança que depositou no meu trabalho. Em 1997, ano de início desse projeto, o tema proposto era um desafio científico e tecnológico. Hoje, 4 anos depois, vejo que conseguimos, pelo menos, avançar o primeiro degrau. Gostaria também de expressar meus agradecimentos a minha co-orientadora não oficial Dra. Débora T. Balogh que, juntamente com o Prof. Faria, teve um papel importantíssimo no desenvolvimento de todas as etapas desse trabalho. A esses dois profissionais meus sinceros agradecimentos.

- Aos Profs. Roberto K. Onmori, Haroldo N. Nagashima e a Profa. Débora Gonçalves pelas valiosas discussões científicas que muito contribuíram à minha formação profissional.

- Aos Profs. Carlos Graeff, Guilherme Ferreira, Tito Bonagamba e Francisco Guimarães pelas valiosas colaborações dadas a esse trabalho, sejam pelas discussões nos corredores do IFSC ou da FFCLRP, ou seja no acompanhamento do desenvolvimento dos modelos teóricos aqui apresentados.

- Ao Prof. Eugene A. Irene e aos colegas do Department of Chemistry, Chapel Hill - USA, pelo excelente ambiente de trabalho e pela oportunidade de utilização e aprendizagem da técnica de elipsometria.

- Aos amigos do Grupo de Polímeros: Carla, Célio, Clarissa, Cristina, Dante, David, Josmary, Karen, Letícia, Luciana, Luis, Marcelo, Maristela, Nara, Sarita, Silmar Valtencir (Xuxa), e Walterlei pelo excelente ambiente de trabalho. Em especial, meus agradecimentos à Flávia, ao Thiago, ao Marletta e ao Lucas pelas inúmeras discussões que fortaleceram a minha formação profissional.

- Aos professores do Grupo de Polímeros: Giacometti, Osvaldo (Chú) e Mariângela pelas inúmeras e valiosas discussões.

- Aos amigos do Laboratório de Microeletrônica da POLI: Rita, Cristina, Marcos, Ely, Carlos e Prof. Adnei pelo apoio e pela infraestrutura necessária para a confecção dos transistores poliméricos.

- Aos amigos Bertho, Níbio, Ademir e Rosângela pelo apoio técnico e pelo ótimo convívio no grupo.

- As famílias Bianchi, Baeta, Campos, Moreira e Santos; a minha esposa Andrea e aos meus pais Luiz e Marylanda pela compreensão, carinho e amor oferecidos.

- A FAPESP pelo apoio financeiro (processo número 97/06083-0). 


\section{Índice}

ÍNDICE

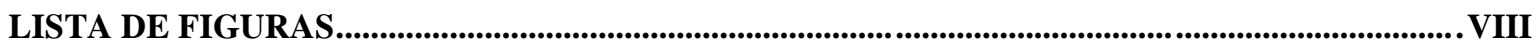

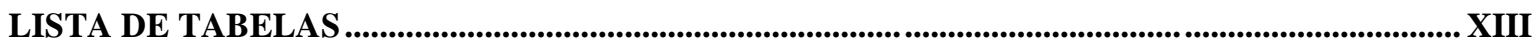

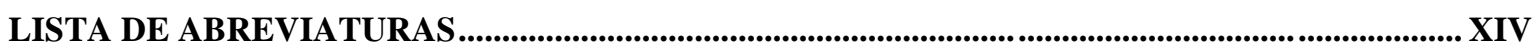

LISTA DE SÍMBOLOS …………..............................................................................................................XV

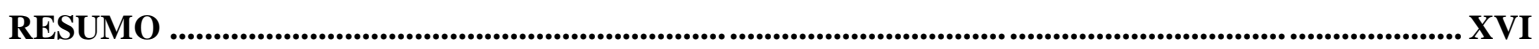

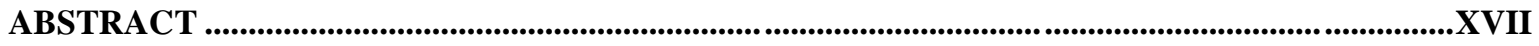

INTRODUÇÃ

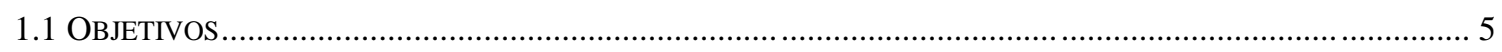

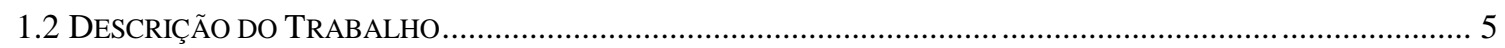

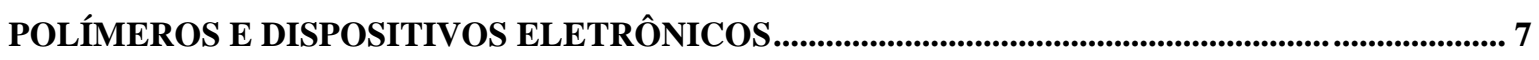

2.1 Propriedades EletrôNICAS dos Polímeros ConJugados. ……............................................................ 7

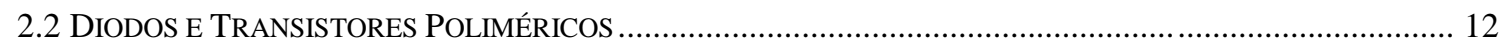

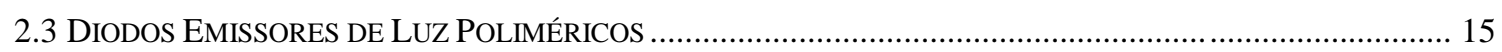

SÍNTESE DOS POLÍMEROS, MÉTODOS DE PREPARAÇÃO DE FILMES E PREPARAÇÃO E

CARACTERIZAÇÃO DE SUBSTRATOS ..............................................................................18

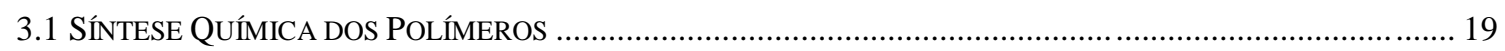

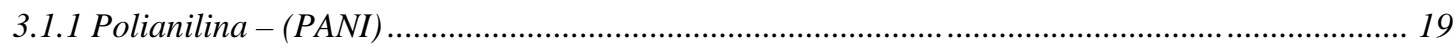

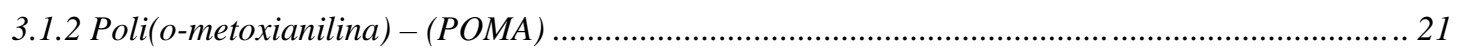

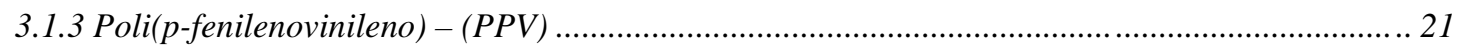

3.1.4 Poli[(2-metóxi-5-hexilóxi)-p-fenilenovinileno] - (MH-PPV) ................................................... 23

3.1.5 Poli[(2-metóxi-5-dodecóxi)-p-fenilenovinileno] - (MD-PPV).................................................. 25

3.1.6 Resultados das sinteses ...................................................................................................... 25

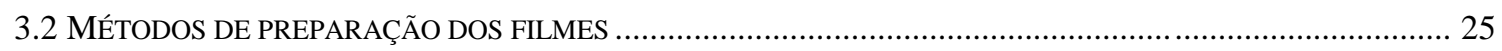

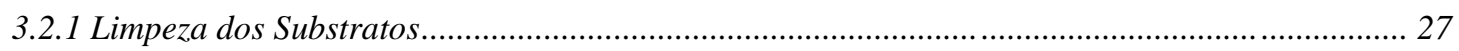

3.2.2 Procedimentos para a obtenção dos filmes poliméricos............................................................. 28

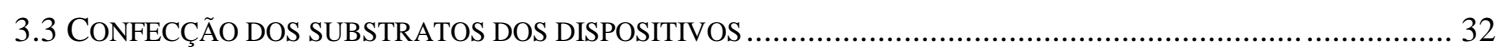

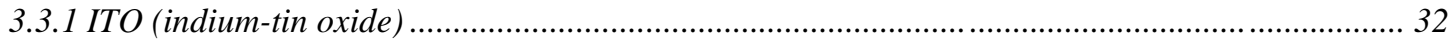




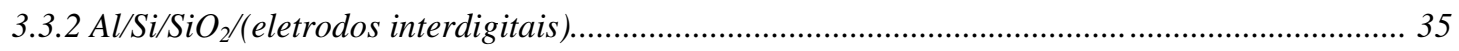

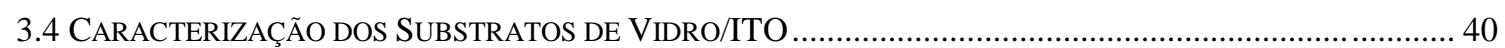

3.4.1 Caracterização dos eletrodos de alumínio.................................................................................. 45

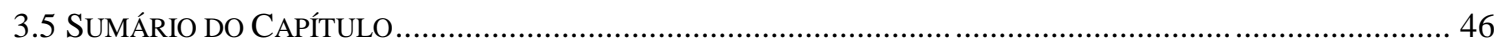

EQUIPAMENTOS E MÉTODOS DE MEDIDAS ........................................................................................ 47

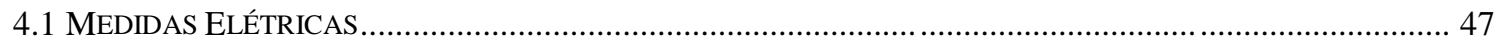

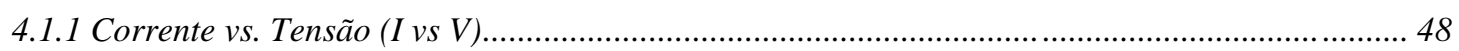

4.1.2 Condutividade em campo alternado (ac) ………………........................................................ 48

4.1.3 Controle da temperatura e da umidade ................................................................................ 49

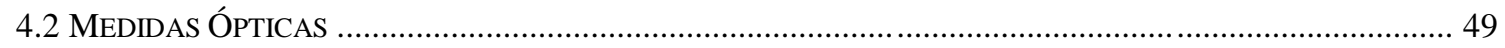

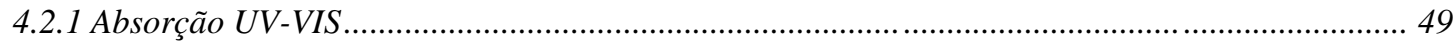

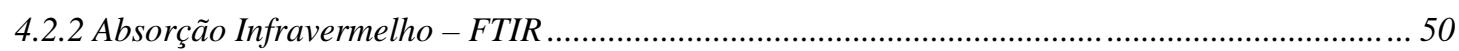

4.2.3 Fotoluminescência e Eletroluminescência ………………………………………………........ 50

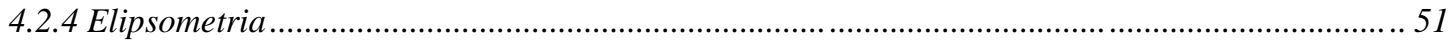

CARACTERIZAÇÕES ÓPTICAS E ELÉTRICAS DOS FILMES POLIMÉRICOS ............................... 53

5.1 CARACTERIZAÇÕES ÓPTICAS DOS FILMES DE PPV, MH-PPV E MD-PPV ............................................. 53

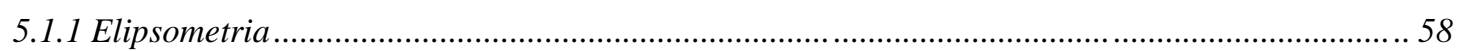

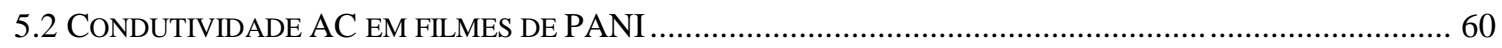

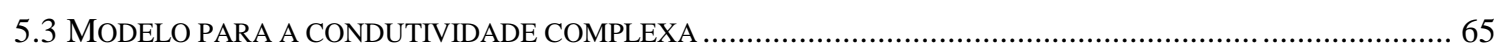

5.3.1 Modelo de Barreiras de Energias Livres Aleatórias - RFEB........................................................ 66

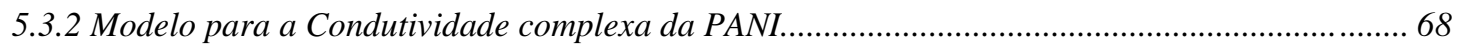

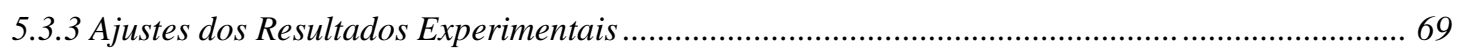

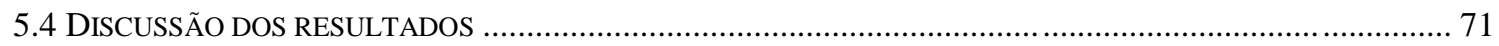

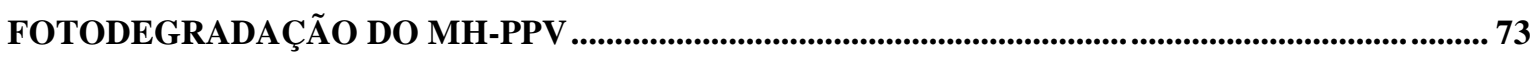

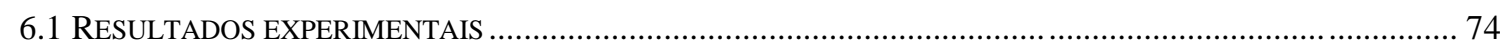

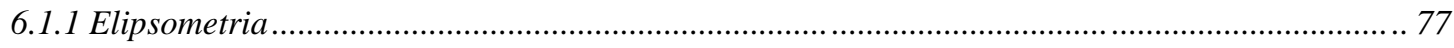

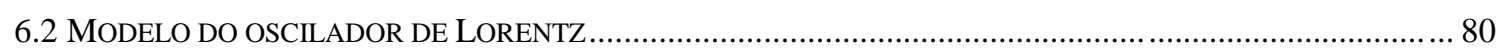

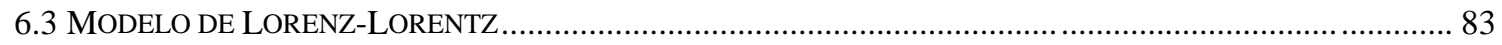

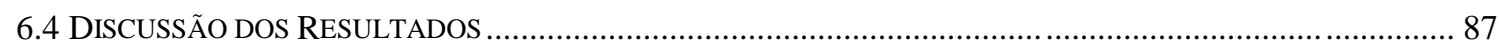

DIODOS ELETROLUMINESCENTES POLIMÉRICOS................................................................... 88

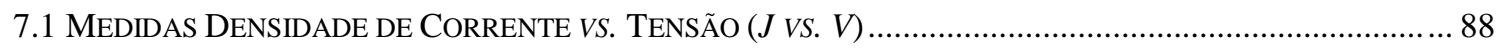

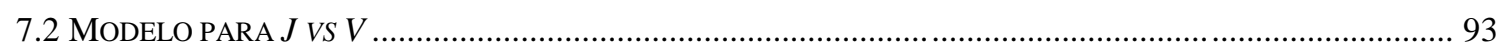

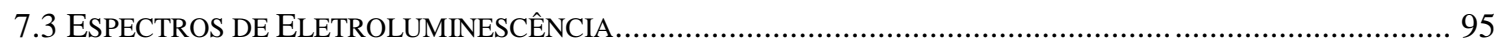

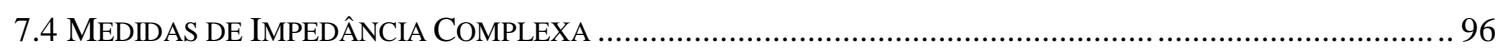

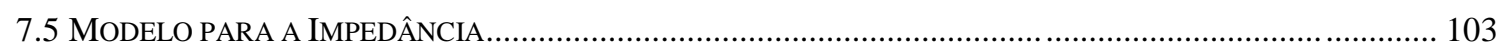

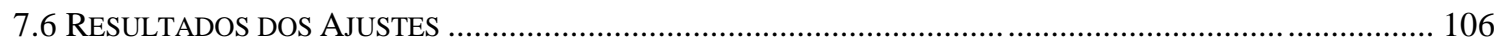

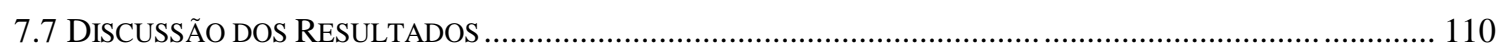


TRANSISTORES DE EFEITO DE CAMPO DE POMA.............................................................................. 113

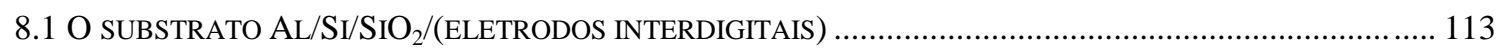

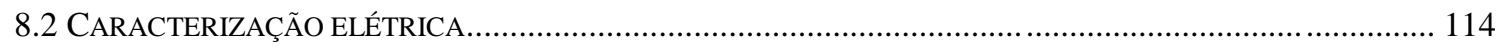

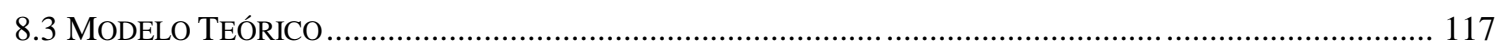

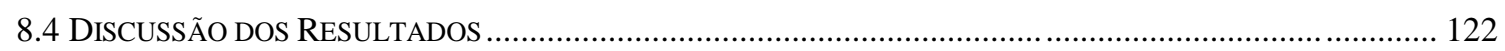

CONCLUSÃO.................................................................................................................................................. 124

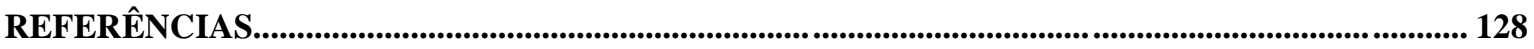

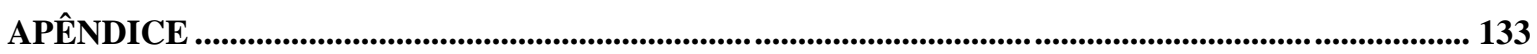

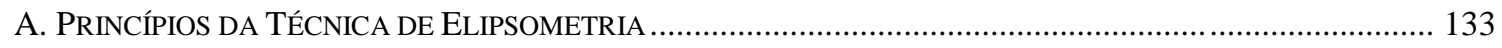

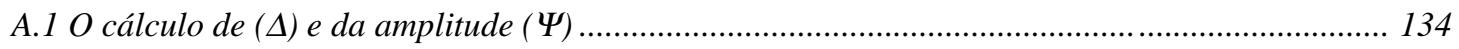

A.2 Usando $\rho(\Delta, \Psi)$ para determinar as propriedades ópticas ..................................................... 135

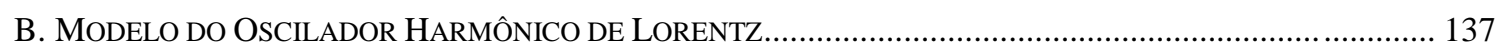




\section{Lista de Figuras}

Figura 1.1: Avanço tecnológico dos dispositivos sinalizadores poliméricos obtidos nos últimos anos.......... 3

Figura 1.2: Desempenho dos LEDs orgânicos e inorgânicos ao longo dos últimos 40 anos ........................ 3

Figura 2.1: Nomes, fórmulas estruturais e gaps (lacunas de energia) de alguns polímeros conjugados ${ }^{[9]} \ldots . . .7$

Figura 2.2: Estrutura de bandas do $t$-PA, onde $\mathrm{k}$ é o vetor de onda e $\varepsilon_{\mathrm{k}}$ é a energia. (a) respeitando a instabilidade de Peierls e (b) caso o sistema não respeitasse essa instabilidade................................... 8

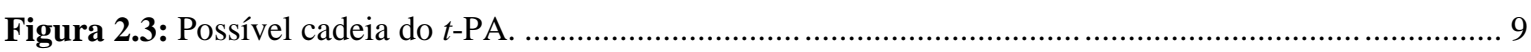

Figura 2.4: Níveis de energia dos sólitons em um estado polimérico degenerado ( $t$ - $P A)$. LU e HO são abreviações de, respectivamente, LUMO e HOMO. ........................................................................ 9

Figura 2.5: Níveis de energia dos pólarons, dos bipólarons e do éxciton singleto em um estado polimérico não degenerado.

Figura 2.6: (a) e (b) estruturas não-degeneradas do PPP e (c) pólaron positivo.

Figura 2.7: Processos de absorção e emissão entre os estados eletrônicos fundamental $\left(\mathrm{S}_{0}\right)$ e excitado $\left(\mathrm{S}_{1}\right)$ de uma molécula orgânica.

Figura 2.8: Esquema representativo da PL. (a) fotoexcitação, (b) éxciton singleto e (c) emissão. ............... 12

Figura 2.9: Estrutura e curva característica $I v s$. $V$ de um diodo polimérico. 13

Figura 2.10: MIS-FET (metal-isolante-semicondutor) usando polímero como camada ativa. Vista lateral do

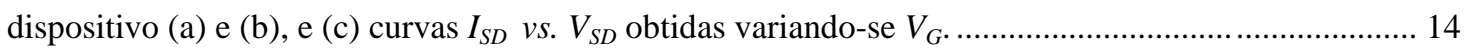

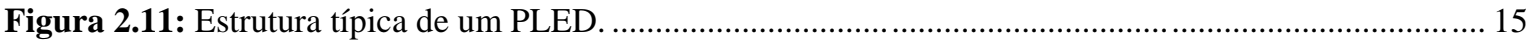

Figura 2.12: Diagrama de energias (função trabalho, HOMO e LUMO) entre o ITO, o PPV e diversos ânodos metálicos 16

Figura 2.13: Passos básicos da eletroluminescência: (1) injeção dos portadores, (2) transporte dos portadores, (3) formação do éxciton e (4) processo de decaimento radiativo. $\phi_{\mathrm{A}}$ : função trabalho do ânodo, $\phi_{C}$ : função trabalho do cátodo, $\Delta_{\mathrm{e}}$ : barreira energética para a injeção de elétrons, $\Delta_{\mathrm{h}}$ : barreira energética para a injeção de buracos

Figura 3.1: Fórmulas estruturais dos polímeros utilizados. Os círculos, ao lado das estruturas dos polímeros luminescentes, representam as cores referentes aos máximos dos seus espectros de emissão. 18

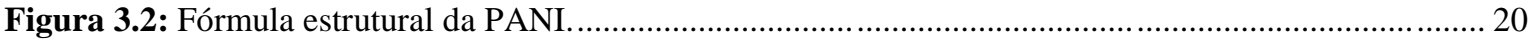

Figura 3.3: Reações químicas envolvidas para a obtenção do PPV ........................................................... 22

Figura 3.4: Reações químicas envolvidas na síntese do MH-PPV ....................................................... 23

Figura 3.6: Aparato experimental usado para a obtenção de filmes poliméricos pelo método casting .......... 26

Figura 3.7: Aparato experimental e procedimentos do método spin coating. ............................................. 27

Figura 3.8: Imagens de microscopia óptica de filmes de PPV obtidos com a deposição da solução PTHT/Água sobre substratos de vidro/ITO por: (a) casting e (b) spin coating. As setas vermelhas indicam a presença de impurezas ou manchas nas superfícies dos filmes. 30 
Figura 3.9: Imagens de microscopia óptica de um filme de PPV obtido com a deposição da solução PTHT/MeOH sobre substratos de vidro/ITO

Figura 3.10: Imagens de microscopia óptica de filmes de PPV obtidos com a deposição da solução PTHT/MeOH/Lenta sobre substratos vidro/ITO por (a) casting e (b) spin coating. As setas vermelhas indicam a presença de impurezas ou manchas nas superfícies dos filmes. 30

Figura 3.11: Imagens de microscopia óptica obtidas com filmes de MH-PPV obtidos com a solução desse polímero em clorofórmio por (a) casting e (b) spin coating. As setas vermelhas indicam a presença de impurezas nas superfícies dos filmes

Figura 3.12: Imagens de microscopia óptica (6 x 5) $\mathrm{mm}^{2}$ obtidas com o filme de MH-PPV obtido com a solução filtrada desse polímero em clorofórmio pelo método casting.

Figura 3.13: Procedimento para a obtenção de padrões de ITO sobre uma lâmina de vidro (letra L)........... 33

Figura 3.14: Detalhes do método de decapagem do ITO apresentados na Fig. 3.13. A Figura inclui o tratamento químico em solução de água-régia diluída e a secagem das lâminas..... 34

Figura 3.15: Imagem de microscopia óptica da superfície de uma lâmina de vidro com faixas de ITO obtidas pelo processo de decapagem.

Figura 3.16: Etapas de preparação de um PFET. 36

Figura 3.17: Processo de litografia para a obtenção dos eletrodos interdigitais. Exemplo com a letra L....... 37

Figura 3.18: Medidas $I_{S D}$ vs. $V_{S D}$ obtidas com a estrutura $\mathrm{Al} / \mathrm{Si} / \mathrm{SiO}_{2} /($ eletrodos interdigitais): antes (a) e depois (b) de aplicar $V_{S D}=10 \mathrm{~V}$.

Figura 3.19: Imagens de microscopia óptica de uma amostra $\mathrm{Al} / \mathrm{Si} / \mathrm{SiO}_{2} /($ eletrodos interdigitais) obtidas (a) antes e (b)/(c) depois de $V_{S D}$ atingir $10 \mathrm{~V}$.

Figura 3.20: Esquema usado para a confecção dos PLED. (a) decapagem do ITO, deposição do polímero, (c) metalização e (d) contatos elétricos.

Figura 3.21: Microscopia óptica de reflexão de substratos vidro/ITO após o processo de decapagem: (a) sem tratamento, e tratado por (b) $15 \mathrm{~min}$, (c) 30 min e (d) 60 min em água-régia

Figura 3.22: Imagens de microscopia de força atômica obtida com os substratos vidro/ITO decapados. (a) e (b) sem o tratamento de limpeza, (c) e (d) com tratamento por imersão em água-régia por 15 min e (d) e (f) com tratamento por imersão em água-régia por $60 \mathrm{~min}$

Figura 3.23: Espectros de EDX obtidos com filmes de ITO (a) antes e (b) depois de terem sido decapados. 44

Figura 3.24: Imagens de microscopia óptica obtidas com PLEDs (a) ITO/MH-PPV/Al e (b) ITO/PPV/Al. de MH-PPV em atmosfera ambiente e após acender o dispositivo.

Figura 4.1: Esquema utilizado para a realização das medidas elétricas e aquisição de dados....................... 47

Figura 4.2: Detalhes do sistema de micromanipuladores e do PFET com eletrodos interdigitais................. 48

Figura 4.3: Sistema de medidas de fotoluminescência e eletroluminescência. ............................................50

Figura 4.4: Configuração óptica do elipsômetro. ............................................................................. 51

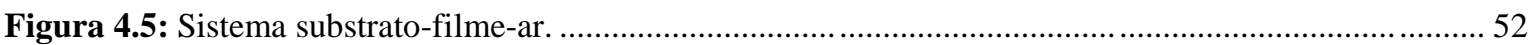

Figura 5.1: (a) Espectros de absorção UV-VIS e (b) de emissão de filmes de PTHT convertidos em 22 , 80, 140 e $200{ }^{\circ} \mathrm{C}$, por duas horas e sob vácuo. As medidas de absorção foram realizadas a temperatura e atmosfera ambientes, e as medidas de fotoluminescência em $73 \mathrm{~K}\left(-200^{\circ} \mathrm{C}\right)$ sob vácuo 54 
Figura 5.2: Espectros de (a) absorção UV-VIS e (b) emissão PL obtidos com filmes MH-PPV tratados em 22 e $50{ }^{\circ} \mathrm{C}$ por $30 \mathrm{~min}$, sob vácuo. Medidas de UV-VIS realizadas em $27{ }^{\circ} \mathrm{C}$ e de PL em $73 \mathrm{~K}\left(-200{ }^{\circ} \mathrm{C}\right) .56$

Figura 5.3: Espectros de (a) absorção UV-VIS e (b) emissão PL obtidos com filmes MD-PPV tratados em 22 e $50{ }^{\circ} \mathrm{C}$ por $30 \mathrm{~min}$., sob vácuo e em $27^{\circ} \mathrm{C}$

Figura 5.4: Espectros de absorção UV-VIS e de emissão PL obtidos com os filmes de (a) $P P V\left(T_{c}=200{ }^{\circ} \mathrm{C}\right)$, (b) $\mathrm{MH}-\mathrm{PPV}$ e (c) $\mathrm{MD}-\mathrm{PPV}$, tratados a $50{ }^{\circ} \mathrm{C}$ sob vácuo. Medidas realizadas em $27{ }^{\circ} \mathrm{C}$ e atmosfera ambiente.

Figura 5.5: Componentes real - $\varepsilon_{1}$ e imaginária $-\varepsilon_{2}$ da função pseudo-dielétrica complexa $<\varepsilon>$ obtidas com os filmes de PPV, MH-PPV e MD-PPV, e a linha contínua (-) o ajuste obtido com a equação do oscilador de Lorentz, Eq. (5.1).

Figura 5.6: Componentes reais, $\sigma^{\prime}(f)$, e imaginária, $\sigma$ ' $(f)$, obtidos com a amostra $\mathrm{PANI}_{\mathrm{ND}}$ nas temperaturas: (a) - 48, (b) - 23, (c) 0 , (d) 27 e (e) $57^{\circ} \mathrm{C}$. (f) apresenta o comportamento de $\sigma^{\prime}(f)$ para as diversas temperaturas estudadas. As linha contínuas (-) são os ajustes obtidos com a Eq. (5.12)

Figura 5.7: Componentes reais, $\sigma^{\prime}(f)$, e imaginárias, $\sigma^{\prime}$ ( $(f)$, de $\sigma^{*}(f)$, obtidas com a amostra PANI $\mathrm{P}_{0,1 \mathrm{M}}$ nas temperaturas: (a) -189 , (b) -148 (c) -73 e (d) $27{ }^{\circ} \mathrm{C}$. (e) apresenta o comportamento de $\sigma^{\prime}(f)$ para as diversas temperaturas estudadas. As linhas contínuas (-) são os ajustes obtidos com a Eq. (5.12)

Figura 5.8: Componentes reais, $\sigma^{\prime}(f)$, e imaginárias, $\sigma^{\prime \prime}(f)$, da condutividade complexa obtidas para a amostra $\mathrm{PANI}_{0,2 \mathrm{M}}$ nas temperaturas: (a) -223 , (b) -200 , (c) -173 , (d) -148 e (e) $-123{ }^{\circ} \mathrm{C}$. (f) apresenta o comportamento de $\sigma^{\prime}(f)$ para as diversas temperaturas estudadas. As linha contínuas (-) são os ajustes obtidos com a Eq. (5.12)

Figura 5.9: Comportamento típico do componente real da condutividade complexa obtida com sistemas sólidos desordenados.

Figura 5.10: $\ln \gamma_{\min }^{\prime} v s . T^{l}$ ajustados pela Eq. (5.4) utilizando-se os resultados obtidos com as amostras PANI $_{\mathrm{ND}}, \mathrm{PANI}_{0,1 \mathrm{M}} \mathrm{E} \mathrm{PANI}_{0,2 \mathrm{M}}$. A curva mostrada para a amostra $\mathrm{PANI}_{0,1 \mathrm{M}}$ apresenta todos os parâmetros obtidas na ref [74].

Figura 6.1: Esquema utilizado para a iluminação de filmes e soluções de MH-PPV................................ 74

Figura 6.2: Espectros de absorção UV-VIS obtidos com filmes de MH-PPV exposto: (a) no ar e no escuro, (b) iluminado em atmosfera de nitrogênio (c) iluminado em atmosfera de ar e (d) mostra os espectros de absorção UV-VIS obtidos com uma solução de MH-PPV em clorofórmio iluminada por 370 horas..... 75

Figura 6.3: Espectros de absorção FTIR obtidos com um filme de MH-PPV como função do tempo de exposição do MH-PPV à iluminação com uma lâmpada branca de $250 \mathrm{~mW} / \mathrm{cm}^{2}$.

Figura 6.4: Esquema utilizado para as medidas com a técnica de elipsometria: (a) iluminação da amostra, (b) realização da medida. (c) apresenta o espectro de intensidade vs. comprimento de onda da lâmpada utilizada.

Figura 6.5: Componentes (a) real e (b) imaginário da função pseudo-dielétrica obtidas com um filme de MH-PPV exposto ao ar e iluminado com uma lâmpada de 25 W por 275 horas. 78

Figura 6.6: Componentes (a) real - $n$ e (b) imaginário - $k$ do índice de refração complexo $\left(\mathrm{N}^{*}\right)$ obtidos com um filme de MH-PPV exposto ao ar e iluminado com um lâmpada de $25 \mathrm{~W}$ por 275 horas.

Figura 6.7: Índice de refração obtido com o MH-PPV como função do tempo de exposição do material com a lâmpada de 25 W. Resultados obtidos com a energia de $3,5 \mathrm{eV}$ 
Figura 6.8: Componentes $\varepsilon_{l}$ e $\varepsilon_{2}$ do MH-PPV ajustados pela equação do átomo de Lorentz, Eq. (5.1), obtidos com diferentes tempos de exposição do polímero à luz: (a) 0, (b) 4, (c) 21, (d) 45, (e) 70, (f) 97, (g) 120 e (h) $140 \mathrm{~h}$

Figura 6.9: Parâmetros obtidos com os ajustes dos componentes $\varepsilon_{1}$ e $\varepsilon_{2}$ pela equação de Lorentz, Eq. (5.1) mostrados na Fig. 6.8

Figura 6.10: (a) unidade monomérica conhecida do MH-PPV (polímero puro) e (b) possível unidade monomérica do MH-PPV após 275 horas de iluminação (completamente degradado).....

Figura 6.11: Possível unidade monomérica do MH-PPV entre 0 h e 275 horas de iluminação. O parâmetro $x$ indica a quantidade degradada do polímero $(0 \leq \mathrm{x} \leq 1)$ e depende do tempo de iluminação.

Figura 6.12: Evolução de $x$ e da razão $\mathrm{A}_{1670} / \mathrm{A}_{1500}$ como função do tempo de iluminação. $t_{i l}$ foi o tempo de medida do índice de refração, e $t^{\prime}{ }_{i l}$ o tempo de iluminação para a medida da razão $\mathrm{A}_{1670} / \mathrm{A}_{1500 .}$.......

Figura 6.13: Índice de refração experimental vs. fração de unidades degradadas $x$ obtidos a partir da Eq. (6.3) e usando os valores de $n$ apresentados na Fig. 6.7. 86

Figura 7.1: Curvas $J$ vs. $V$ de amostras Au/MH-PPV/Au, com (a) $L=400 \mathrm{~nm}$ e $L=1,1 \mu \mathrm{m}$, (b) $L=14 \mu \mathrm{m}$ e $A r=0,03 \mathrm{~cm}^{2}$. Medidas realizadas no escuro, sob vácuo, a $27^{\circ} \mathrm{C}$ e com umidade relativa de $10 \% \ldots . . .89$

Figura 7.2: Curvas $J$ vs. $V$, em escalar linear e mono-log, obtidos com amostras: (a) e (b) ITO/MH-PPV/Au, e (c) e (d) ITO/MH-PPV/Al, ambas com L = $400 \mathrm{~nm}$ e $A r=0,3 \mathrm{~cm}^{2}$. Medidas realizadas em temperatura ambiente, sob vácuo, no escuro e com umidade relativa de $10 \%$.

Figura 7.3: Gráficos da densidade de corrente vs. tensão ( $I$ vs. $V$ ) obtidos com as amostras (a) ITO/MH$\mathrm{PPV} / \mathrm{Al}$ com $\mathrm{L}=250 \mathrm{~nm}$, (b) ITO/MH-PPV/Al com L $=920 \mathrm{~nm}$ e (c) ITO/PPV/AL com L $=400 \mathrm{~nm}$ em diferentes temperaturas. As medidas realizadas sob vácuo e na ausência de luz. 92

Figura 7.4: $J$ vs. $V$ da amostra ITO/MH-PPV/Al com $L=250 \mathrm{~nm}$ em temperatura ambiente. A linha contínua é o resultado do ajuste pela Eq. (7.6). 95

Figura 7.5: Espectros de Eletroluminescência obtidos com (a) ITO/PPV/Al ( $L=400 \mathrm{~nm}$ ) e (b) ITO/MH$\mathrm{PPV} / \mathrm{Al}(L=920 \mathrm{~nm})$ com diferentes tensões. Medidas realizadas sob vácuo, a $27{ }^{\circ} \mathrm{C}$ para o PPV e $0{ }^{\circ} \mathrm{C}$ para o MH-PPV. 96

Figura 7.6: Curvas $J$ vs. $V$ e Emissão total vs. $V$ obtidas com os dispositivos (a) ITO/PPV/Al e (b) ITO/MHPPV/Al a partir dos gráficos das Figs. 7.3-(a), 7.3-(b) e 7.5. 96

Figura 7.7: Gráficos $Z$ ' e $Z$ ' vs. $f$ das amostras: (a) Au/MH-PPV/Au ( $L=14 \mu \mathrm{m})$, (b) ITO/MH-PPV/Au ( $L=400 \mathrm{~nm})$, (c) ITO/MH-PPV/Al $(L=5 \mu \mathrm{m})$ e (d) ITO/PPV/Al $(L=400 \mathrm{~nm})$. Medidas realizadas com $V_{a c}=50 \mathrm{mV}, V_{\text {bias }}=0 \mathrm{~V}$, no vácuo, com umidade relativa de $10 \%$ e no escuro. As linhas contínuas são os ajustes pela Eq. (7.10).

Figura 7.8: Gráficos Z’ vs. Z” das amostras apresentadas na Fig. 7.7. As linhas contínuas são os ajustes pela Eq. (7.10).

Figura 7.9: Z' e Z" vs. $f$ como função de $V_{a c}$ e $V_{\text {bias }}$ obtidos com a amostra ITO/MH-PPV/Al $(L=400 \mathrm{~nm})$ : (a.1) e (a.2) com $V_{a c}$ variando de $50 \mathrm{mV}$ a 3,0 V, (b.1) e (b.2) para $V_{\text {bias }}$ variando de 0 a $4 \mathrm{~V}$, e (c.1) e (c.2) para $V_{\text {bias }}$ igual a 0 e - $4 \mathrm{~V}$. As medidas foram obtidas no escuro, em temperatura ambiente e com umidade relativa controlada de $10 \%$. 101 
Figura 7.10: Gráficos $Z$ ” vs. Z' variando-se (a) $V_{a c}$, (b) $V_{\text {bias }}$ positivamente e (c) $V_{\text {bias }}$ negativamente com a amostra ITO/MH-PPV/Al $(\mathrm{L}=400 \mathrm{~nm})$. A Fig. 7.9 apresentou esses resultados em gráficos de $Z$ ' e $Z^{\prime}$ vs. $f$. 102

Figura 7.11: Representação do sistema ITO/MH-PPV/metal em termos de um circuito equivalente ${ }^{[91,92]}{ }^{104}$

Figura 7.12: Z'e Z" vs. $f$ da amostra ITO/MH-PPV/Al $(L=400 \mathrm{~nm}) \mathrm{com}$ : (a.1) e (a.2) $V_{a c}=2,0 \mathrm{~V}$ e $V_{\text {bias }}=0$, (b.1) e (b.2) $V_{a c}=50 \mathrm{mV}$ e $V_{\text {bias }}=2,0 \mathrm{~V}$, e (c.1) e (c.2) $V_{a c}=50 \mathrm{mV}$ e $V_{\text {bias }}=-2,0 \mathrm{~V}$. As curvas cheias mostram os ajustes dos resultados experimentais pela Eq. (7.10).

Figura 7.13: Gráficos $\sigma^{\prime}(f)$ e $\sigma^{\prime \prime}(f)$ vs. $f$ obtidos com as amostras (a) Au/MH-PPV/Au, (b) ITO/MH-PPV/Al espessa e (c) ITO/MH-PPV/Al fina pela Eq. (7.12). 109

Figura 8.1: Imagens de microscopia óptica dos substratos $\mathrm{Al} / \mathrm{Si} / \mathrm{SiO}_{2} /($ eletrodos interdigitais). A figura mostra os eletrodos sobre a camada de $\mathrm{SiO}_{2}$ obtidos com uma fina deposição de $\mathrm{Cr}$ (20 nm), seguido de uma fina deposição de Au (30 nm) através dos processos de litografia apresentados no item 3.3........ 114

Figura 8.2: Medidas $I_{S D}$ vs. $V_{S D}$ obtidas com estruturas PFET de POMA com W $=10 \mu \mathrm{m}$ e $V_{G}$ variando de -50 a $20 \mathrm{~V}$. 115

Figura 8.3: Medidas $I_{S D}$ vs. $V_{S D}$ obtidas (a) com PFETs de POMA não dopada variando-se W de 10, 20 e 30 $\mu \mathrm{m}$, e (b) com FETs de POMA ( $\mathrm{W}=10 \mu \mathrm{m}$ ) variando-se o grau de dopagem química do polímero em solução aquosa de ácido clorídrico $10^{-3}, 10^{-2}, 10^{-1} \mathrm{M}$. 116

Figura 8.4: (a) Representação de um sistema cartesiano do PFET e (b) descrição das variáveis utilizadas. 117

Figura 8.5: Esquema representativo das considerações usadas no modelo do PFET. (a) características físicas do dispositivo, e esquematização da: (b) variação da mobilidade ao longo de $y$, (c) variação da densidade de portadores ao longo de y (no caso, portadores positivos) e (d) corrente de injeção (jo) e de retrodifusão (j')

Figura 8.6: Medidas $I_{S D}$ vs. $V_{S D}$, ajustadas pela Eq. (8.10), curvas cheias, do PFET de POMA não dopada com $\mathrm{W}=10 \mu \mathrm{m}$ e diferentes valores de $V_{G}$

Figura 8.7: Medida $I_{S D}$ vs. $V_{S D}, V_{G}=-50$, do PFET de POMA não dopada com $\mathrm{W}=10 \mu \mathrm{m}$ e as curvas obtidas com o ajuste pela Eq. (7.8), levando-se em consideração $\mu \equiv \mu_{0}(1-\mathrm{k} y / b)(a)$ e $v=v_{\mathrm{s}}(b) \ldots . . .122$

Figura 9.1: Imagens de microscopia óptica de padrões de ITO obtidos pelo processo de litografia lift off e de decapagem com $\mathrm{HCl}+\mathrm{Zn}$. A figura (a) apresenta 3 eletrodos de ITO com largura de 1,4 mm e separação de 1,0 mm. A Figura (b) apresenta 15 pares de eletrodos com largura e separação de $0,1 \mathrm{~mm}$.... 126

Figura 9.2: PLED ITO/PPV/Al em operação no Grupo de Polímero Bernhard Gross. 126 


\section{Lista de Tabelas}

Tabela 3.I: Solubilidade e massa molar média ponderal $\left(\overline{\mathrm{M}}_{\mathrm{w}}\right)$ dos polímeros sintetizados....

Tabela 3.II: Rugosidade $(R u)$, espessura $(L)$, condutividade $(\sigma)$ e composição dos elementos químicos de amostras de ITO decapadas e não-decapadas, tratadas e não tratadas em água régia. T é o tempo de imersão das lâminas durante o tratamento em água-régia, e a região analisada foi a superfície do vidro com ITO.

Tabela 5.I: Valores dos comprimentos de onda, das energias, dos máximos de absorção no visível $\left(E_{a b s}\right)$ e dos máximos mais intensos da emissão $\left(E_{\text {emis }}\right)$ obtidos com os filmes de PPV e MH-PPV e MD-PPV.. 57

Tabela 5.II: Resultado obtidos com os ajustes dos componentes real, $\varepsilon_{1}$, e imaginária, $\varepsilon_{2}$, da função pseudodielétrica complexa pela Eq. (5.1) obtidos com os filmes de PPV, MH-PPV e MD-PPV.

Tabela 5.III: Nomenclatura utilizada para a identificação das amostras de PANI.

Tabela 5.IV: Parâmetros obtidos dos ajustes pela Eq. (5.12) dos componentes $\sigma^{\prime}(f)$ e $\sigma^{\prime \prime}(f)$ da amostra $\mathrm{PANI}_{\mathrm{ND}}$ em diferentes temperaturas, e com $\eta=0$ em todos os ajustes.

Tabela 5.V: Parâmetros obtidos dos ajustes pela Eq. (5.12) dos componentes $\sigma^{\prime}(f)$ e $\sigma^{\prime \prime}(f)$ da amostra $\mathrm{PANI}_{0,1 \mathrm{M}}$, em diferentes temperaturas, e com $\eta=0,50$ em todos os ajustes.

Tabela 5.VI: Parâmetros obtidos dos ajustes pela Eq. (5.12) dos componentes $\sigma^{\prime}(f)$ e $\sigma^{\prime \prime}(f)$ da amostra $\mathrm{PANI}_{0,2 \mathrm{M}}$ em diferentes temperaturas, e com $\eta=0,55 \mathrm{em}$ todos os ajustes.

Tabela 5.VII: Resultados obtidos com os ajustes mostrados na Fig. 5.10. 71

Tabela 6.I: Parâmetros obtidos com os ajustes mostrados na Fig. 6.8. 82

Tabela 6.II: Volumes molares dos grupos funcionais do MH-PPV disponíveis na literatura. 85

Tabela 7.I: Parâmetros de ajustes dos componentes Z' e Z”, através da Eq. (7.10), das amostras $\mathrm{Au} / \mathrm{MH}-\mathrm{PPV} / \mathrm{Au}(L=14 \mu \mathrm{m}), \mathrm{ITO} / \mathrm{MH}-\mathrm{PPV} / \mathrm{Au}(L=400 \mathrm{~nm}), \mathrm{ITO} / \mathrm{MH}-\mathrm{PPV} / \mathrm{Al}$ espessa $(L=5 \mu \mathrm{m}) \mathrm{e}$ ITO/MH-PPV/Al $(L=400 \mathrm{~nm})$. 106

Tabela 7.II: Parâmetros obtidos através dos ajustes dos componentes Z' e Z” apresentadas nas Fig. 7.9 e 7.12 através da Eq. (7.10) da amostra ITO/MH-PPV/Al $\left(L=400 \mathrm{~nm}\right.$ e $A r=0,5 \mathrm{~cm}^{2}$ variando-se $V_{a c}$, e $V_{\text {bias }}$ positiva e negativamente. Em todos os ajustes $\mathrm{R}_{\mathrm{ITO}}<<\mathrm{R}_{\mathrm{MH}}$. 108

Tabela 7.III: Parâmetros de ajustes dos componentes $\sigma^{\prime}(f)$ e $\sigma^{\prime \prime}(f)$ das amostras Au/MH-PPV/Au $(L=14$ $\mu \mathrm{m})$, e ITO/MH-PPV/Al espessa $(L=5 \mu \mathrm{m})$ e ITO/MH-PPV/Al fina obtidas com a Eq. (7.12) 110

Tabela 8.I: Parâmetros obtidos com o ajuste das curvas da Fig. 8.6 com a Eq. (8.10). Para todos os ajustes: $\mathrm{k}=0,5, \chi=1,5 \times 10^{-14} \mathrm{C}, \alpha=0,112(\mathrm{~cm} / \mathrm{V})^{1 / 2}$ e $\mu_{0}=7,0 \times 10^{-5} \mathrm{~cm}^{2} / \mathrm{Vs}$ 121 


\section{Lista de Abreviaturas}

\begin{tabular}{|c|c|}
\hline AFM & Atomic Force Microscopy \\
\hline $\mathrm{Au} / \mathrm{MH}-\mathrm{PPV} / \mathrm{Au}$ & Dispositivo PLED com filme de MH-PPV entre eletrodos de Au \\
\hline EDX & Energy Dispersive X-Ray Analysis \\
\hline EL & Eletroluminescência \\
\hline FTIR & Fourier Transform Infrared \\
\hline ITO & Indium-tin oxide (óxido de estanho e índio) \\
\hline ITO/MH-PPV/Al & Dispositivo PLED com filme de MH-PPV entre eletrodos de ITO e Al \\
\hline ITO/MH-PPV/Au & Dispositivo PLED com filme de MH-PPV entre eletrodos de ITO e Au \\
\hline ITO/PPV/Al & Dispositivo PLED com filme de PPV entre eletrodos de ITO e Al \\
\hline MH-PPV & Poli[(2-metóxi,5-hexilóxi)-p-fenilenovinileno] \\
\hline MD-PPV & Poli[(2-metóxi,5-dodecóxi)-p-fenilenovinileno] \\
\hline PANI & Polianilina \\
\hline $\mathrm{PANI}_{0,1 \mathrm{M}}$ & Polianilina dopada em solução aquosa de ácido clorídrico $0,1 \mathrm{M}$ \\
\hline $\mathrm{PANI}_{0,2 \mathrm{M}}$ & Polianilina dopada em solução aquosa de ácido clorídrico $0,2 \mathrm{M}$ \\
\hline $\mathrm{PANI}_{\mathrm{ND}}$ & Polianilina não dopada \\
\hline PFET & Polymer field-effect transistor (transistor de efeito de campo polimérico) \\
\hline PL & Fotoluminescência \\
\hline PLED & Polymer light-emitting diode (diodo eletroluminescente polimérico) \\
\hline POMA & Poli(o-metoxianilina) \\
\hline PPV & Poli( $p$-fenilenovinileno) \\
\hline PTHT & Politetrahidrotiofeno \\
\hline PTHT/ÁGUA & Solução aquosa de PTHT \\
\hline $\mathrm{PTHT} / \mathrm{MeOH}$ & Solução de PTHT em metanol \\
\hline PTHT/MeOH/LENTA & Solução de PTHT em metanol obtida através de secagem lenta da solução aquosa \\
\hline RFEB & Random free energy barrier model (modelo de energias livres aleatórias) \\
\hline UV-VIS & Ultraviolet-Visible \\
\hline
\end{tabular}




\section{Lista de Símbolos}

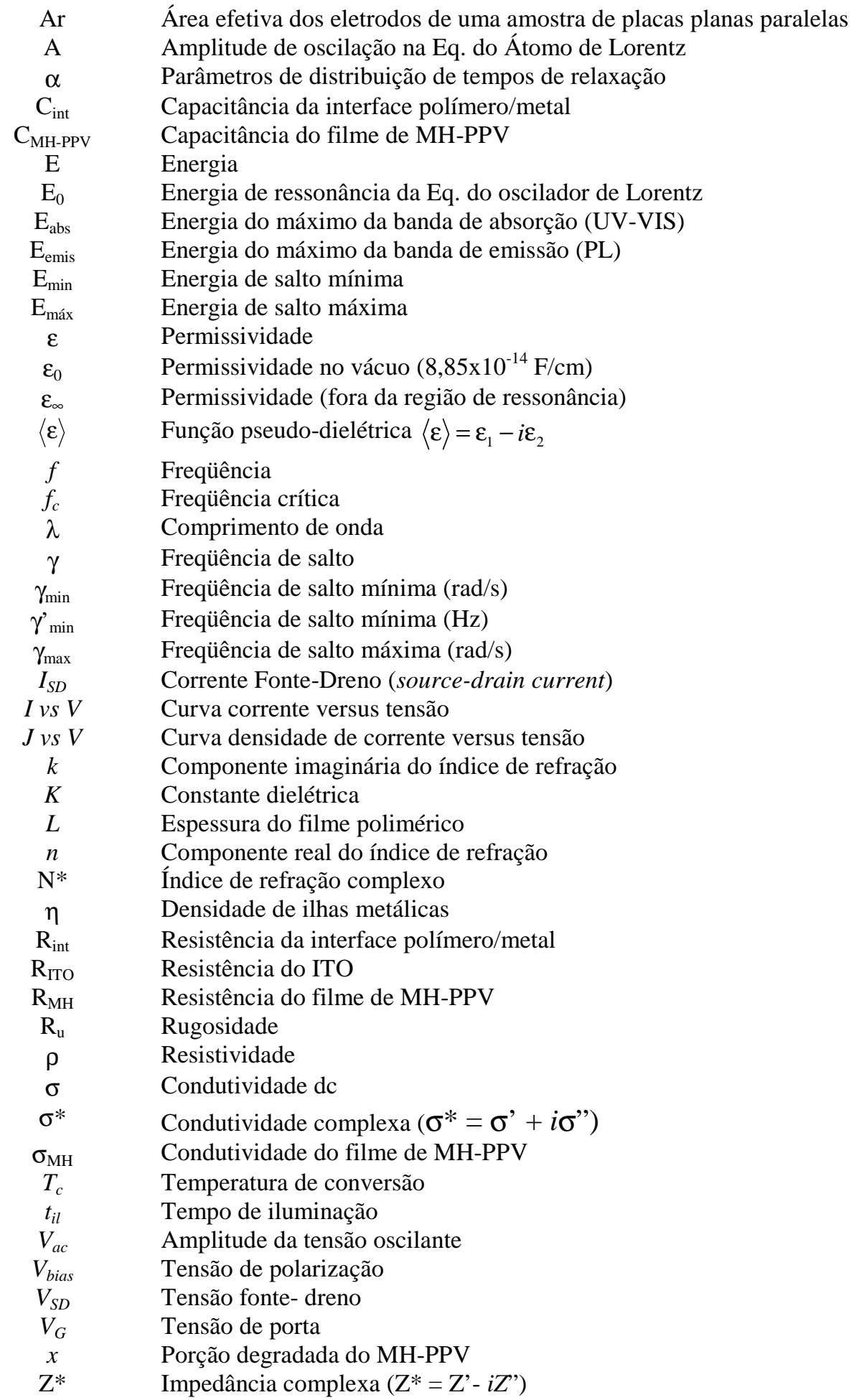




\section{Resumo}

Nesse trabalho apresentamos o estudo das propriedades ópticas e elétricas de filmes e dispositivos eletrônicos de polímeros luminescentes, poli(p-fenilenovinilenos) - PPVs, semicondutores, polianilinas - PANI, e derivados desses dois polímeros. São apresentadas todas as etapas de preparação e caracterização dos dispositivos, desde as rotas de síntese dos polímeros, até a modelagem de dispositivos eletroluminescentes e de transistores de efeito de campo. Os filmes luminescentes foram caracterizados por propriedades de absorção e emissão ópticas, e função pseudo-dielétrica, mostrando dependência com a presença de grupos laterais. Filmes de PANI, por sua vez, foram caracterizados através de medidas de condutividade complexa, e os resultados obtidos mostram-se típicos de sistemas sólidos desordenados. Para interpretá-las, foi utilizado o modelo de distribuição aleatória de barreiras de energia livre (random free energy barrier model - RFEB) aplicado como ajuste aos resultados experimentais. Outra característica importante dos PPVs, estudada nessa tese, foi à degradação em condições ambientais sob iluminação. Esse efeito foi acompanhado por medidas de absorção óptica e de elipsometria, mostrando que a combinação dos efeitos do oxigênio e da luz é a principal responsável pela degradação desse material. Para explicar tal efeito, elaboramos um modelo baseado nas propriedades individuais dos cromóforos do polímero e na substituição de ligações vinílicas $\mathrm{C}=\mathrm{C}$ por ligações carbonilas $\mathrm{C}=\mathrm{O}$, cuja comparação com os resultados experimentais forneceu uma estimativa para a fração degradada do polímero como função do tempo de iluminação. Foram caracterizados dispositivos emissores de luz de PPVs através de medidas corrente $v s$. tensão e de condutividade complexa, que através do ajuste por modelos de circuitos equivalentes e pelo modelo $R F E B$ forneceu grandezas fundamentais como a resistividade e a constante dielétrica da camada polimérica. Finalizando, transistores de efeito de campo de poli(o-metoxianilina) - POMA (um derivado da PANI) apresentaram modulação pela tensão de porta, e um modelo baseado nas propriedades de condução da POMA levando-se em conta gradientes de mobilidade e de densidade de portadores ortogonais à superfície do polímero foi elaborado e se ajustou muito bem aos resultados experimentais. 


\section{Abstract}

In this thesis we report the electrical and optical characterization of polymeric thinfilm and luminescent and electronic devices. The studied materials were the luminescent poly(p-phenylenevinylenes) - PPVs, semiconducting polyanilines - PANI and their derivatives. All the steps in the material preparation are described: the synthesis and the film preparation. Also, the technological details of the fabrication of the devices, lightemitting diodes (LEDs) and field-effect transistor (FETs), are presented. Luminescent films were studied by optical absorption and emission and by ellipsometry measurements, giving emphasis on the influence of lateral groups. The PANI films were electrically investigated by the analysis of the complex conductivity, whose results were adjusted by the random free energy barrier model used for disordered solids. Another important investigation was related to the photodegradation of the luminescent polymers, a deleterious effect owing to a concomitant action of oxygen and light. To explain such effect we proposed a model based on the properties of individual cromophores of the molecules, and in the incorporation of ketone groups $(\mathrm{C}=\mathrm{O})$, cleaving the vinyl $\mathrm{C}=\mathrm{C}$ bonds. The luminescent devices were electrically and optically characterized. The current density vs. voltage and complex impedance were fit by macroscopic models taking into account a hopping process, and an equivalent circuit was also used to study ITO/polymer/metal structures. Finally, the field-effect transistor made by poly $(o-$ methoxyaniline) were experimentally studied and a model that assumes gradients of carrier density and mobility orthogonal to the film surface fit with good agreement the $I_{S D} v s . V_{S D}$ for different gate voltages, $V_{G}$. 
JUST KEEPING THE FAITH, putting one foot in front of the other, and keeping your eyes on the goal...

S. Bueher, Editor-in-Chef

Semiconductor Magazine 2, SEP, p. 6 (2001) 


\section{Capítulo 1}

\section{Introdução}

Os materiais poliméricos, principalmente os termoplásticos, tinham suas aplicações na área elétrica e eletrônica como materiais de excelente isolação elétrica, devido à sua natural elevada resistividade elétrica combinada com a sua facilidade de processamento. Esse quadro começou a mudar a partir da década de 70, do século XX, com a descoberta da ferroeletricidade intrínseca nos poli(fluoretos de vinilideno) e suas elevadas atividades piezo e piroelétricas ${ }^{[1]}$. A partir de então ficaram consolidadas as aplicações de materiais poliméricos em dispositivos eletroacústico $\mathrm{s}$, já iniciadas com o eletreto de fluoropolímero na década anterior ${ }^{[2]}$. Porém, uma grande revolução no estudo desses materiais ocorreu em 1977 quando, acidentalmente no laboratório do Prof. H. Shirakawa, foram produzidos filmes de poliacetileno que apresentavam um brilho metálico, características bem diferentes das até então conhecidas ${ }^{[3]}$. Esse fato chamou a atenção do Prof. A. G. MacDiarmid que, junto com o Prof. H. Shirakawa e o Prof. A. J. Heeger, estudou diversas propriedades desse "novo polímero", o que resultou em um impacto científico tão grande que, no ano 2000, esses três pesquisadores foram laureados com o Nobel de Química. Em seus primeiros estudos, eles doparam o polímero com iodo e obtiveram filmes dourados e com valor de condutividade elétrica bilhões de vezes maior que a obtida com o material não dopado ${ }^{[3]}$. Desde então, despertou-se o interesse por polímeros que tem a sua condutividade muitas vezes aumentada sob dopagem química ${ }^{[4,5]}$. No início da década de 80, do século XX, vários outros polímeros condutores foram sintetizados e estudados e, no final dessa década, utilizações do poliacetileno semicondutor em diodos e transistores abriram novas perspectivas para a utilização desses materiais como elementos ativos em dispositivos eletrônicos ${ }^{[6]}$. No entanto, a dificuldade em se obter filmes finos e homogêneos, a baixa mobilidade dos portadores eletrônicos e a instabilidade dos dispositivos impossibilitaram suas aplicações comerciais.

Com os avanços nas técnicas de preparação de filmes finos, em 1987 dois pesquisadores da Eastman Kodak anunciaram propriedades eletroluminescentes de materiais orgânicos (não-poliméricos) ${ }^{[7]}$, e três anos mais tarde no grupo do Prof. R. 
Friend, na Universidade de Cambridge - UK, a fabricação de um diodo emissor de luz (polymer light-emitting diodes - PLEDs) usando poli( $p$-fenilenovinileno) (PPV) como camada emissiva ${ }^{[8,9]}$ consolidou os polímeros conjugados como materiais ativos na eletrônica e optoeletrônica. Nos anos seguintes, a síntese de novos polímeros e copolímeros e a preparação de blendas e heteroestruturas orgânico-inorgânicas com características condutoras ou luminescentes foram intensificadas ${ }^{[5,10-12]}$. Em 1993, o Prof. A. J. Heeger estimou em cerca de 1 bilhão de dólares o mercado dos possíveis produtos eletrônicos poliméricos já no início dos anos 2000. Após essa estimativa, muitas empresas de porte como a Philips, a Sony, a Pioneer, a Du Pont e a Kodak começaram a investir em pesquisas e desenvolvimentos de dispositivos eletrônicos poliméricos. No final da década de 1990, a utilização de polímeros condutores e/ou luminescentes em sensores de gases, em sensores químicos e em músculos artificiais já eram uma realidade ${ }^{[13-15]}$. PLEDs, em particular, apresentam altas eficiências, baixa tensão de operação e com emissão em vários comprimentos de onda do espectro visível (correspondendo ao amarelo, laranja, vermelho, verde, azul e violeta) ${ }^{[16]}$. Um exemplo de aplicação dos materiais luminescentes ocorre em 1995 pela empresa americana Uniax, que fabrica o primeiro PLED flexível ${ }^{[17]}$. Em 1998, a associação das empresas Seiko-Epson e Cambridge Display Technology (CDT) apresentaram o primeiro painel monocromático usando PPV, com cerca de $50 \mathrm{~mm}^{2} \mathrm{e}$ amplo ângulo de visão $\left(165^{0}\right)^{[18]}$. No final do ano 2000, a Du Pont-Uniax prometeu a comercialização para 2002 do telefone celular $\operatorname{Tetrus}^{T M}$, que combina as propriedades emissivas dos polímeros e dos sólidos orgânicos no seu mostrador alfanumérico, sugerindo um futuro promissor para os dispositivos poliméricos sinalizadores ${ }^{[17]}$.

A Fig. 1.1 mostra o avanço tecnológico dos dispositivos sinalizadores poliméricos obtidos nos últimos anos. Nessa figura são mostradas, desde a foto de um diodo emissor de PPV semelhante ao obtido em 1990, até a foto de um telefone celular que deve estar disponível no mercado nos próximos anos, passando por todo o desenvolvimento de novos polímeros e seus dispositivos optoeletrônicos ${ }^{[17-19]}$. Acompanhando essa evolução, a Fig. $1.2^{[15,20]}$ mostra como vem aumentando o desempenho dos dispositivos emissores de luz (light-emitting diodes - LEDs) inorgânicos e orgânicos nas últimas 4 décadas. Como pode ser observado, o desempenho dos LEDs orgânicos (sólidos moleculares ou polímeros) vem crescendo continuamente, já alcançando os valores das tradicionais lâmpadas de filamento incandescentes não filtradas, e estando próximos ao desempenho dos materiais inorgânicos mais eficientes. 


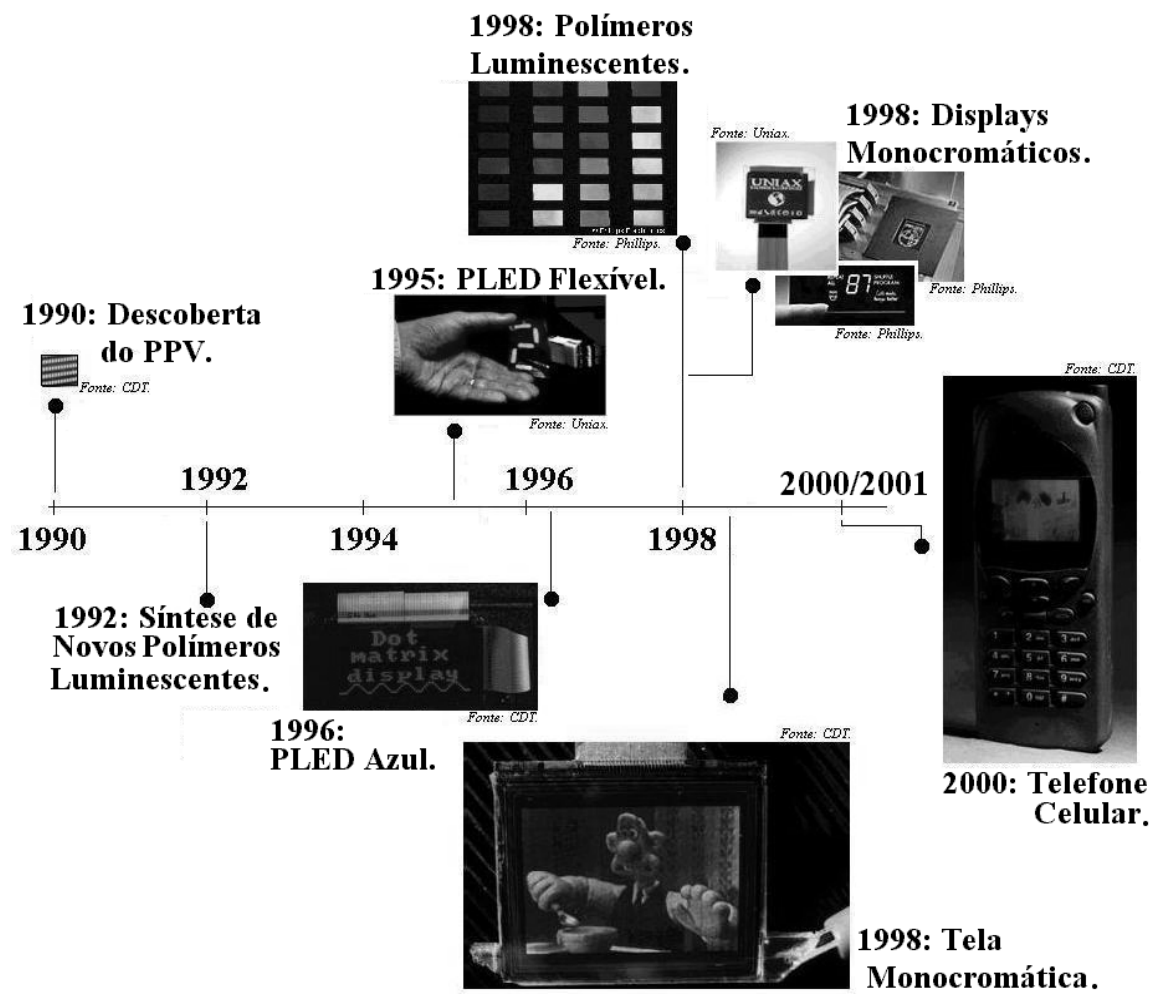

Figura 1.1: Avanço tecnológico dos dispositivos sinalizadores poliméricos obtidos nos últimos anos ${ }^{[17-19]}$.

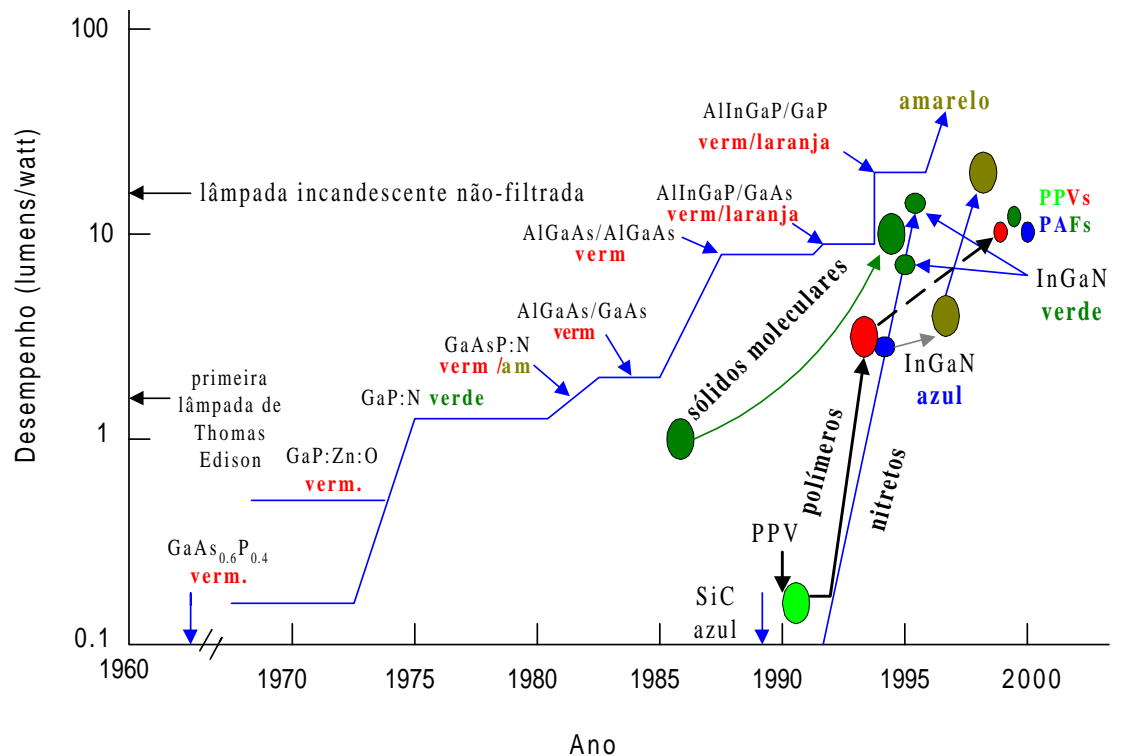

Figura 1.2: Desempenho dos LEDs orgânicos e inorgânicos ao longo dos últimos 40 anos ${ }^{[15,20]}$.

Entretanto, apesar do atual estágio de desenvolvimento tecnológico dos dispositivos eletrônicos poliméricos, fenômenos responsáveis pela eficiência e pela degradação desses sistemas ainda são pouco compreendidos. Enquanto as promessas de novos dispositivos crescem a cada dia, o controle e a otimização das suas propriedades ópticas e elétricas ainda devem ser solucionados para torná-los disponíveis comercialmente. Dentro desse contexto, a fotoxidação dos polímeros é uma das principais causas dessa restrição ${ }^{[21-25]}$. 
Embora as eficiências dos dispositivos poliméricos alcancem valores altos (veja Fig. 1.2.), a foto-oxi-degradação é um dos responsáveis pela sua rápida redução. Inúmeros autores têm se preocupado com a identificação desse fenômeno, mas pouco se conhece a ponto de evitá-lo. Sabe-se, apenas, que ele é minimizado quando o polímero está na ausência de ${ }_{\text {luz }}{ }^{[26]}$. Porém, ainda é uma questão em aberto avaliar qual a porção degradada do polímero com o tempo de sua exposição à luz, o que merece especial atenção ${ }^{[21]}$. Encontrar essa resposta, um dos objetivos desse trabalho, pode vir a contribuir no desenvolvimento de métodos mais eficientes para o encapsulamento dos dispositivos poliméricos.

Outro fenômeno muito estudado, mas ainda não totalmente esclarecido, é o da injeção de portadores pelos eletrodos na camada emissiva polimérica em uma estrutura do tipo metal/polímero/ITO. Essa é a estrutura padrão dos PLEDs e o ITO (óxido de estanho e índio, ou indium-tin oxide) é usado por ser condutor, bom injetor de buracos no PPV e, principalmente, por ser transparente na região do visível. Os mecanismos de condução no volume são igualmente responsáveis pelo desempenho dos dispositivos eletrônicos diodos e transistores - e ainda não são completamente compreendidos. Nos estudos de injeção e transporte, a estrutura morfológica desordenada dos sistemas poliméricos deve ser levada em consideração. Não obstante esta dificuldade estrutural, vários resultados têm mostrado que os mecanismos de injeção parecem obedecer aos processos de tunelamento de Fowler-Nordhein (FN) e ao de emissão termiônica de Richardson-Schottky (RS) ${ }^{[27-29]}$, onde a injeção de portadores dos eletrodos no polímero ocorre através de uma única barreira energética $\Delta$, originária da diferença entre a função trabalho do metal, usado como eletrodo, e a afinidade eletrônica dos polímeros. Devido à ausência de estados estendidos, o transporte de cargas não ocorre através de estruturas de bandas bem definidas, mas provavelmente através de um processo estocástico, dispersivo ${ }^{[30]}$ ou não. Além disso, impurezas nos polímeros atuam como fontes de armadilhas de portadores de carga, limitando drasticamente as suas mobilidades ${ }^{[31]}$. Defeitos estruturais e conformacionais, reações químicas nas interfaces metal-polímero, impurezas residuais de síntese química, e mudanças nas estruturas poliméricas devidos a fenômenos de degradação têm se mostrado fontes dessas armadilhas ${ }^{[31-34]}$. Entender e desenvolver modelos que interpretem corretamente as propriedades elétricas dos filmes e dispositivos poliméricos, também um dos objetivos dessa tese, deve contribuir para o controle e para a otimização da eficiência dos dispositivos. Alcançar esses objetivos significa conhecer a influência das interfaces metal-polímero e os mecanismos de injeção e de transporte dos portadores de carga nesses sistemas. 


\subsection{Objetivos}

Este trabalho é voltado ao estudo das propriedades ópticas e elétricas de poli( $p$ fenilenovinilenos) (PPV), polianilinas (PANI), derivados desses polímeros e suas aplicações em dispositivos eletrônicos. Foi desenvolvido desde a síntese dos polímeros até as suas aplicações como elementos ativos em PLEDs e dispositivos por efeito de campo (polymer field-effect transistor - PFETs), passando por estudos da absorção, emissão de luz, permissividade, curvas corrente vs. tensão, índice de refração e condutividade complexa dos filmes e/ou dos dispositivos fabricados.

\subsection{Descrição do Trabalho}

No CAPÍTULO 2, apresentamos as características eletrônicas dos polímeros e dos dispositivos poliméricos (PLEDs e PFETs). No CAPÍTULO 3, descrevemos as rotas de síntese química e os métodos de preparação dos filmes e substratos. Também apresentamos as caracterizações dos substratos preparados. No CAPÍTULO 4, descrevemos as técnicas de medidas elétricas (condutividade ac e dc), medidas ópticas (absorção no ultravioletavisível e infravermelho, luminescência e elipsometria), e os equipamentos utilizados nesse trabalho. No CAPÍTULO 5, apresentamos as caracterizações ópticas e elétricas dos filmes poliméricos. Destaca-se: o estudo do comportamento da condutividade elétrica ac da polianilina, como função do seu grau de dopagem em ácido clorídrico, através do modelo de energias livres aleatórias (random free energy barrier model-RFEB). No CAPÍTULO 6, apresentamos o estudo da fotoxidação do poli[(2-metóxi-5-hexilóxi)-p-fenilenovinileno] (MH-PPV), através de medidas de absorção (no ultravioleta-visível e no infravermelho), do índice de refração e da função pseudo-dielétrica. Destaca-se o modelo baseado na equação de Lorenz-Lorentz, que foi desenvolvido e utilizado para descrever tal efeito como função do tempo de exposição do polímero à luz. No CAPÍTULO 7, apresentamos as caracterizações elétricas e ópticas dos PLEDs de PPV e MH-PPV, destacando-se os modelos de circuitos equivalentes e de barreiras livres aleatórias (RFEB), utilizados para explicar o comportamento da impedância complexa dos dispositivos como função dos materiais usados como eletrodo e da espessura da camada polimérica. No CAPÍTULO 8, apresentamos as características de PFETs utilizando poli(o-metoxianilina) (POMA) como elemento ativo desse dispositivo, e o modelo elaborado e utilizado para explicar o seu 
comportamento elétrico. Por último, no CAPÍTULO 9, apresentamos as conclusões dessa Tese e as perspectivas de trabalhos futuros. 


\section{Capítulo 2}

\section{Polímeros e Dispositivos Eletrônicos}

Polímeros conjugados são materiais com características semicondutoras que podem apresentar altos valores de condutividade elétrica ou propriedades luminescentes. Nesse capítulo apresentamos uma breve descrição das origens dessas propriedades, passando pelas características ópticas e elétricas dos polímeros, até as suas aplicações como elementos ativos de dispositivos eletrônicos.

\subsection{Propriedades Eletrônicas dos Polímeros Conjugados.}

As propriedades eletrônicas no campo dos materiais poliméricos basicamente se reduzem àqueles que apresentam estrutura conjugada, isto é, alternância de ligações simples e duplas. A Fig. 2.1 apresenta os nomes e as fórmulas estruturais de alguns polímeros conjugados encontrados na literatura ${ }^{[9]}$. Essa figura também mostra a estrutura química simplificada da polianilina, que apesar de ter sua conjugação interrompida pela presença de nitrogênios amina, também se comporta como um sistema conjugado.

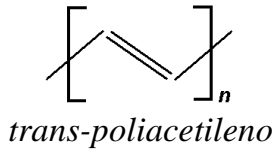

$(1,5 \mathrm{eV})$

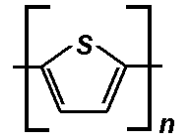

politiofeno $(2,0 \mathrm{eV})$

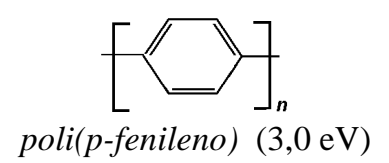

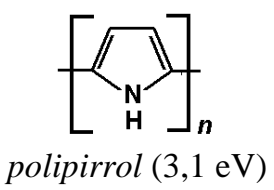

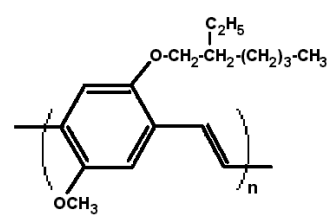

poli[2-metóxi, 5-(2'etil-hexiloxi)-pfenilenovinileno] $(2,1 \mathrm{eV})$

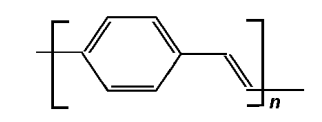

poli(p-fenilenovinileno)

$(2,5 \mathrm{eV})$

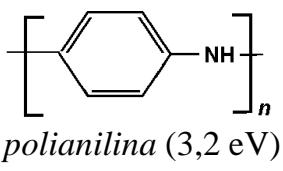

Figura 2.1: Nomes, fórmulas estruturais e gaps (lacunas de energia) de alguns polímeros conjugados ${ }^{[9]}$.

A estrutura eletrônica desses polímeros pode ser convenientemente descrita em termos da sobreposição de orbitais $p_{z}$ provenientes da hibridação $s p^{2}+p_{z}$ dos seus átomos de carbono ${ }^{[9]}$. Nesse caso, ligações $\sigma$ (formadas pela sobreposição dos orbitais híbridos 
$s p^{2}$ ) unem os átomos de carbono na cadeia polimérica principal, enquanto ligações $\pi$ (formadas pela sobreposição dos orbitais $p_{z}$ ) dão origem a orbitais ocupados $\pi$ e vazios $\pi^{*}$, que se abrem, obedecendo a instabilidade de Peierls ${ }^{[9,35-37]}$ (ligações C-C são mais longas que ligações $\mathrm{C}=\mathrm{C}$ ), originando orbitais moleculares análogos às conhecidas bandas de condução e de valência encontradas nos semicondutores inorgânicos. Denominados de HOMO (highest occupied molecular orbital) e de LUMO (lowest unoccupied molecular orbital), a diferença de energia entre esses orbitais (gap ou gap $\pi$ - $\pi^{*}$ ) situa-se entre 1,5 e 4,0 eV, fornecendo a esses materiais propriedades eletrônicas importantes. Os valores dos gaps de alguns polímeros conjugados ${ }^{[9]}$ são indicados na Fig. 2.1.

Dentre os polímeros conjugados, o trans-poliacetileno ( $t$-PA) é o material que apresenta a estrutura química mais simples e, por esse motivo, tem sido usado como um protótipo para o estudo das propriedades eletrônicas desses materiais. A Fig. 2.2-(a) mostra a configuração dos átomos de carbono e a estrutura de bandas do $t$-PA dimerizado, ou seja, respeitando a instabilidade de Peierls ${ }^{[37]}$. Nesse caso, uma diferença de $0,1 \AA^{[35]}$ entre os comprimentos das suas ligações $\mathrm{C}-\mathrm{C}$ e $\mathrm{C}=\mathrm{C}$ dá origem a um gap de $1,5 \mathrm{eV}$. Os níveis entre $-\pi / 2 \mathrm{a}$ e $\pi / 2 \mathrm{a}$ estão todos ocupados, e fora deles, todos vazios. A título de ilustração, a Fig. 2.2-(b) mostra a possível estrutura de bandas do $t$-PA caso os seus átomos de carbono não respeitassem a instabilidade de Peierls. Nesse caso o polímero apresentaria um arranjo de rede quasi-unidimensional, que o caracterizaria como um metal ${ }^{[35]}$, pois a banda entre $-\pi / 2$ a e $\pi / 2$ a estaria semi-preenchida.

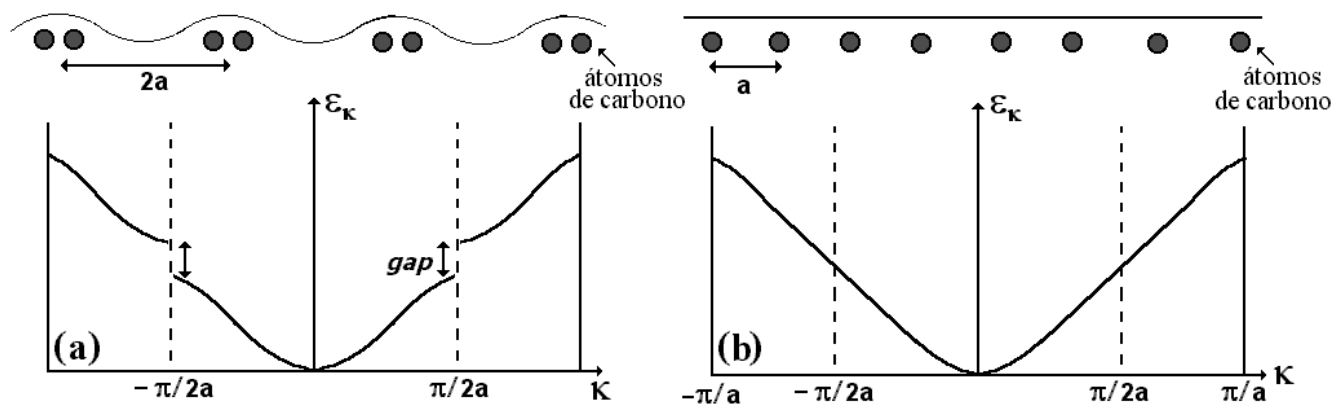

Figura 2.2: Estrutura de bandas do $t$-PA, onde $\mathrm{k}$ é o vetor de onda e $\varepsilon_{\mathrm{k}}$ é a energia. (a) respeitando a instabilidade de Peierls e (b) caso o sistema não respeitasse essa instabilidade.

Outra característica única e muito importante do $t$-PA é que a sua estrutura polimérica no estado fundamental pode apresentar duas sequiências de ligações $\mathrm{C}-\mathrm{C}$ e $\mathrm{C}=\mathrm{C}$ com a mesma energia, ou seja, uma seqüência de ligações simples/dupla e uma outra de ligações dupla/simples (Fig. 2.3). Através da introdução de defeitos estruturais a cadeia 
polimérica pode adotar configurações que se alternam entre essas duas sequiências e mantendo a sua energia. Esses defeitos são denominados de sólitons, pela sua localização e translação sem perda energética, e sua presença está ligada à introdução de um nível de energia localizado no meio do gap do polímero ${ }^{[35,36]}$. A Fig. 2.3 mostra uma possível cadeia do $t$-PA formada pelas duas sequiências degeneradas (A e B) e um defeito sóliton.

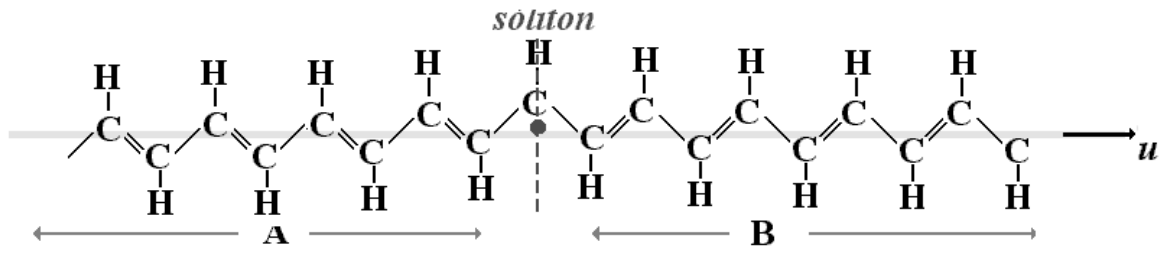

Figura 2.3: Possível cadeia do $t$-PA.

O sóliton é um defeito eletricamente neutro e possui spin eletrônico $1 / 2\left(s^{0}\right)$. Ele também pode existir em dois outros estados, caso espécies doadoras ou receptoras sejam adicionadas à cadeia do $t$-PA. Em ambos os casos, o sóliton não apresenta spin eletrônico, mas torna-se um portador de carga positivo $\left(s^{+}\right)$, quando um elétron é removido, e negativo $\left(s^{-}\right)$, quando um elétron é adicionado. A Fig. 2.4 mostra, simplificadamente, a representação dos níveis desses defeitos.

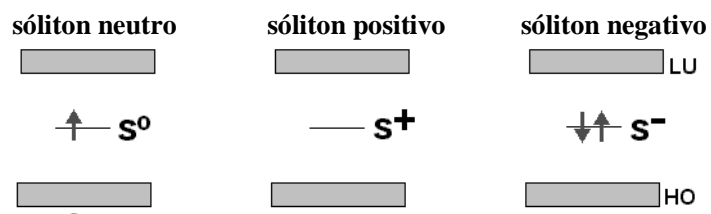

Figura 2.4: Níveis de energia dos sólitons em um estado polimérico degenerado ( $t$ - $P A)$. LU e HO são abreviações de, respectivamente, LUMO e HOMO.

O $t$-PA é o único polímero que apresenta a degenerescência de estados. Em todos os outros polímeros conjugados, inclusive o cis-poliacetileno (cis-PA), as duas regiões que são separadas por um defeito estrutural possuem energias diferentes ${ }^{[9,12]}$. Para estabelecer uma condição de equilíbrio, ou uma minimização de energia, os defeitos nesses materiais sempre ocorrem juntamente com a presença de um anti-defeito (ou anti-sóliton), de tal forma que a seqüência de energia mais alta esteja disposta entre eles ${ }^{[35,36]}$. Esse par de sólitons pode decair rapidamente se ambos os defeitos forem neutros, mas pode se estabelecer se forem carregados positiva ou negativamente. Esses defeitos são denominados de pólarons e a sua criação está diretamente ligada a formação de estados ligantes e anti-ligantes dentro do gap desses polímeros. Quando carregados positivamente, eles são denominados de pólarons positivos $\left(p^{+}\right)$, e quando carregados negativamente de 
pólarons negativos $\left(p^{-}\right)^{[35]}$. Esses pares possuem spin eletrônico $1 / 2$ e quando um pólaron positivo encontra um negativo eles podem se ligar e se recombinar emitindo luz. A esse defeito dá-se o nome de éxciton singleto ${ }^{[9]}$. Por fim, quando dois pares sóliton-(antisóliton) se encontram eles dão origem a outro tipo de defeito, que possui spin eletrônico nulo, e é denominado de bipólaron. Quando seus estados são ocupados por 4 elétrons eles são denominados de bipólarons negativos $\left(b p^{2-}\right)$ e quando não são ocupados por elétrons, de bipólarons positivos $\left(b p^{2+}\right)^{[35,36]}$. A Fig. 2.5 mostra, simplificadamente, a representação dos níveis de energias dos estados pólarons e bipólarons.
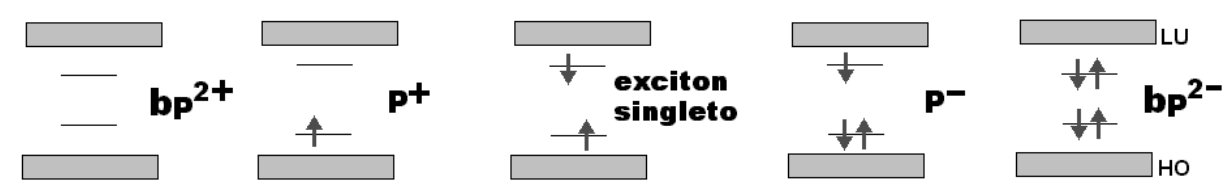

Figura 2.5: Níveis de energia dos pólarons, dos bipólarons e do éxciton singleto em um estado polimérico não degenerado.

Um exemplo claro de formação de pólarons é observado na cadeia do poli( $p$ fenileno) (PPP). Nesse polímero, duas são as suas possíveis estruturas no estado fundamental: uma de menor energia (sequiência de anéis aromáticos benzenóides) e outra de mais alta energia (seqüência de anéis quinóides). As Figs. 2.6-(a) e 2.6-(b) mostram essas estruturas, enquanto a Fig. 2.6-(c) mostra a representação de um pólaron positivo nesse polímero, que possui uma possível sequiência de dois anéis quinóides disposta entre um defeito sóliton e seu antidefeito ${ }^{[35]}$.

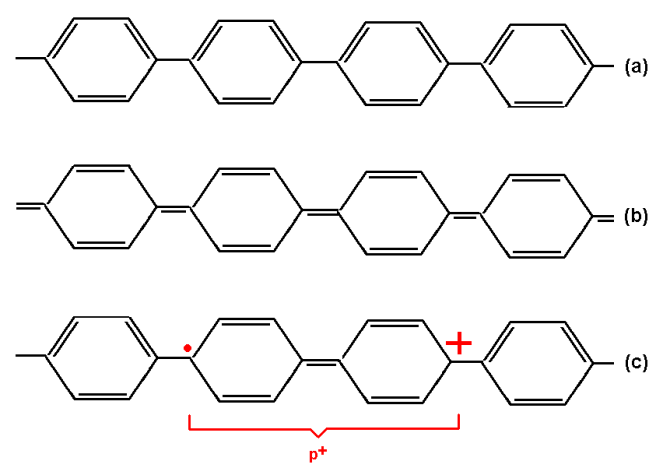

Figura 2.6: (a) e (b) estruturas não-degeneradas do PPP e (c) pólaron positivo.

De um modo geral, éxcitons singletos são os grandes responsáveis pelas propriedades luminescentes dos polímeros conjugados. Nesse caso, a promoção de elétrons do estado fundamental para o excitado, que depois podem se relaxar e emitir luz, pode ocorrer através de injeção de cargas ou luz (excitação) ${ }^{[9,38,39]}$. A energia característica 
dessa transição pode ser obtida a partir de espectros de absorção na região do ultravioletavisível, ou a partir de espectros de emissão na região do visível. Polímeros também podem apresentar um espectro eletrônico com uma estrutura fina vibracional associado aos movimentos vibracionais das suas moléculas. Nesse caso, espectros de absorção fornecem as energias associadas às transições eletrônicas do nível vibracional mais baixo do estado eletrônico fundamental para diferentes subníveis vibracionais de um estado eletrônico excitado, enquanto os espectros de emissão podem fornecer as energias de transição do nível vibracional mais baixo do estado eletrônico excitado para os diferentes subníveis vibracionais do estado eletrônico fundamental. Como conseqüência, uma diferença de energia pode ser observada entre os máximos dos espectros de absorção e de emissão. Essa diferença é conhecida como deslocamento de Stokes ${ }^{[9,39]}$ e está associado às perdas por transições não-radiativas dos portadores de carga e pares excitados devido às características químicas, morfológicas e estruturais dos polímeros. Como exemplo, a Fig. 2.7 mostra os processos de emissão e absorção entre os estados eletrônicos fundamental $\left(\mathrm{S}_{0}\right)$ e o excitado $\left(\mathrm{S}_{1}\right)$ de uma molécula orgânica e a sua respectiva estrutura fina vibracional.

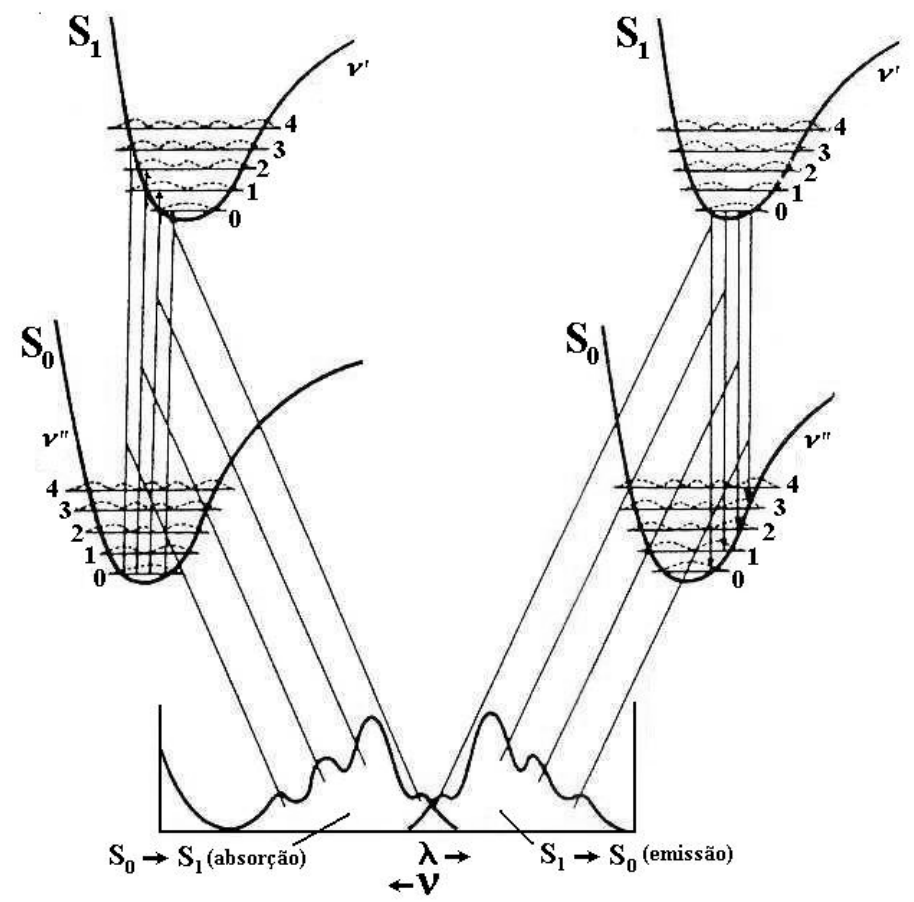

Figura 2.7: Processos de absorção e emissão entre os estados eletrônicos fundamental $\left(\mathrm{S}_{0}\right)$ e excitado $\left(\mathrm{S}_{1}\right)$ de uma molécula orgânica ${ }^{[39]}$.

Uma das técnicas mais usadas para se obter os espectros de emissão dos polímeros é a excitação do material com um feixe de luz de energia bem definida. Esse processo é 
denominado de fotoluminescência (photoluminescence - PL) ${ }^{[9,38]}$, e ocorre através da fotoexcitação de elétrons do orbital HOMO para o orbital LUMO, que depois podem se recombinar em um segmento da cadeia, formando um éxciton singleto, e decair emitindo um fóton. A Fig. $2.8^{[9,38]}$ exemplifica o mecanismo de PL mostrando: (a) a excitação do polímero, (b) a formação do éxciton singleto e (c) a recombinação do éxciton singleto emitindo um fóton (emissão). Os éxcitons também podem decair não radiativamente em estados tripletos, ou ainda serem capturados por defeitos (armadilhas), o que limita a emissão, ou eficiência, desse processo.

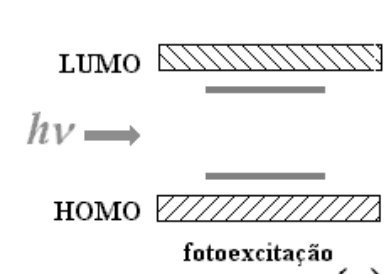

(a)

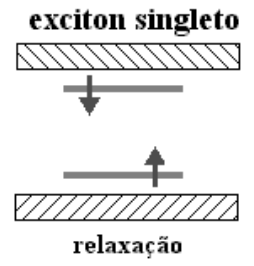

(b)

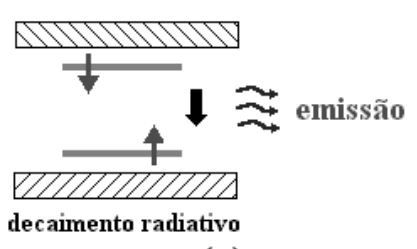

(c)

Figura 2.8: Esquema representativo da PL. (a) fotoexcitação, (b) formação do éxciton singleto e (c) emissão.

Outro fenômeno de excitação muito importante é o fenômeno de eletroluminescência (electroluminescence - EL) ${ }^{[9,31,38]}$. Nesse caso, o polímero é ensanduichado entre dois eletrodos metálicos diferentes que, de acordo com as suas funções trabalho e sob a aplicação de um campo elétrico, podem injetar elétrons no orbital HOMO ou buracos no orbital LUMO, gerando pólarons negativos e positivos, que podem migrar sob a influência do campo e se combinar em um segmento da molécula formando éxcitons singletos, seguindo os mesmos passos descritos para a fotoluminescência.

\subsection{Diodos e Transistores Poliméricos}

Na década de 80, do século XX, a identificação de barreiras Schottky formadas nas interfaces poliacetileno/metal incentivou o uso de polímeros conjugados como elementos ativos em dispositivos eletrônicos ${ }^{[6,9,12]}$. Desde então, com o aprimoramento das rotas de síntese química e o avanço das técnicas de deposição nas décadas seguintes, vários dispositivos eletrônicos foram estudados, destacando-se os diodos Schottky e os transistores tipo MIS-FETs (metal-isolante-semicondutor) poliméricos. A seguir destacamos as características desses dois dispositivos. 
Diodos poliméricos de barreira Schottky são compostos de uma fina camada de polímero dopado colocada entre dois eletrodos metálicos que, sob tensão aplicada, fornece uma corrente que depende tanto da escolha das funções trabalho dos metais, quanto das propriedades semicondutoras dos polímeros. A Fig. 2.9 mostra a estrutura desse diodo e uma curva característica corrente vs. tensão ( $I$ vs. V) desse dispositivo. Em muitos casos, valores de corrente obtidos no modo direto $(V>0)$ são milhões de vezes maiores que os valores obtidos no modo reverso, o que intensifica a potencialidade desses materiais como candidatos a elementos ativos desses dispositivos eletrônicos.

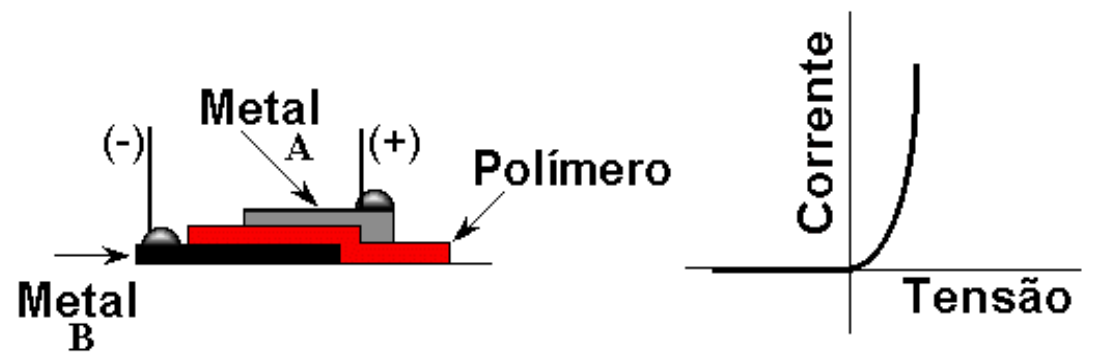

Figura 2.9: Estrutura e curva característica $I v s . V$ de um diodo polimérico.

Nas décadas de 80 e 90, do século XX, o domínio das técnicas de litografia desenvolvidas para os dispositivos a base de silício incentivou alguns grupos de pesquisa a desenvolver técnicas similares e que pudessem ser usadas na fabricação de transistores de efeito de campo inteiramente poliméricos ${ }^{[40-42]}$. Nesses dispositivos, polímeros dopados funcionariam como os eletrodos dreno, fonte e porta, polímeros convencionais funcionariam como a camada isolante, e polímeros conjugados, em seu estado semicondutor, funcionariam como elemento ativo. Entretanto, a difusão de dopantes entre as junções de polímeros dopados e não-dopados limitaram a caracterização elétrica desses dispositivos ${ }^{[43]}$. Desde então, adaptações das estruturas de transistores convencionais tornaram-se as alternativas mais viáveis a serem realizadas. Nesse contexto, estruturas do tipo MIS-FET utilizando silício dopado ( $\mathrm{Si}$ ) como eletrodo porta, dióxido de silício $\left(\mathrm{SiO}_{2}\right)$ como camada isolante, eletrodos metálicos interdigitais como contatos dreno e fonte, e um polímero conjugado em seu estado semicondutor como elemento ativo passaram a ser as configurações mais utilizadas ${ }^{[6,9,44-46]}$. A Fig. 2.10 mostra a estrutura típica de um transistor de efeito de campo polimérico (polymer field-effect transistor, PFET) e suas características físicas e elétricas ${ }^{[45]}$. 
(a)
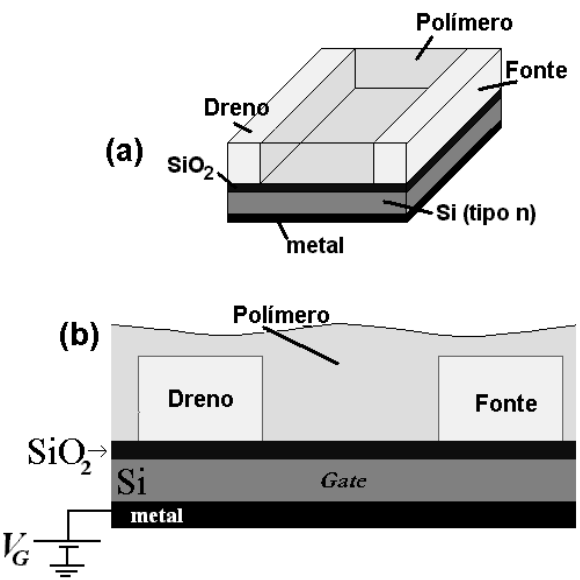

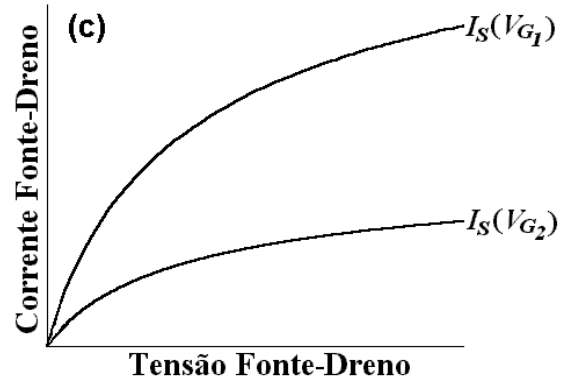

Figura 2.10: MIS-FET (metal-isolante-semicondutor) usando polímero como camada ativa. Vista lateral do dispositivo (a) e (b), e (c) curvas $I_{S D} v s$. $V_{S D}$ obtidas variando-se $V_{G}$.

Nessa figura, o polímero é depositado sobre dois eletrodos metálicos, previamente confeccionados sobre um filme fino de $\mathrm{SiO}_{2}$. Sob a aplicação de uma tensão entre esses dois eletrodos ( $V_{S D}$, do inglês, $S$ - source, $D$ - drain), uma corrente $\left(I_{S D}\right)$ pode ser detectada. Aplicando-se uma tensão na lâmina de silício sob o filme de óxido ( $V_{G}$, do inglês gate voltage), ou seja, polarizando o óxido, variações no comportamento das curvas $I_{S D} v s$. $V_{S D}$ passam a ser observadas. Dependendo do valor de $V_{G}$ e da espécie do portador (carga positiva ou negativa), uma corrente de saturação $\left(I_{S}\right)$ alta ou baixa pode ser detectada, como mostra a Fig. 2.10-(c). Caso os portadores sejam positivos, nessa mesma figura, a corrente de saturação para $V_{G}$ negativo $\left(V_{G l}\right)$ é maior que a obtida para um valor de $V_{G}$ positivo $\left(V_{G 2}\right)^{[46]}$.

Embora as curvas dos PFETs sejam similares às dos tradicionais FETs inorgânicos, Fig. 2.10-(c), os conceitos de camada de inversão e de portadores minoritários não são aplicados para esses dispositivos, o que exige uma nova modelagem para os mecanismos de funcionamento desses transistores ${ }^{[46]}$. Além disso, devido à estrutura desordenada dos polímeros conjugados e as altas densidades de armadilhas de portadores de carga desses materiais, a mobilidade eletrônica dos portadores ainda é muito baixa $\left(<1 \mathrm{~cm}^{2} / \mathrm{Vs}\right)^{[31,43]}$, o que é um fator limitante para a aplicação desses dispositivos em telecomunicações. Porém, estudos sobre o comportamento das curvas características desses sistemas podem fornecer indícios sobre as origens das propriedades elétricas e das características dos portadores de carga dos polímeros, o que é um dos objetivos desse trabalho. 


\subsection{Diodos Emissores de Luz Poliméricos}

Os dispositivos emissores de luz de polímeros (polymer light-emitting diodes PLEDs) têm estrutura e curvas características $I$ vs. $V$ semelhantes às dos diodos Schottky, Fig. 2.9. De um modo geral, PLEDs são preparados a partir de uma fina camada (algumas de centenas de nanômetros) de um polímero luminescente entre dois eletrodos que, sob voltagem aplicada, injetam elétrons e buracos no interior do material, descrevendo o processo de EL descrito no item 2.1 ${ }^{[31,38]}$. A Fig. 2.11 mostra a estrutura de um PLED com um eletrodo metálico e um eletrodo transparente de óxido de estanho e índio (ITO, do inglês indium-tin oxide).

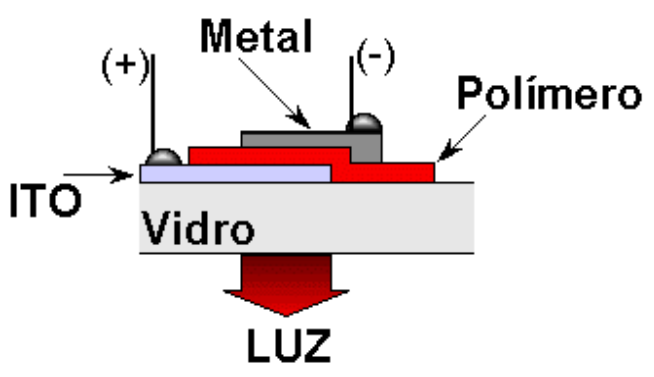

Figura 2.11: Estrutura típica de um PLED.

A escolha dos eletrodos é um fator importante no desempenho e no funcionamento dos PLEDs, pois eles controlam diretamente a injeção dos elétrons e dos buracos no interior do polímero ${ }^{[9,28,31]}$. Assim, os cátodos devem possuir baixo valor de função trabalho, facilitando a injeção de elétrons, enquanto os ânodos, por outro lado, devem possuir alto valor de função trabalho, justamente para facilitar a injeção de buracos. O ITO é o ânodo mais utilizado na preparação dos PLEDs por ser transparente, possuir baixa resistência superficial ( $c$ a $10-30 \Omega /$ ) e ter função trabalho próxima a energia HOMO dos polímeros da família do PPV ${ }^{[16]}$. Já o cálcio (Ca) é atualmente o material mais adequado usado como cátodo, por possuir baixo valor de função trabalho, o que, do ponto de vista eletrônico, é o melhor injetor de elétrons conhecido, entretanto sua limitação de uso vem do fato de ser bastante reativo na presença de água e oxigênio. A Fig. 2.12 ilustra o diagrama de energias para um PLED de PPV com anôdo de ITO e diferentes cátodos metálicos ${ }^{[16,28]}$. Os valores das funções trabalho apresentados podem variar de acordo com a pureza do metal utilizado e/ou da interação metal-polímero formada ${ }^{[28]}$. 


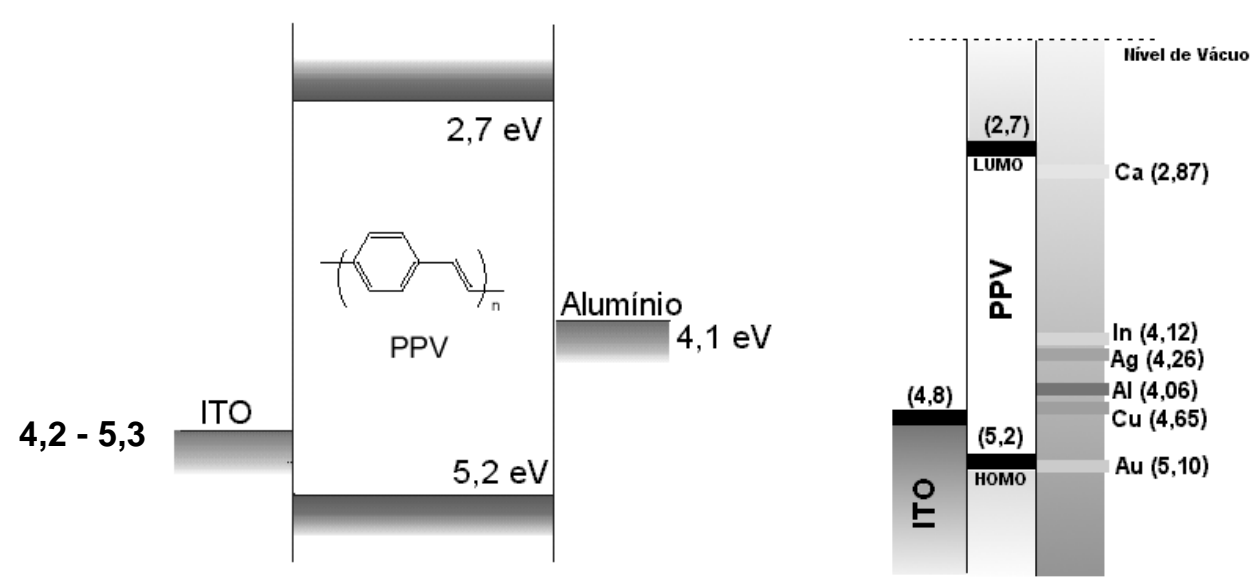

Figura 2.12: Diagrama de energias (função trabalho, HOMO e LUMO) entre o ITO, o PPV e diversos ânodos metálicos ${ }^{[16,28]}$.

A cor emitida dos PLEDs depende do valor do gap $\pi$ - $\pi^{*}$ dos polímeros utilizados ${ }^{[15]}$. Já a eficiência quântica desses dispositivos depende, entre outros fatores, da taxa de recombinação e do decaimento radiativo dos éxcitons singletos ${ }^{[9]}$. Quando pólarons negativos e positivos se recombinam para formar um éxciton singleto, os spins eletrônicos podem apontar na mesma direção (estados tripletos) ou em direções opostas (estados singletos,). No entanto, segundo obediência a estatística de spins, e não considerando efeitos cruzados, apenas os estados excitados singletos podem decair para o estado fundamental emitindo um fóton, limitando o máximo de eficiência em $25 \%$ ${ }^{[9,12]}$,

Em termos das funções trabalhos dos metais usados como eletrodos e dos processos de injeção e transporte de portadores, o mecanismo de eletroluminescência pode ser explicado seguindo os passos apresentados na Fig. $2.13^{[31]}$. Nesse esquema, portadores positivos são injetados pelo ânodo e essa injeção depende, em primeira aproximação, da diferença de energia $\left(\Delta_{\mathrm{h}}\right)$ entre a função trabalho do ânodo $\left(\phi_{\mathrm{A}}\right)$ e a energia do nível HOMO ( $\left.\phi_{\text {Номо }}\right)$ do polímero. Portadores negativos, por sua vez, são injetados pelo cátodo e dependem da diferença de energia $\left(\Delta_{\mathrm{e}}\right)$ entre a função trabalho $\left(\phi_{\mathrm{C}}\right)$ e da energia do nível LUMO ( $\phi_{\text {LUMO }}$ ), como mostra o passo (1). Uma vez injetados no material, esses portadores dão origem a pólarons positivos e negativos nas cadeias desse material que são transportados pelo efeito do campo elétrico até atingirem seu contra-eletrodo (2), ou relaxarem em um único segmento formando um éxciton singleto (3), ou ainda serem aprisionados nas diferentes fontes de armadilhas dispostas no volume do polímero. No caso dos éxcitons singletos, esses ainda podem decair (4) emitindo luz. 


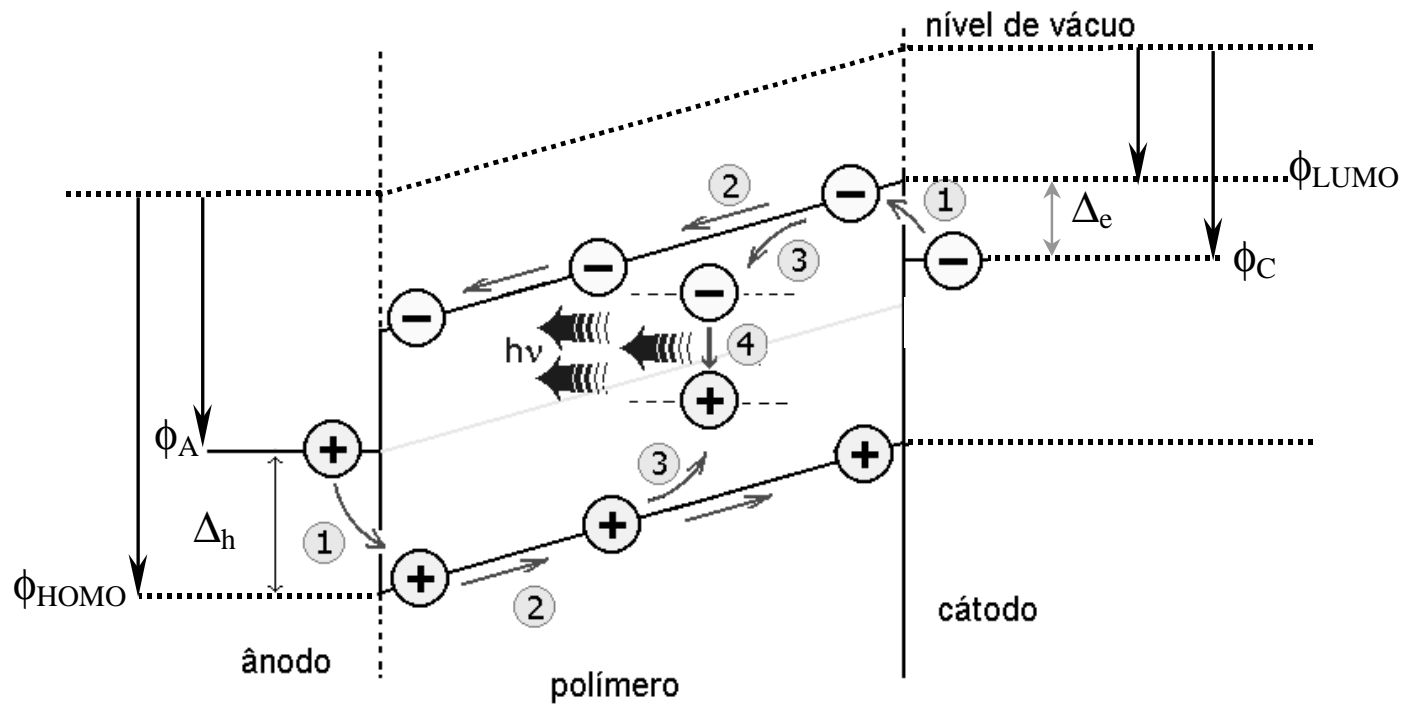

Figura 2.13: Passos básicos da eletroluminescência: (1) injeção dos portadores, (2) transporte dos portadores, (3) formação do éxciton e (4) processo de decaimento radiativo. $\phi_{\mathrm{A}}$ : função trabalho do ânodo, $\phi_{\mathrm{C}}$ : função trabalho do cátodo, $\Delta_{\mathrm{e}}$ : barreira energética para a injeção de elétrons, $\Delta_{\mathrm{h}}$ : barreira energética para a injeção de buracos ${ }^{[31]}$. 


\section{Capítulo 3}

\section{Síntese dos Polímeros, Métodos de Preparação de Filmes, e Preparação e Caracterização de Substratos}

Nesse capítulo serão apresentadas as rotas de síntese química dos polímeros, os métodos de preparação de filmes, os métodos de confecção, limpeza, tratamento químico e caracterização dos substratos utilizados nesse trabalho. Foram selecionados dois polímeros condutores para a fabricação de transistores - a polianilina (PANI) e a poli $(o$ metoxianilina) (POMA) - e três polímeros luminescentes para a fabricação de dispositivos emissores de luz - o poli(p-fenilenovinileno) (PPV), o poli[(2-metóxi,5-hexilóxi)-pfenilenovinileno] (MH-PPV) e o poli[(2-metóxi,5-dodecóxi)-p-fenilenovinileno] (MDPPV). A Fig. 3.1 mostra as fórmulas estruturais desses polímeros.
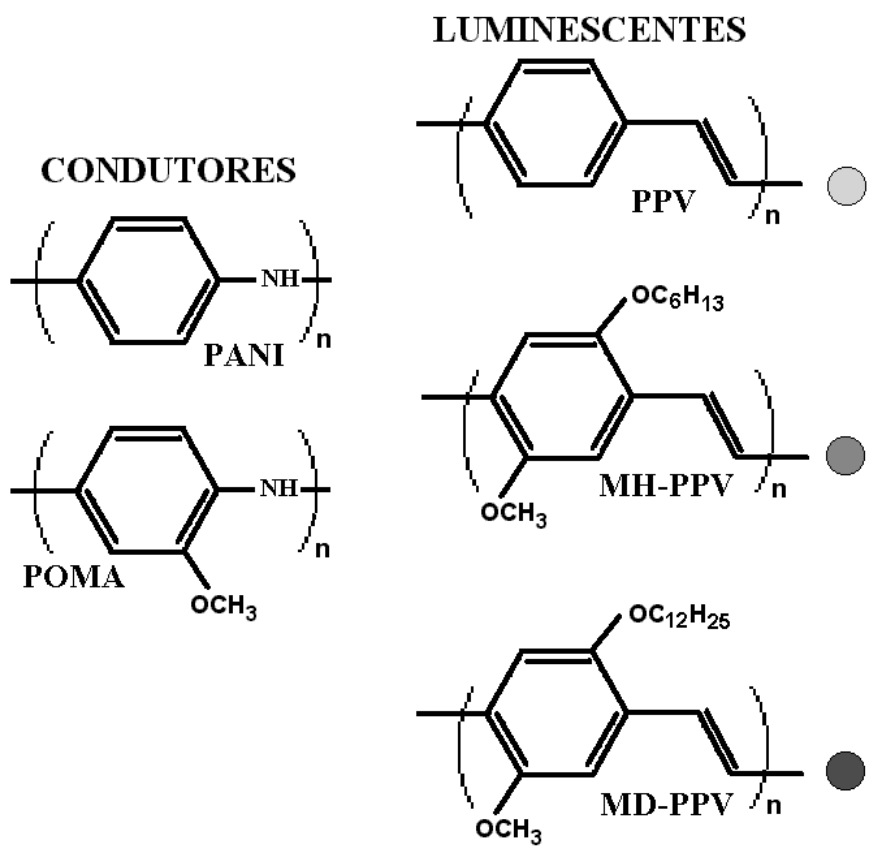

Figura 3.1: Fórmulas estruturais dos polímeros utilizados. Os círculos, ao lado das estruturas dos polímeros luminescentes, representam as cores referentes aos máximos dos seus espectros de emissão. 


\subsection{Síntese Química dos Polímeros}

Após a descoberta do poliacetileno em 1977, inúmeros polímeros conjugados foram quimicamente sintetizados. Entretanto, os primeiros materiais apresentavam baixa resistência mecânica, baixa massa molar, e difícil processabilidade, o que prejudicava a formação de filmes finos ${ }^{[12]}$. Para modificar essas características, inúmeras rotas de síntese foram elaboradas e aperfeiçoadas no decorrer dos anos. Em especial no caso dos polímeros luminescentes, uma das primeiras estratégias realizadas foi a preparação de filmes poliméricos através da conversão de um polímero precursor ${ }^{[9,12,47-49]}$, normalmente um polieletrólito solúvel em água ou outro solvente apropriado. Nesse processo, filmes finos do polieletrólito são depositados sobre substratos adequados e, posteriormente, convertidos “in situ” em um polímero conjugado. Exemplos desses polímeros são o poli(p-fenileno) PPP e o poli( $p$-fenilenovinileno) - PPV. Outra técnica mais recente e muito utilizada é a introdução de cadeias laterais longas e flexíveis, por exemplo, através de grupos alquila e alcóxi ${ }^{[9,50,51]}$ nos anéis aromáticos das cadeias poliméricas. A presença desses grupos diminui a rigidez da cadeia, aumentando a solubilidade do material em alguns solventes orgânicos e possibilitando a formação de filmes sem a necessidade da etapa de conversão. Exemplos desses polímeros são os poli(3-alquiltiofeno) - P3AT, o poli[2-metóxi,5-(2'etilhexiloxi)-p-fenilenovinileno] - MEH-PPV, e o poli[(2-metóxi,5-hexiloxi)-pfenilenovinileno] - MH-PPV. Outras rotas de síntese têm sido comumente realizadas, como é o caso da síntese química da polianilina - PANI ${ }^{[52-54]}$, que emprega um agente oxidante para promover a polimerização da anilina, produzindo um polímero com boa capacidade de formação de filmes e boas estabilidades química e térmica.

A seguir são descritas as rotas de síntese usadas para obtenção dos polímeros usados nesse trabalho.

\subsubsection{Polianilina - (PANI)}

A polianilina ${ }^{[52-54]}$ é um dos polímeros condutores com forte potencial para ser utilizado em dispositivos eletrônicos devido, principalmente, à sua fácil obtenção e ao controle da sua condutividade com ácidos/bases de Brönsted. Esse polímero pode existir na forma de base ou sal, dependendo do método de preparação utilizado. Sua fórmula 
estrutural consiste de uma fração de unidades reduzidas (contendo grupos amina: y) e uma fração de unidades oxidadas (contendo grupos imina: 1-y), como mostra a Fig. $3.2^{\text {[54] }}$. Quando y = 0,5 ela é denominada de base esmeraldina, sendo a sua forma mais estável e condutora ${ }^{[52]}$.

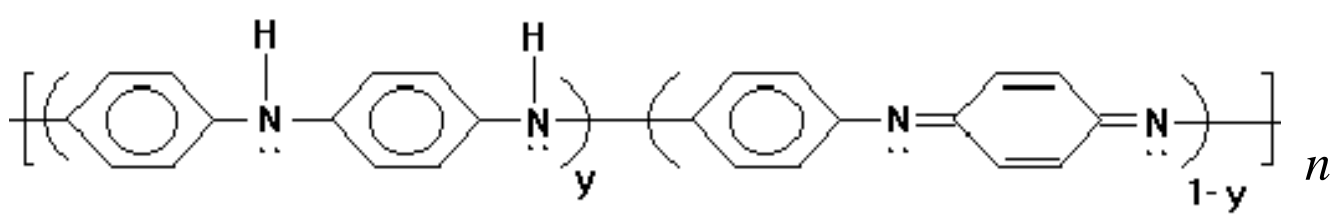

Figura 3.2: Fórmula estrutural da PANI.

Em solução aquosa de ácido clorídrico, a PANI pode ter sua condutividade aumentada em até 13 ordens de grandeza. Essa variação ocorre através da protonação do nitrogênio do grupo imina e, conseqüentemente, pela formação de um pólaron positivo. De um modo geral, o ácido clorídrico $(\mathrm{HCl})$ é o dopante mais utilizado por possuir um alto grau de dissociação em meio aquoso, visto que é um ácido forte. O processo de dopagem é reversível e o retorno ao polímero original, processo de desdopagem, acarreta pouca ou nenhuma degradação da sua cadeia polimérica principal.

Para a realização da síntese química desse polímero foi utilizada a técnica que emprega um excesso de monômero em meio fortemente ácido em baixa temperatura, por ser de fácil realização e acompanhamento experimental ${ }^{[54]}$. Para isso, foi utilizado como monômero a anilina, a qual foi purificada pelo método de destilação fracionada a fim de eliminar todas as substâncias oxidadas. Após a polimerização, o polímero foi tratado com solução básica de hidróxido de amônio $\left(\mathrm{NH}_{4} \mathrm{OH}\right)$ 0,1 M. Finalmente, o polímero foi lavado com acetona, para eliminar oligômeros e resíduos orgânicos resultantes do processo de polimerização. A seguir são apresentadas as etapas de síntese e obtenção do polímero.

A primeira etapa da síntese é chamada de polimerização. Para isso, 11,52 g de peroxidissulfato de amônio (agente oxidante) são dissolvidos em $200 \mathrm{ml}$ de solução aquosa de $\mathrm{HCl} 1 \mathrm{M}$. Em um segundo béquer, $20 \mathrm{ml}$ de anilina são dissolvidos em $300 \mathrm{ml}$ da mesma solução ácida. Em seguida, os frascos são levados a um banho de gelo e mantidos próximos a temperatura de $0{ }^{\circ} \mathrm{C}$ por cerca de $10 \mathrm{~min}$, ou até a estabilização das suas temperaturas. Logo após, o agente oxidante é lentamente adicionado à anilina e a mistura final é deixada sob agitação a temperatura constante. Após duas horas, a solução apresenta uma coloração verde escura, característica da PANI em seu estado condutor. Esta solução é 
filtrada em um funil de Büchner, com papel Whatman número 41, e posteriormente o polímero é lavado com acetona até o filtrado obtido tornar-se praticamente incolor. A segunda etapa do processo é a desdopagem do material. Para isto, o pó resultante no processo anterior é colocado em $1000 \mathrm{ml}$ de solução de $\mathrm{NH}_{4} \mathrm{OH}$ 0,1 $\mathrm{M}$ e deixado sob agitação por 16 h. A última etapa é a chamada de processo de secagem, onde o material é novamente filtrado e depois espalhado sobre placas de Petri, sendo deixado sob vácuo por 24 horas.

\subsubsection{Poli(o-metoxianilina) - (POMA)}

Um dos derivados da polianilina muito utilizado nas pesquisas científicas é a poli(o-metoxianilina), ou POMA. Esse polímero apresenta um grupo metóxi ligado em posição orto ao grupo amina no anel aromático, o que o torna solúvel em diversos solventes orgânicos, facilitando a sua capacidade de formação de filmes, (veja Fig. 3.1). Para a realização da sua síntese química foi empregado o mesmo método de síntese descrita para a PANI ${ }^{[52]}$. Nesse caso, os $20 \mathrm{ml}$ de anilina foram substituídos por $28 \mathrm{ml} \mathrm{de}$ anisidina (ou orto-metoxianilina) e o tempo de polimerização passou de 2 para 4 horas. Além disso, $120 \mathrm{~g}$ de cloreto de lítio $(\mathrm{LiCl})$ foram adicionados com o agente oxidante na solução, durante a etapa de polimerização, a fim de aumentar a sua massa molar média.

\subsubsection{Poli $(p$-fenilenovinileno) - (PPV)}

O PPV é o primeiro polímero luminescente a ser utilizado como elemento ativo de PLEDs ${ }^{[8]}$. Sua síntese química pode ser dividida em 3 etapas: (a) preparação do monômero, (b) preparação do polieletrólito precursor - poli(xilidenotetrahidrotiofeno) (PTHT), e (c) obtenção do PPV. A metodologia de síntese empregada nas etapas (a) e (b) foi idêntica à descrita na literatura ${ }^{[47,55]}$, enquanto a rota de Massardier et al. ${ }^{[48]}$ foi a empregada para a obtenção do polímero. Nesse item são descritas as etapas da síntese química desse polímero, que foi realizada juntamente com a Dra. Débora Gonçalves. A Fig. 3.3 exemplifica essa síntese química. 


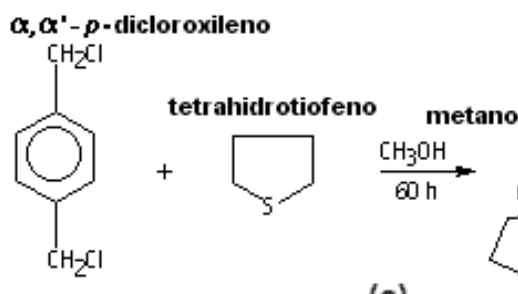

(a)
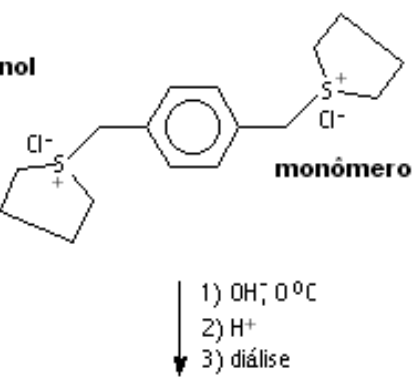

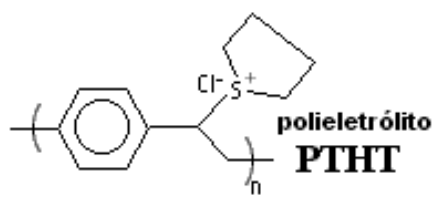

(b)

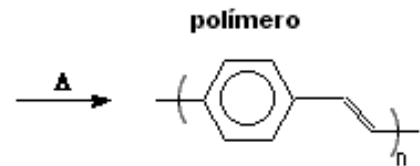

PPV (c)

Figura 3.3: Reações químicas envolvidas para a obtenção do PPV.

Para a preparação do monômero, Fig 3.3-(a), $4 \mathrm{~g}$ de $\alpha, \alpha^{\prime}$-p-dicloroxileno são dissolvidos em $8 \mathrm{ml}$ de metanol em um balão de fundo redondo. A solução é desoxigenada com $\mathrm{N}_{2}$ por alguns minutos e, em seguida, $8 \mathrm{ml}$ de tetrahidrotiofeno são adicionados, gota a gota, à solução utilizando-se um funil de adição. O sistema é deixado em repouso por $c a$. $60 \mathrm{~h}$ e, através da evaporação do metanol, via aquecimento, um precipitado branco é obtido. Para purificação do material, são adicionados $40 \mathrm{ml}$ de acetona resfriada a $0{ }^{\circ} \mathrm{C}$, sob constante agitação, seguido de uma filtração simples. Como produto das reações, ca. $6 \mathrm{~g}$ do monômero são obtidos. Para a preparação do precursor, Fig. 3.3-(b), 4 g do monômero são dissolvidos em $30 \mathrm{ml}$ de metanol resfriado a $0{ }^{\circ} \mathrm{C}$ e desoxigenado com $\mathrm{N}_{2}$. Em seguida, $30 \mathrm{ml}$ de $\mathrm{NaOH}$ 0,4 M desoxigenado são adicionados, gota a gota, à solução sob fraca e constante agitação. Após a total adição, a solução permanece sob agitação por 20 min, quando se adiciona $30 \mathrm{ml}$ de solução $\mathrm{HCl}$ 0,4 M da mesma maneira que a solução de $\mathrm{NaOH}$. A solução resultante é colocada em uma membrana de diálise (10000 $12500 \mathrm{~g} / \mathrm{mol}$ ) dentro de uma proveta, sob proteção da luz, com água trocada a cada duas horas nas primeiras $12 \mathrm{~h}$, e depois a cada $12 \mathrm{~h}$ durante uma semana, para eliminar oligômeros e subprodutos da síntese química. Como resultado, uma solução aquosa de ca. $1,2 \mathrm{mg} / \mathrm{ml}$ do PTHT foi obtida. Para a obtenção do polímero, a solução do precursor é depositada sobre substratos planos que, em seguida, são aquecidos até $200{ }^{\circ} \mathrm{C}$, sob vácuo, permanecendo nessa temperatura por 2 h, Fig. 3.3-(c) 


\subsubsection{Poli[(2-metóxi-5-hexilóxi)-p-fenilenovinileno] - (MH-PPV)}

O MH-PPV é um dos derivados do PPV solúvel em clorofórmio que foi inicialmente sintetizado em nosso grupo pela Dra. Débora T. Balogh. Para a sua obtenção adotou-se uma modificação da rota de síntese química do MEH-PPV proposta por Wudl e Srdanov ${ }^{[50] .}$ Dessa forma, sua síntese pode ser dividida em quatro partes: (a) obtenção do fenóxido, (b) síntese do éter, (c) síntese do bis-cloreto e (d) preparação do polímero. A Fig. 3.4 mostra as reações químicas envolvidas.

(a)

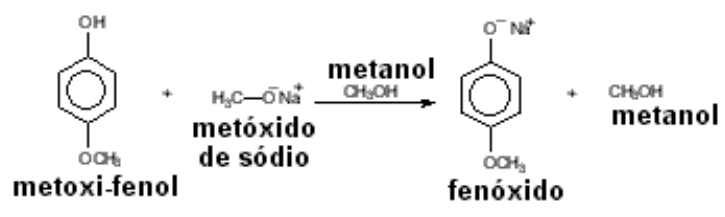

(b)

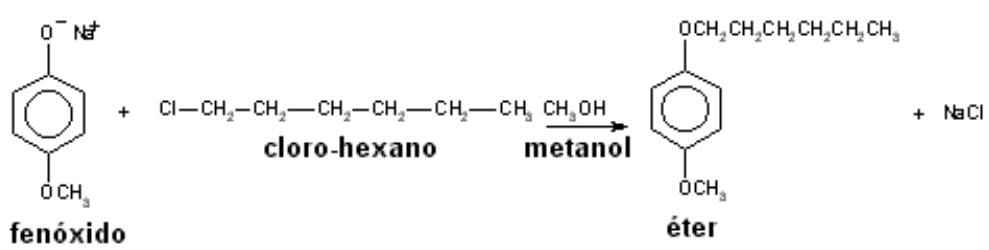

(c)

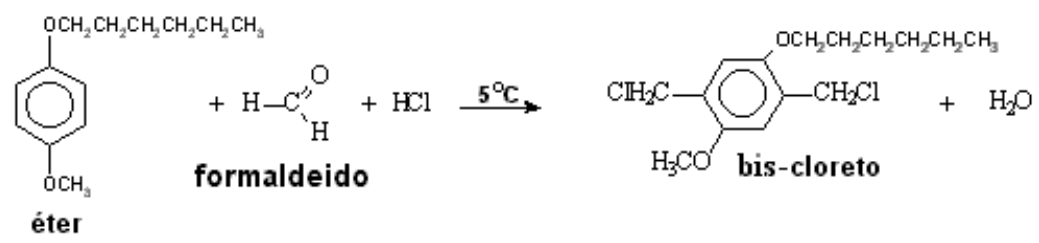

(d)
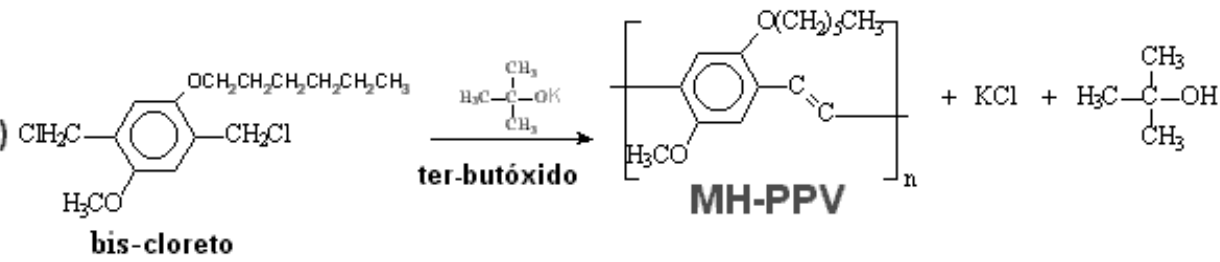

Figura 3.4: Reações químicas envolvidas na síntese do MH-PPV.

Inicialmente, para a obtenção do fenóxido, Fig 3.4-(a), 11 g de metóxi-fenol são dissolvidos em $20 \mathrm{ml}$ de solução de metóxido de sódio em metanol, desoxigenado, e deixado em repouso por $14 \mathrm{~h}$. Em seguida, após a adição de $20 \mathrm{ml}$ de cloro-hexano e $20 \mathrm{ml}$ de metanol, Fig 3.4-(b), a solução é refluxada a $80^{\circ} \mathrm{C}$ durante 9 h. Evapora-se o solvente e $50 \mathrm{ml}$ de éter etílico são adicionados. A solução é transferida para um funil de separação e adiciona-se $20 \mathrm{ml}$ de solução de hidróxido de sódio a $10 \%$. Nesse momento, duas fases são observadas. A fase inferior (aquosa) é coletada em um Erlenmeyer e $50 \mathrm{ml}$ de solução de hidróxido de sódio são adicionados à fase éter, retirando-se, novamente, a fase aquosa. 
Repetiu-se a adição do hidróxido de sódio e a retirada da fase aquosa até que a fase aquosa estivesse incolor. Para finalizar, água destilada é adicionada no funil até que fase aquosa apresente $p H$ neutro. A fase resultante (éter) é coletada em um béquer e um fluxo de nitrogênio é passado na solução, até que essa começasse a cristalizar. Os cristais são separados por decantação, lavados com éter gelado e levados para um dessecador, até a total cristalização do éter (cerca de 24 - 48 h). Para finalizar, os cristais são guardados protegidos da luz e sob vácuo.

Na etapa de obtenção do bis-cloreto, Fig. 3.4-(c), foi necessário montar o sistema de geração de ácido clorídrico $(\mathrm{HCl})$ mostrado na Fig. 3.5, onde $15 \mathrm{~g}$ de cloreto de sódio $(\mathrm{NaCl})$ são colocados no Erlenmeyer e ácido sulfúrico concentrado no funil de separação com a torneira fechada. No balão, resfriado a $5{ }^{\circ} \mathrm{C}, 2,2 \mathrm{~g}$ do éter obtido na etapa anterior são dissolvidos em $100 \mathrm{ml}$ de dioxano. Em seguida, $9 \mathrm{ml}$ de ácido clorídrico concentrado e $5 \mathrm{ml}$ de solução de formaldeído em metanol a 37 \% são adicionados à solução com o éter. Logo após, abrindo-se a torneira do funil, o $\mathrm{HCl}$ será gerado e borbulhado na solução durante 30 min. A solução é tampada e deixada, sob agitação, em temperatura ambiente por $3 \mathrm{~h}$. Logo depois, a solução é resfriada e mais $5 \mathrm{ml}$

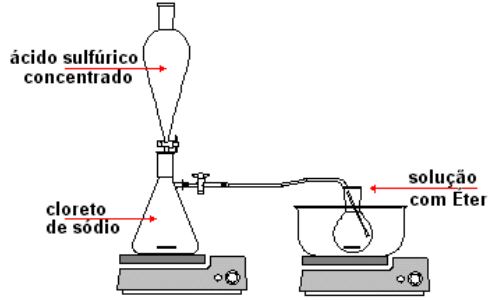

Figura 3.5: Sistema de geração de gás de ácido clorídrico. de formaldeído são a ela adicionados e, novamente, o $\mathrm{HCl}$ é borbulhado durante $10 \mathrm{~min}$. Em seguida, a solução é deixada sob agitação, por $1 \mathrm{~h}$, a temperatura ambiente. Os procedimentos de resfriamento, adição de formaldeído e borbulhamento de $\mathrm{HCl}$ são repetidos por mais duas vezes, quando a solução é deixada em agitação por $16 \mathrm{~h}$ e em seguida, refluxada por mais 3 h. O solvente é então evaporado até a formação de uma "pasta branca", que é dissolvida em $30 \mathrm{ml}$ de hexanos a quente. Para finalizar, metanol é adicionado à solução até a formação de precipitados brancos na forma de algodão (bis-cloreto), que são filtrados, lavados com metanol gelado e secos em dessecador a vácuo.

Para a obtenção do polímero, Fig. 3.4-(d), 0,5 g de bis-cloreto são dissolvidos em $10 \mathrm{ml}$ de THF seco e deixados sob agitação. Em seguida, $40 \mathrm{ml}$ de solução de ter-butóxido de potássio em THF (0,24 M) são adicionados, gota a gota, à solução, que permanece em agitação por 24 horas. O polímero é então precipitado em $250 \mathrm{ml}$ de metanol, filtrado e lavado com esse solvente em um funil de Büchner. Para finalizar, o produto da reação é dissolvido em $250 \mathrm{ml}$ de THF a $60{ }^{\circ} \mathrm{C}$ e, posteriormente, precipitado em $400 \mathrm{ml}$ de 
metanol. O polímero é filtrado, lavado com metanol e transferido para um dessecador a vácuo protegido da luz.

\subsubsection{Poli[(2-metóxi-5-dodecóxi)-p-fenilenovinileno] - (MD-PPV)}

Outro derivado do PPV, o MD-PPV possui como principal característica a solubilidade em diversos solventes orgânicos e emissão máxima na faixa de $550 \mathrm{~nm}$. Esse polímero foi sintetizado pela mestranda Flávia M. Marconi, utilizando a mesma rota de síntese do MH-PPV, onde o clorohexano foi substituído por cloro-dodecano no esquema apresentado na Fig. 3.4.

\subsubsection{Resultados das sínteses}

A tabela abaixo apresenta a solubilidade e a massa molar média ponderal $\left(\overline{\mathrm{M}}_{\mathrm{W}}\right)$ dos polímeros preparados. $\mathrm{O} \overline{\mathrm{M}}_{\mathrm{w}}$ foi determinado pela técnica de cromatografia de exclusão por tamanho. No caso do PPV, por ser um polímero insolúvel, não foi possível determinar o seu $\overline{\mathrm{M}}_{\mathrm{w}}$ por essa técnica.

Tabela 3.I: Solubilidade e massa molar média ponderal $\left(\overline{\mathrm{M}}_{\mathrm{w}}\right)$ dos polímeros sintetizados.

\begin{tabular}{||c|l|c||}
\hline POLÍMERO & \multicolumn{1}{|c|}{ SOLVENTES } & $\overline{\mathrm{M}}_{\mathrm{w}}(\mathbf{g} / \mathbf{m o l})$ \\
\hline PANI & $N$-(metil-2)pirrolidona $(\mathrm{NMP})$. dimetilsulfóxido (DMSO) & $5 \times 10^{4}$ \\
\hline POMA & NMP, clorofórmio $\left(\mathrm{CHCl}_{3}\right)$ & $2 \times 10^{5}$ \\
\hline PPV & insolúvel e intratável & --- \\
\hline PTHT & água, metanol $(\mathrm{MeOH})$, etanol & --- \\
\hline MH-PPV & $\mathrm{CHCl}_{3}$, tetrahidrofurano (THF) & $1,8 \times 10^{5}$ \\
\hline MD-PPV & $\mathrm{CHCl}_{3}, \mathrm{THF}$, benzeno, xileno, tolueno. & $2,8 \times 10^{5}$ \\
\hline
\end{tabular}

* polieletrólito

\subsection{Métodos de preparação dos filmes}

Os métodos mais utilizados para a preparação de filmes poliméricos finos e homogêneos são os métodos de spin coating e casting. Em ambos os métodos uma solução 
do polímero é depositada sobre um substrato desejado, que deve estar devidamente limpo (item 3.2.1).

No método casting, a solução polimérica é espalhada sobre substratos com o auxílio de uma pipeta e, em seguida, o solvente é eliminado por evaporação com o aumento da temperatura, resultando na formação de uma película (ou filme) do material desejado. Embora simples de ser realizado, a qualidade dos filmes formada depende, fortemente, de parâmetros como a temperatura, a taxa de aquecimento, a concentração da solução e o solvente utilizado. A vantagem desse método é a obtenção de filmes uniformes de variadas espessuras, incluindo a preparação de filmes auto-sustentáveis ${ }^{[54]}$. A Fig. 3.6 mostra o aparato experimental utilizado para a obtenção de filmes pelo método casting. Nesse sistema, os substratos são colocados sobre uma chapa aquecedora, onde também está acoplado um controlador de temperatura. A solução do polímero é derramada sobre as lâminas de vidro que, posteriormente, são lentamente aquecidas até uma temperatura próxima à temperatura de ebulição do solvente, onde permanecem até ficarem totalmente secos.

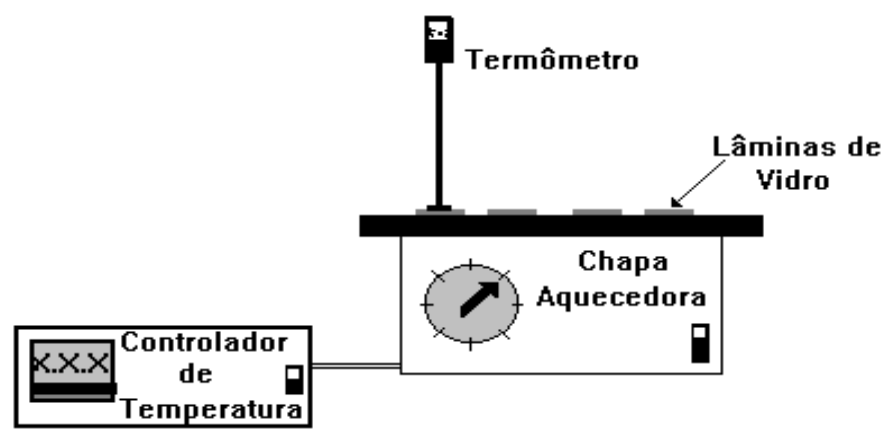

Figura 3.6: Aparato experimental usado para a obtenção de filmes poliméricos pelo método casting.

No método spin coating a solução polimérica é depositada sobre um substrato desejado que, por meio de centrifugação, elimina todo o excesso da solução da superfície das lâminas. Como resultado, filmes finos e homogêneos são facilmente obtidos. Os procedimentos desse método são mostrados na Fig. 3.7. Nesse caso, um substrato é fixado sobre uma plataforma giratória, Fig. 3.7-(a) e 3.7-(b), e a solução do polímero é sobre ele depositada, Fig. 3.7-(c). Em seguida, o substrato gira com uma freqüência angular ( $\omega$ ) fixa e por um intervalo de tempo pré-determinado, Fig. 3.7-(d). Por último, um filme fino e homogêneo sobre o substrato é obtido, Figs. 3.7-(e) e 3.7-(f). 


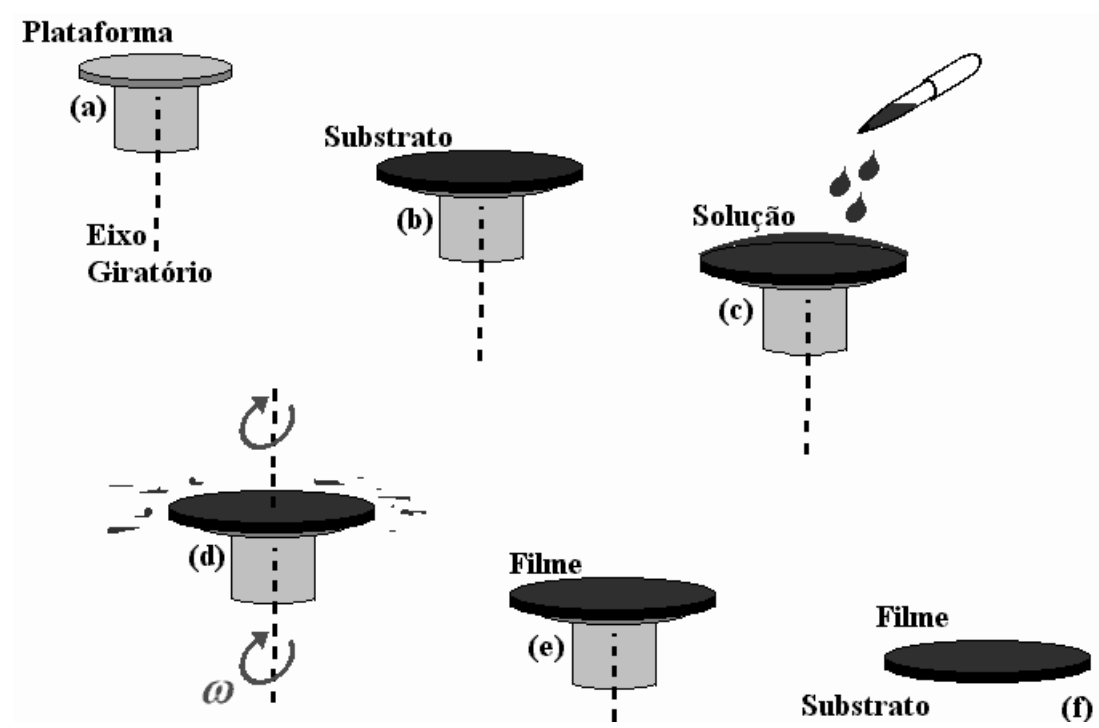

Figura 3.7: Aparato experimental e procedimentos do método spin coating.

\subsubsection{Limpeza dos Substratos}

A natureza das interfaces substrato/polímero é de fundamental importância para o estudo das propriedades ópticas e/ou elétricas dos polímeros conjugados e de seus dispositivos eletrônicos. Desse modo, a limpeza dos substratos deve ser realizada de modo rigoroso e criterioso antes da deposição dos filmes poliméricos.

Para a limpeza de lâminas de quartzo, silício e vidro, foi utilizado o método $R C A^{[56]}$ de hidrofilização, desenvolvido em 1984 para a limpeza de lâminas de silício e dióxido de silício. Nesse método, os substratos são imersos em uma solução 1:1:5 (em volume), respectivamente, de hidróxido de amônio $\left(\mathrm{NH}_{4} \mathrm{OH}\right) 28 \%$, de peróxido de hidrogênio $\left(\mathrm{H}_{2} \mathrm{O}_{2}\right) 30 \%$ e de água ultrapura. Em seguida, a solução é aquecida até $75^{\circ} \mathrm{C}$, permanecendo nessa temperatura por 10 a 15 minutos, quando as lâminas são retiradas e lavadas com água ultrapura em abundância. Como segunda parte da limpeza, uma solução de 1:1:6 (em volume), respectivamente, de ácido clorídrico $(\mathrm{HCl})$, de peróxido de hidrogênio $\left(\mathrm{H}_{2} \mathrm{O}_{2}\right)$ e de água ultrapura é aquecida até $70{ }^{\circ} \mathrm{C}$, quando as lâminas são imersas e deixadas por 10 a 15 min. Por último, as lâminas são lavadas em água ultrapura em abundância, imersas em acetona aquecida, depois em álcool isopropílico em ebulição e secas com nitrogênio. Para o caso específico dos substratos de silício, antes da etapa de secagem em acetona e álcool isopropílico, as lâminas são ainda imersas em solução de 
ácido fluorídrico concentrado por $10 \mathrm{~s}$, para a remoção de óxidos que tenham se formado nas suas superfícies.

Para a limpeza dos substratos vidro/ITO foi utilizado um dos métodos propostos, recentemente, por Kim et al. ${ }^{[57]}$ no estudo da influência dos tratamentos químicos desses substratos na eficiência de PLEDs de PPV. Nesse método, as lâminas são limpas com solução de água-régia diluída $\left(20 \mathrm{H}_{2} \mathrm{O}: 1 \mathrm{HCl}: 1 \mathrm{HNO}_{3}\right)$ em ultra-som por 15 min e, posteriormente, lavadas com água ultrapura em abundância. Em seguida, as lâminas são limpas com acetona, seguido de álcool isopropílico quentes e secas com nitrogênio. Segundo os resultados obtidos por Kim, essa limpeza aumenta a rugosidade da superfície do ITO, aumentando a aderência dos filmes de PPV sobre esse óxido e, consequientemente, a eficiência dos seus PLEDs.

\subsubsection{Procedimentos para a obtenção dos filmes poliméricos.}

Filmes de polianilina, poli( $p$-fenilenovinileno) e derivados desses polímeros foram obtidos seguindo os procedimentos apresentados nos próximos itens. Antes da deposição das soluções poliméricas é importante acrescentar que todos os substratos eram levados a uma estufa a vácuo e aquecidos até $100{ }^{\circ} \mathrm{C}$ por $1 \mathrm{~h}$ para remoção de água ou solvente, residuais dos processos de limpeza.

\subsubsection{Filmes de PANI}

Filmes de PANI foram obtidos pelo método casting para a realização do estudo das suas propriedades elétricas como função da sua dopagem química em $\mathrm{HCl}$. Os filmes foram preparados dissolvendo o polímero em N-metil-2-pirrolidona (NMP) em concentrações de $3 \%$. A solução, após filtragem, foi depositada sobre lâminas de vidro e, posteriormente, aquecidas até $50{ }^{\circ} \mathrm{C}$, permanecendo por 15 ou $16 \mathrm{~h}$. Em seguida, as lâminas com os filmes foram levadas a uma base de vidro, a temperatura ambiente, quando permaneceram por 30 a 40 min. Por último, filmes com espessura média de $10 \mu \mathrm{m}$ foram retirados das lâminas com o auxílio de uma espátula. 


\subsubsection{Filmes de PPV}

Para a preparação de filmes de PPV, três soluções do PTHT foram preparadas. A primeira delas foi obtida com o PTHT fornecido pela etapa de diálise, ou seja, em solução aquosa de concentração 1,2 mg/ml. Chamaremos essa solução de PTHT/Água. A segunda solução foi obtida secando-se a solução PTHT/Água em uma câmara a vácuo ( $10^{-2}$ Torr), em temperatura ambiente e, depois, redissolvendo o polieletrólito em metanol seco, sob agitação. A vantagem dessa solução em relação à primeira é obter uma solução mais volátil e, por esse motivo, que permita a obtenção de filmes mais homogêneos. Chamaremos essa solução de PTHT/MeOH. A terceira e última solução foi obtida colocando-se $30 \mathrm{ml}$ da solução de PTHT/Água em um béquer dentro da câmara a vácuo, e reduzindo a pressão interna da câmara vagarosamente, i.e., durante 10 dias até a total evaporação da água (pressão final de $10^{-2}$ Torr). Em seguida, o PTHT foi redissolvido em metanol seco a temperatura de $0{ }^{\circ} \mathrm{C}$ e sob constante agitação. Em analogia a segunda solução, chamaremos essa de PTHT/MeOH/Lenta. Todas as soluções foram obtidas a temperatura ambiente e suas concentrações foram mantidas iguais a 1,2 $\mathrm{mg} / \mathrm{ml}$. Para a preparação dos filmes poliméricos, as soluções foram depositadas, por casting e spin coating (otimizado com velocidade de $3000 \mathrm{rpm}$ por $90 \mathrm{~s}$ ) em lâminas de vidro recobertas com uma fina camada de ITO (indium-tin oxide). Em seguida, os substratos recobertos com o polímero foram levados a uma estufa a vácuo e lentamente evacuados (até $10^{-2}$ Torr) para a remoção do solvente, onde foram mantidos por mais $3 \mathrm{~h}$. Em seguida, eles foram aquecidos a uma taxa de $20{ }^{\circ} \mathrm{C} / \mathrm{min}$ até atingirem a temperatura de $200{ }^{\circ} \mathrm{C}$, onde foram mantidos por mais duas horas. Por último, os substratos recobertos com os filmes foram resfriados vagarosamente (cerca de $2 \mathrm{~h}$ ) até atingirem a temperatura ambiente, quando foram retirados da estufa e armazenados em um dessecador sob vácuo e protegidos da luz.

As Figs. 3.8, 3.9 e 3.10 mostram as imagens de microscopia óptica obtidas com os filmes preparados sobre substratos vidro/ITO. As setas vermelhas nessas figuras indicam a presença de manchas ou impurezas (originárias, provavelmente, de resíduos da síntese química do polímero, da adsorção de poeira na superfície do filme ou do substrato, ou ainda da formação de agregados durante o processo de formação dos filmes). 


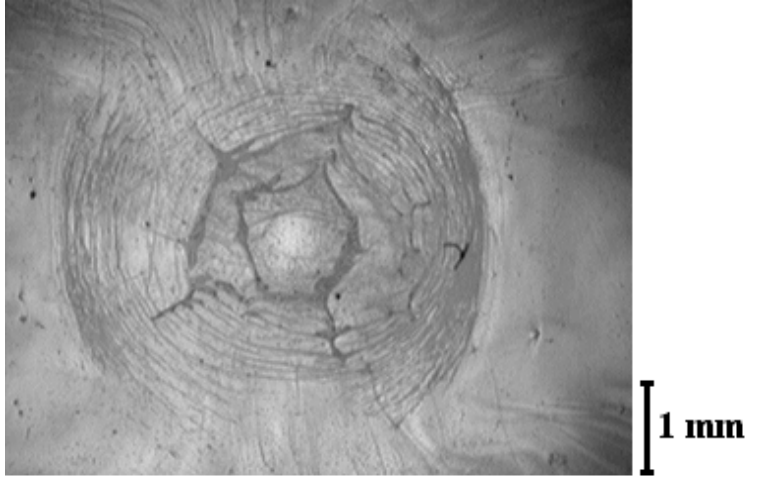

(a)

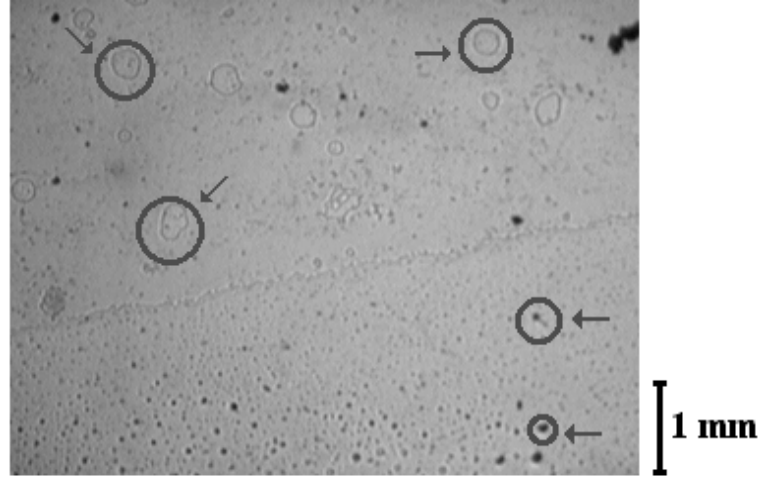

(b)

Figura 3.8: Imagens de microscopia óptica de filmes de PPV obtidos com a deposição da solução PTHT/Água sobre substratos de vidro/ITO por: (a) casting e (b) spin coating. As setas vermelhas indicam a presença de impurezas ou manchas nas superfícies dos filmes.

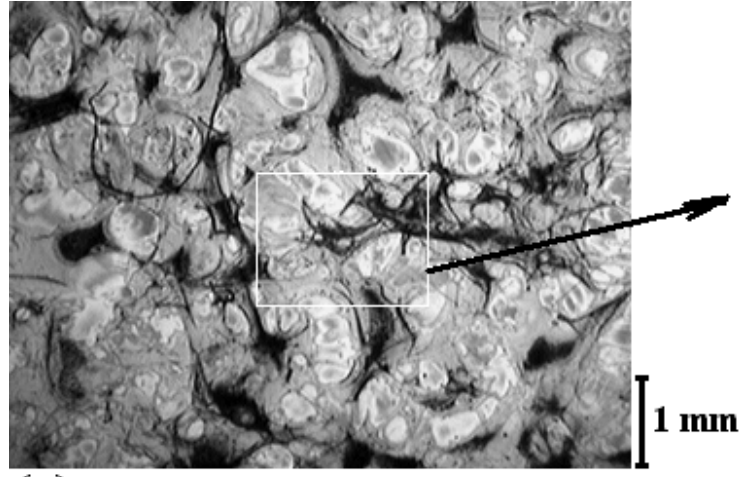

(a)

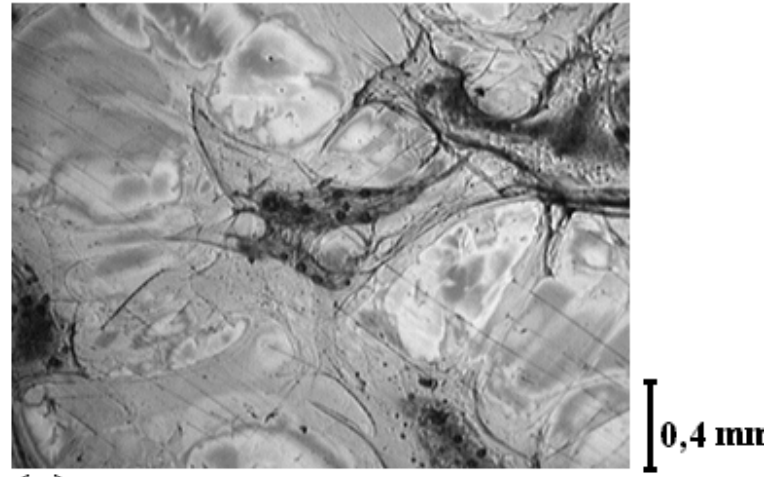

(b)

Figura 3.9: Imagens de microscopia óptica de um filme de PPV obtido com a deposição da solução PTHT/MeOH sobre substratos de vidro/ITO.

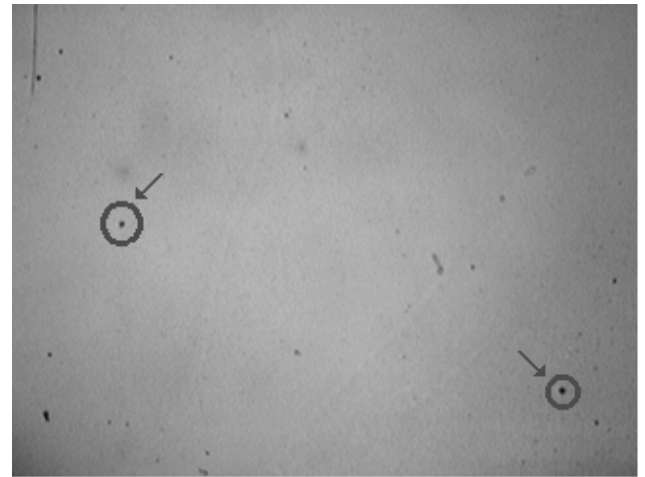

(a)

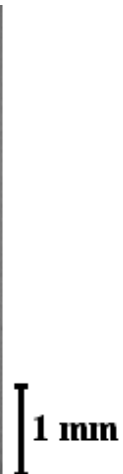

(b)

Figura 3.10: Imagens de microscopia óptica de filmes de PPV obtidos com a deposição da solução PTHT/MeOH/Lenta sobre substratos vidro/ITO por (a) casting e (b) spin coating. As setas vermelhas indicam a presença de impurezas ou manchas nas superfícies dos filmes

De acordo com as imagens mostradas na Figs. 3.8 e 3.9, os filmes preparados com as soluções PTHT/Água PTHT/MeOH não formam filmes homogêneos nem por casting e nem por spin coating. Entretanto, filmes lisos, com boa uniformidade e baixa quantidade 
de impurezas são obtidos com a PTHT/MeOH/Lenta, Fig. 3.10. Visando um controle da homogeneidade dos filmes preparados para a preparação de PLEDs, essa última solução será usada como padrão dos nossos dispositivos.

\subsubsection{Filmes de MH-PPV e MD-PPV}

Filmes de MH-PPV e MD-PPV foram obtidos dissolvendo esses polímeros em concentrações $1 \mathrm{mg} / \mathrm{ml}$ em clorofórmio, e depositando essa solução sobre os substratos de vidros recobertos com ITO pelos métodos casting e spin coating (otimizado com velocidade de $3000 \mathrm{rpm}$ por $90 \mathrm{~s}$ ). Para eliminar resíduos de clorofórmio, as amostras foram levadas para uma estufa a $50{ }^{\circ} \mathrm{C}$ e deixadas entre 30 a $40 \mathrm{~min}$. Imagens de microscopia óptica dos filmes de MH-PPV preparados são mostrados na Fig. 3.11. As setas vermelhas nessas imagens indicam a presença de impurezas na superfície dos filmes.

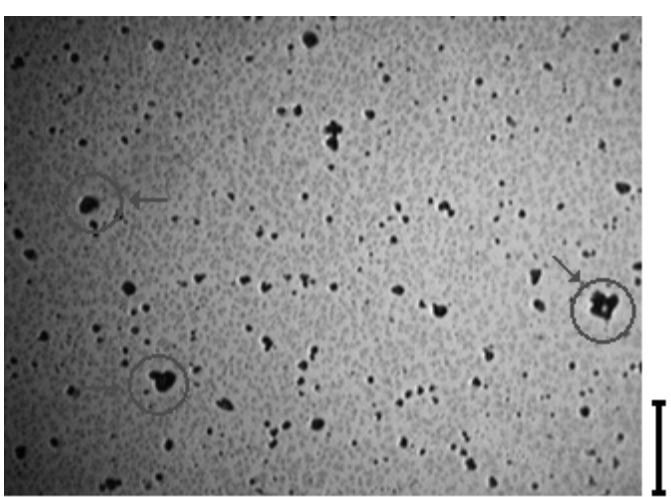

(a)

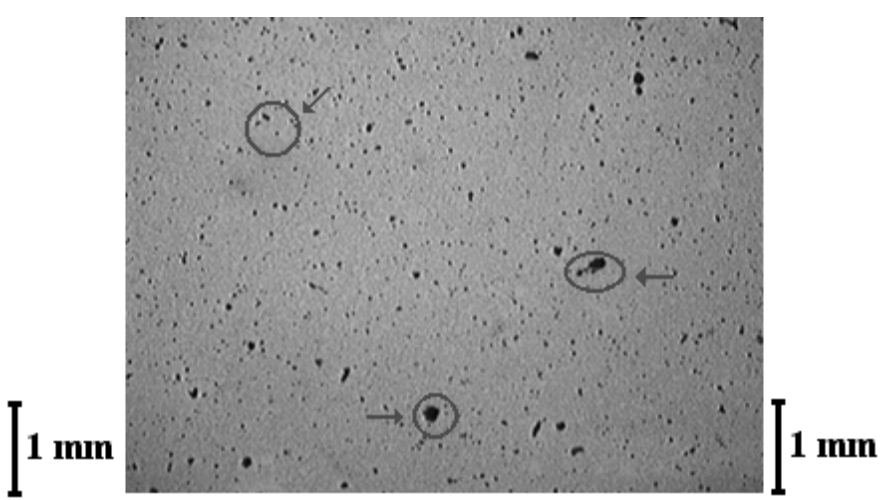

(b)

Figura 3.11: Imagens de microscopia óptica obtidas com filmes de MH-PPV obtidos com a solução desse polímero em clorofórmio por (a) casting e (b) spin coating. As setas vermelhas indicam a presença de impurezas nas superfícies dos filmes

Como podemos observar os filmes preparados não são homogêneos, pois as imagens indicam a presença de uma quantidade muito grande de impurezas nas suas superfícies. Como uma tentativa para eliminar essas impurezas, as soluções foram filtradas (em filtro Millipore 0,45 $\mu \mathrm{m}$ ) e, novamente, os filmes foram preparados por casting. Em seguida, os filmes foram tratados termicamente a $50{ }^{\circ} \mathrm{C}$. A Fig. 3.12 mostra a imagem óptica obtida com o filme preparado por casting com a solução filtrada. 


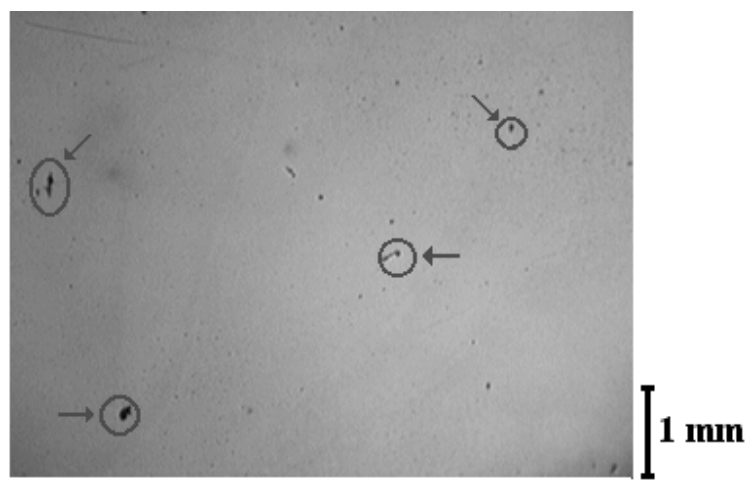

Figura 3.12: Imagens de microscopia óptica $(6 \times 5) \mathrm{mm}^{2}$ obtidas com o filme de MH-PPV obtido com a solução filtrada desse polímero em clorofórmio pelo método casting.

De acordo com a imagem mostrada na Fig. 3.12, o filme preparado com a solução filtrada apresenta uma menor concentração de impurezas e uma boa uniformidade. Dessa forma, esse procedimento será adotado na confecção dos dispositivos emissores de luz preparados com esses materiais. Resultados semelhantes foram obtidos com o MD-PPV.

\subsection{Confecção dos substratos dos dispositivos}

Nesse item apresentamos os métodos de confecção dos substratos usados nos dispositivos poliméricos. São apresentados os métodos de confecção de padrões de ITO sobre vidro e os métodos de oxidação de lâminas de silício e confecção de eletrodos, interdigitais usados na construção dos PFETs.

\subsubsection{ITO (indium-tin oxide)}

Em geral, PLEDs são preparados com uma camada de material ativo (polímero) depositada entre dois eletrodos metálicos, Fig. $2.11^{[16-18]}$. Dentro desse contexto, a confecção de padrões de ITO sobre os substratos de vidro é importante tanto para o controle das regiões de emissão do dispositivo, quanto para se evitar curto circuito e a difusão de solvente entre os eletrodos. Visando buscar um método simples e eficaz, substratos de vidro recobertos com uma fina camada de ITO, disponíveis comercialmente, foram submetidos a um processo químico de corrosão descrito na literatura ${ }^{[58]}$. Esse método consiste em proteger a superfície do ITO desejada com uma fita adesiva ou um 
polímero fotoresiste, e retirar todo o restante do óxido com cloreto de zinco, resultante da reação de zinco com ácido clorídrico, formando sais de estanho e índio que são solúveis em água. Por ser um método de simples realização experimental, ele se torna de fundamental importância para a confecção dos PLEDs. Denominaremos esse método de corrosão como processo de decapagem do ITO. Amostras que foram submetidas a esse processo serão denominadas de amostras decapadas ao longo do texto. A Fig. 3.13 exemplifica esse processo para a obtenção de padrões de ITO sobre o vidro (no caso, a letra $L)$.

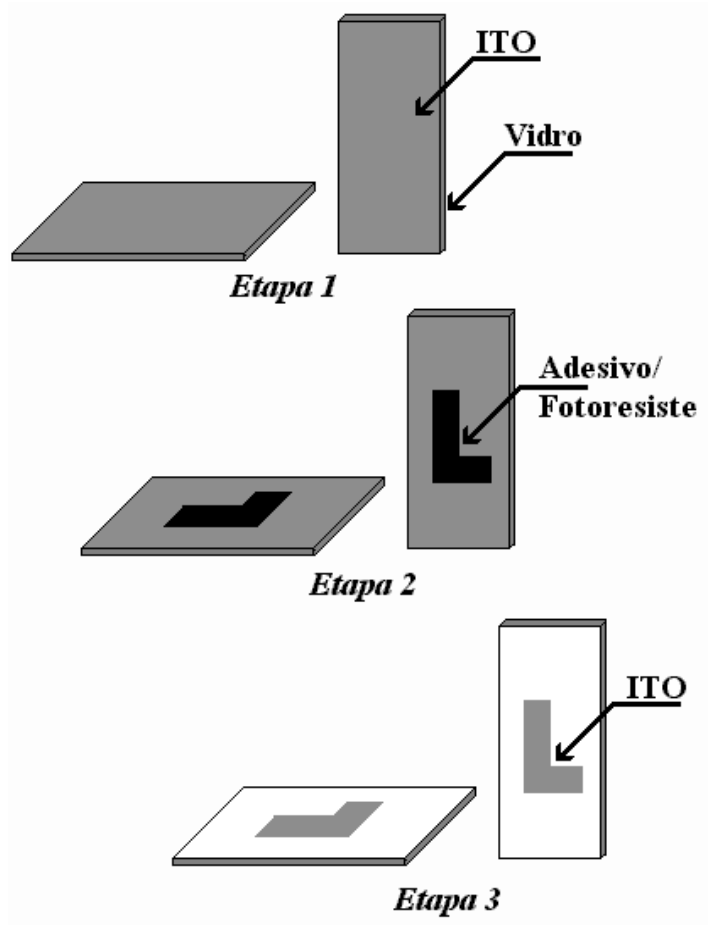

Figura 3.13: Procedimento para a obtenção de padrões de ITO sobre uma lâmina de vidro (no caso a letra $L$ ).

Na Fig. 3.13, etapa 1, os substratos de vidro/ITO são limpos com acetona e álcool isopropílico para a retirada de eventuais produtos orgânicos adsorvidos pela superfície. Em seguida - etapa 2 - adesivos plásticos, com o formato da letra L, são colados sobre o ITO. Uma suspensão de pó de zinco em água é espalhada sobre a superfície do substrato e, após as lâminas estarem secas, essas são imersas em solução aquosa de ácido clorídrico $1 \mathrm{M}$ por ca. 30 s. Em seguida, a reação $\mathrm{Zn}+\mathrm{HCl}$ corrói a superfície do ITO não protegida pelo adesivo e, com o auxílio de um bastão ou um "cotonete", esse óxido é facilmente removido da superfície do vidro. Por último, etapa 3, as lâminas são lavadas com acetona e álcool isopropílico em ebulição e, posteriormente, secas em nitrogênio. Como resultado, a região 
do ITO que foi protegida com o adesivo permanece na amostra, enquanto em toda a superfície de vidro restante ele foi removido. A Fig. 3.14 exemplifica esse processo mostrando, em detalhes, os processos de limpeza, decapagem e ainda o tratamento químico (descrito no item 3.2.1) e a secagem das lâminas.

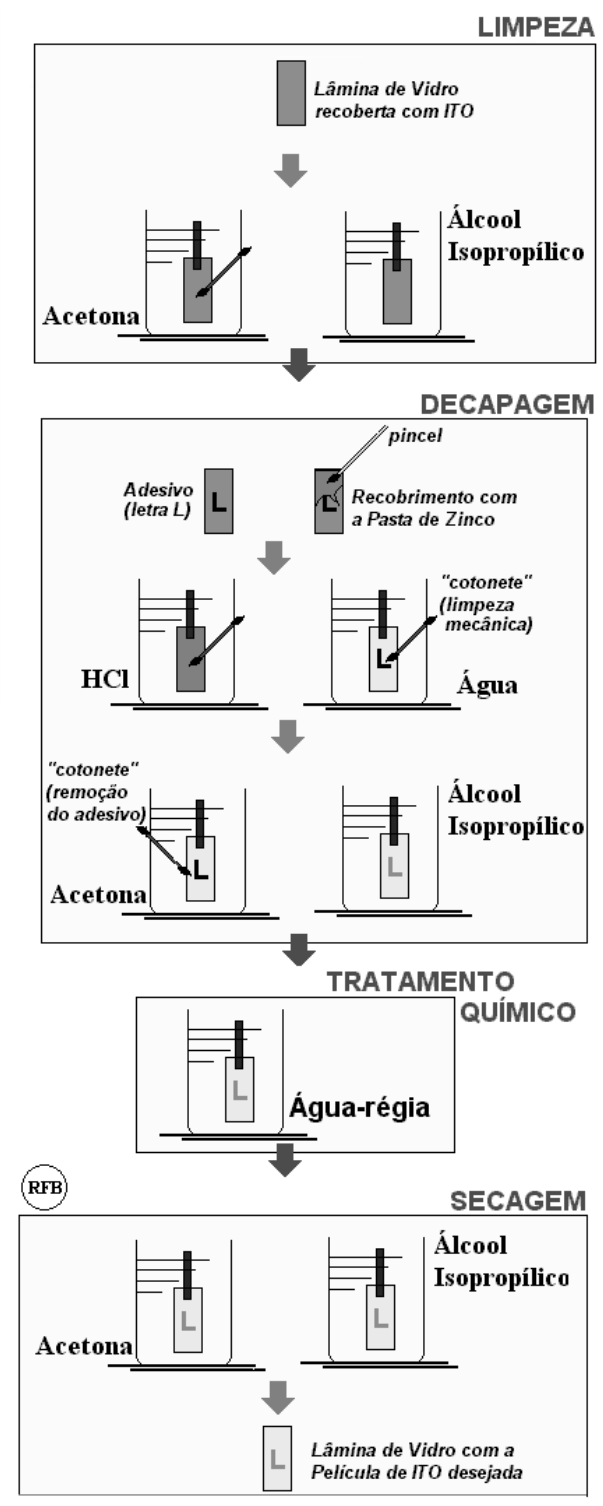

Figura 3.14: Detalhes do método de decapagem do ITO apresentados na Fig. 3.13. A Figura inclui o tratamento químico em solução de água-régia diluída e a secagem das lâminas

A Fig. 3.15 mostra uma imagem óptica obtida com uma lâmina de vidro recoberta com faixas de ITO (largura igual a 1,4 $\mathrm{mm}$ ) produzida pelo processo de decapagem. Nessa figura as setas vermelhas indicam as faixas decapadas (superfície do vidro) e as faixas de ITO. Como podemos notar, o método de decapagem é bem eficiente para a formação de padrões do ITO sobre o substrato de vidro. 


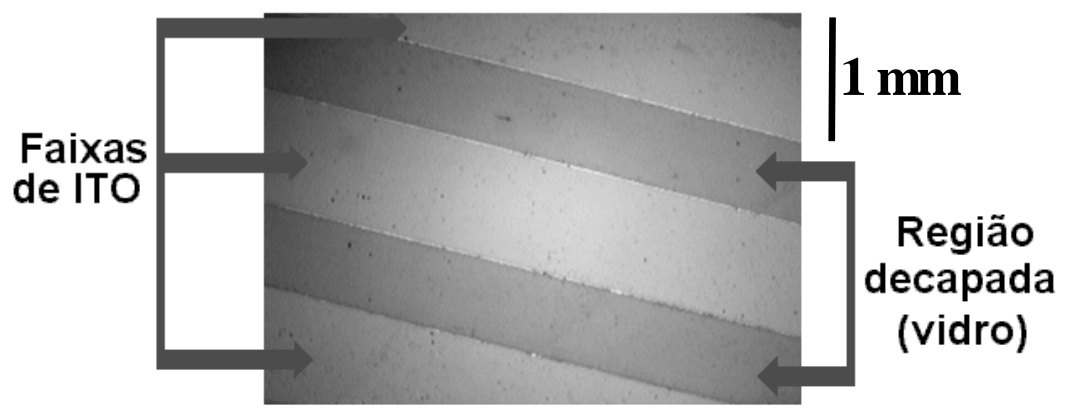

Figura 3.15: Imagem de microscopia óptica da superfície de uma lâmina de vidro com faixas de ITO obtidas pelo processo de decapagem.

\subsection{2 $\mathrm{Al} / \mathrm{Si} / \mathrm{SiO}_{2} /($ eletrodos interdigitais $)$}

A preparação de dispositivos PFETs foi realizada utilizando-se uma estrutura tipo MIS-FET simples e usual e que, com a remoção do polímero, pudesse ser reaproveitada facilmente. Para isso, optamos em utilizar uma estrutura idêntica à mostrada na Fig. 2.10-(a), que é ideal também para as medidas elétricas, pois favorece o ganho de corrente dos dispositivos.

A Fig. 3.16 mostra os passos para a obtenção da estrutura tipo MIS-FET. Nessa figura, a etapa (a) é a escolha de uma lâmina condutora que servirá como eletrodo de porta. Sobre a sua superfície, uma fina camada de um material isolante, etapa (b), é obtida ou depositada. Em geral, lâminas de silício ( $\mathrm{Si}$ ) dopadas e polidas são usadas como a lâmina condutora, e dióxido de silício $\left(\mathrm{SiO}_{2}\right)$ como a camada isolante. A terceira etapa, (c), é a obtenção de um conjunto de eletrodos interdigitais, os quais funcionam como eletrodos fonte ou dreno e são obtidos por técnicas de microeletrônica convencionais. A última etapa, (d), é a deposição do polímero sobre essa estrutura. Nesse caso, a espessura do óxido é denotada por $a$, à distância entre os eletrodos dreno e fonte por $W$, e o comprimento e espessura dos eletrodos por, respectivamente, $L$ e $b$. 

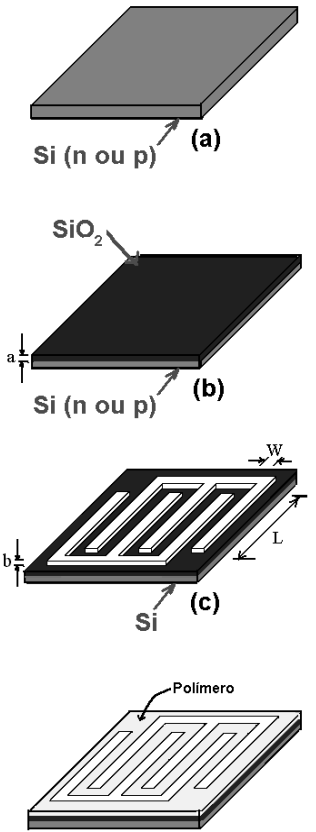

(d)

Figura 3.16: Etapas de preparação de um PFET.

Nas estruturas MIS-FETs utilizadas, o $\mathrm{SiO}_{2}$ foi obtido via oxidação térmica das lâminas de silício em altas temperaturas no Laboratório de Microeletrônica (LME) da Escoa Politécnica/USP, com a colaboração do Prof. Roberto K. Onmori. Esse método tem, como principais vantagens, a obtenção de uma camada de $\mathrm{SiO}_{2}$ com baixa porosidade e alta resistividade, o que melhora, consideravelmente, as características isolantes desse material. Dessa forma, lâminas de silício (Si) dopadas tipo $p$ (dopante Boro, orientação 100 e resistividade $0,3 \Omega \mathrm{cm}$ ) foram limpas pelo procedimento $R C A$ e, em seguida, levadas a um forno a $1000{ }^{\circ} \mathrm{C}$ com fluxo de $\mathrm{N}_{2}\left(50 \mathrm{~cm}^{3} / \mathrm{min}\right)$, seguido de fluxo de oxigênio $\left(50 \mathrm{~cm}^{3} / \mathrm{min}\right)$ constante, onde a oxidação da superfície da lâmina ocorre. Finalmente, após um tempo prédeterminado, as lâminas são retiradas do interior do forno quando a região não polida do silício é atacada com ácido fluorídrico $(\mathrm{HF})$ para a retirada do $\mathrm{SiO}_{2}$. Para isso, a região polida é protegida com apiezon (ou piche), que inibe a corrosão do óxido pelo ácido. Após esse processo, as lâminas são limpas, novamente, pelo método $R C A$ e em acetona quente, seguido de álcool isopropílico em ebulição. Para melhorar os contatos elétricos na superfície da lâmina de silício não polida, e que funcionará como o eletrodo de porta do dispositivo, alumínio foi depositado sobre toda a sua superfície.

Após a preparação das lâminas de $\mathrm{Si} / \mathrm{SiO}_{2}$ realizamos o processo de fotogravação litográfico lift-off para a obtenção dos eletrodos interdigitais. A Fig. 3.17 ilustra esse processo, também para a obtenção da letra $L$. 

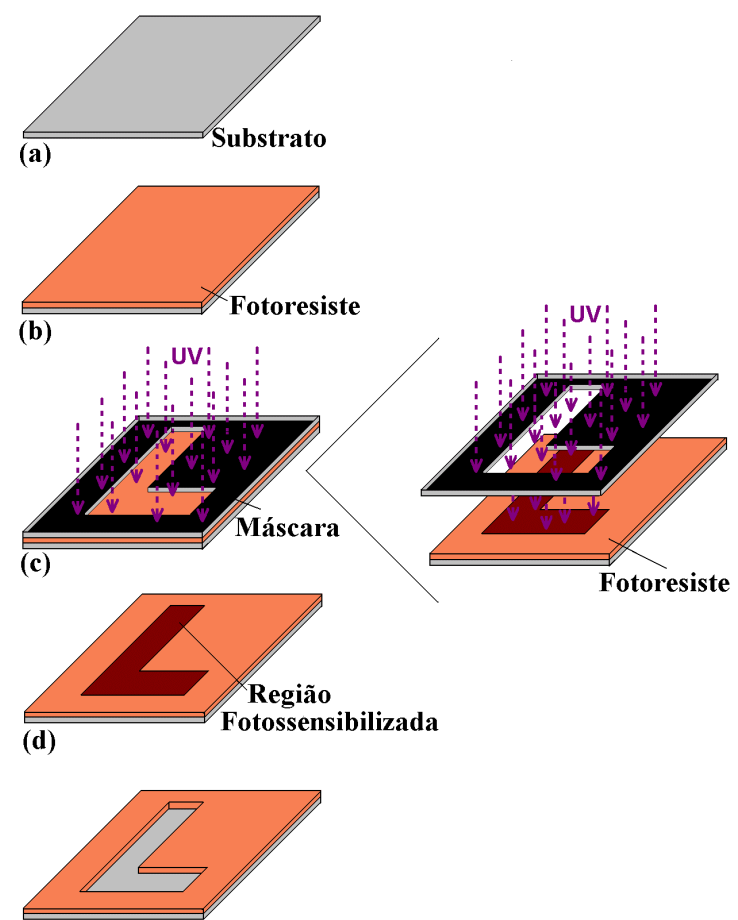

(e)
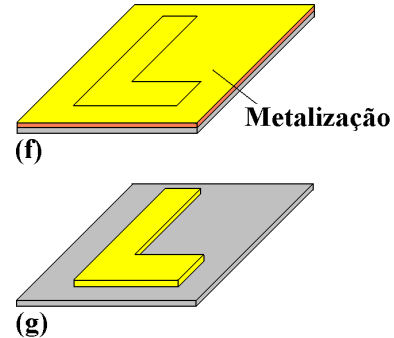

Figura 3.17: Processo de litografia para a obtenção dos eletrodos interdigitais. Exemplificação com a letra L.

Nesse método, o polímero fotossensível (ou fotoresiste) é depositado sobre um substrato, Figs. 3.17-(a) e 3.17-(b), e fotossensibilizado com luz ultravioleta (UV). Assim, utilizando máscaras ópticas, Fig. 3.17-(c), é possível obter regiões fotossensibilizadas e não fotossensibilizadas com as mais variadas geometrias, Fig 3.17-(d). Usando uma solução reveladora, as regiões fotossensibilizadas podem ser facilmente removidas, enquanto as outras regiões permanecem sobre o óxido, Fig. 3.17-(e). Em decorrência, metalizando-se toda a superfície da lâmina com cromo/ouro, Fig 3.17-(f), e retirando-se as regiões não fotossensibilizadas com acetona, obtemos regiões metalizadas sobre o substrato com as mesmas geometrias das regiões sensibilizadas, Fig. 3.17-(g). O cromo foi usado para aumentar a aderência do ouro sobre a lâmina. Para a preparação dos eletrodos interdigitais, as lâminas com $\mathrm{SiO}_{2}$ foram, inicialmente, limpas com acetona e álcool isopropílico e secas com $\mathrm{N}_{2}$. Em seguida, para melhorar a aderência do fotoresiste, hexametildisilizano/xilol (HMDS) foi depositado sobre a superfície do óxido. O fotoresiste 
utilizado foi o AZ®1518 da Hoechst, que é sensível ao ultravioleta (UV) e ambos, fotoresiste e HMDS, foram depositados por spin coating (1000 rpm, 60 s). Após a aplicação do AZ®1518, as lâminas foram levadas a uma estufa a $70{ }^{\circ} \mathrm{C}$ e mantidas por 20 min, quando se encontravam prontas para serem expostas a radiação UV. Por último, as lâminas com o fotoresiste e protegidas com máscaras ópticas foram expostas à luz ultravioleta por 30 segundos e, em seguida, imersas em, respectivamente, monoclorobenzeno (90 segundos) e revelador 351 Microposit da Shipley em solução diluída em água (1:5) por $30 \mathrm{~s}$ e levadas em um banho com água por $10 \mathrm{~min}$. As lâminas são secas e uma camada de cromo $(20 \mathrm{~nm})$ seguida de uma camada de ouro $(30 \mathrm{~nm})$ foram metalizadas sobre a superfície do óxido. Por último, o fotoresiste é retirado das lâminas e os eletrodos interdigitais são obtidos.

Para verificar a qualidade do óxido formado, isto é., verificar se há fuga de corrente entre os eletrodos dreno-porta e fonte-porta, curvas de $I_{S D} v s$. $V_{S D}$ foram realizadas em um substrato $\mathrm{Al} / \mathrm{Si} / \mathrm{SiO}_{2} /\left(\right.$ eletrodos interdigitais), sem o polímero, aplicando-se $V_{G}=0 \mathrm{e}$ variando $V_{S D}$ de $-2,5$ a $2,5 \mathrm{~V}$, seguindo os procedimentos de medidas que serão apresentados no Cap. 4. Os eletrodos interdigitais foram preparados com uma estrutura idêntica à mostrada na Fig. 3.16-(c), com 25 pares de eletrodos, $W=100 \mu \mathrm{m}$ e $L=8 \mathrm{~mm}$. A Fig. 3.18-(a) mostra o resultado obtido. Em seguida à obtenção dessa curva, foram aplicados $10 \mathrm{~V}$ entre os eletrodos dreno e fonte, mantendo-se $V_{G}=0 \mathrm{~V}$, e uma nova curva $I_{S D}$ vs. $V_{S D}$ foi obtida, como mostra a Fig. 3.18-(b). Todas as medidas foram obtidas em temperatura e em atmosfera ambientes.
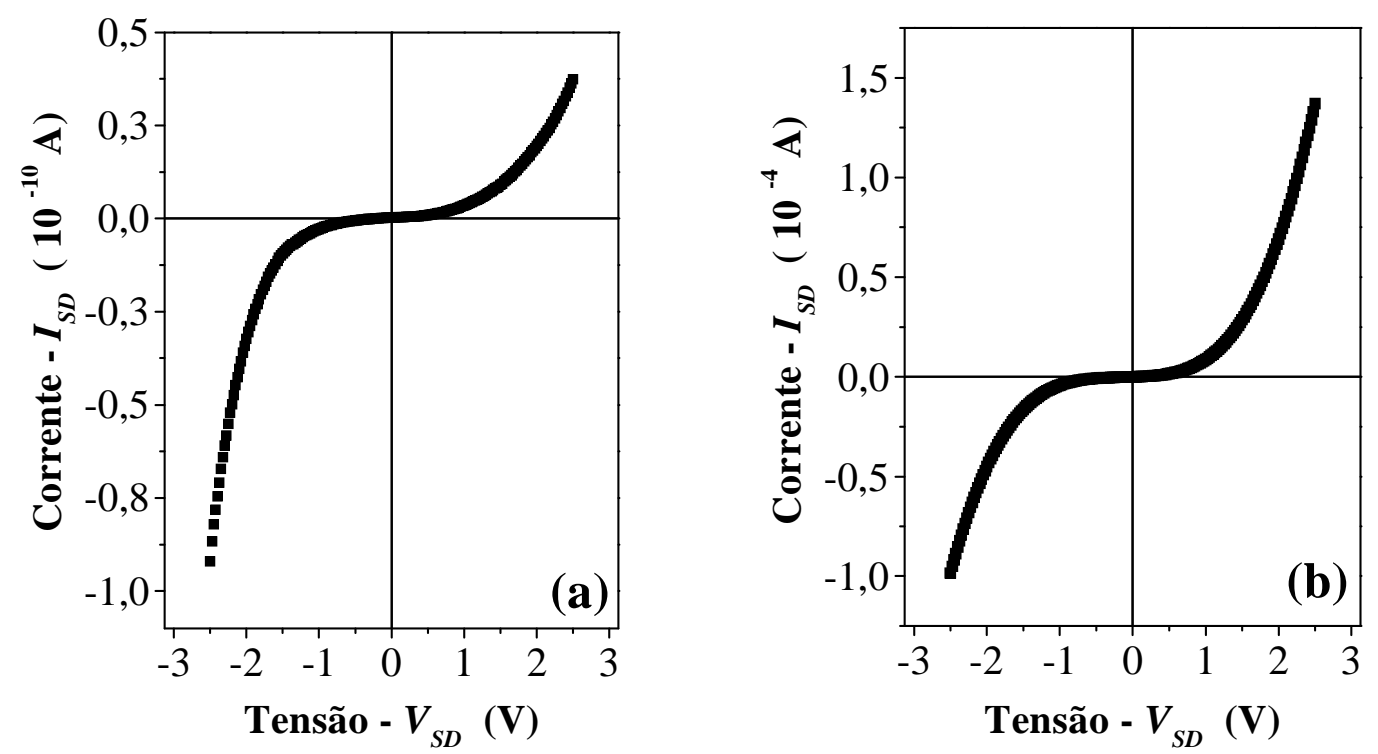

Figura 3.18: Medidas $I_{S D}$ vs. $V_{S D}$ obtidas com a estrutura $\mathrm{Al} / \mathrm{Si} / \mathrm{SiO}_{2} /($ eletrodos interdigitais): antes (a) e depois (b) de aplicar $V_{S D}=10 \mathrm{~V}$. 
Como podemos notar nos gráficos apresentados na Fig. 3.18, o valor de $I_{S D}$ para $V_{S D}=2 \mathrm{~V}$ salta de $4,0 \times 10^{-11} \mathrm{~A}$ para $1,5 \times 10^{-4} \mathrm{~A}$, após se aplicar $V_{S D}=10 \mathrm{~V}$, um salto de 7 ordens de grandeza. Da mesma maneira, as correntes dreno-porta e fonte-porta saltaram de $10^{-11}$ para $1 \mathrm{~mA}$. Para corroborar esses resultados, a Fig. 3.19 mostra as imagens de microscopia óptica obtidas da superfície dos eletrodos antes (a) e depois (b e c) de ser aplicado $10 \mathrm{~V}$.

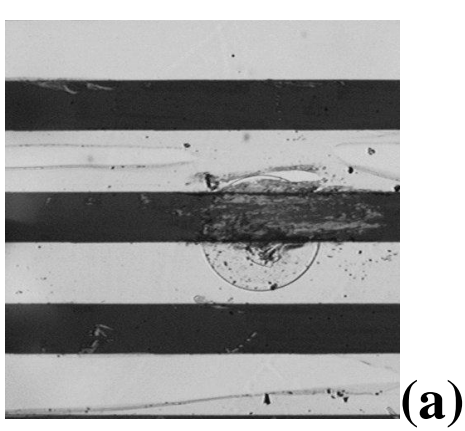

(700 $\times 700) \mu \mathbf{m}^{2}$

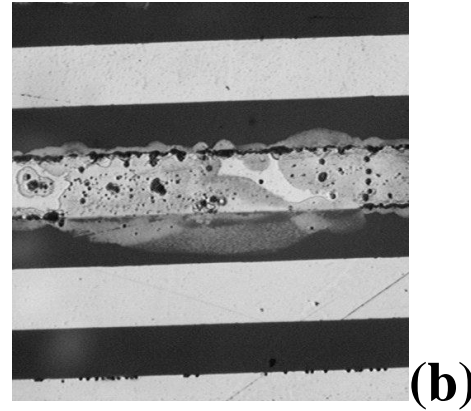

(700 x 700) $\mu \mathrm{m}^{2}$

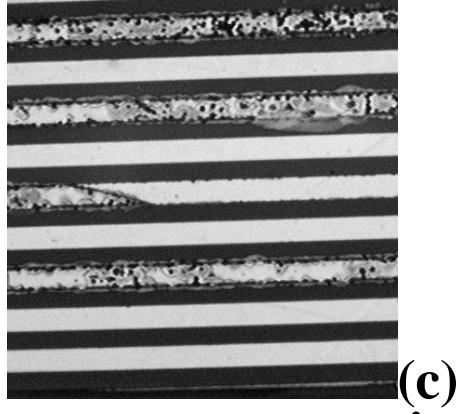

$(0,2 \times 0,2) \mathrm{cm}^{2}$

Figura 3.19: Imagens de microscopia óptica de uma amostra $\mathrm{Al} / \mathrm{Si} / \mathrm{SiO}_{2} /$ (eletrodos interdigitais) obtidas (a) antes e (b)/(c) depois de $V_{S D}$ atingir $10 \mathrm{~V}$.

A Fig 3.19-(a) mostra uma parte dos eletrodos interdigitais sobre o $\mathrm{SiO}_{2}$ antes da aplicação de $V_{S D}=10 \mathrm{~V}$. Como podemos observar, com exceção de uma mancha localizada no centro da figura, os eletrodos metálicos parecem estar em perfeitas condições. A Fig. 3.19-(b) mostra a mesma região da amostra depois de ser aplicado $V_{S D}=$ 10 V. Nesse caso vê-se, claramente, que os eletrodos metálicos estão danificados. A Fig. 3.19-(c) ainda mostra as imagens ópticas dos eletrodos em uma escala menor, onde é possível observar que as superfícies do óxido e dos eletrodos metálicos foram danificadas.

Como uma tentativa para eliminar o problema de degradação do óxido e dos eletrodos, novas lâminas de silício foram limpas e oxidadas seguindo o procedimento padrão descrito nesse item. Porém, ao finalizar o processo de oxidação térmica, as lâminas foram novamente imersas em solução decapante de ácido fluorídrico (HF) para eliminar toda e qualquer oxidação da superfície do silício. Com isso, espera-se que impurezas que por ventura pudessem estar adsorvidas na superfície do silício, e que não foram removidas com a primeira decapagem com HF, sejam agora eliminadas. Em seguida, todos os processos de limpeza, oxidação e litografia foram realizadas novamente. Novas curvas $I_{S D}$ vs. $V_{S D}$ foram, então, obtidas em amostras semelhantes às primeiras variando-se $V_{S D}$ de $-10 \mathrm{~V}$ a $10 \mathrm{~V}$. Como resultado obtido, as correntes $I_{S D}$, dreno-porta e fonte-porta ficaram limitadas entre $10^{-10}$ e $10^{-11} \mathrm{~A}$, o que confirma a boa qualidade do óxido formado. Dessa 
forma, esse será o procedimento usado para a obtenção das estruturas $\mathrm{Al} / \mathrm{Si} / \mathrm{SiO}_{2}$ para a preparação dos PFETs, cujos resultados são mostrados no Cap. 8.

\subsection{Caracterização dos Substratos de Vidro/ITO}

A inclusão dessa seção visa caracterizar as características do ITO das amostras decapadas e tratadas em água-régia diluída (itens 3.2.1 e 3.3.1). Apresentamos as características desse óxido através de medidas de condutividade, de EDX (energy dispersive x-ray analysis) e de imagens de microscopia de força atômica (atomic force microscopy - AFM). Nossos objetivos são investigar os efeitos da decapagem e do tratamento químico na condutividade elétrica, na rugosidade, na espessura e na composição de elementos químicos do óxido. As imagens de AFM foram realizadas em um microscópio Nanoscope III, da Digital Instruments, no Instituto de Física de São Carlos, utilizando o modo contato (tapping mode). Medidas de EDX, por sua vez, foram realizadas em um equipamento Zeiss, no Instituto de Química de São Carlos, com uma ampliação de 1000 vezes (área analisada: $0,65 \mathrm{~mm}^{2}$ ) e utilizando a contagem de elementos químicos como referência. Todas as medidas foram realizadas pelo Dr. Marcelo Assumpção.

Medidas de condutividade, por sua vez, foram realizadas pelo método 4 pontas, o qual consiste em se pressionar 4 contatos elétricos sobre a superfície de uma amostra plana, e separados por uma distância $d$. A partir da corrente (I) fornecida por uma fonte de corrente entre os eletrodos externos, e da tensão (V) obtida entre os dois eletrodos internos, a condutividade do material é obtida através da equação:

$$
\sigma=\frac{\mathrm{I}}{\mathrm{V}} \frac{1}{4,53 \ell}
$$

onde o parâmetro 4,53 é um fator geométrico relacionado à área e a distância dos eletrodos utilizados, e $\ell$ é a espessura da amostra. Tais medidas foram realizadas na Escola Politécnica/USP pelo Prof. Roberto Onmori.

Dispositivos emissores de luz poliméricos são, usualmente, preparados seguindo os procedimentos apresentados na Fig. 3.20. Na Fig. 3.20 -(a) tem-se a decapagem do ITO, na Fig. 3.20-(b) a deposição do polímero, na Fig. 3.20-(c) a metalização do cátodo, e na Fig. 3.20-(d) os contatos elétricos e a área luminescente do dispositivo, definida pela sobreposição das áreas dos dois eletrodos (ITO e metal). 


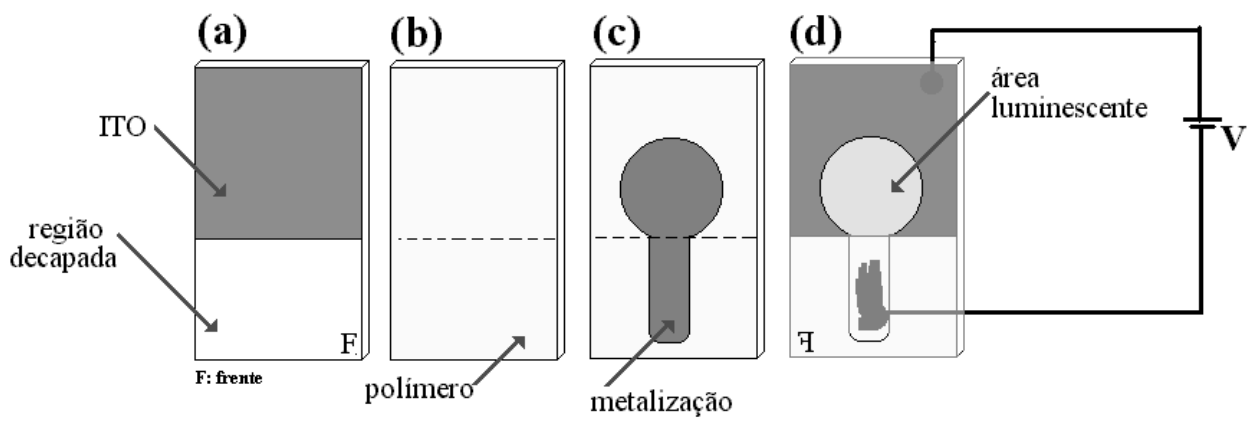

Figura 3.20: Esquema usado para a confecção dos PLED. (a) decapagem do ITO, deposição do polímero, (c) metalização e (d) contatos elétricos.

A seguir descrevemos as caracterizações dos substratos utilizados. Todos os resultados apresentados nas Figs. 3.21 a 3.22 foram obtidos após as amostras terem sido limpas com água ultrapura Milli-Q em abundância, acetona e álcool isopropílico quentes, secas em gás de nitrogênio e aquecidas por $1 \mathrm{~h}$ a $100{ }^{\circ} \mathrm{C}$ em estufa a vácuo.

A Fig. 3.21 mostra as imagens da interface entre as regiões decapadas (vidro) e com ITO de amostras decapadas de vidro/ITO (veja Fig. 3.15). As imagens foram obtidas por microscopia óptica de reflexão na escala $(2 \times 1,5) \mathrm{mm}^{2}$. A Fig. 3.21-(a) foi obtida após a imagem ter sido decapada, enquanto as Figs. 3.21-(b), 3.21-(c) e 3.21 -(d), após o tratamento das lâminas por, respectivamente, 15 min, 30 min e 60 min em solução de águarégia diluída em ultra-som.
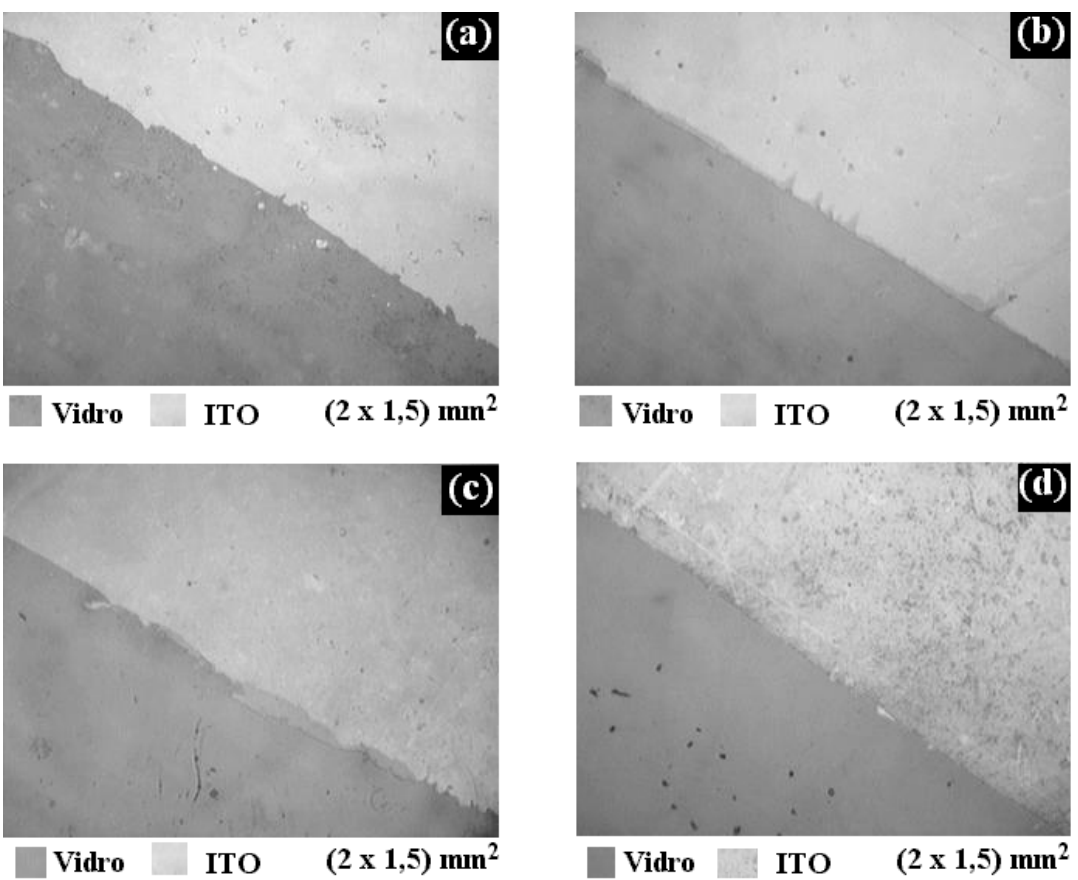

Figura 3.21: Microscopia óptica de reflexão de substratos vidro/ITO após o processo de decapagem: (a) sem tratamento, e tratado por (b) $15 \mathrm{~min}$, (c) $30 \mathrm{~min}$ e (d) $60 \mathrm{~min}$ em água-régia. 
Da Fig, 3.21 observamos uma boa interface entre as regiões decapadas (superfície do vidro) e não decapadas (superfície com ITO). Entretanto, o ITO sobre o vidro na amostra tratada por $60 \mathrm{~min}$, Fig. 3.21-(d) apresenta-se amarela, enquanto em todas as outras azul. Tal efeito pode estar associado a uma modificação na estrutura química do óxido ou à provavelmente uma diminuição da sua espessura, que seria um fenômeno semelhante ao que ocorre em filmes de dióxido de silício.

A Fig. 3.22 mostra as imagens de microscopia de força atômica da interface vidro/ITO apresentadas na Fig. 3.21. Nas Figs. 3.22-(a) e (b) têm-se as imagens em duas e três dimensões da amostra não tratadas por água-régia. Nas Figs. 3.22-(c) e (d) da amostra tratada por 15 min e, por último, as Figs. 3.22-(e) e (f) da amostra tratada por 60 min. As imagens são apresentadas em duas e três dimensões para facilitar a visualização da superfície do óxido e da sua interface com a região decapada (vidro).
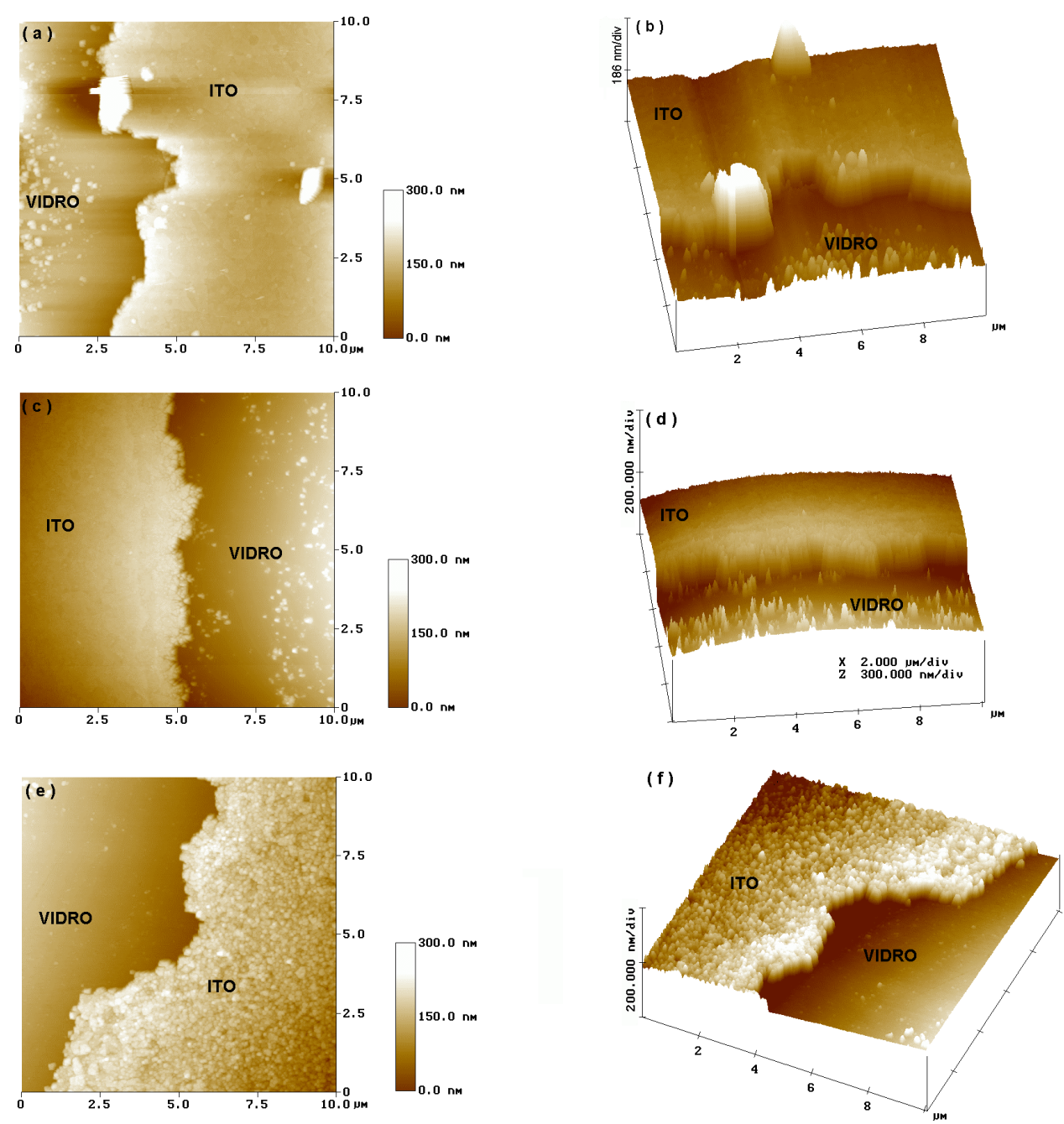

Figura 3.22: Imagens de microscopia de força atômica obtida com os substratos vidro/ITO decapados. (a) e (b) sem o tratamento de limpeza, (c) e (d) com tratamento por imersão em água-régia por 15 min e (d) e (f) com tratamento por imersão em água-régia por $60 \mathrm{~min}$. 
Da Fig. 3.22 observamos um aparente aumento da rugosidade da superfície do ITO com o tempo de tratamento em água-régia. Para verificar o valor dessa grandeza, as imagens foram processadas utilizando-se o software Z-Scan e os resultados da rugosidade média quadrática $(R u)$ e da espessura $(L)$ da camada do óxido são apresentados na Tabela 3.II. Essa tabela também apresenta os resultados obtidos com amostras decapadas e tratadas por diferentes tempos em água-régia.

Tabela 3.II: Rugosidade $(R u)$, espessura $(L)$, condutividade $(\sigma)$ e composição dos elementos químicos de amostras de ITO decapadas e não-decapadas, tratadas e não tratadas em água régia. T é o tempo de imersão das lâminas durante o tratamento em água-régia, e a região analisada foi a superfície do vidro com ITO.

\begin{tabular}{|c|c|c|c|c|c|c|}
\hline Amostras & Região analisada & $\begin{array}{c}\mathbf{T} \\
(\mathbf{m i n})\end{array}$ & $\begin{array}{c}\boldsymbol{R u} \\
(\mathrm{nm})\end{array}$ & $\begin{array}{c}\mathbf{L} \\
(\mathbf{n m})\end{array}$ & $\begin{array}{c}\sigma \\
10^{3} \mathrm{~S} / \mathrm{cm}\end{array}$ & In/Sn \\
\hline Não Decapada & Superfície do ITO & 0 & 4 & - & - & $77 / 23$ \\
\hline \multirow{6}{*}{ Decapadas* } & \multirow{6}{*}{ Superfície de ITO } & 0 & 3 & 168 & 7,2 & $77 / 23$ \\
\hline & & 5 & 4 & 154 & 7,6 & $77 / 23$ \\
\hline & & 15 & 4 & 140 & 8,3 & $76 / 24$ \\
\hline & & 20 & 4 & 136 & 8,3 & $76 / 24$ \\
\hline & & 30 & 6 & 137 & 8,0 & $79 / 21$ \\
\hline & & 60 & 17 & 130 & 5,2 & $78 / 22$ \\
\hline
\end{tabular}

* região de ITO protegida com fita adesiva durante o processo de decapagem.

Da Tabela 3.II observamos que a amostra não decapada, isto é, não submetida ao processo de decapagem, apresenta rugosidade semelhante às amostras decapadas e tratadas em água-régia por até 20 min. Por outro lado, os resultados mostram que a espessura do ITO diminui com o tratamento em água-régia, e a rugosidade começa a aumentar após 20 min desse tratamento.

A Fig. 3.23 mostra os espectros da energia do feixe incidente vs. contagem dos elementos químicos presentes nos filmes de ITO das amostras apresentadas na Fig. 3.22. Foram investigadas: Fig. 3.23-(a), uma amostra virgem (sem decapagem ou limpeza química), e Fig. 3.23-(b), uma amostra na qual o ITO foi protegido com fita adesiva durante o processo de decapagem, mas não tratado em água-régia. Ambas as amostras foram limpas apenas com acetona e álcool isopropílico em ebulição. Os gráficos foram obtidos pela técnica de $E D X$ na temperatura ambiente e a vácuo $\left(10^{-6} \mathrm{Torr}\right)$. 

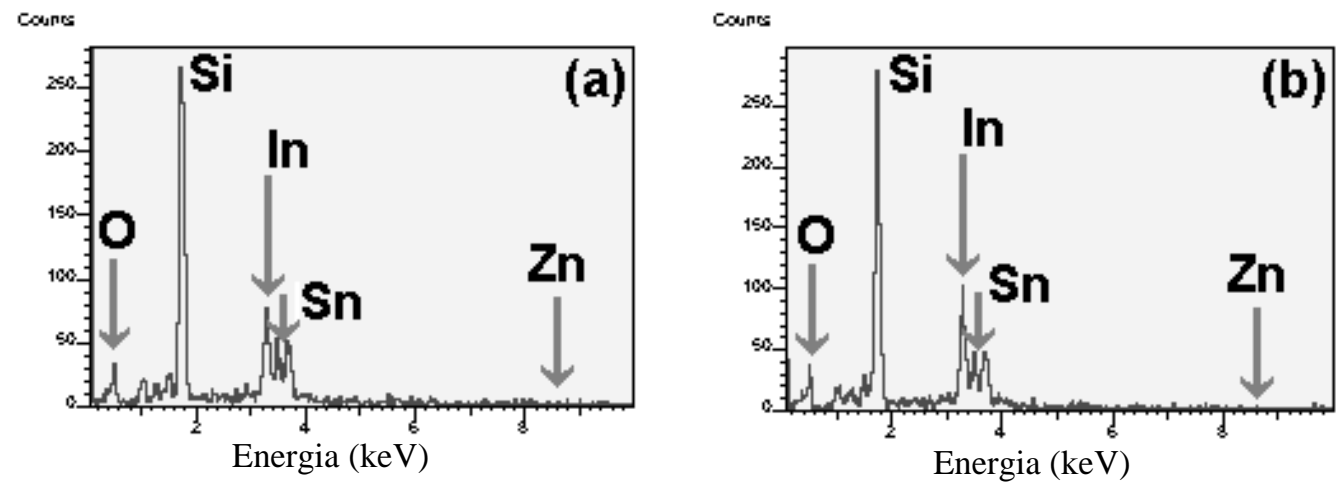

Figura 3.23: Espectros de $E D X$ obtidos com filmes de ITO (a) antes e (b) depois de terem sido decapados.

A Fig. 3.23 destaca as possíveis posições dos picos referentes aos elementos químicos $\mathrm{Si}, \mathrm{O}, \mathrm{In}, \mathrm{Sn}$ e $\mathrm{Zn}$ presentes nas amostras. Si e O são elementos presentes no vidro, In, Sn e O são elementos presentes no ITO $\left(\mathrm{SnO}_{2}+\mathrm{In}_{2} \mathrm{O}_{3}\right)$, e $\mathrm{Zn}$ o elemento químico usado no processo de decapagem. Para os nossos objetivos, somente as quantidades dos elementos Sn, In e Zn serão analisadas: o Sn e In por serem os elementos presentes no ITO, e o Zn por ser um possível elemento químico residual e contaminante do processo de decapagem. Como resultado das caracterizações, ambas as amostras apresentaram uma relação de contagem de elementos químicos In/Sn igual a 77/23, e nenhum traço de Zn, o que indica que o processo de decapagem não modifica a razão entre as quantidades de $\mathrm{In} / \mathrm{Sn}$, e nem deixa traços de $\mathrm{Zn}$ residuais sobre o ITO, podendo ser usado satisfatoriamente. Análise por EDX da superfície do vidro da região decapada não apresentaram traços de $\mathrm{Sn}$, In e $\mathrm{Zn}$, o que corrobora o fato de que o processo de decapagem é bastante eficaz na remoção do ITO. Os resultados obtidos são mostrados na Tabela 3.II, que também apresenta os valores das espessuras e rugosidade do ITO obtidos por AFM, e da condutividade do ITO, obtida através da Eq. (3.1).

Da Tabela 3.II constatamos que os filmes de ITO não decapado e decapado, mas não tratado quimicamente em água-régia, apresentam valores de $R u(4 \mathrm{~nm})$ muito semelhantes. Já para as amostras que foram decapadas e tratadas quimicamente em águarégia, observa-se que o tempo de imersão das amostras age no sentido de aumentar a rugosidade e diminuir a espessura do filme de ITO. Porém, a razão In/Sn, para todas as amostras, é praticamente a mesma, ficando em torno de 77/23. Em relação à condutividade, ela passa por um valor máximo com 15 min de tratamento em água-régia, e cai à metade do seu valor inicial após 60 min de tratamento. Com esses resultados fica claro que o método de decapagem não modifica e nem contamina a camada de óxido, enquanto que o tratamento químico em solução de água-régia diluída aumenta a rugosidade 
e diminui a espessura da camada do óxido. Além disso, a condutividade passa por um máximo com 15 min de tratamento, e a superfície do vidro de onde foi removido o óxido não apresenta traços de $\mathrm{Sn}$, In e $\mathrm{Zn}$. Resultados semelhantes foram obtidos por Kim et al. ${ }^{[57]}$, que mostraram que o aumento da rugosidade do ITO aumenta a área de contato entre esse óxido e os filmes de derivados do PPV, aumentando a injeção de portadores positivos no interior do polímero e, conseqüentemente, melhorando o desempenho do dispositivo.

Baseados nesses resultados, adotamos o processo de decapagem como o método de formação de padrões de ITO sobre vidro, e a imersão das lâminas decapadas em solução de água-régia, por 15 min em ultra-som, como o método de limpeza desse óxido.

\subsubsection{Caracterização dos eletrodos de alumínio}

Nesse item apresentamos imagens de microscopia óptica dos eletrodos de alumínio utilizados nos PLEDs. Essa caracterização foi importante para determinar as condições de operação dos dispositivos estudados, e que são apresentados no Cap. 7.

A Fig. 3.24 mostra imagens de microscopias ópticas da superfície dos eletrodos de alumínio dos dispositivos: Fig.3.24-(a) ITO/MH-PPV/Al e Fig. 3.24-(b) ITO/PPV/Al, em atmosfera e temperatura ambientes. Para a realização dos contatos elétricos, fios de ouro são soldados com tinta prata na região externa a área de luminescência, evitando-se, assim, a difusão de solvente na região de aplicação do campo elétrico. As imagens foram obtidas após os dispositivos terem sido acesos, modo direto, mantendo-se a corrente entre os eletrodos em $2 \mathrm{~mA}$. A área mais clara da amostra é a região do alumínio. Os filmes poliméricos têm espessura de $400 \mathrm{~nm}$ (obtida por AFM) e a espessura do Al é de $50 \mathrm{~nm}$.
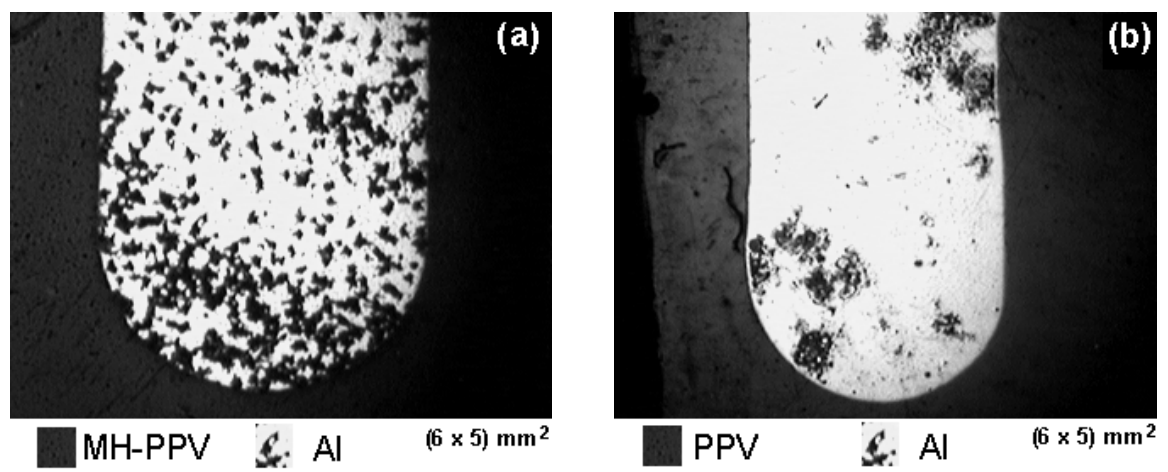

Figura 3.24: Imagens de microscopia óptica obtidas com PLEDs (a) ITO/MH-PPV/Al e (b) ITO/PPV/Al. de MH-PPV em atmosfera ambiente e após acender o dispositivo. 
Da Fig. 3.24 notamos que a área do eletrodo de alumínio apresenta-se fortemente danificada. Tal fenômeno é conhecido na literatura como pontos não emissivos (“dark spots") ${ }^{[59-61]}$, e ocorre devido às reações do polímero com o metal na presença de umidade ou oxigênio, ou mesmo devido ao acúmulo de cargas em impurezas na interface polímerometal. Para minimizar esse efeito, medidas elétricas foram realizadas em novas amostras em atmosferas com controle de umidade relativa (10\%) e sob vácuo ( $c a .10^{-1}$ Torr). Como resultado, uma redução significativa na ocorrência dos dark spots foi observada, assim como uma estabilização e reprodutibilidade das medidas $I v s$. $V$. Desse modo, todas as medidas elétricas em PLEDs foram realizadas com o controle da temperatura, sob vácuo e no escuro.

\subsection{Sumário do Capítulo}

Nesse capítulo apresentamos:

(i) os métodos de síntese química do PPV, MH-PPV, MD-PPV, PANI e POMA.

(ii) Os métodos casting e spin coating de preparação de filmes finos desses polímeros.

(iii) Os métodos de formação de padrões (litografia) de ITO sobre lâminas de vidro, e de eletrodos metálicos de $\mathrm{Cr} / \mathrm{Au}$ sobre superfícies de $\mathrm{SiO}_{2}$.

(iv) As caracterizações do óxido de silício submetido ao processo de decapagem e ao tratamento químico em água-régia diluída. 


\section{Capítulo 4}

\section{Equipamentos e Métodos de Medidas}

No estudo das propriedades ópticas e elétricas dos filmes e dispositivos poliméricos, medidas elétricas de corrente vs. tensão ( $I$ vs. $V)$, condutividade ou impedância em campo alternado (ac), medidas ópticas de absorção (UV-VIS e FTIR), de emissão (PL e EL) e de elipsometria (função pseudo-dielétrica e índice de refração complexos) tornam-se importantes ferramentas para a caracterização e a análise dos materiais e sistemas estudados. Nesse capítulo apresentamos os principais equipamentos e métodos de medidas utilizados no desenvolvimento desse trabalho.

\subsection{Medidas Elétricas}

Dois dos métodos mais importantes para estudar os mecanismos de condução e os fenômenos de interfaces de sistemas sólidos desordenados e/ou dispositivos eletrônicos são os métodos de correntes constante (dc) e alternada (ac). A Fig. 4.1 mostra o esquema geral utilizado para essas medidas.

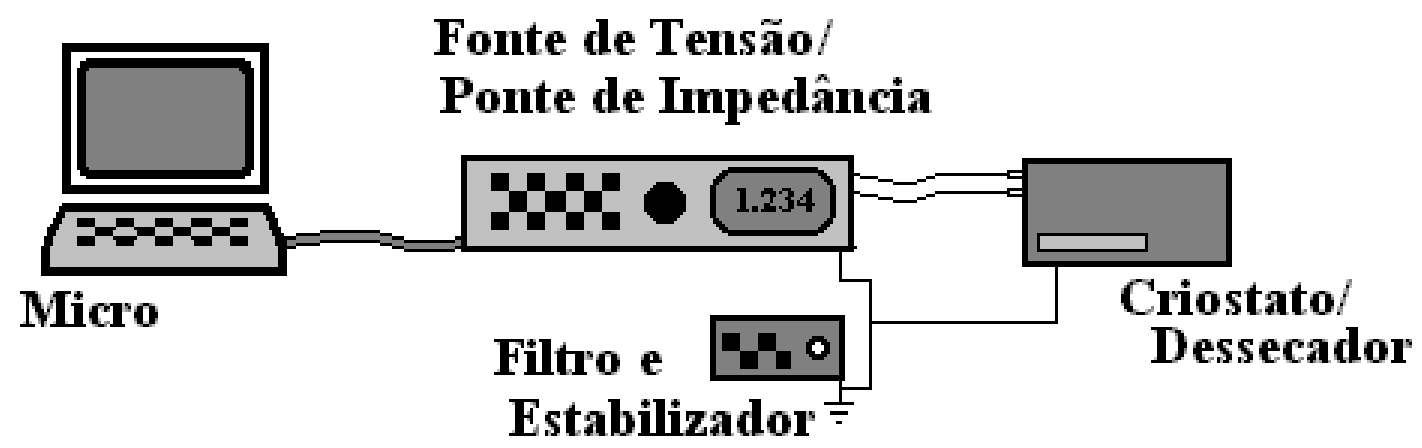

Figura 4.1: Esquema utilizado para a realização das medidas elétricas e aquisição de dados. 


\subsubsection{Corrente vs. Tensão (I vs $V$ )}

No método de corrente constante, a tensão (V) é aplicada entre as faces de uma amostra plana e paralela, e a corrente (I) que flui pelo sistema é detectada como função de V. Para as medidas elétricas de amostras planas de polímeros e de PLEDs foi utilizada uma fonte Keithley modelo 238, e para as medidas dos transistores, um analisador de parâmetros semicondutores HP 4145B. Ambas as unidades permitem a aplicação de tensão de -100 a $100 \mathrm{~V}$ e leitura de corrente de $10^{-9}$ a $20 \mathrm{~mA}$. No caso específico dos PFETs, para facilitar os contatos dos eletrodos dreno e fonte, foi utilizado um sistema de micromanipuladores da WentWorth. Nesse sistema, pontas de prova (agulhas) são colocadas diretamente nos eletrodos interdigitais com o auxílio de um microscópio de reflexão óptica e cabos elétricos fazem a conexão dessas pontas com as fontes de medidas.

A Fig. 4.2 mostra o esquema dos micromanipuladores utilizados.

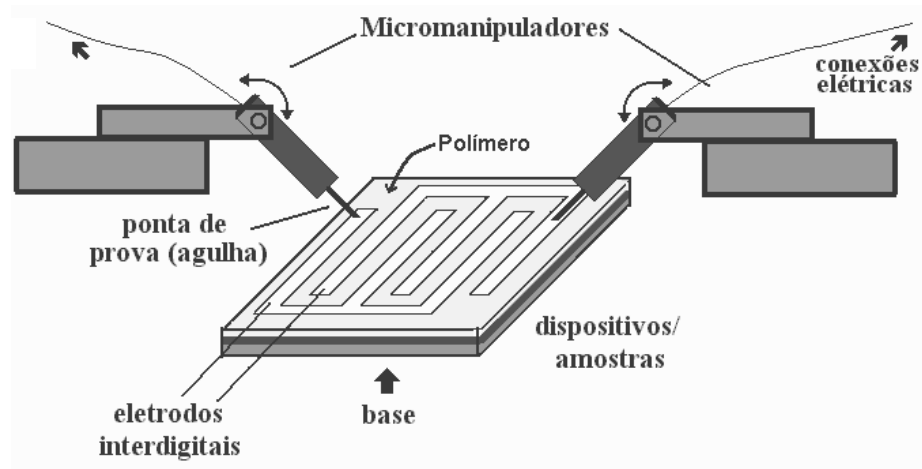

Figura 4.2: Detalhes do sistema de micromanipuladores e um dispositivo PFET com eletrodos interdigitais.

\subsubsection{Condutividade em campo alternado (ac)}

Medidas de condutividade elétrica em campo alternado (ac) também foram realizadas em amostras planas, paralelas e com eletrodos depositados em ambas as suas faces. Nesse caso, a aplicação de uma tensão $V$, com uma amplitude fixa $\left(V_{a c}\right)$ e frequiência angular de oscilação $\omega$, fornece os componentes da impedância complexa $\left(Z^{*}=Z^{\prime}-i Z^{\prime}\right)$ como função de $\omega$ que, por sua vez, permitem o cálculo da condutividade complexa de um sistema sólido se a área $(A r)$ do eletrodo e a espessura $(L)$ do filme forem conhecidas $\left(\sigma^{*}=L / A r Z^{*}\right)$. Medidas ac também foram realizadas aplicando-se uma tensão de 
polarização na amostra (denominada de $V_{\text {bias }}$ ). Medidas de impedância complexa foram realizadas com um Impedanciômetro Solartron, Modelo 1260 Impedance/Gain Phase Analyser, que permite aplicação de uma amplitude de tensão de 0 a $3 \mathrm{~V}$ em um intervalo de freqüência $(f)$ de $100 \mathrm{mHz}$ a $2 \mathrm{MHz}$.

\subsubsection{Controle da temperatura e da umidade}

Algumas medidas elétricas dc e ac foram realizadas com temperatura controlada em ambiente de umidade relativa em torno de $10 \%$. Para isso, dois sistemas foram utilizados. Para a variação da temperatura sob vácuo, um criostato APD, modelo DE-202, e para o controle da umidade, um dessecador com conexões elétricas apropriadas. O criostato APD possui, como principal característica, a variação da temperatura das amostras $13 \mathrm{~K}$ a $350 \mathrm{~K}$ (ou -260 a $77{ }^{\circ} \mathrm{C}$ ), e o dessecador, conectores tipo BNC adaptados a sua lateral que permitem o acesso elétrico interno e externo de sistema entre a amostra e uma fonte de medida.

Em todas as medidas, as fontes de tensão ou a ponte de impedância eram ligadas a um filtro de linha/estabilizador de tensão, e os dados eram obtidos via computador, como esboçado na Fig. 4.1.

\subsection{Medidas Ópticas}

Medidas de absorção UV-VIS, fotoluminescência (PL), eletroluminescência (EL) e índice de refração $\left(\mathrm{N}^{*}\right)$ dos polímeros foram realizadas para caracterizar as propriedades ópticas dos materiais e dos seus dispositivos.

\subsubsection{Absorção UV-VIS}

Para medidas de absorção na região do UV-VIS foi utilizado um espectrofotômetro Hitachi, modelo U-2001, do Grupo de Polímeros que permite a realização de medidas de absorção por transmitância no intervalo entre 190 e 1100 nm. 


\subsubsection{Absorção Infravermelho - FTIR}

Medidas de absorção na região do infravermelho foram realizadas no grupo de Biofísica do IFSC usando-se um espectrômetro FTIR Nicolet 560, no intervalo de 500 a $2000 \mathrm{~cm}^{-1}$ em temperatura e atmosfera ambientes.

\subsubsection{Fotoluminescência e Eletroluminescência}

Medidas de foto (PL) e eletroluminescência (EL) foram realizadas com um sistema disponível no laboratório de semicondutores do IFSC. Esse sistema consiste de um laser de Argônio $\left(25 \mathrm{~mW} / \mathrm{cm}^{2}\right)$, um monocromador $(0,5 \mathrm{~m})$ e uma fotomultiplicadora, além de instrumentos ópticos para colimar e melhorar a intensidade do sinal. Nesse aparato, o feixe do laser atinge a superfície de uma amostra e, em seguida, a intensidade luminosa emitida pelo polímero é colimada e captada por um monocromador, passando depois por uma fotomultiplicadora. O sinal da amostra entra no "Lock-in" e, em seguida, o sinal da intensidade luminosa emitida, como função do comprimento de onda $(\lambda)$, é gravado num micro PC. O esquema desse sistema é mostrado na Fig. 4.3.

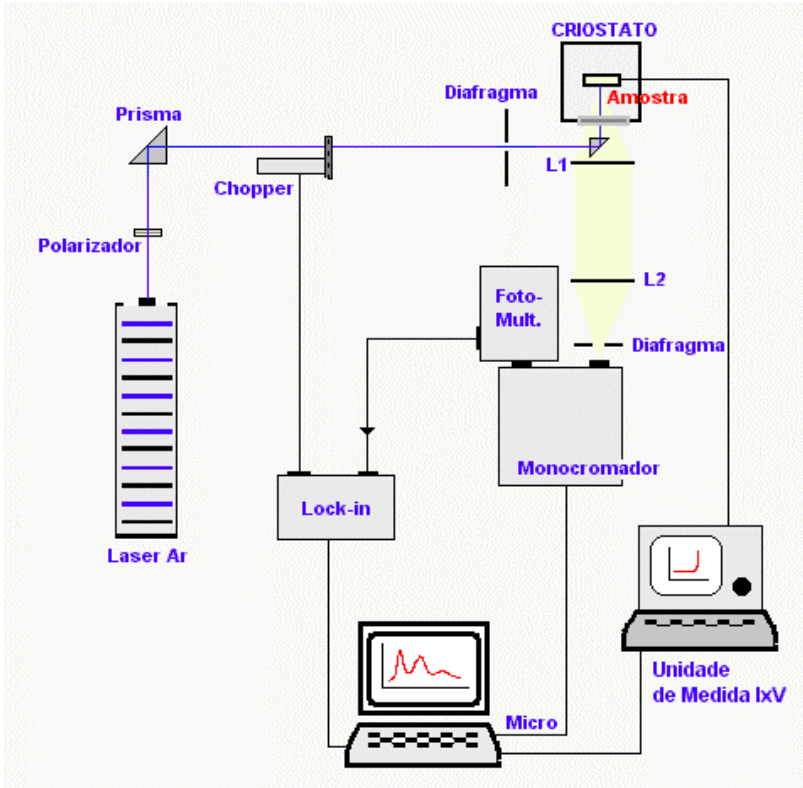

Figura 4.3: Sistema de medidas de fotoluminescência e eletroluminescência. 
Para a variação da temperatura das amostras foi utilizado o criostato Cryo, modelo 22, que permite uma variação de temperatura de $13 \mathrm{~K}$ a $350 \mathrm{~K}$ (ou -260 a $67{ }^{\circ} \mathrm{C}$ ), sob atmosfera de hélio gasoso. Para as medidas de eletroluminescência (EL) dos PLEDs, uma tensão V é aplicada entre os eletrodos desses dispositivos e a luz emitida é coletada com o mesmo arranjo experimental usado para medidas de PL.

\subsubsection{Elipsometria}

Para realizar as medidas de elipsometria, foi utilizado um elipsômetro Thin Film Elipsometer, modelo 43702-200E, da Rudolf Research, que é um equipamento simples e usual montado e instalado no Laboratório de Microeletrônica da Universidade da Carolina do Norte. Nesse equipamento, é possível obter as mudanças da fase $(\Delta)$ e intensidade $(\Psi)$ de um feixe incidente e refletido de uma amostra como função do seu comprimento de onda e, a partir desses sinais, obter a função pseudo-dielétrica e o índice de refração complexos dos polímeros como função da energia (E) ou comprimento de onda $(\lambda)$ do feixe incidente. A configuração óptica do equipamento é mostrada na Fig. 4.4.

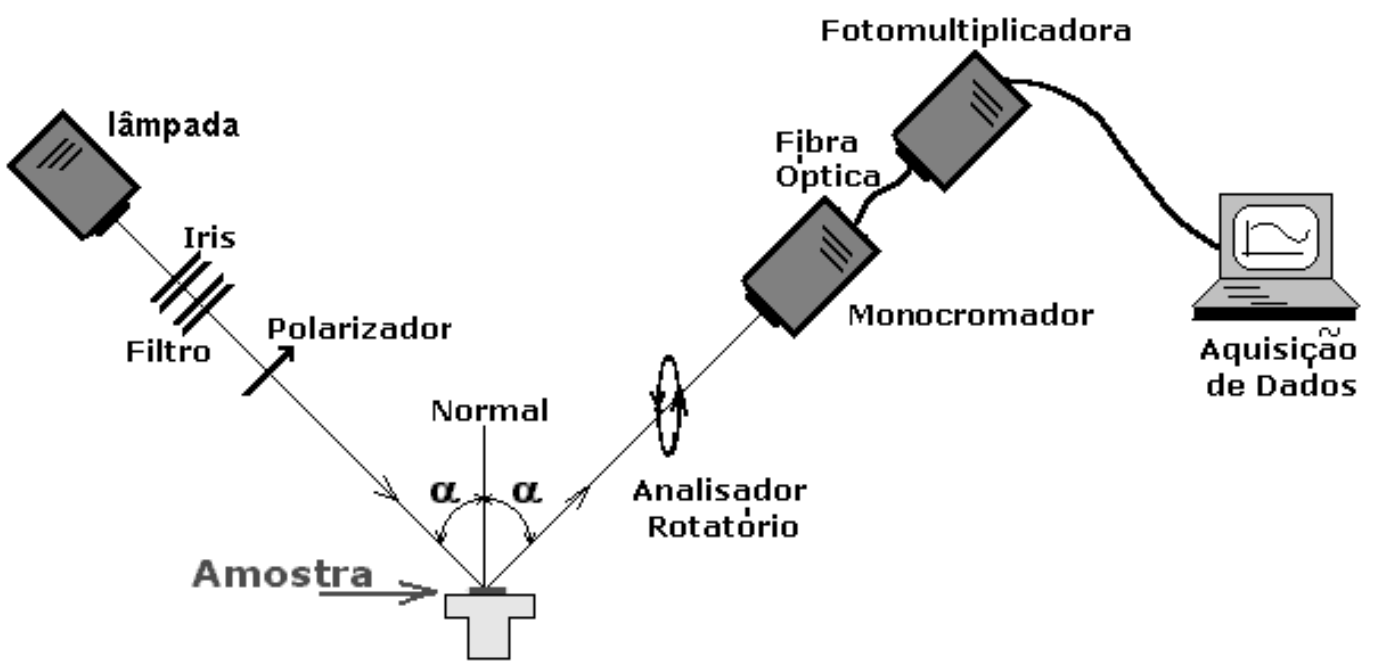

Figura 4.4: Configuração óptica do elipsômetro.

Nesse equipamento, o feixe de luz incidente (lâmpada de arco de xenônio) passa por um polarizador, sendo, posteriormente, refletido pela superfície de um filme com o mesmo ângulo $\alpha$. Como resultado, o feixe refletido passa por um analisador rotatório e emerge como uma função periódica em relação ao ângulo de rotação do analisador $(\beta)$. Em 
seguida, o feixe passa por um monocromador e por uma fotomultiplicadora, a qual fornece os valores das intensidades e das amplitudes do feixe luminoso como função de $\beta$ e do comprimento de onda do feixe $(\lambda)$. Por último, a aquisição de dados é realizada através de um software e as diferenças $\Delta$ e $\Psi$ são obtidas como função de $\lambda$, i.e., $\Delta(\lambda)$ e $\Psi(\lambda)^{[62,64]}$.

Para um sistema substrato-filme-ar, Fig. 4.5, o coeficiente de reflexão complexo $\rho$ depende da espessura $\left(\ell_{f}\right)$ do filme, do ângulo de incidência $(\alpha)$, de $\lambda$ e dos índices de refração do substrato $\left(\mathrm{n}_{s}\right)$, do filme $\left(\mathrm{n}_{f}\right)$ e do $\operatorname{ar}\left(\mathrm{n}_{\mathrm{o}}\right)^{[62,64]}$ :

$$
\rho=\tan \Psi \mathrm{e}^{\mathrm{i} \Delta}=\rho\left(\mathrm{n}_{\mathrm{s}}, \mathrm{n}_{\mathrm{f}}, \mathrm{n}_{\mathrm{ar}}, \ell_{\mathrm{f}}, \alpha, \lambda\right)
$$

$\operatorname{Ar}\left(\mathbf{n}_{\mathbf{0}}\right)$

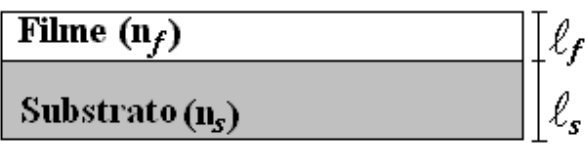

Figura 4.5: Sistema substrato-filme-ar.

Para o caso em que a espessura do filme e os índices de refração do substrato e do ar serem conhecidos, a obtenção de $\rho(\lambda)$ se reduz à obtenção do índice de refração $\mathrm{N}^{*}$ do filme que, por sua vez, pode fornecer a sua função pseudo-dielétrica $\langle\varepsilon\rangle$ através da equação ${ }^{[62,64]}$ :

$$
\mathrm{N}^{*}=\mathrm{n}+\mathrm{ik}=\sqrt{\operatorname{sen}^{2} \phi_{0}\left[1+\tan ^{2} \alpha\left(\frac{1-\rho}{1+\rho}\right)^{2}\right]}=\sqrt{\langle\varepsilon\rangle}=\sqrt{\varepsilon_{1}-\mathrm{i} \varepsilon_{2}}
$$

onde $\varepsilon_{1}$ e $\varepsilon_{2}$ são respectivamente os componentes real e imaginário de $\langle\varepsilon\rangle$, e $n$ e $k$, respectivamente, os componentes real e imaginária de $\mathrm{N}^{*}$. Uma descrição mais detalhada sobre a técnica de elipsometria é apresentada no apêndice A. 


\section{Capítulo 5}

\section{Caracterizações Ópticas e Elétricas dos Filmes Poliméricos}

$\mathrm{Na}$ investigação tecno-científica de dispositivos orgânicos, muitos desafios relacionados às interfaces polímero/eletrodo e aos fenômenos de degradação e transporte devem ser estudados e compreendidos. Nesse capítulo apresentamos os resultados experimentais de absorção (UV-VIS), emissão (PL), índice de refração e função pseudodielétrica dos polímeros luminescentes, e condutividade complexa dos polímeros semicondutores usados nesse trabalho. Foram estudados os seguintes efeitos: $(i)$ da temperatura no processo de conversão do PTHT em PPV, (ii) da influência dos grupos laterais na função pseudo-dielétrica e nos espectros de absorção e emissão óptica dos polímeros luminescentes, e (iii) da dopagem química nas propriedades elétricas da PANI. No estudo da contribuição dos grupos laterais, os espectros de função pseudo-dielétrica foram ajustados pela equação clássica do oscilador de Lorentz, que forneceu parâmetros importantes, como a energia de ressonância e a constante de amortecimento dos osciladores. Medidas de condutividade alternada com filmes de polianilina, por sua vez, foram ajustadas pelo modelo de barreiras de energias livres aleatórias (random free energy barrier model - RFEB), fornecendo a energia máxima de salto dos portadores de carga em função do grau de dopagem do polímero em solução de ácido clorídrico (HCl).

\subsection{Caracterizações ópticas dos filmes de PPV, MH-PPV e MD-PPV}

O controle e a investigação das propriedades ópticas dos polímeros luminescentes são de fundamental importância para a avaliação das características desses materiais como elementos ativos de dispositivos optoeletrônicos. Resultados da literatura ${ }^{[65-67]}$ mostram que os espectros de absorção UV-VIS e emissão óptica de filmes do PPV dependem tanto 
da rota e das condições ambientais de síntese, como da temperatura de conversão utilizadas. Por outro lado, a preparação de filmes dos derivados do PPV (MH-PPV e MDPPV) dispensa a etapa de conversão, mas depende da escolha do solvente utilizado ${ }^{[68-69]}$. No Cap. 3, mostramos que filmes de PPV obtidos com a solução PTHT/MeOH/Lenta, e de MH-PPV e MD-PPV tratados termicamente a $50{ }^{\circ} \mathrm{C}$, apresentam as melhores condições de homogeneidade. Visando estudar a influência de algumas dessas condições nas propriedades de absorção e emissão dos filmes, nesse item apresentamos as características ópticas de filmes de PTHT, convertidos em diferentes temperaturas, e de filmes de $\mathrm{MH}$ PPV e MD-PPV, tratados e não tratados a $50{ }^{\circ} \mathrm{C}$. Também são apresentados os espectros da função pseudo-dielétrica desses polímeros em temperatura e atmosfera ambientes.

A Fig. 5.1 apresenta as medidas de absorção UV-VIS e de PL obtidas com filmes de PTHT preparados por spin coating, sobre substratos de quartzo e convertidos em diferentes temperaturas $\left(22,80,140\right.$ e $\left.200{ }^{\circ} \mathrm{C}\right)$, obtidos seguindo os procedimentos apresentados no item 3.2.2 (Cap. 3). A Fig. 5.1-(a) mostra os espectros de absorção UVVIS obtidos em temperatura ambiente, e a Fig. 5.1-(b) mostra os espectros de emissão obtidos a $-200{ }^{\circ} \mathrm{C}$ e sob vácuo, temperatura essa em que os espectros de PL são melhor definidos. Todas as medidas foram realizadas imediatamente após a preparação dos filmes para minimizar o efeito de fotoxidação dos polímeros preparados.
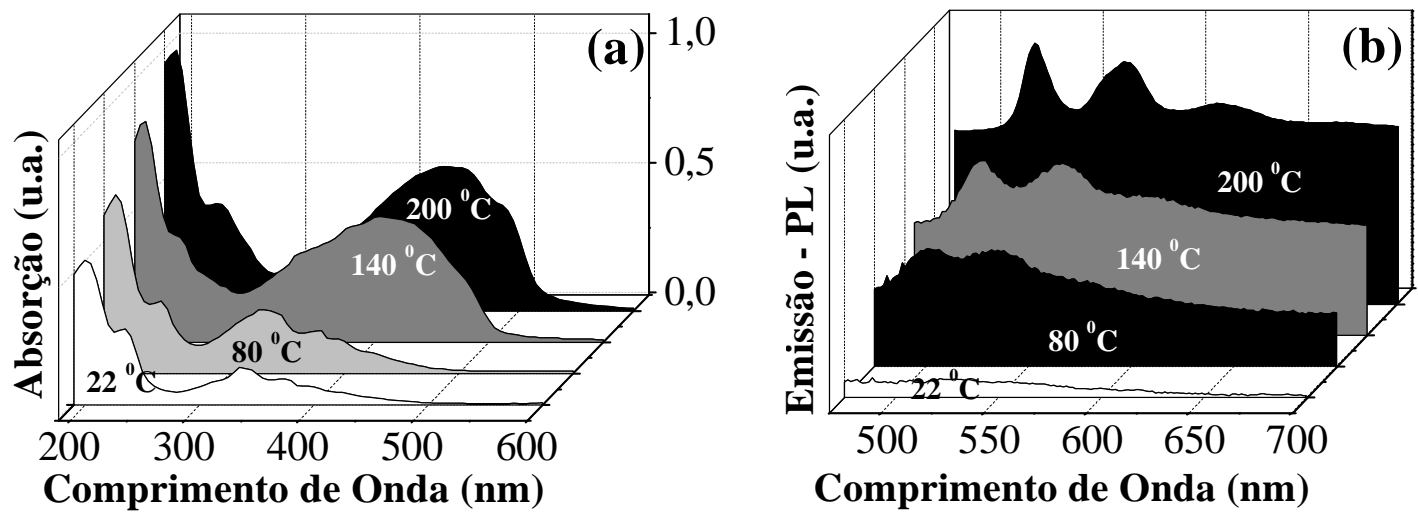

Figura 5.1: (a) Espectros de absorção UV-VIS e (b) de emissão de filmes de PTHT convertidos em 22 , 80, 140 e $200{ }^{\circ} \mathrm{C}$, por duas horas e sob vácuo. As medidas de absorção foram realizadas a temperatura e atmosfera ambientes, e as medidas de fotoluminescência em $73 \mathrm{~K}\left(-200{ }^{\circ} \mathrm{C}\right)$ sob vácuo. 
Os espectros de absorção obtidos com os filmes convertidos em $22{ }^{\circ} \mathrm{C}$ e $80{ }^{\circ} \mathrm{C}$, Fig. 5.1-(a), apresentam máximos da banda de absorção próximos de 200, 240 e 340 nm. Segundo comparações com os resultados da literatura ${ }^{[67]}$, esses máximos estão relacionados a transições eletrônicas referentes aos grupos fenila $(200 \mathrm{~nm})$, sulfônio $(235 \mathrm{~nm})$ e estilbeno $(325 \mathrm{~nm})$. À medida que a temperatura de conversão $\left(\boldsymbol{T}_{\boldsymbol{c}}\right)$ aumenta, o máximo centrado em $340 \mathrm{~nm}$ transforma-se em uma banda larga com máximo em torno de 440 nm. Nos espectros de emissão, PL, mostrados na Fig. 5.1-(b), o filme de PPV não convertido apresenta uma baixa intensidade de emissão. À medida que $T_{c}$ aumenta, máximos de intensidade surgem próximos a 525, 570 e $615 \mathrm{~nm}$, sendo mais bem resolvidos quanto maior o valor de $T_{c}$. O máximo de emissão situado em $525 \mathrm{~nm}$, enquanto os outros dois são as réplicas de fônons, que são comparáveis aos resultados da literatura ${ }^{[65,66]}$. Desse modo podemos concluir que, para temperaturas de conversão maiores, o processo de conversão é mais eficiente, gerando uma população maior de segmentos conjugados.

As Figs. 5.2 e 5.3 apresentam as curvas de absorção UV-VIS e PL de filmes de MH-PPV, a $73 \mathrm{~K}\left(-200{ }^{\circ} \mathrm{C}\right)$, e MD-PPV, em temperatura ambiente. Os filmes foram preparados sobre lâminas de quartzo pelo método spin coating, tratados termicamente em 22 e $50{ }^{\circ} \mathrm{C}$, por $30 \mathrm{~min}$. e sob vácuo $\left(10^{-2}\right.$ Torr $)$. O objetivo desse tratamento é a eliminação do clorofórmio residual nos filmes. Na Fig. 5.2-(a), para o MH-PPV, observamos que as curvas de absorção apresentam máximos em torno de 200, 330 e $510 \mathrm{~nm}$, enquanto as curvas de emissão, Fig. 5.2-(b) apresentam máximos em torno de 610 nm, 670 nm e 725 nm. Já para o MD-PPV, Fig. 5.3-(a), os espectros apresentam máximos de intensidade em torno de 200, 330 e 510 nm, enquanto os espectros de emissão, Fig. 5.3-(b), apresentam máximos em 600 nm e suas réplicas. Portanto, podemos concluir através desses resultados que o tratamento térmico não tem influência na forma de linha dos espectros e, portanto, não alteram as propriedades ópticas do MH-PPV e do MD-PPV. 

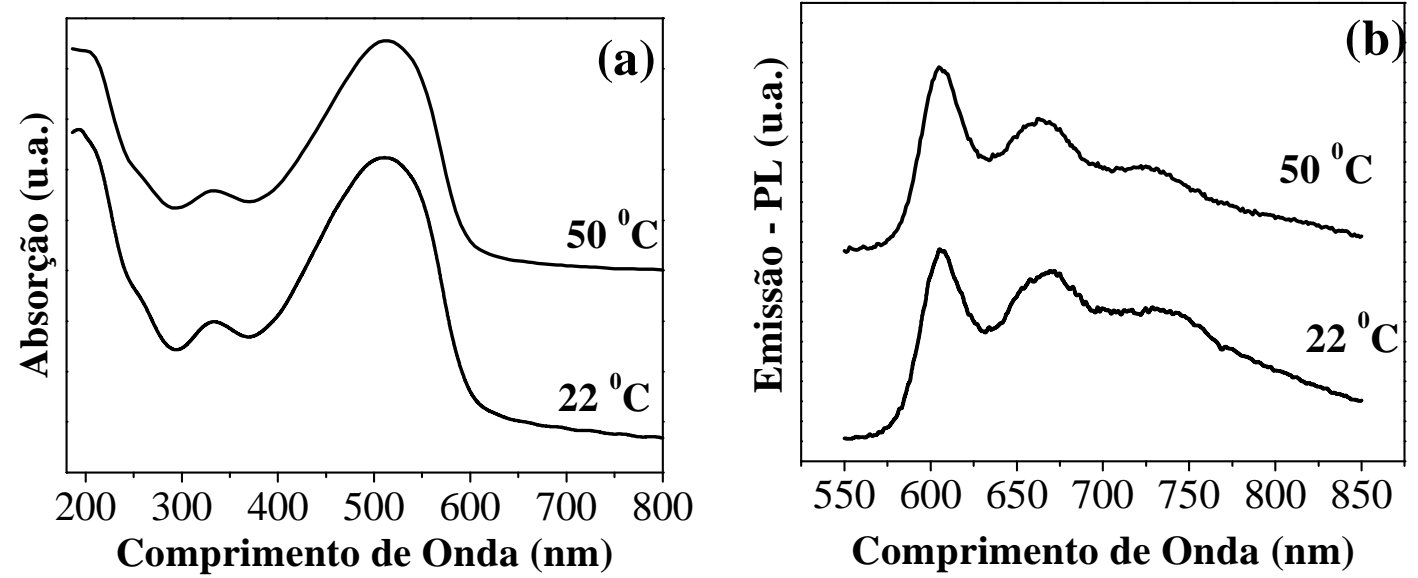

Figura 5.2: Espectros de (a) absorção UV-VIS e (b) emissão PL obtidos com filmes MH-PPV tratados em 22 e $50{ }^{\circ} \mathrm{C}$ por $30 \mathrm{~min}$, sob vácuo. Medidas de UV-VIS realizadas em $27^{\circ} \mathrm{C}$ e de PL em $73 \mathrm{~K}\left(-200{ }^{\circ} \mathrm{C}\right)$.
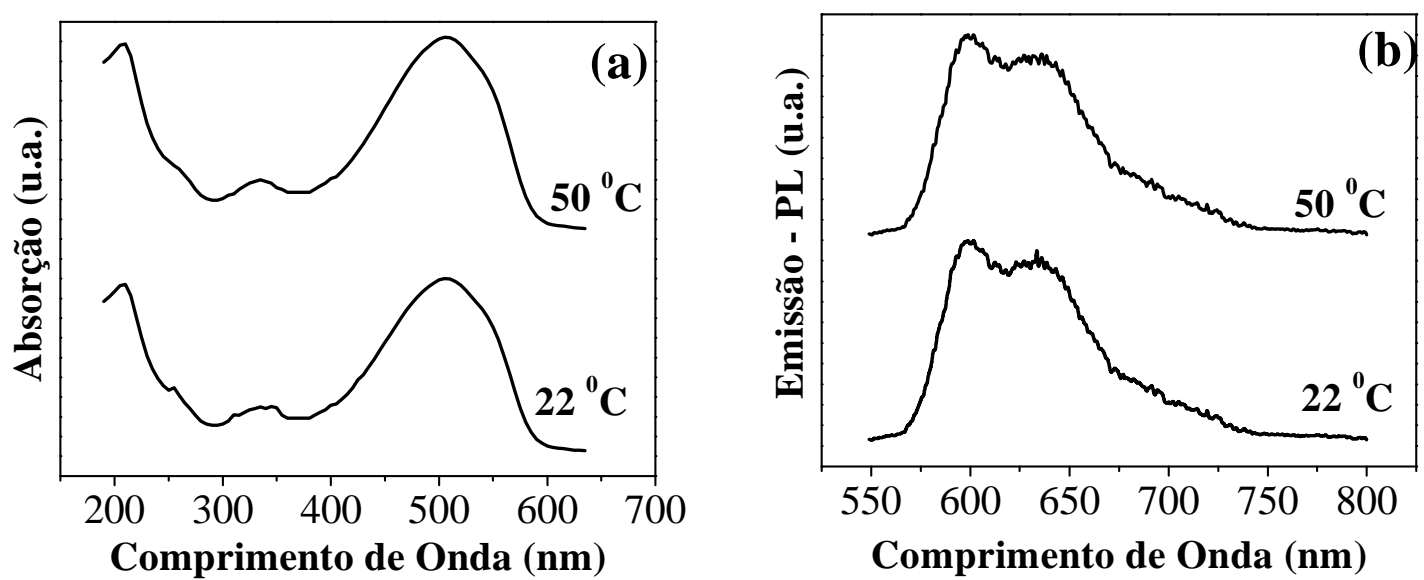

Figura 5.3: Espectros de (a) absorção UV-VIS e (b) emissão PL obtidos com filmes MD-PPV tratados em 22 e $50{ }^{\circ} \mathrm{C}$ por $30 \mathrm{~min}$, sob vácuo e em $27^{\circ} \mathrm{C}$.

A Fig. 5.4 apresenta, para fins de comparação, os gráficos de absorção UV-VIS (一) e PL (-) obtidos a temperatura ambiente com os mesmos filmes usados nas medidas apresentadas nas Figs. 5.1, 5.2 e 5.3 (PPV convertido a $200{ }^{\circ} \mathrm{C}$, e MH-PPV e MD-PPV tratados termicamente a $50{ }^{\circ} \mathrm{C}$ ). A Tabela 5.I apresenta os valores da energia (e do comprimento de onda) dos máximos das curvas de emissão $\left(\boldsymbol{E}_{\text {emis }}\right)$, e das curvas de absorção $\left(\boldsymbol{E}_{\boldsymbol{a b s}}\right)$ na região do visível. 


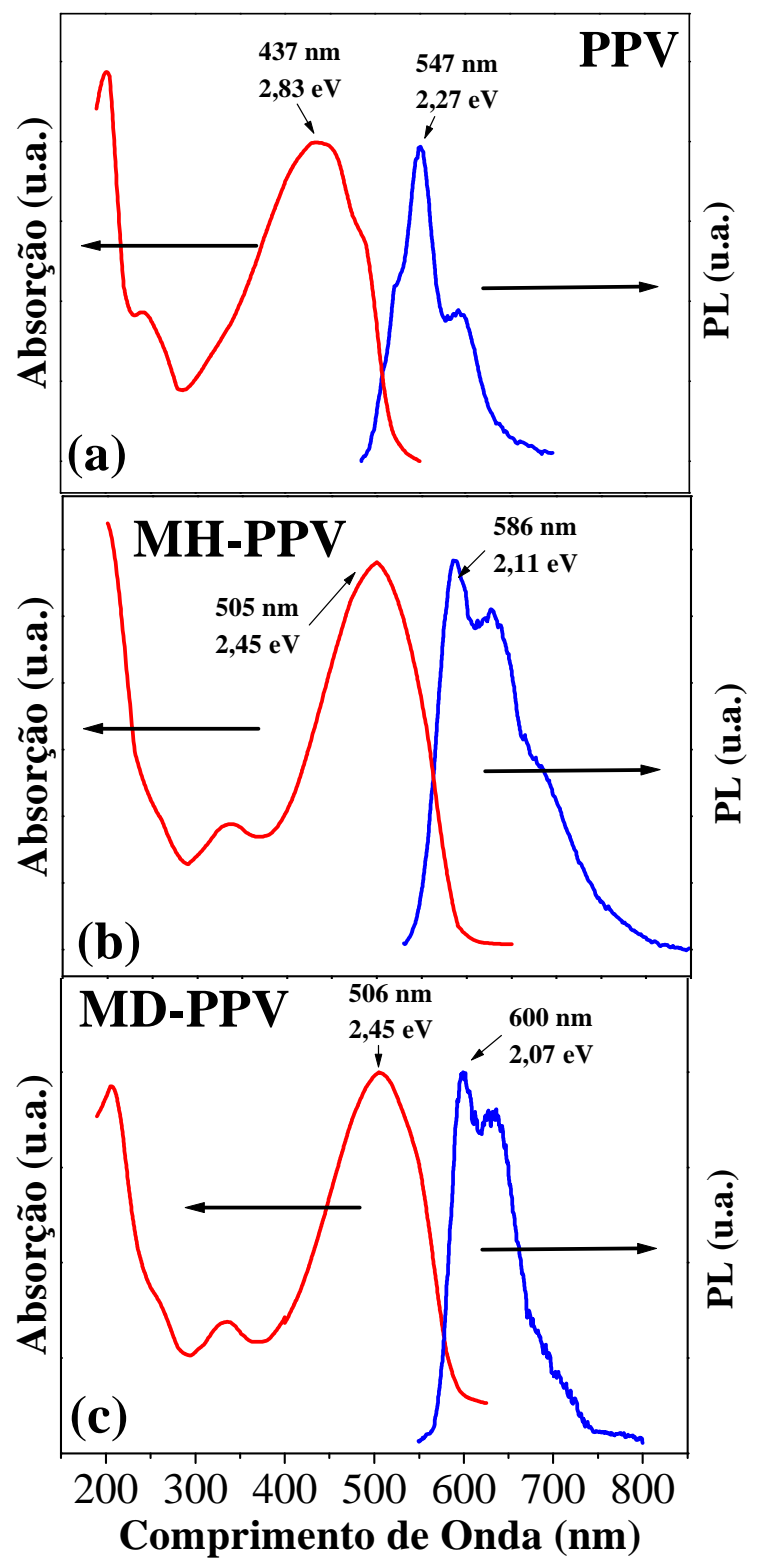

Figura 5.4: Espectros de absorção UV-VIS e de emissão PL obtidos com os filmes de (a) $P P V\left(T_{c}=200{ }^{\circ} \mathrm{C}\right)$, (b) MH-PPV e (c) MD-PPV, tratados a $50{ }^{\circ} \mathrm{C}$ sob vácuo. Medidas realizadas em $27{ }^{\circ} \mathrm{C}$ e atmosfera ambiente.

Tabela 5.I: Valores dos comprimentos de onda, das energias, dos máximos de absorção no visível $\left(E_{a b s}\right)$ e dos máximos mais intensos da emissão $\left(E_{\text {emis }}\right)$ obtidos com os filmes de PPV e MH-PPV e MD-PPV

\begin{tabular}{||c|c|c||}
\hline Polímero & $\boldsymbol{E}_{a b s}(\mathbf{n m} / \mathbf{e V})$ & $\boldsymbol{E}_{\text {emis }}(\mathbf{n m} / \mathbf{e V})$ \\
\hline PPV & $437 / 2,83$ & $547 / 2,27$ \\
\hline MH-PPV & $505 / 2,45$ & $586 / 2,11$ \\
\hline MD-PPV & $506 / 2,45$ & $600 / 2,07$ \\
\hline
\end{tabular}

A partir dos resultados apresentados na Tabela 5.I, observamos que o valor de $E_{a b s}$ desloca-se para o vermelho quando grupos alcóxi são incorporados à cadeia do PPV. Esse deslocamento, no entanto, parece não depender do tamanho desses grupos (12 carbonos para o MD-PPV e 6 carbonos para o MH-PPV). Já na emissão, o tamanho do grupo alcóxi parece ter alguma influência: quanto maior o número de carbonos, menor a energia 
$E_{\text {emis }}(\mathrm{em} \mathrm{eV)}$. O valor obtido para o deslocamento de Stokes do MH-PPV é de 0,34 eV, e para o MD-PPV é de $0,38 \mathrm{eV}$

\subsubsection{Elipsometria}

A Fig. 5.5 mostra os componentes real $-\varepsilon_{1}$ (O) e imaginário - $\varepsilon_{2}(\mathrm{O})$ da função pseudo-dielétrica no intervalo de energia $(\boldsymbol{E})$ entre 1,8 a 4,0 eV obtidas com os filmes de MH-PPV, MD-PPV e PPV preparados por casting sobre uma fina camada de ouro (60 $\mathrm{nm}$ ), depositado sobre um substrato de vidro recoberto com cromo (40 nm). O cromo foi usado para aumentar a aderência do filme de ouro sobre a lâmina de vidro que, por sua vez, foi utilizado por ser um metal inerte. As medidas foram realizadas pela técnica de elipsometria, em atmosfera e temperatura ambientes, e os filmes poliméricos possuíam espessura em torno de $1 \mu \mathrm{m}$.

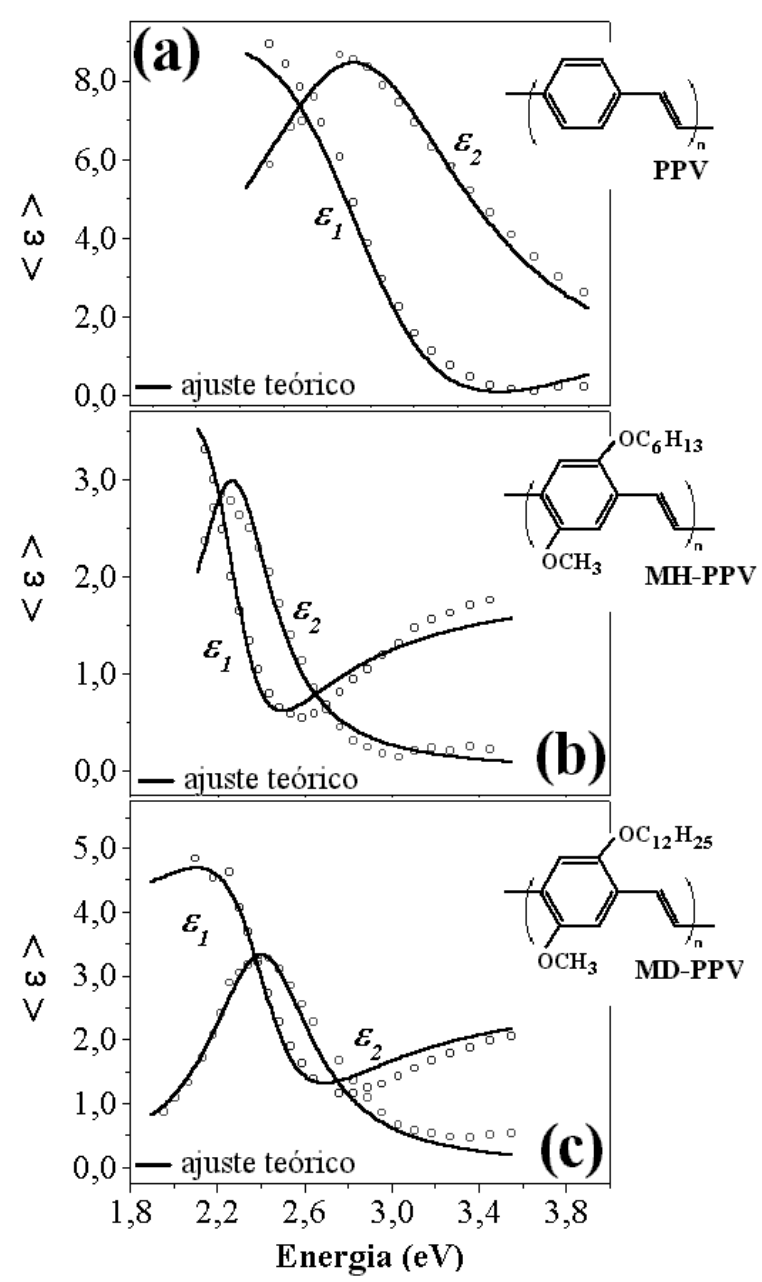

Figura 5.5: Componentes real $-\varepsilon_{l}(\circ)$ e imaginária $-\varepsilon_{2} \quad(\circ)$ da função pseudo-dielétrica complexa $\langle\varepsilon\rangle$ obtidas com os filmes de PPV, MH-PPV e MD-PPV, e a linha contínua (-) o ajuste obtido com a equação do oscilador de Lorentz, Eq. (5.1). 
$\mathrm{Na}$ Fig. 5.5 todas as curvas $\varepsilon_{l}$ têm valores relativamente altos para energias mais baixas, decaindo rapidamente com o aumento de E. Para o PPV, a curva tende a um valor estacionário para energias maiores que 3,2 eV, e para o MD-PPV e MH-PPV, a curva de $\varepsilon_{1}$ apresenta um mínimo em torno de 2,6 eV. Já as curvas de $\varepsilon_{2}$ apresentam um pico de máximo em 2,8 eV para o PPV, em 2,4 eV para o MD-PPV e em 2,3 eV para o MH-PPV.

Para explicar tais comportamentos, os componentes real e imaginário de $\langle\varepsilon\rangle$ foram estudadas através do modelo do oscilador de Lorentz ${ }^{[64,70-72]}$, cuja equação descreve o sistema molecular simplificadamente como uma nuvem eletrônica oscilando ao redor de um núcleo fixo. A expressão de $<\varepsilon>$ nesse modelo é dada por:

$$
<\varepsilon>=\varepsilon_{\infty}\left[1+\frac{A^{2}}{E_{0}^{2}-E(E+\mathrm{iv})}\right]
$$

Nesta expressão, $E$ é a energia do feixe incidente, $A$ é uma constante definida como a amplitude do oscilador, $E_{0}$ a energia na ressonância, $\varepsilon_{\infty}$ a permissividade do material fora da região de ressonância e $v$ é um parâmetro proporcional à constante de amortecimento que relaciona as interações da nuvem eletrônica com os átomos vizinhos (veja apêndice $B$ ). As curvas cheias (-) nos gráficos da Fig. 5.5 mostram os ajustes dos componentes $\varepsilon_{1}$ e $\varepsilon_{2}$ pela Eq. (5.1). A Tabela 5.II apresenta os parâmetros obtidos através desses ajustes, sendo que os valores de $E_{0}$ são definidos pelas curvas experimentais.

Tabela 5.II: Resultado obtidos com os ajustes dos componentes real, $\varepsilon_{l}$, e imaginária, $\varepsilon_{2}$, da função pseudodielétrica complexa pela Eq. (5.1) obtidos com os filmes de PPV, MH-PPV e MD-PPV.

\begin{tabular}{|c|c|c|c|c||}
\hline \hline Polímero & $\boldsymbol{E}_{\boldsymbol{0}}(\mathbf{e V})$ & $\boldsymbol{\varepsilon}_{\infty}$ & $\boldsymbol{v}(\mathbf{e V})$ & $\boldsymbol{A}(\mathbf{e V})$ \\
\hline PPV & 2,850 & 3,610 & 1,200 & 3,00 \\
\hline MD-PPV & 2,420 & 2,800 & 0,580 & 1,680 \\
\hline MH-PPV & 2,278 & 1,946 & 0,461 & 1,261 \\
\hline
\end{tabular}

Observa-se que a incorporação de grupos laterais alcóxi na cadeia do PPV reduz a constante de amortecimento - $v$, a energia $E_{0}$, e os parâmetros $A$ e $\varepsilon_{\infty}$ Além disso, $E_{0}$ é muito próximo da energia $E_{a b s}$, e $\varepsilon_{\infty}$ próximo ao valor da permissividade imaginária em altas energias. É conhecido da literatura ${ }^{[12]}$ que os derivados do PPV são mais volumosos 
que o PPV e, por esse motivo, menos propensos a interações entre cadeia, o que explicaria o comportamento do parâmetro $v$ observado. A título de ilustração, o apêndice $B$ apresenta uma evolução das curvas $\varepsilon_{1}$ e $\varepsilon_{2}$ com o parâmetro $A$ e $v$.

Esse estudo inicial elipsométrico dos filmes usados em dispositivos PLEDs é relevante no nosso trabalho, pois essa técnica também foi usada para o estudo de degradação por mecanismos de fotoxidação, como será visto no próximo capítulo.

\subsection{Condutividade AC em filmes de PANI}

As propriedades eletrônicas da polianilina têm se mostradas promissoras para seu uso em transistores orgânicos ${ }^{[12,44,46]}$. Nesse item realizamos um breve estudo dos mecanismos de condução desse polímero.

A técnica de medida de condutividade AC em sistemas sólidos desordenados tem sido bastante usada na análise de mecanismos de condução elétrica, iônica ou eletrônica, em diversos tipos de materiais: semicondutores, compósitos, cerâmicos e polímeros ${ }^{[73,74]}$. As medidas experimentais realizadas se encontram na faixa de freqüência - $f$ - que vai de aproximadamente $10^{-2}$ a $10^{7} \mathrm{~Hz}$, e inúmeros trabalhos têm mostrado que, além da condutividade intrínseca de cada material, parâmetros como a concentração de impurezas ou de dopantes determina não só os valores de condutividade, como também os processos de transporte envolvidos ${ }^{[73]}$.

Nesse item apresentamos e discutimos medidas de condutividade alternada obtidas com filmes de PANI em função do seu grau de dopagem, em solução aquosa de ácido clorídrico, e da temperatura. As medidas foram realizadas em amostras auto-sustentáveis, preparadas pelo método casting e com espessura em torno de $10 \mu \mathrm{m}$, seguindo os procedimentos apresentados no item 3.2.2. Filmes não-dopados e dopados por imersão em soluções aquosas de $\mathrm{HCl}$ 0,1 $\mathrm{M}$ e 0,2 $\mathrm{M}$ foram preparados e, posteriormente, secos entre folhas de papel absorvente em um dessecador a vácuo por 24 horas. Logo após, eletrodos de ouro com área de $0,3 \mathrm{~cm}^{2}$ foram metalizadas em ambas as faces desses filmes. A Tabela 5.III apresenta a nomenclatura adotada para a identificação das amostras. 
Tabela 5.III: Nomenclatura utilizada para a identificação das amostras de PANI.

\begin{tabular}{||c|c||}
\hline \hline Nomenclatura & Descrição das características da amostra \\
\hline PANI $_{\mathrm{ND}}$ & Amostra de PANI não dopada (isto é, sem imersão em $\mathrm{HCl}$ ). \\
\hline PANI $_{0,1 \mathrm{M}}$ & Amostra de PANI dopada por 15 minutos em solução aquosa $0,1 \mathrm{M} \mathrm{de} \mathrm{HCl}$. \\
\hline PANI $_{0,2 \mathrm{M}}$ & Amostra de PANI dopada por 5 minutos em solução aquosa $0,2 \mathrm{M} \mathrm{de} \mathrm{HCl}$. \\
\hline
\end{tabular}

Esse trabalho foi iniciado durante o programa de mestrado, e aqui ampliamos o estudo realizando medidas com amostras não-dopadas e com dopagem relativamente elevada.

A seguir são apresentadas as medidas dos componentes real, $\sigma^{\prime}(f)$, e imaginário, $\sigma$ "' $(f)$, da condutividade obtidas com as amostras $\mathrm{PANI}_{\mathrm{ND}}, \mathrm{PANI}_{0,1 \mathrm{M}}$ e $\mathrm{PANI}_{0,2 \mathrm{M}}$. As medidas foram realizadas como função da frequiência do campo elétrico $(f)$ e da temperatura, a vácuo, na ausência de luz e com tensão de oscilação $\left(V_{a c}\right)$ de $500 \mathrm{mV}$ e tensão de polarização $\left(V_{\text {bias }}\right)$ nula.

A Fig. 5.6 mostra os resultados dos componentes real (O), $\sigma^{\prime}(f)$, e imaginário $(\square)$, $\sigma$ " $(f)$, obtidos com a amostra PANI ${ }_{N D}$ nas temperaturas: (a) - 48, (b) - 23, (c) 0, (d) 27 e (e) $57{ }^{\circ} \mathrm{C}$. As limitações da ponte de impedância para medidas em amostras bastante resistivas impossibilitaram a realização de medidas abaixo de $-48{ }^{\circ} \mathrm{C}$, enquanto as limitações do criostato restringiram as medidas a $57{ }^{\circ} \mathrm{C}$. A título de comparação, a Fig. 5.6-(f) mostra o comportamento dos componentes reais obtidos nas diferentes temperaturas. Como pode ser analisado, os componentes real e imaginário, $\sigma$ ' $(f)$ e $\sigma^{\prime \prime}(f)$ apresentam o comportamento típico dos sistemas sólidos desordenados ${ }^{[73]}$ : enquanto $\sigma$ ' $(f)$ segue uma dependência linear em um gráfico $\ln \sigma^{\prime}$ 'vs. $\ln f, \sigma^{\prime}(f)$ apresenta um patamar em baixas freqüências (regime $\mathrm{dc}, \sigma_{\mathrm{dc}}$ ), passando a obedecer a uma lei de potências do tipo $\sigma^{\prime}(f) \propto f^{n}(0 \leq n \leq 1)$ a partir de uma frequiência crítica $\left(f_{c}\right)$. Quanto maior a temperatura da amostra, maiores os valores de $f_{c}$ e $\sigma_{\mathrm{dc}}$, como mostra a Fig. 5.6-(f). 

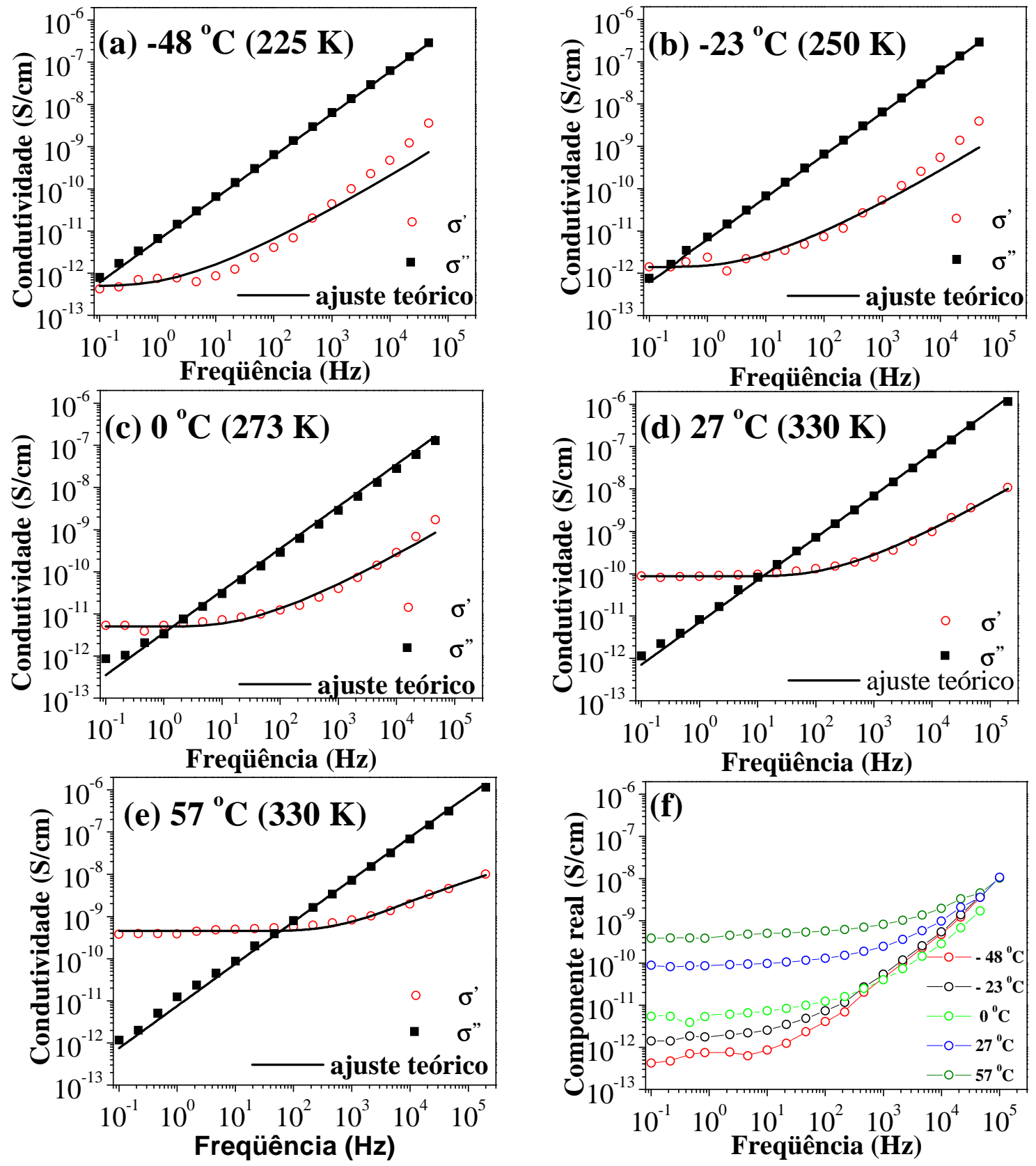

Figura 5.6: Componentes reais real $(\mathrm{O}), \sigma^{\prime}(f)$, e imaginária $(\square), \sigma^{\prime \prime}(f)$, obtidos com a amostra $\mathrm{PANI}_{\mathrm{ND}} \mathrm{nas}$ temperaturas: (a) - 48, (b) - 23, (c) 0 , (d) 27 e (e) $57{ }^{\circ} \mathrm{C}$. (f) apresenta o comportamento de $\sigma^{\prime}(f)$ para as diversas temperaturas estudadas. As linha contínuas (-) são os ajustes obtidos com a Eq. (5.12)

A Fig. 5.7 mostra os resultados dos componentes real (O), $\sigma^{\prime}(f)$, e imaginário $(\square)$, $\sigma "(f)$, obtidos com a amostra $\mathrm{PANI}_{0,1 \mathrm{M}}$ nas temperaturas: (a) -189 , (b) -148 (c) -73 e (d) $27{ }^{\circ} \mathrm{C}$. Essas medidas foram realizadas em um criostato de fluxo de nitrogênio durante parte do trabalho de mestrado do aluno R. F. Bianchi ${ }^{[54]}$. Esse criostato possui, como principal característica, a variação da temperatura de $-190{ }^{\circ} \mathrm{C}$ a $30^{\circ} \mathrm{C}$. Como resultado, as limitações técnicas da ponte de impedância e do criostato limitaram as medidas nos 
intervalo de -190 a $27{ }^{\circ} \mathrm{C}$. A Fig. 5.7-(e) ainda mostra, a titulo de comparação, o comportamento de $\sigma^{\prime}(f) v s . f$ como função da temperatura das amostras.
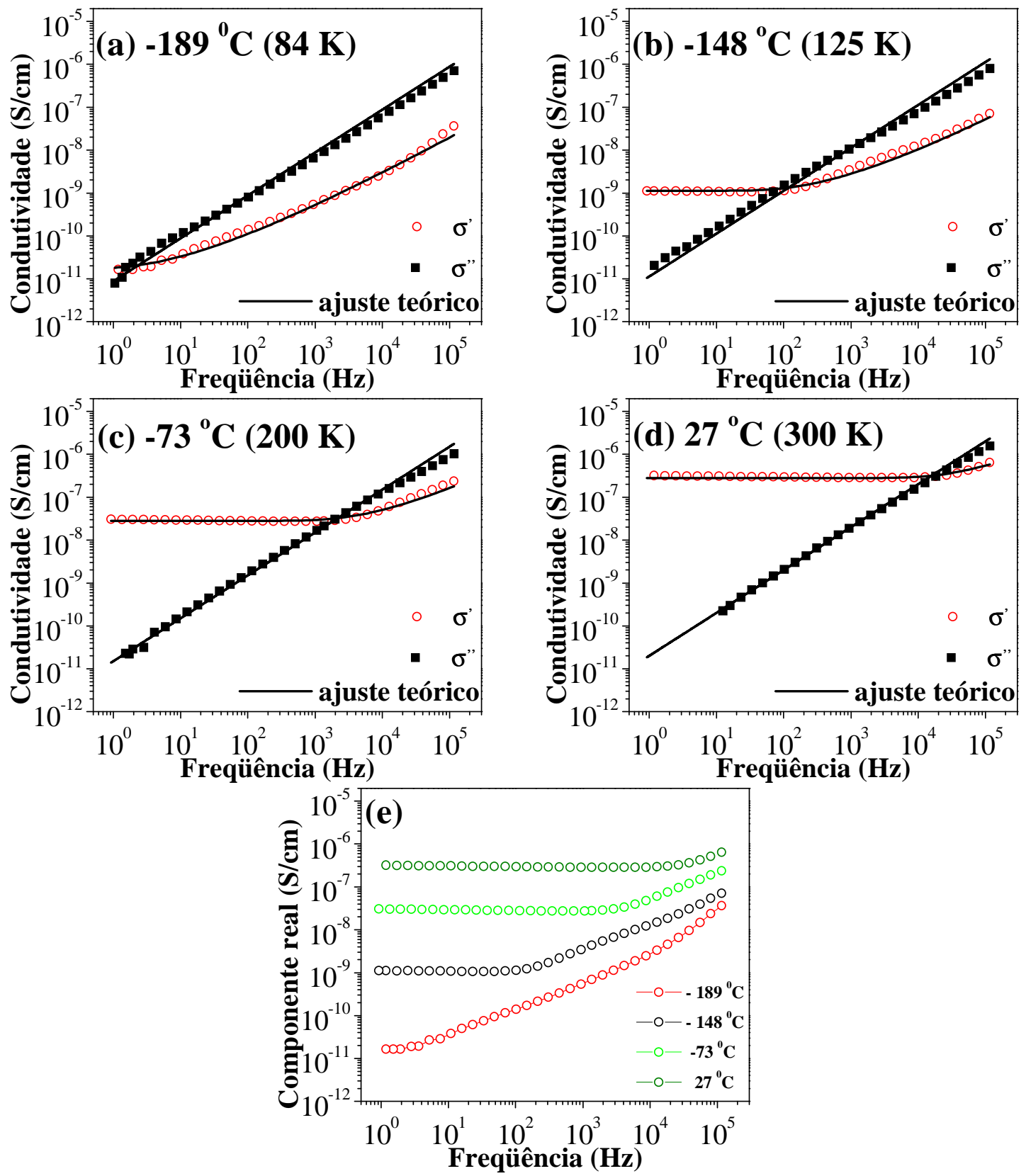

Figura 5.7: Componentes reais $(O), \sigma^{\prime}(f)$, e imaginárias $(\square), \sigma^{\prime \prime}(f)$, de $\sigma^{*}(f)$, obtidas com a amostra PANI $_{0,1 \mathrm{M}}$ nas temperaturas: (a) -189 , (b) -148 (c) -73 e (d) $27{ }^{\circ} \mathrm{C}$. (e) apresenta o comportamento de $\sigma^{\prime}(f)$ para as diversas temperaturas estudadas. As linhas contínuas (-) são os ajustes obtidos com a Eq. (5.12).

Na Fig. 5.7 as curvas $\sigma^{\prime}(f)$ e $\sigma^{\prime \prime}(f)$ também seguem o comportamento típico de sistemas sólidos desordenados, $\operatorname{com} f_{c}$ e $\sigma_{\mathrm{dc}}$ aumentando com a temperatura. Em especial, comparando-se os resultados obtidos a $27^{\circ} \mathrm{C}$, a amostra de $\mathrm{PANI}_{\mathrm{ND}}$, Fig. 5.6-(d), apresenta $\sigma_{\mathrm{dc}}=1 \times 10^{-10} \mathrm{~S} / \mathrm{cm}$ e $f_{c}=15 \mathrm{~Hz}$, enquanto a amostra PANI $\mathrm{P}_{0,1 \mathrm{M}}$, Fig. 5.7-(d), $\sigma_{\mathrm{dc}}=3 \times 10^{-7}$ $\mathrm{S} / \mathrm{cm}$ e $f_{c}=2 \times 10^{4} \mathrm{~Hz}$. Desses resultados podemos concluir que, quanto maior a 
condutividade da amostra, maior o valor de $f_{c}$. À medida que a amostra $\mathrm{PANI}_{0,1 \mathrm{M}}$ se torna mais condutivas, $\sigma$ ' passa a não depender da frequiência, atingindo o modelo metálico de Drude.

A Fig. 5.8 mostra os resultados da componente $\sigma^{\prime}(f),(O)$, e $\sigma^{\prime \prime}(f),(\square)$, obtidos com a amostra $\mathrm{PANI}_{0,2 \mathrm{M}}$ nas temperaturas: (a) -223 , (b) -200 , (c) -173 , (d) -148 e (e) $-123{ }^{\circ} \mathrm{C}$. As limitações técnicas do criostato impossibilitaram medidas abaixo de $-223{ }^{\circ} \mathrm{C}$, enquanto que, acima de $-123{ }^{\circ} \mathrm{C}$, a componente real passou a apresentar o comportamento metálico.
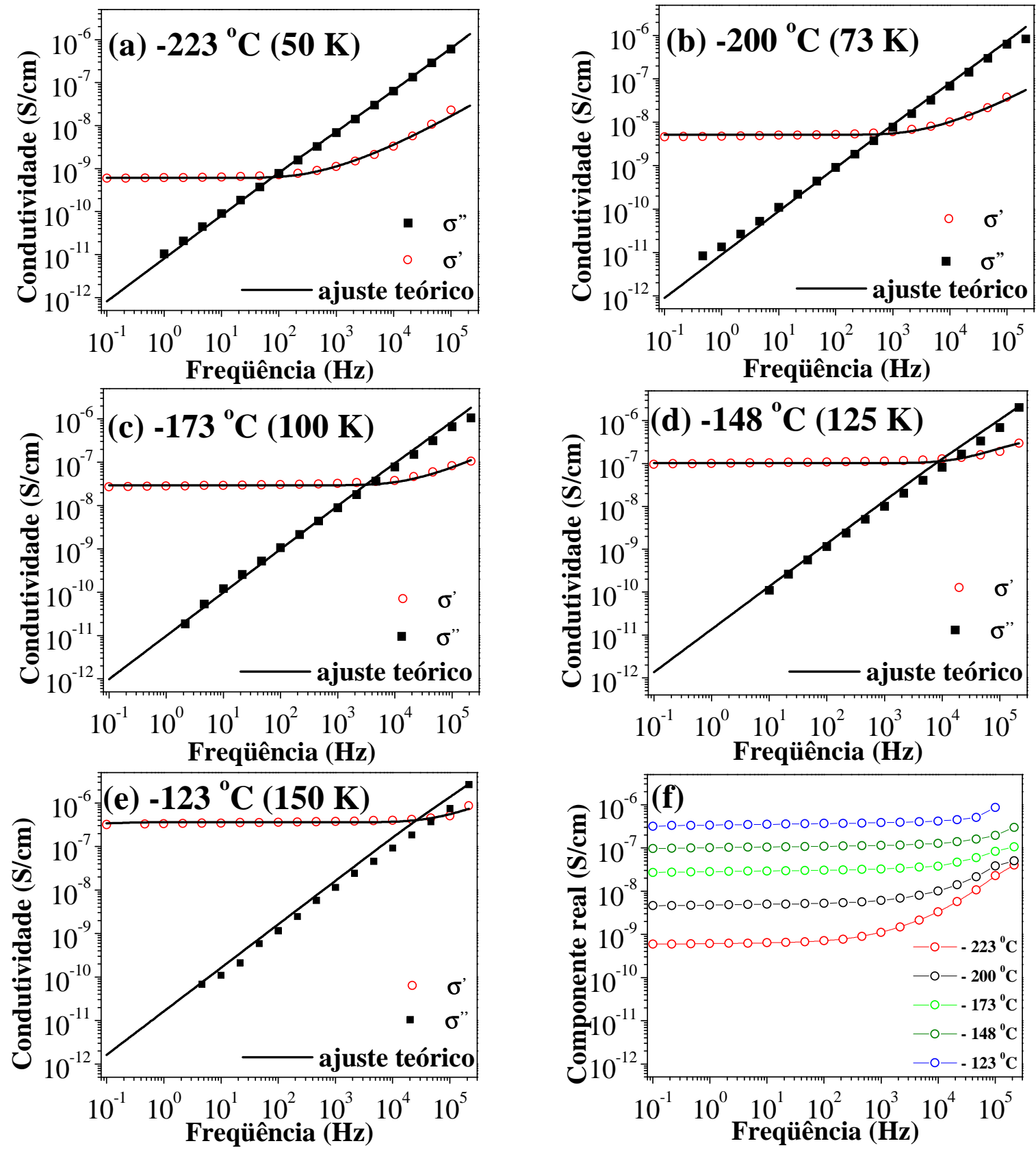

Figura 5.8: Componentes reais $(O), \sigma^{\prime}(f)$, e imaginárias $(\square), \sigma^{\prime \prime}(f)$, da condutividade complexa obtidas para a amostra PANI $\mathrm{PA}_{0,2 \mathrm{M}}$ nas temperaturas: (a) -223 , (b) -200 , (c) -173 , (d) -148 e (e) $-123{ }^{\circ} \mathrm{C}$. (f) apresenta o comportamento de $\sigma^{\prime}(f)$ para as diversas temperaturas estudadas. As linha contínuas (-) são os ajustes obtidos com a Eq. (5.12). 
As curvas apresentadas nos gráficos da Fig. 5.8 apresentam comportamentos similares aos observados nas Figs. 5.7 e 5.6: $f_{c}$ e $\sigma_{\mathrm{dc}}$ aumentam à medida que a temperatura aumenta.

É bem conhecido na literatura que a dopagem da polianilina não acontece de maneira homogênea no interior do material, mas se dá, preferencialmente, através de formação de aglomerados denominados "ilhas condutoras" ${ }^{[75]}$. A partir desse quadro foi proposto um modelo de sistema heterogêneo composto de ilhas condutoras (região dopada) embebidas em uma matriz isolante (região não dopada). Esse modelo foi inicialmente proposto por Lepienski et al. ${ }^{[76]}$ em 1997 para o estudo do comportamento de filmes de POMA como função da sua dopagem química em $\mathrm{HCl}$, e posteriormente utilizado por Bianchi et al. ${ }^{[74]}$ para descrever o comportamento da amostra $\mathrm{PANI}_{0,1 \mathrm{M}}$ como função da temperatura. O modelo desenvolvido leva em consideração que as ilhas condutoras apresentam comportamento tipicamente metálico, e a matriz isolante carrega todas as informações sobre a desordem do polímero, através de uma função distribuição de energia de salto dos portadores de carga entre sítios localizados, e separados por barreiras de energia continuamente distribuídas entre um valor mínimo $\left(E_{\min }\right)$ e máximo $\left(E_{\text {máx }}\right)$. A seguir descrevemos o modelo utilizado.

\subsection{Modelo para a condutividade complexa}

A estrutura morfológica da PANI e seus derivados é altamente desordenada. Por isso, o uso de uma estrutura de bandas para o volume do material é uma aproximação grosseira. Muito provavelmente o mecanismo de condução se dá via saltos (hopping) e os estados localizados devem se distribuir em energias de diferentes profundidades, existindo entre vizinhos quaisquer uma barreira de potencial a ser vencida. Deve, também, haver uma distribuição de altura dessas barreiras, limitadas entre um valor mínimo $E_{\min } \mathrm{e}$ máximo $E_{\max }$ de maneira que, há uma frequiência de escape característica, ou um tempo de espera antes de transpô-las. Essa freqüência, seguindo um processo de Arrhenius, pode ser definida por $\gamma=\gamma_{\mathrm{o}} \mathrm{e}^{-\mathrm{E} / \mathrm{kT}}$, com $E_{\min } \leq \mathrm{E} \leq E_{\max }$. Seguindo essas considerações, o transporte ao longo do volume do material pode ser explicado pelo modelo de barreiras de energia livres aleatórias (random free energy barrier model-RFEB) ${ }^{[73]}$. 


\subsubsection{Modelo de Barreiras de Energias Livres Aleatórias - RFEB}

Em um meio desordenado, onde existe uma distribuição de energia de estados localizados (sítios de residência para os portadores) ${ }^{[74]}$, a função tempo de residência $\Phi(t)$ é obtida pela média de todos os processos possíveis de decaimento $\mathrm{Q}_{\mathrm{i}}(\mathrm{t})$ :

$$
\Phi(\mathrm{t})=\left\langle\mathrm{Q}_{\mathrm{i}}(\mathrm{t})\right\rangle
$$

Cada processo de decaimento é considerado exponencial com o tempo, com $\Phi(\mathrm{t})$ escrito como:

$$
\Phi(\mathrm{t})=\left\langle\mathrm{e}^{-\gamma_{\mathrm{i}} \mathrm{t}}\right\rangle
$$

onde $\gamma_{\mathrm{i}}$ é ativado seguindo um processo de Arrhenius:

$$
\gamma_{i}=\gamma_{0} e^{-E_{i} / k T}
$$

As barreiras de energia livre $E_{i}$ são uniforme e continuamente distribuídas entre um mínimo, $E_{\min }$, e um máximo, $E_{\max }$, respectivamente, o mais baixo e o mais alto valores de energia, e $\gamma_{0}$ é um fator de freqüência o qual depende da distância média r entre os sítios de salto (hopping sites). Então, $\Phi(\mathrm{t})$ pode ser calculada por:

$$
\Phi(t)=\frac{1}{E_{\max }-E_{\min }} \int_{E_{\min }}^{E_{\max }} e^{-\left(\gamma o e^{-E / k T}\right) t} d E
$$

que, após uma mudança de variáveis, $\gamma_{\max }=\gamma_{o} e^{-E_{\min } / k T}$ e $\gamma_{\min }=\gamma_{o} e^{-E_{\max } / k T}$, fornece:

$$
\Phi(\mathrm{t})=\frac{1}{\ln \gamma_{\max } / \gamma_{\min }} \int_{\gamma_{\min }}^{\gamma_{\max }} \mathrm{e}^{-\gamma \mathrm{t}} \mathrm{d} \gamma / \gamma
$$


Aplicando a transformada de Laplace a $\Phi(\mathrm{t})$, obtemos:

$$
\phi^{*}(u)=(1 / u \ln \lambda) \ln \left[\left(1+u / \gamma_{\min }\right) /\left(1+u / \gamma_{\max }\right)\right]
$$

$\operatorname{com} \lambda=\gamma_{\max } / \gamma_{\min }$

Através da equação do transporte estocástico aplicado a uma rede ${ }^{[77]}$ :

$$
\sigma(\omega)=C[1 / \phi *(i \omega)-i \omega]
$$

com $\phi^{*}(i \omega)$ a transformada de Laplace de $\Phi(t)$, obtemos, a partir das equações (5.7) e (5.8), a equação para a condutividade de um meio sólido desordenado.

$$
\sigma(\omega)=C\left[\frac{i \omega \ln \lambda}{\ln \left(\frac{1+i \omega / \gamma_{\min }}{1+i \omega / \gamma_{\max }}\right)}-i \omega\right]
$$

sendo C um parâmetro que depende da densidade de portadores do material.

Tomando-se $\sigma_{0}=C \gamma_{\min } \ln \left(\gamma_{\max } / \gamma_{\min }\right)$, obtemos a Eq. (5.9) em termos de $\sigma_{0}$ :

$$
\sigma_{D}^{*}(\omega)=\frac{\frac{\omega}{\gamma_{\min }} \sigma_{0} i}{\ln \left(\frac{1+\frac{\omega i}{\gamma_{\min }}}{1+\frac{\omega i}{\gamma_{\max }}}\right)}-\frac{\omega \sigma_{0} i}{\gamma_{\min } \ln \left(\frac{\gamma_{\max }}{\gamma_{\min }}\right)}
$$

Da Eq. (5.10), os parâmetros $\sigma_{0}, \gamma_{\min }$ e $\gamma_{\max }$ são obtidos diretamente das curvas experimentais $\sigma^{\prime}(\omega)$ e $\sigma^{\prime \prime}(\omega) v s$. $\omega$. A Fig. 5.9 apresenta ilustrações de curvas $\sigma^{\prime}(\omega) v s$. $\omega$ típicas de sistemas sólidos desordenados. 

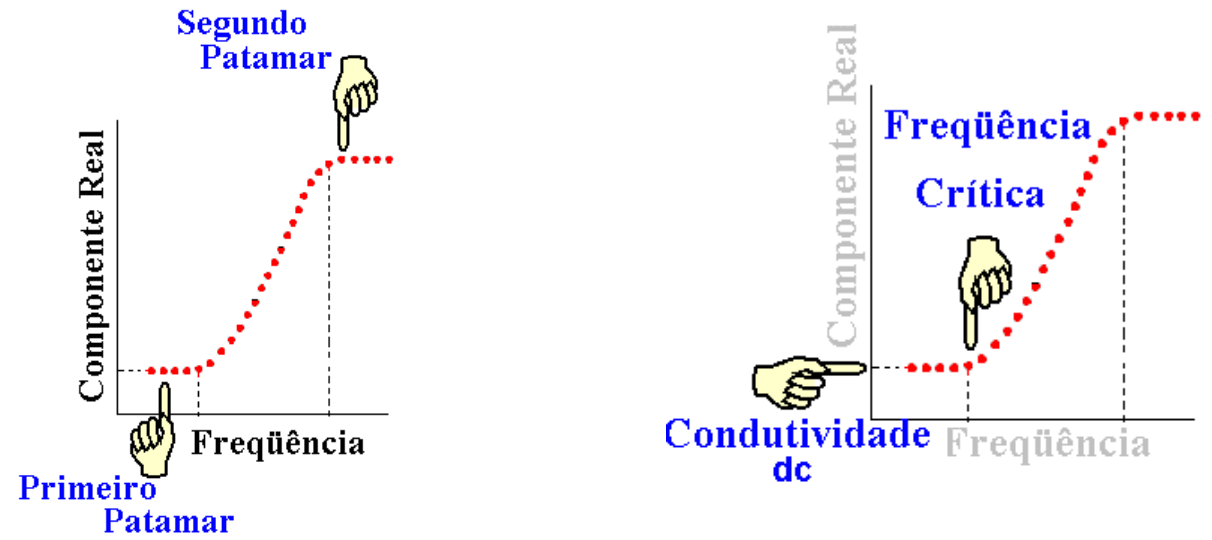

Figura 5.9: Comportamento típico do componente real da condutividade complexa obtida com sistemas sólidos desordenados.

Nessa figura os dois patamares do componente real definem os parâmetros $\gamma_{\min }$ (ou frequiência crítica) e $\gamma_{\max }$, onde o primeiro ainda define o valor de $\sigma_{0}$, que é o valor da condutividade em regime dc.

De um modo geral, o valor de $\gamma_{\max }$ é muito maior do que o máximo valor de frequiência alcançado pelos equipamentos de medida. Desse modo, a Eq. (5.10) pode ser reescrita como:

$$
\sigma^{*}{ }_{D}(\omega)=\frac{\frac{\omega i}{\gamma_{\min }} \sigma_{0}}{\ln \left(1+\frac{\omega i}{\gamma_{\min }}\right)}
$$

que representa a expressão para a condutividade complexa quando $\gamma_{\max } \gg \gamma_{\min }$.

A Eq. 5.10 foi pela primeira vez deduzida por Dyre em $1985^{\text {[73] }}$ através do tratamento estatístico da Teoria do Campo Médio e da Teoria do Passeio ao Acaso Contínuo no tempo. Porém, a dedução da expressão por esse caminho é muito trabalhosa e difícil.

\subsubsection{Modelo para a Condutividade complexa da PANI}

A elaboração do modelo de condução proposto por Lepienski et al. ${ }^{[74,76]}$ atribuía valores médios efetivos às permissividades complexas das ilhas metálicas (meio 1) e da 
matriz isolante (meio 2). O cálculo da condutividade média efetiva é então realizado utilizando-se a equação de Clausius-Mossotti, relacionando-se uma condutividade média efetiva a esses dois meios, obtendo a seguinte expressão para a condutividade complexa de polianilina e seus derivados ${ }^{[74]}$ :

$$
\sigma^{*}(\omega)=i \omega\left[\varepsilon^{*}-\frac{i \sigma_{D}^{*}(\omega)}{\omega}\right] \frac{2(1-\eta)\left[\varepsilon *-\frac{i \sigma_{D}^{*}(\omega)}{\omega}\right]-(1+2 \eta) \frac{i \sigma_{m}}{\omega}}{(2+\eta)\left[\varepsilon *-\frac{i \sigma_{D}^{*}(\omega)}{\omega}\right]-(1-\eta) \frac{i \sigma_{m}}{\omega}}
$$

onde $\eta$ a fração de volume de ilhas metálicas $(0 \leq \eta \leq 1), \sigma_{m}$ a condutividade das ilhas, $\varepsilon^{*}$ a permissividade da matriz isolante, e $\sigma_{D}^{*}$ a condutividade da matriz, dada pela Eq. (5.11).

\subsubsection{Ajustes dos Resultados Experimentais}

Utilizando a Eq. (5.12), os componentes real e imaginária da condutividade obtidos com as amostras $\mathrm{PANI}_{\mathrm{ND}}, \mathrm{PANI}_{0,1 \mathrm{M}} \mathrm{e} \mathrm{PANI}_{0,2 \mathrm{M}}$ foram ajustados como mostra as linhas cheias nas Figs. 5.6, 5.7 e 5.8. As Tabelas 5.IV, 5.V e 5.VI apresentam os valores dos parâmetros obtidos pelos ajustes, com $\gamma_{\min }^{\prime}=\gamma_{\min } / 2 \pi$.

Tabela 5.IV: Parâmetros obtidos dos ajustes pela Eq. (5.12) dos componentes $\sigma^{\prime}(f)$ e $\sigma^{\prime \prime}(f)$ da amostra $\mathrm{PANI}_{\mathrm{ND}}$ em diferentes temperaturas, e com $\eta=0$ em todos os ajustes.

\begin{tabular}{||c|c|c|c|c||}
\hline \hline TEMP $\left({ }^{\mathbf{O}} \mathbf{C}\right)$ & $\sigma_{\mathbf{D C}}(\mathbf{S} / \mathbf{c m})$ & $\sigma_{\mathbf{O}}(\mathbf{S} / \mathbf{c m})$ & $\boldsymbol{\gamma}_{\min }(\mathbf{H z})$ & $\mathbf{K}$ \\
\hline-48 & $5,0 \times 10^{-13}$ & $5,0 \times 10^{-13}$ & 0,4 & 68 \\
\hline-23 & $1,4 \times 10^{-12}$ & $1,4 \times 10^{-12}$ & 0,9 & 70 \\
\hline 0 & $5,0 \times 10^{-12}$ & $5,0 \times 10^{-12}$ & 6,0 & 75 \\
\hline 27 & $8,7 \times 10^{-11}$ & $8,7 \times 10^{-11}$ & $3,5 \times 10^{1}$ & 80 \\
\hline 57 & $4,5 \times 10^{-10}$ & $4,5 \times 10^{-10}$ & $1,6 \times 10^{2}$ & 85 \\
\hline
\end{tabular}

Tabela 5.V: Parâmetros obtidos dos ajustes pela Eq. (5.12) dos componentes $\sigma^{\prime}(f)$ e $\sigma^{\prime \prime}(f)$ da amostra $\mathrm{PANI}_{0,1 \mathrm{M}}$, em diferentes temperaturas, e com $\eta=0,50$ em todos os ajustes ${ }^{[74]}$.

\begin{tabular}{||c|c|c|c|c||}
\hline \hline TEMP $\left({ }^{\mathbf{O}} \mathbf{C}\right)$ & $\sigma_{\mathbf{D C}}(\mathbf{S} / \mathbf{c m})$ & $\sigma_{\mathbf{O}}(\mathbf{S} / \mathbf{c m})$ & $\boldsymbol{\gamma}_{\min }(\mathbf{H z})$ & $\mathbf{K}$ \\
\hline-189 & $1,6 \times 10^{-11}$ & $5,9 \times 10^{-12}$ & 1,0 & 35 \\
\hline-148 & $1,1 \times 10^{-9}$ & $4,0 \times 10^{-10}$ & $5,8 \times 10^{1}$ & 45 \\
\hline-73 & $2,8 \times 10^{-8}$ & $9,9 \times 10^{-9}$ & $1,2 \times 10^{3}$ & 60 \\
\hline 27 & $3,0 \times 10^{-7}$ & $9,9 \times 10^{-8}$ & $1,0 \times 10^{4}$ & 80 \\
\hline
\end{tabular}


Tabela 5.VI: Parâmetros obtidos dos ajustes pela Eq. (5.12) dos componentes $\sigma^{\prime}(f)$ e $\sigma^{\prime \prime}(f)$ da amostra $\mathrm{PANI}_{0,2 \mathrm{M}}$ em diferentes temperaturas, e com $\eta=0,55 \mathrm{em}$ todos os ajustes.

\begin{tabular}{||c|c|c|c|c||}
\hline \hline TEMP $\left({ }^{\mathbf{o}} \mathbf{C}\right)$ & $\sigma_{\mathbf{d c}}(\mathbf{S} / \mathbf{c m})$ & $\sigma_{\mathbf{o}}(\mathbf{S} / \mathbf{c m})$ & $\boldsymbol{\gamma}_{\min }(\mathbf{H z})$ & $\mathbf{K}$ \\
\hline-223 & $6,0 \times 10^{-10}$ & $1,3 \times 10^{-11}$ & $1,5 \times 10^{2}$ & 14 \\
\hline-200 & $4,6 \times 10^{-8}$ & $1,1 \times 10^{-11}$ & $1,0 \times 10^{3}$ & 16 \\
\hline-173 & $2,7 \times 10^{-8}$ & $6,3 \times 10^{-9}$ & $5,5 \times 10^{3}$ & 18 \\
\hline-148 & $9,7 \times 10^{-8}$ & $2,2 \times 10^{-8}$ & $7,5 \times 10^{3}$ & 19 \\
\hline-123 & $3,2 \times 10^{-7}$ & $7,8 \times 10^{-8}$ & $2,0 \times 10^{4}$ & 20 \\
\hline
\end{tabular}

Os resultados apresentados nas Tabela 5.IV, 5.V e 5.VI mostram que todos os parâmetros aumentam com a temperatura. Além disso, $\eta$ aumenta de 0 a 0,55 à medida que a concentração do ácido aumenta. Para a amostra PANI ${ }_{N D}$, Tabela 5.IV, $\sigma_{o}$ é igual a $\sigma_{d c}$ para todas as temperaturas, em concordância com o modelo. Para as outras duas amostras, $\sigma_{\mathrm{dc}}$ é maior que $\sigma_{\mathrm{o}}$, sendo sua diferença maior para a amostra $\mathrm{PANI}_{0,2 \mathrm{M}}$. Além disso, os valores de $\gamma_{\text {min }}^{\prime}$ obtidos estão em torno da freqüência crítica das curvas experimentais, e esse parâmetro aumenta à medida que a amostra se torna mais condutora, seja por dopagem química, seja com o aumento da temperatura. Por último, a constante dielétrica diminuiu à medida que a temperatura diminui, que concorda com a evolução da condutividade dc do material.

Baseados na Eq. (5.4), podemos graficar $\ln \left(\gamma_{\min }^{\prime}\right)$ vs. $1 / T$ e verificar se o comportamento de $\gamma_{\min }$ segue um processo de Arrhenius. A Fig. 5.10 mostra as curvas obtidas.

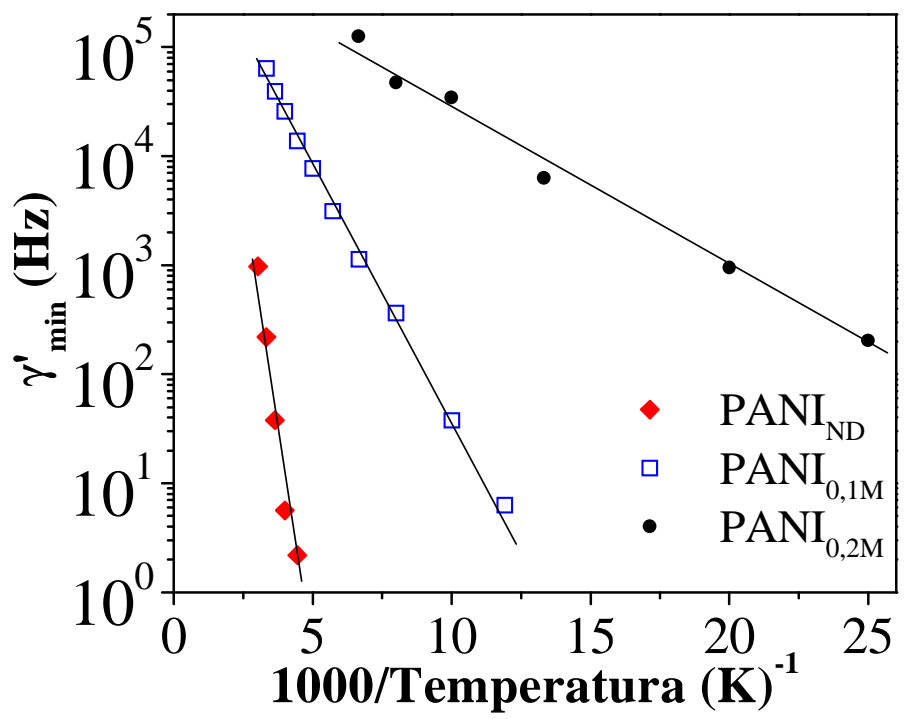

Figura 5.10: $\ln \gamma_{\min }^{\prime} v s . T^{l}$ ajustados pela Eq. (5.4) utilizando-se os resultados obtidos com as amostras $\mathrm{PANI}_{\mathrm{ND}}, \mathrm{PANI}_{0,1 \mathrm{M}} \mathrm{E} \mathrm{PANI}_{0,2 \mathrm{M}}$. A curva mostrada para a amostra $\mathrm{PANI}_{0,1 \mathrm{M}}$ apresenta todos os parâmetros obtidos na ref [74]. 
Observamos que as três curvas apresentadas no gráfico da Fig. 5.10 seguem um processo de Arrhenius. Logo, a partir da Eq. (5.4), obtemos os valores das energias máximas de salto dos portadores para cada amostra, ou seja, como função da condutividade do material. Esse resultado é mostrado na Tabela 5.VII.

Tabela 5.VII: Resultados obtidos com os ajustes mostrados na Fig. 5.10.

\begin{tabular}{||c|c||}
\hline AMOSTRAS & $\mathbf{E}_{\mathbf{M A ́ x}}(\mathbf{e V})$ \\
\hline PANI $_{\mathrm{ND}}$ & 0,38 \\
\hline PANI $_{0,1 \mathrm{M}}$ & 0,09 \\
\hline PANI $_{0,2 \mathrm{M}}$ & 0,03 \\
\hline
\end{tabular}

Conforme podemos notar, $E_{\text {máx }}$ diminui com o aumento da condutividade, passando de $0,38 \mathrm{eV}$ (amostra não dopada) para $0,03 \mathrm{eV}$ para a amostra dopada em solução de ácido clorídrico 0,2 M, de acordo com os valores de condutividade dessas amostras.

\subsection{Discussão dos resultados}

Nesse capítulo apresentamos os resultados experimentais de medidas ópticas obtidos com filmes de PPV, MH-PPV e MD-PPV, e medidas de condutividade complexa de PANI.

$\mathrm{Na}$ primeira parte desse capítulo apresentamos medidas de absorção UV-VIS e emissão PL obtidos com filmes de PPV, MH-PPV e MD-PPV. Os resultados mostraram que as características dos filmes de PPV preparados são similares às propriedades descritas na literatura ${ }^{[67]}$, o que indica que a solução de PTHT/MeOH/Lenta pode ser usada sem alterar as propriedades ópticas desse polímero. Além disso, resultados obtidos com o MHPPV e o MD-PPV mostram que o tratamento químico em $50{ }^{\circ} \mathrm{C}$ pode ser usado sem modificar as propriedades do material.

Na segunda parte, medidas da função pseudo-dielétrica de filmes de PPV, MD-PPV e MH-PPV foram estudados através do modelo do oscilador de Lorentz. Os resultados dos ajustes mostraram que a incorporação de grupos laterais alcóxi na cadeia do PPV reduz o parâmetro relacionado com a constante de amortecimento $-v$ dos filmes preparados. Da literatura é conhecido que a incorporação desses grupos diminui a rigidez da cadeia 
polimérica (item 3.1) ${ }^{[12]}$. Tal efeito aumenta o espaçamento dessas cadeias, o que deve diminuir as interações das nuvens eletrônicas de uma molécula com os seus átomos vizinhos. Como resultado, é de se esperar que o parâmetro $v$ deve diminuir com a incorporação desses grupos. Por outro lado, o parâmetro $A$ parece depender da intensidade máxima da curva de $\varepsilon_{2}$, sendo maior para o PPV. Inúmeros resultados obtidos com sistemas inorgânicos, principalmente compostos à base de silício, indicam que a intensidade e a largura da curva de $\varepsilon_{2}$ estão relacionadas a uma média efetiva entre porções do material e regiões de espaços vazios (voids) ${ }^{[78]}$. Como resultado, $A$ poderia indicar que o PPV deve possuir um coeficiente de absorção maior do que os outros dois polímeros estudados, ou um volume livre menor. Por último, o parâmetro $E_{0}$ obtido é muito próximo da energia $E_{a b s}$.

$\mathrm{Na}$ terceira parte, foram apresentadas e analisadas medidas de condutividade alternada obtidas com filmes de polianilina sob diferentes condições de dopagem e temperatura. Os resultados mostraram que o comportamento dos componentes real e imaginário é típico de sistemas sólidos desordenados, apresentando a universalidade descrita por J. C. Dyre ${ }^{[73]}$, R.F. Bianchi ${ }^{[54]}$ e co-autores. Independente do grau de dopagem das amostras, a freqüência crítica e a condutividade dc dos filmes aumentam com a temperatura. As curvas foram ajustadas por um modelo que descreve a polianilina como um meio heterogêneo composto de ilhas condutoras embebidas em uma matriz isolante ${ }^{[74]}$. Os resultados dos ajustes teórico-experimentais mostraram que, à medida que a concentração de $\mathrm{HCl}$, usada para a dopagem das amostras, aumenta, a fração de ilhas condutoras $(\eta)$ também aumenta, o que era de se esperar, já que $\eta$ é a fração do volume de ilhas condutoras pelo volume total do polímero. Para a amostra $\mathrm{PANI}_{\mathrm{ND}}$, esse parâmetro é igual à condutividade $\mathrm{dc}\left(\sigma_{\mathrm{dc}}\right)$ em todo intervalo de temperatura medido mas, para as amostras mais condutoras, $\sigma_{\mathrm{dc}}$ se distancia de $\sigma_{0}\left(\sigma_{\mathrm{dc}}>\sigma_{0}\right)$. Nesse caso, o aumento da condutividade do polímero aumenta a razão de ilhas condutoras, o que está intrinsecamente ligado ao aumento de $\eta$. A constante dielétrica $K$, por sua vez, diminui com a temperatura para todas as amostras. Por último, a energia máxima de salto diminui com o aumento da dopagem do polímero, passando de 0,38 eV (amostra não dopada) para 0,03 eV (amostra $\mathrm{PANI}_{0,2 \mathrm{M}}$ ), resultado esse que acompanhando o aumento da condutividade do material, portanto, estando de acordo com o modelo proposto. 


\section{Capítulo 6}

\section{Fotodegradação do MH-PPV}

O atual estágio de desenvolvimento da área dos polímeros luminescentes tem contribuído, cada vez mais, para o estudo e para a investigação do potencial tecnológico desses materiais como elementos ativos de dispositivos sinalizadores. Inúmeras indústrias e grupos de pesquisa têm demonstrado grande interesse na compreensão e na elucidação das propriedades ópticas e elétricas desses materiais, com o objetivo principal de melhorar o desempenho e a vida útil dos dispositivos ${ }^{[17-19]}$. Entretanto, a degradação desses polímeros quando em presença de luz e/ou ao contato do ar e da umidade tem sido um dos principais efeitos que limitam a eficiência comercial dos seus dispositivos ${ }^{[21,26]}$. Vários autores têm se preocupado em entender como esses agentes atuam na degradação dos polímeros, mas pouco ainda se conhece a ponto de evitá-los ${ }^{[22,26]}$. Um dos primeiros trabalhos a estudar efeito da degradação foi realizado por J. S. Arwin et al. ${ }^{[70]}$ em 1994, que mostrou que a luz alterava, irreversivelmente, as propriedades ópticas do poli(3hexiltiofeno). Outros trabalhos mostraram que alguns polímeros luminescentes em contato com o ar, mais especificamente com o oxigênio, tinham suas propriedades ópticas e elétricas alteradas sob iluminação, reduzindo drasticamente o tempo de vida de seus dispositivos eletrônicos ${ }^{[22,33,79,80]}$. Para explicar tal efeito, conhecido como fenômeno de fotoxidação ou fotodegradação, vários autores verificaram que o oxigênio atua na quebra da cadeia polimérica, ou na interrupção de sua conjugação, através, principalmente, da

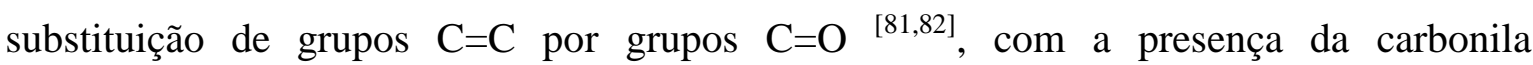
funcionando como centro de aniquilação dos éxcitons singletos ${ }^{[79,82]}$, reduzindo a eficiência de recombinação dos dispositivos. Uma das primeiras tentativas para eliminar esse efeito foi o encapsulamento dos dispositivos em atmosfera inerte, que reduziu o efeito, mas não se mostrou muito eficaz ${ }^{[22,26]}$. Atualmente, sabe-se que a combinação de oxigênio e luz é um dos principais fatores responsáveis pela fotoxidação desses materiais ${ }^{[26,82]}$. Porém, avaliar qual a porção degradada do polímero com o tempo de exposição à luz em atmosferas de oxigênio e/ou umidade ainda é uma questão em aberto e que merece especial $\operatorname{atenção~}^{[21,79]}$. 
Nesse capítulo apresentamos um estudo de fotodegradação do poli[(2-metóxi,5hexiloxi)-p-fenilenovinileno] (MH-PPV) usando as técnicas experimentais de elipsometria e de absorção óptica. Apresentamos medidas de índice de refração, de função pseudodielétrica e de espectros de absorção no UV-VIS e FTIR obtidos com filmes de MH-PPV expostos em diferentes condições ambientes. Para explicar o comportamento dos componentes real e imaginária da função pseudo-dielétrica, o modelo do oscilador de Lorentz, descrito no Cap. 5, foi usado com sucesso nesse capítulo para descrever o comportamento da função pseudo-dielétrica como função do tempo de iluminação $\left(t_{i l}\right)$ por luz branca. Baseados na substituição dos grupos $\mathrm{C}=\mathrm{C}$ por $\mathrm{C}=\mathrm{O}$, no modelo de LorenzLorentz e na evolução do índice de refração durante o efeito de fotoxidação, foi possível desenvolver um modelo teórico e avaliar a porção degradada do polímero como função de $t_{i l}$. Esses resultados visam contribuir para o entendimento do efeito da fotodegradação nos polímeros luminescentes quando expostos ao mesmo tempo à luz e ao ar, o que, do ponto de vista tecnológico, é um dos efeitos cruciais que limitam a estabilidade, a eficiência e a durabilidade dos PLEDs.

\subsection{Resultados experimentais}

A Figura 6.1 mostra o aparato experimental utilizado para a iluminação dos filmes poliméricos. Nesse sistema, uma lâmpada halogênea de $150 \mathrm{~W}$ foi colocada a uma distância de $15 \mathrm{~cm}$ da amostra, com valor local de potência de $250 \mathrm{~mW} / \mathrm{cm}^{2}$. A superfície do filme foi, então, iluminada, e as medidas de absorção óptica foram realizadas. Para continuar o processo de degradação com a luz, o filme foi novamente iluminado nas mesmas condições. O mesmo procedimento foi utilizado com a solução do polímero. Para padronizar as condições de iluminação, todos os filmes foram colocados dentro de uma cubeta de quartzo, de modo que se pudesse controlar a atmosfera de $\mathrm{N}_{2}$ em contato com o filme, e todos os filmes fossem iluminados com a mesma intensidade luminosa.

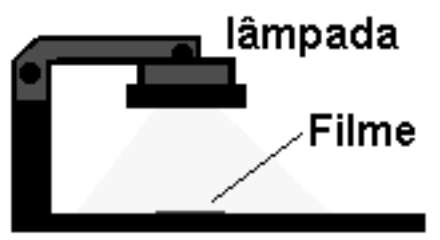

Figura 6.1: Esquema utilizado para a iluminação de filmes e soluções de MH-PPV. 
As Figs. 6.2-(a), 6.2-(b) e 6.2-(c) apresentam os resultados de absorção UV-VIS obtidos com filmes de MH-PPV preparados pelo método casting. Os filmes foram preparados utilizando-se uma solução $1 \mathrm{mg} / \mathrm{ml}$ do polímero em clorofórmio, sobre substratos de quartzo, nas seguintes condições: (a) antes e depois de armazenado no escuro e no ar por 6 meses, (b) iluminado em atmosfera de nitrogênio por até 142 horas e (c) em atmosfera de ar e iluminado por até 23 horas. A Fig. 6.2-(d) mostra, a título de comparação, os espectros obtidos com a solução do polímero em clorofórmio $\left(\mathrm{CHCl}_{3}\right)$ iluminada por até 370 horas em uma cubeta de vidro.
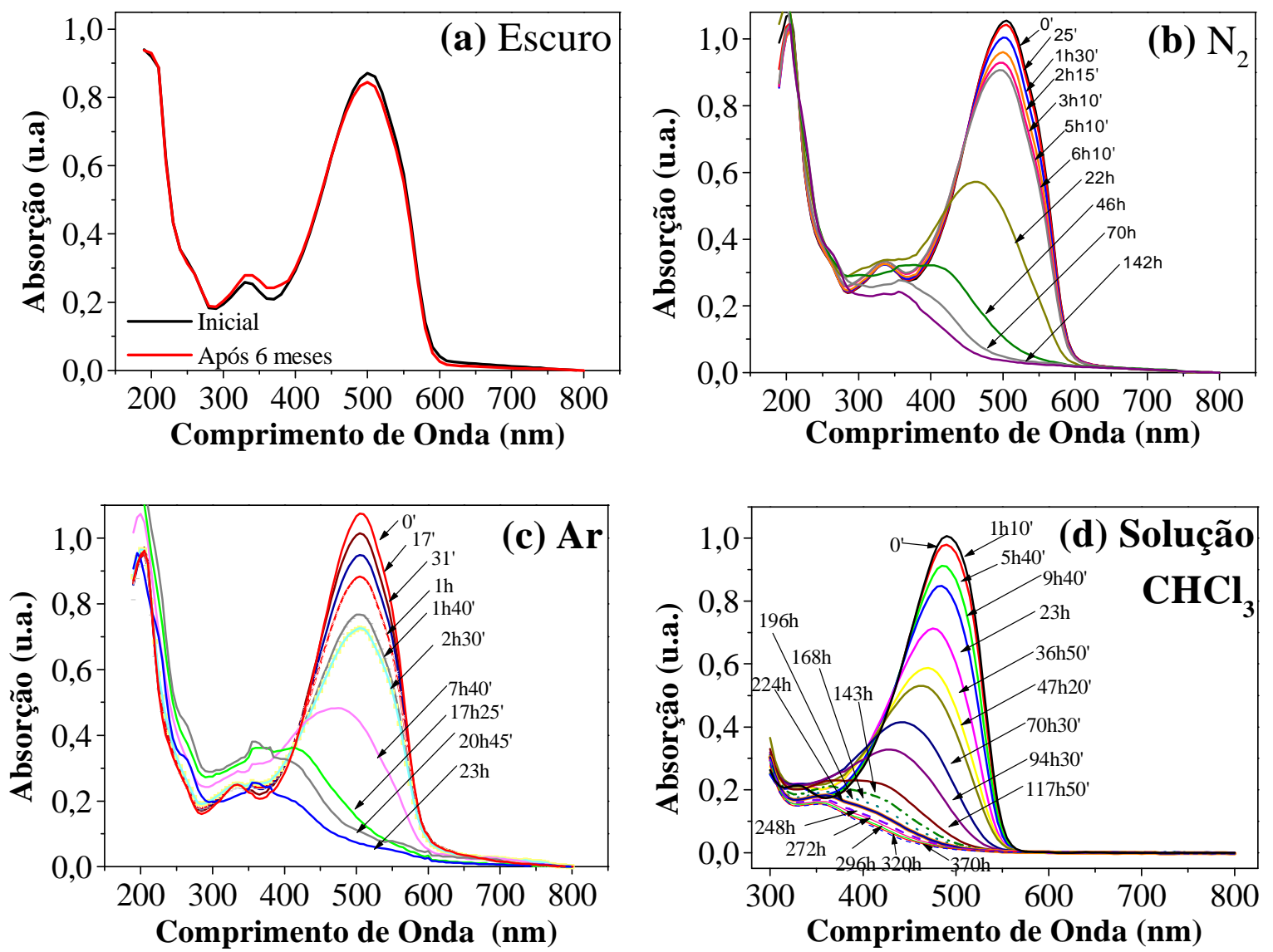

Figura 6.2: Espectros de absorção UV-VIS obtidos com filmes de MH-PPV exposto: (a) no ar e no escuro, (b) iluminado em atmosfera de nitrogênio (c) iluminado em atmosfera de ar e (d) mostra os espectros de absorção UV-VIS obtidos com uma solução de MH-PPV em clorofórmio iluminada por 370 horas.

A Fig. 6.2-(a) mostra, inequivocamente, que se a amostra fica ao abrigo da luz não há qualquer alteração em sua curva de absorção UV-VIS, mesmo tendo ficado em contato 
direto com o ar por longo tempo. Já a Fig. 6.2-(b) mostra que sob claridade, mesmo encerrada numa atmosfera de nitrogênio, o máximo da banda de absorção, situado na região entre 500-515 nm, tende a desaparecer com o tempo. Essa absorção é devida às transições eletrônicas que ocorrem nos níveis que existem os segmentos conjugados da molécula, cuja relaxação provoca a emissão de luz. Após uma semana de contínua irradiação luminosa o seu pico é praticamente eliminado. Esse efeito de eliminação do pico é muito mais rápido se a amostra é deixada em contato com o ar durante a irradiação, Fig. 6.2-(c). Mesmo em solução, o fenômeno de degradação do polímero ocorre, Fig. 6.2-(d). Os espectros apresentados nos gráficos dessas figuras mostram que os filmes apresentam máximos de intensidade de absorção em torno de $505 \mathrm{~nm}$, enquanto que para a solução, um deslocamento de cerca de $15 \mathrm{~nm}$ para o azul é observado. Esse fenômeno está ligado as diferentes configurações adotadas pelas cadeias dos polímeros quando em solução ou em filme ${ }^{[69]}$. Observamos nos gráficos dessa figura que à medida que o tempo de iluminação $\left(t_{i l}\right)$ aumenta, os máximos de absorção se deslocam para o azul, com exceção dos espectros obtidos com o filme que foi armazenado no escuro. Visualmente, é possível notar que os filmes e a solução apresentam-se inicialmente vermelhos, mas passam para o laranja, depois para o amarelo e, finalmente, tornam-se incolores com o aumento de $t_{i l}$. Dos resultados obtidos podemos concluir que a degradação óptica do MH-PPV é devida à combinação da presença da luz e do oxigênio, gerando o efeito de fotoxidação. Essa conclusão é corroborada pelo fato de que a diminuição do pico de absorção é mais rápida quando o polímero é iluminado em atmosfera de ar (alta concentração de oxigênio), e muito mais lenta quando o filme é exposto em atmosfera de $\mathrm{N}_{2}$. Nossos resultados estão de acordo com outros encontrados na literatura, que mostram que esses dois agentes, oxigênio e luz, são dois dos principais responsáveis pela fotodegradação ${ }^{[21,22,26,79]}$ dos polímeros luminescentes.

Para avaliar o papel da luz e do oxigênio na estrutura química do polímero, a Fig. 6.3 mostra os espectros de absorção óptica no infravermelho obtidos com os filmes expostos à luz, e em atmosfera ambiente, por diferentes intervalos de tempo. Os filmes foram preparados por casting sobre substratos de silício polidos, em ambas as faces, e limpos seguindo o procedimento RCA apresentado no item 3.2.1. 


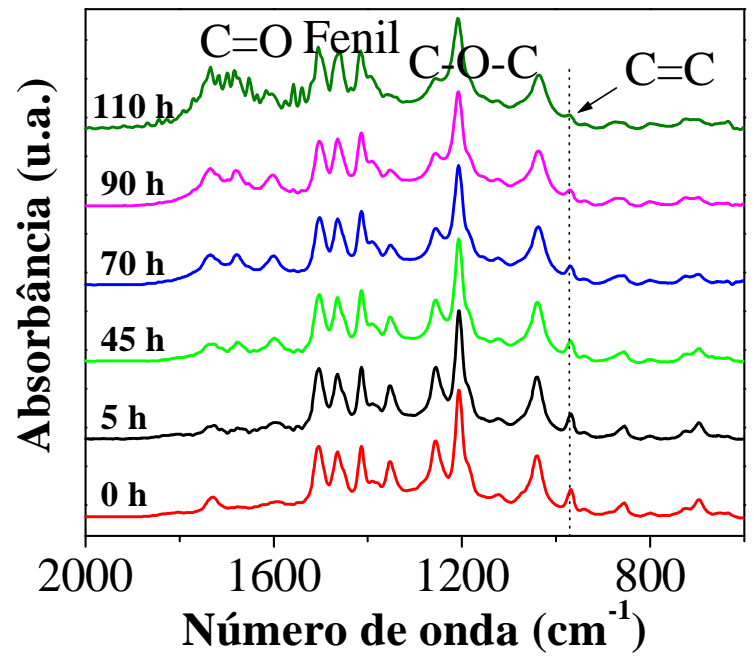

Figura 6.3: Espectros de absorção FTIR obtidos com um filme de MH-PPV como função do tempo de exposição do MH-PPV à iluminação com uma lâmpada branca de $250 \mathrm{~mW} / \mathrm{cm}^{2}$.

Dos espectros apresentados na Fig. 6.3, as bandas de absorção mais intensas estão associadas aos modos de vibração dos anéis aromáticos $\left(1035,1415,1500,1600 \mathrm{~cm}^{-1}\right)$, às deformações $\mathrm{CH}_{2}$ and $\mathrm{CH}_{3}\left(1160,1353,1365,1380\right.$ e $\left.1445 \mathrm{~cm}^{-1}\right)$, às ligações $\mathrm{CH}$ dos carbonos vinílicos $\mathrm{C}=\mathrm{C}$ (wagging, $975 \mathrm{~cm}^{-1}$ ) e aos grupos carbonilas $\mathrm{C}=\mathrm{O}(1730$ $1650 \mathrm{~cm}^{-1}$ ). Segundo os resultados obtidos, fica claro que a intensidade das bandas do grupo fenila $\left(1500 \mathrm{~cm}^{-1}\right)$ e das ligações C-O-C $\left(1208,1255 \mathrm{~cm}^{-1}\right)$ praticamente não se alteram com o tempo de iluminação, enquanto a intensidade das bandas wagging das ligações $\mathrm{C}=\mathrm{C}$ diminuem e das bandas de estiramento das ligações $\mathrm{C}=\mathrm{O}$ aumentam. Desses resultados podemos concluir que, à medida que o tempo de iluminação aumenta, a intensidade das ligações vinílicas $\mathrm{C}=\mathrm{C}$ diminuem e das ligações $\mathrm{C}=\mathrm{O}$ aumentam. Resultados similares foram obtidos por Cumpston et al. ${ }^{[21,80,81]}$, quando mostraram que as ligações vinílicas, em derivados alkoxi-substituídos do PPV, são as ligações mais reativas da cadeia polimérica desses polímeros.

\subsubsection{Elipsometria}

Dando continuidade ao estudo da fotoxidação do MH-PPV, medidas de elipsometria foram realizadas em um filme desse polímero com espessura média de 1,1 $\mu \mathrm{m}$. O polímero foi depositado por casting, sobre uma lâmina de vidro recoberta com cromo e ouro, utilizando uma solução de MH-PPV em clorofórmio $3 \mathrm{mg} / \mathrm{ml}$. Para iluminar a amostra foi utilizada uma lâmpada de $25 \mathrm{~W}\left(30 \mathrm{~mW} / \mathrm{cm}^{2}\right)$, acoplada ao elipsômetro, com 
o filme exposto ao ar durante as medidas. A Fig. 6.4 mostra o arranjo experimental, onde a amostra é mantida em uma posição fixa ora iluminada, Fig. 6.4-(a), ora caracterizada por elipsometria com a luz apagada, Fig. 6.4-(b). A Fig. 6.4-(c) mostra o espectro da lâmpada utilizada, que apresenta um máximo de intensidade entre 450 e $650 \mathrm{~nm}$, isto é, abrangendo todo intervalo de absorção dos filmes de MH-PPV na região do visível.
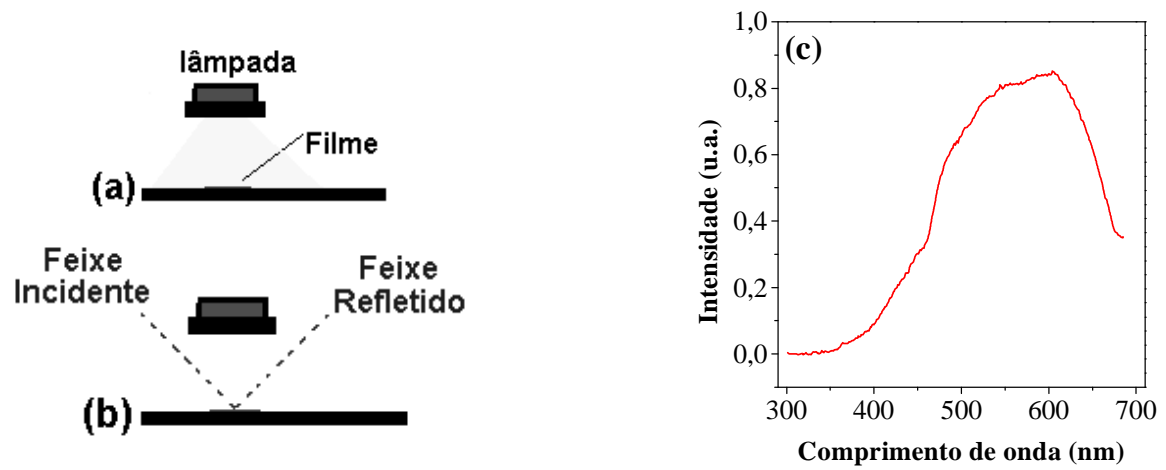

Figura 6.4: Esquema utilizado para as medidas com a técnica de elipsometria: (a) iluminação da amostra, (b) realização da medida. (c) apresenta o espectro de intensidade vs. comprimento de onda da lâmpada utilizada.

A Fig. 6.5 mostra os componentes $\varepsilon_{1}$ e $\varepsilon_{2}$ da função pseudo-dielétrica do MH-PPV obtidas a partir das medidas de elipsometria para diferentes tempos de iluminação.

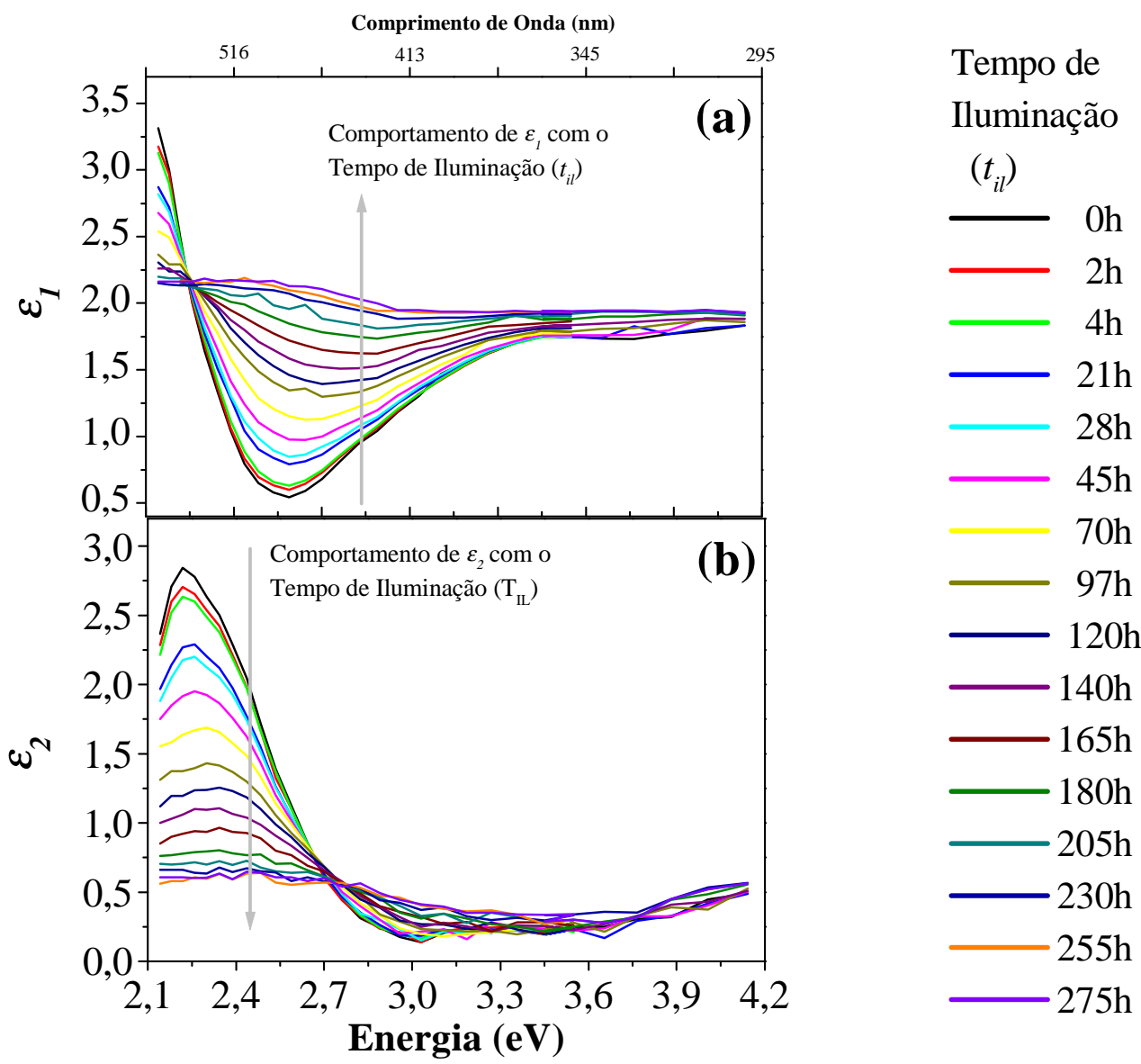

Figura 6.5: Componentes (a) real e (b) imaginário da função pseudo-dielétrica obtidas com um filme de MH-PPV exposto ao ar e iluminado com uma lâmpada de $25 \mathrm{~W}$ por 275 horas. 
Inicialmente, a curva de $\varepsilon_{1}$ exibe um valor de mínimo em $2,55 \mathrm{eV}$ e um ponto isosbéstico em 2,25 eV. Abaixo desse ponto, outra banda não pode ser completamente observada devido à limitação do equipamento utilizado. À medida que $t_{i l}$ aumenta, os picos das duas bandas diminuem, e para $t_{i l}$ maior que $200 \mathrm{~h}, \varepsilon_{l}$ tende a um valor constante e igual a 2,1 eV em todo o intervalo de energia medido. Já o espectro de $\varepsilon_{2}$ apresenta uma banda com pico em 2,25 eV, que é coincidente ao ponto isosbéstico de $\varepsilon_{l}$, e um mínimo em torno de $3,0 \mathrm{eV}$. À medida que $t_{i l}$ aumenta, o pico em $2,25 \mathrm{eV}$ diminui e um ponto isosbéstico passa a ser observado em $2,7 \mathrm{eV}$.

A Fig. 6.6 mostra os resultados da componente real, $n(\mathrm{E})$, e imaginária, $k(\mathrm{E})$, do índice de refração complexo $\left(N^{*}=n+\mathrm{i} k\right)$ obtidos a partir dos resultados da Fig. 6.5 e da Eq. (4.2).

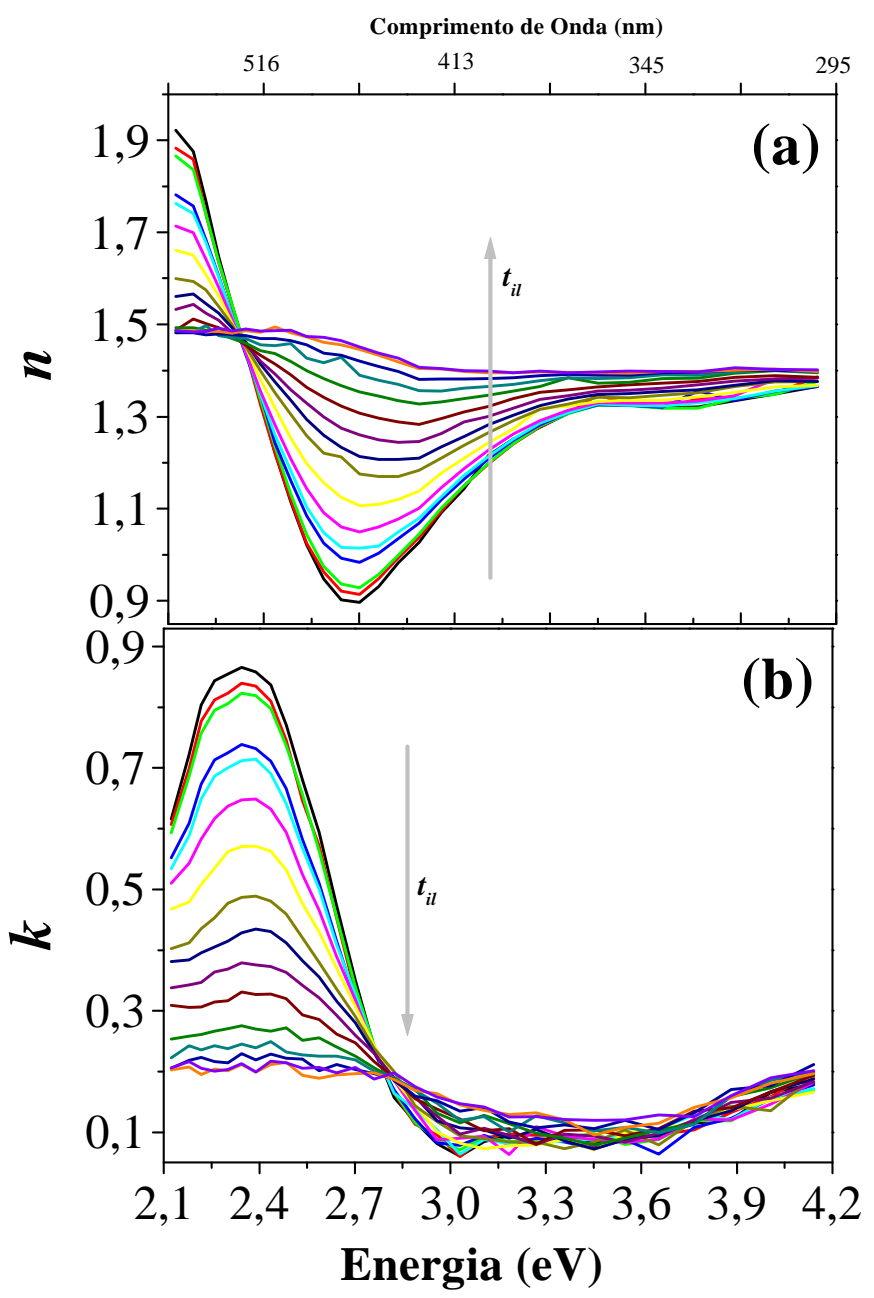

Tempo de

Iluminação
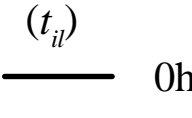

- $2 \mathrm{~h}$

- $4 \mathrm{~h}$

$-21 \mathrm{~h}$

- $28 \mathrm{~h}$

$-45 \mathrm{~h}$

$70 \mathrm{~h}$ 97h $120 \mathrm{~h}$ $140 \mathrm{~h}$

$-165 \mathrm{~h}$

$-180 \mathrm{~h}$

$-205 \mathrm{~h}$

$230 \mathrm{~h}$

$255 \mathrm{~h}$

$275 \mathrm{~h}$

Enia (eV)

Figura 6.6: Componentes (a) real - $n$ e (b) imaginário - $k$ do índice de refração complexo $\left(\mathrm{N}^{*}\right)$ obtidos com um filme de MH-PPV exposto ao ar e iluminado com um lâmpada de $25 \mathrm{~W}$ por 275 horas. 
Os comportamentos dos componentes $n$ e $k$, Fig. 6.6, são semelhantes aos espectros de $\varepsilon_{1}$ e $\varepsilon_{2}$ mostrados na Fig. 6.5, o que inclui também os picos de máximo, valores de mínimo e/ou pontos isosbésticos. Da literatura, até o momento, foi possível comparar apenas o valor de $n$ em torno $590 \mathrm{~nm}$. Yang C.J. et al. ${ }^{[85]}$ obtiveram $n=2,0$ para filmes de PPV alcóxi-substituídos, enquanto nossos resultados mostram um valor similar em torno de 1,9 para a amostra não degradada.

No intervalo de energia onde $k \approx 0$ (ou $k$ muito menor que $n$ ) é possível determinar o índice de refração do polímero fora da região de ressonância e avaliar qual o seu comportamento com o tempo de iluminação. Para investigar essa variação, valores de $N^{*} \cong n$ foram obtidos a partir das curvas da Fig. 6.6-(a) na energia de 3,5 eV. Os resultados obtidos são mostrados na Fig. 6.7. Nessa figura observamos que $n$ aumenta de 1,32 $\left(t_{i l}=0\right)$ para 1,40 $\left(t_{i l}=275 \mathrm{~h}\right)$, tendendo a um valor constante acima de 250 horas de iluminação.

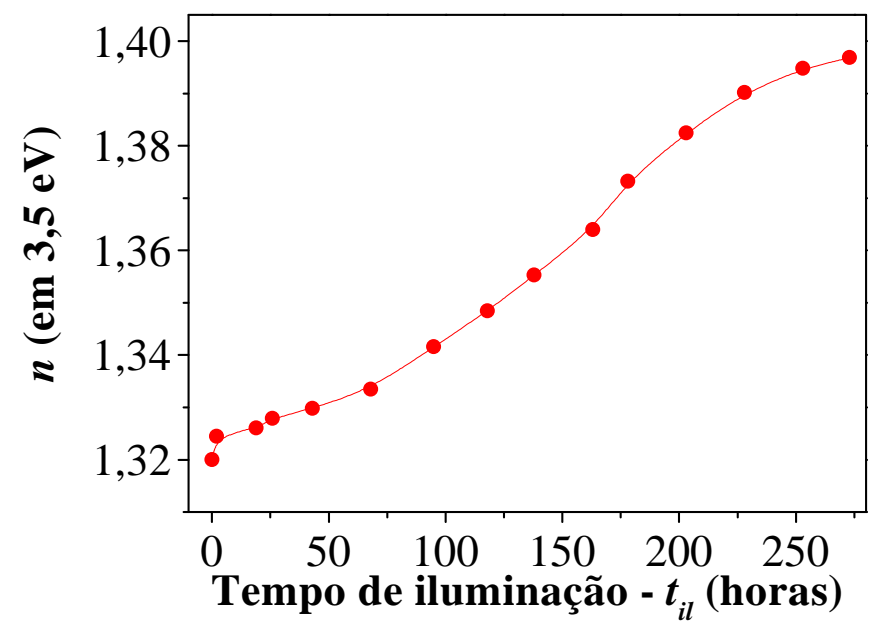

Figura 6.7: Índice de refração obtido com o MH-PPV como função do tempo de exposição do material com a lâmpada de $25 \mathrm{~W}$. Resultados obtidos com a energia de 3,5 eV.

\subsection{Modelo do oscilador de Lorentz}

O comportamento dos componentes real e imaginário da função pseudo-dielétrica nos motivou a explicar os resultados obtidos através do modelo do oscilador de Lorentz ${ }^{[64,70-72]}$. Dessa forma, os componentes $\varepsilon_{1}$ e $\varepsilon_{2}$ apresentadas na Fig. 6.5 foram ajustados pela Eq. (5.1), no intervalo de 2,1 a 3,4 eV (região de ressonância). A Fig. 6.8 mostra esses ajustes e a Tabela 6.I os parâmetros $E_{0}, v, \varepsilon_{\infty}$ e $A$ obtidos. Já a Fig. 6.9 mostra a evolução desses quatro parâmetros com $t_{i l}$. As curvas cheias (-) nos gráficos dessa figura sugerem a dependência linear desses parâmetros com $t_{i l}$. 

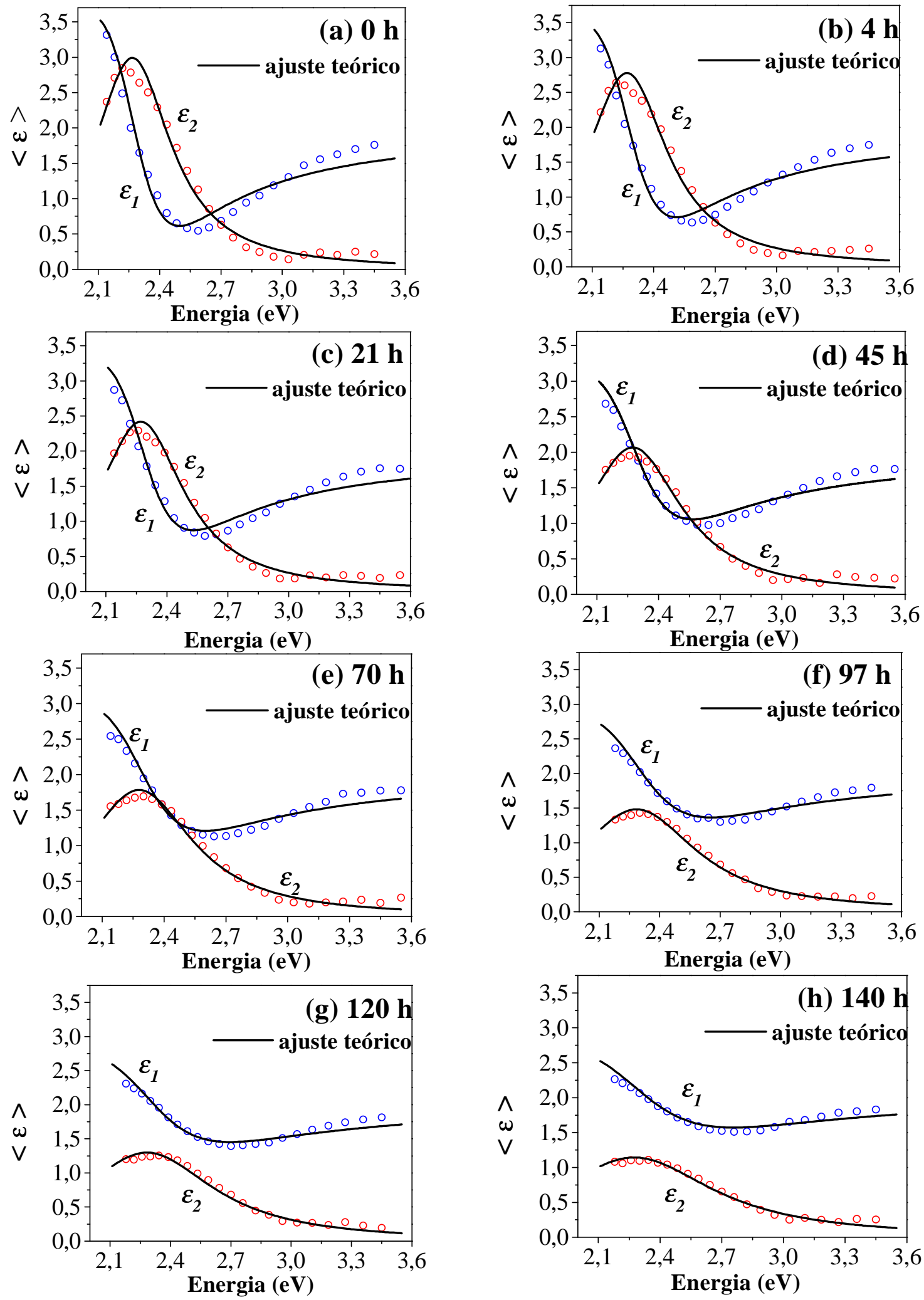

Figura 6.8: Componentes $\varepsilon_{l}$ (O) e $\varepsilon_{2}$ (O) do MH-PPV ajustados pela equação do átomo de Lorentz Eq. (5.1) (-) - obtidos com diferentes tempos de exposição do polímero à luz: (a) 0 , (b) 4, (c) 21, (d) 45, (e) 70, (f) 97, (g) 120 e (h) $140 \mathrm{~h}$. 
Tabela 6.I: Parâmetros obtidos com os ajustes mostrados na Fig. 6.8.

\begin{tabular}{||c|c|c|c|c||}
\hline $\begin{array}{c}\text { Tempo de } \\
\text { iluminação }-\boldsymbol{t}_{\boldsymbol{i l}} \text { (horas) }\end{array}$ & $\begin{array}{c}\boldsymbol{E}_{\boldsymbol{0}} \\
(\mathbf{e V})\end{array}$ & $\begin{array}{c}\boldsymbol{v} \\
(\mathbf{e V})\end{array}$ & $\boldsymbol{\varepsilon}_{\infty}$ & $\begin{array}{c}\boldsymbol{A} \\
(\mathbf{e V})\end{array}$ \\
\hline 0 & 2,278 & 0,461 & 1,946 & 1,261 \\
\hline 2 & 2,278 & 0,472 & 1,947 & 1,249 \\
\hline 4 & 2,282 & 0,482 & 1,950 & 1,246 \\
\hline 21 & 2,286 & 0,517 & 1,956 & 1,207 \\
\hline 28 & 2,289 & 0,536 & 1,963 & 1,200 \\
\hline 45 & 2,292 & 0,580 & 1,968 & 1,179 \\
\hline 70 & 2,301 & 0,640 & 1,986 & 1,147 \\
\hline 97 & 2,314 & 0,731 & 2,001 & 1,116 \\
\hline 120 & 2,319 & 0,818 & 2,015 & 1,105 \\
\hline 140 & 2,323 & 0,947 & 2,042 & 1,104 \\
\hline
\end{tabular}

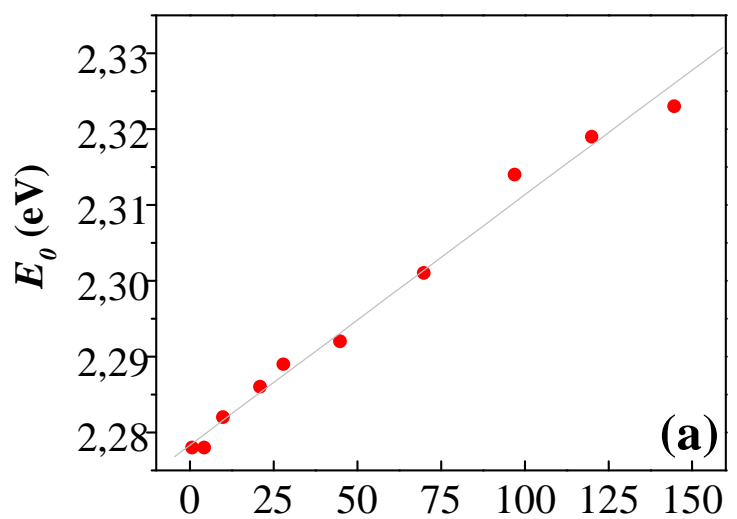

Tempo de iluminação $-t_{i l}$ (horas)

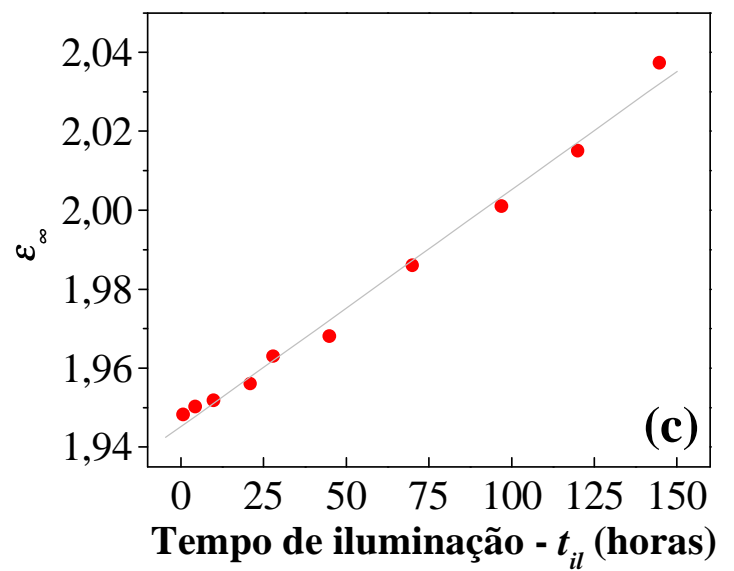

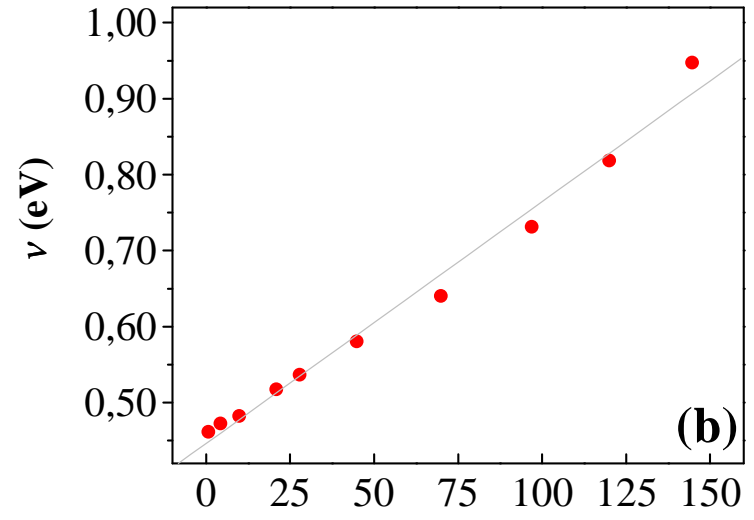

Tempo de iluminação $-t_{i l}$ (horas)

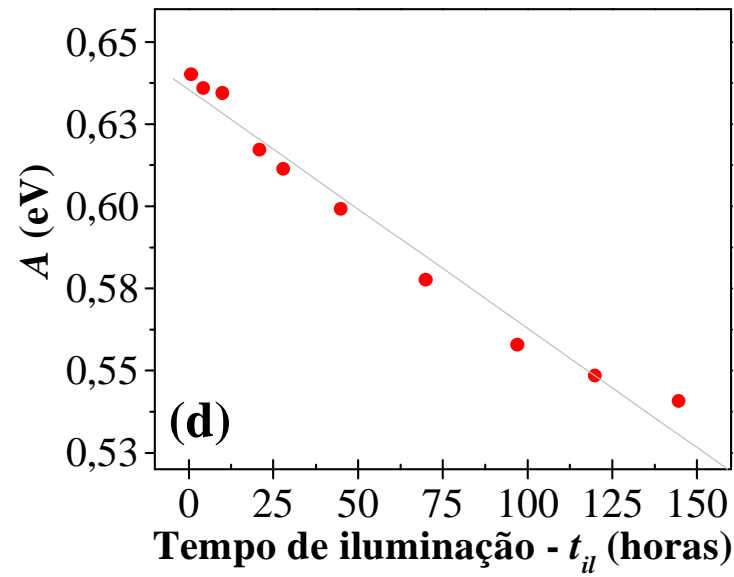

Figura 6.9: Parâmetros obtidos com os ajustes dos componentes $\varepsilon_{1}$ e $\varepsilon_{2}$ pela equação de Lorentz, Eq. (5.1) mostrados na Fig. 6.8 .

Na Tabela 6.I observamos que os parâmetros $E_{0}, v$ e $\varepsilon_{\infty}$ aumentam com $t_{i l}$, enquanto $A$ diminui. De acordo com os resultados de absorção UV-VIS, Fig. 6.2, que mostra um 
deslocamento do pico de absorção para o azul, e FTIR, Fig. 6.3, a evolução de $E_{0}$ para maiores energias está ligada à redução da conjugação das cadeias poliméricas principais, através da substituição de ligações $\mathrm{C}=\mathrm{C}$ por $\mathrm{C}=\mathrm{O}$. $\mathrm{O}$ aumento das ligações $\mathrm{C}=\mathrm{O}$ pode ainda contribuir para o aumento das ligações de hidrogênio entre as cadeias poliméricas adjacentes, o que poderia explicar o aumento do parâmetro $v$. O parâmetro $A$, por sua vez, está associado à amplitude de oscilação da nuvem eletrônica, o que poderia estar associado à redução da conjugação da cadeia polimérica principal. Por último, embora $\varepsilon_{\infty}$ varie com o tempo de iluminação, sua variação é praticamente desprezível.

\subsection{Modelo de Lorenz-Lorentz}

No intervalo de energia onde $k \approx 0$ (ou $k$ muito menor que $n$ ), a equação de LorenzLorentz $^{[63,83-96]}(\mathrm{LL})$ oferece a possibilidade de se calcular o valor de $n$ de um polímero desconhecido se as frações $\left(R_{\mathrm{j}}\right)$ e os volumes $\left(V_{\mathrm{j}}\right)$ molares dos seus grupos funcionais são conhecidos. Nesse caso, $n$ pode ser obtido a partir da equação:

$$
\frac{n^{2}-1}{n^{2}+2} \sum_{\mathrm{j}=1}^{\mathrm{J}} a_{\mathrm{j}} V_{\mathrm{j}}=\sum_{\mathrm{j}=1}^{\mathrm{J}} a_{\mathrm{j}} R_{\mathrm{j}}
$$

onde j é o índice relativo a cada um dos grupos funcionais ( $\mathrm{J}$ ) com contribuição $a_{j}$, refração molar $R_{j}$ e volume molar $V_{j}$. Dessa forma, para investigar a variação do índice de refração do MH-PPV com o tempo de iluminação, desenvolvemos um modelo baseado na Eq. (6.1) para explicar o comportamento de $n v s$. $t_{i l}$ apresentado na Fig. 6.7 a partir das seguintes hipóteses:

(i) antes de o polímero ser iluminado se considera que a estrutura molecular do MH-PPV é altamente conjugada, como mostra a Fig. 6.10-(a). Após 275 horas de iluminação, ou seja, depois que as mudanças dos espectros de $n$ e $k$ não são mais verificadas, a estrutura química do polímero apresenta uma substituição total das ligações $\mathrm{C}=\mathrm{C}$ vinílicas por ligações $\mathrm{C}=\mathrm{O}$, como mostra a Fig. 6.10-(b), o que deve diminuir consideravelmente o comprimento médio dos segmentos conjugados. 


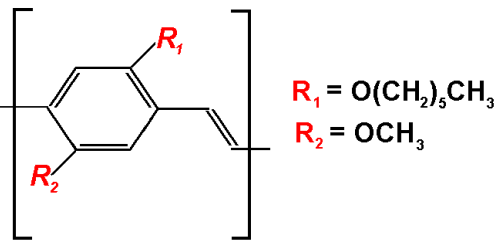

(a)

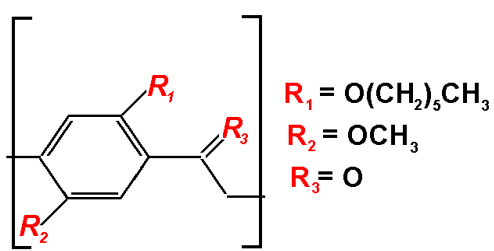

(b)

Figura 6.10: (a) unidade monomérica conhecida do MH-PPV (polímero puro) e (b) possível unidade monomérica do MH-PPV após 275 horas de iluminação (completamente degradado).

(ii) para um estágio intermediário, i.e. para $0 \leq t_{i l} \leq 275 \mathrm{~h}$, assumimos que a unidade monomérica do MH-PPV é composta de uma porção degradada $(x)$ e uma porção complementar não degradada $(1-x)$, onde $x \equiv x\left(t_{i l}\right)$ e $0 \leq x \leq 1$, como mostra a Fig. 6.11. Considerações similares foram propostas por Gelinck et al. ${ }^{[25]}$ no estudo da interrupção da conjugação da cadeia do PPV através da reação de substituição de um grupo tiofeno por um grupo metóxi.

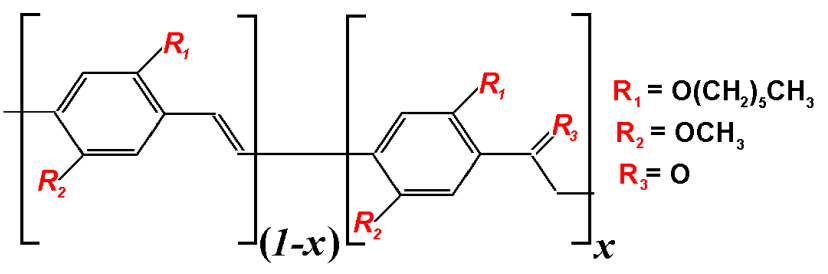

Figura 6.11: Possível unidade monomérica do MH-PPV entre 0 h e 275 horas de iluminação. O parâmetro $x$ indica a quantidade degradada do polímero $(0 \leq \mathrm{x} \leq 1)$ e depende do tempo de iluminação.

(iii) a fração molar total do polímero em um instante $0 \leq t_{i l} \leq 275 \mathrm{~h}$ pode ser representada como a soma aritmética das contribuições das frações molares do polímero não degradado $\left(R^{\mathrm{ND}}, t_{i l}=0\right)$ e do polímero completamente degradado $\left(R^{\mathrm{CD}}, t_{i l}=275 \mathrm{~h}\right)$. A fração molar total, em um instante $t_{i l}$ qualquer, é então obtida a partir da soma $R(x)=x R^{\mathrm{ND}}$ $+(1-\mathrm{x}) R^{\mathrm{CD}}$, e o volume molar total a partir de $V(x)=x V^{\mathrm{ND}}+(1-x) V^{\mathrm{CD}}$.

Tomando-se essas 3 hipóteses, podemos reescrever a Eq. (6.1) como:

$$
\frac{n^{2}-1}{n^{2}+2}\left[(1-x) V^{\mathrm{ND}}+x V^{\mathrm{CD}}\right]=(1-x) \sum_{\mathrm{j}=1}^{5} R_{\mathrm{j}}^{\mathrm{ND}}+x \sum_{\mathrm{j}=1}^{5} R_{\mathrm{j}}^{\mathrm{CD}}
$$

onde $V^{\mathrm{ND}}$ e $V^{\mathrm{CD}}$ são determinados a partir dos volumes molares dos grupos metóxibenzeno, vinil, carbonil, éter, metileno e metil presentes nas unidades monoméricas do 
MH-PPV não degradado e/ou completamente degradado. A Tabela 6.II mostra os volumes molares desses grupos obtidos da literatura ${ }^{[83-85]}$, onde os valores de $V^{\mathrm{ND}}$ e $\mathrm{V}^{\mathrm{CD}}$ são iguais a: $V_{\mathrm{ND}}=V_{\mathrm{a}}+V_{\mathrm{b}}+V_{\mathrm{d}}+5 V_{\mathrm{e}}+V_{\mathrm{f}}=232,8 \mathrm{~cm}^{3} / \mathrm{mol} \mathrm{e} V_{\mathrm{CD}}=V_{\mathrm{a}}+V_{\mathrm{c}}+V_{\mathrm{d}}+6 V_{\mathrm{e}}+V_{\mathrm{f}}=234,5$ $\mathrm{cm}^{3} / \mathrm{mol}$.

Tabela 6.II: Volumes molares dos grupos funcionais do MH-PPV disponíveis na literatura ${ }^{\left[{ }^{[3-85]}\right.}$.

\begin{tabular}{||c|c|c|c|c|c|c||}
\hline $\begin{array}{c}\text { Grupos } \\
\text { funcionais }\end{array}$ & $-\Downarrow-$ & -1 & $-\mathrm{O}$ & $-\mathrm{O}-$ & $-\mathrm{CH}_{2}-$ & $-\mathrm{CH}_{3}$ \\
\hline $\mathrm{V}_{\mathrm{j}}\left(\mathrm{cm}^{3} / \mathrm{mol}\right)$ & $\mathrm{V}_{\mathrm{a}} \cong 93,4$ & $\mathrm{~V}_{\mathrm{b}}=27,0$ & $\mathrm{~V}_{\mathrm{c}}=13,2$ & $\mathrm{~V}_{\mathrm{d}}=9,1$ & $\mathrm{~V}_{\mathrm{e}}=15,5$ & $\mathrm{~V}_{\mathrm{f}}=25,8$ \\
\hline
\end{tabular}

Também os valores das frações molares $R^{\mathrm{ND}}$ e $R^{\mathrm{CD}}$ podem ser obtidos a partir das somas $R^{\mathrm{ND}}=R_{\mathrm{a}}+R_{\mathrm{b}}+R_{\mathrm{d}}+5 R_{\mathrm{e}}+R_{\mathrm{f}}$ e $R^{\mathrm{CD}}=R_{\mathrm{a}}+R_{\mathrm{c}}+R_{\mathrm{d}}+6 R_{\mathrm{e}}+R_{\mathrm{f}}$. Entretanto, algumas das frações molares dessas somas, na energia de $3,5 \mathrm{eV}$, não são tabeladas ou conhecidas. Dessa forma, estimamos os valores de $R^{\mathrm{ND}}\left(46,2 \mathrm{~cm}^{3} / \mathrm{mol}\right)$ e $\mathrm{R}^{\mathrm{CD}}\left(56,8 \mathrm{~cm}^{3} / \mathrm{mol}\right)$ utilizando, como condições de contorno, os valores experimentais de $n$ obtidos em $t_{i l}=0$ ( $n=1,32, x=0)$ e $t_{i l}=275$ horas $(n=1,4, x=1)$ na Eq. (6.2). Reescrevendo essa equação com esses novos parâmetros, obtemos a expressão para $x$ como função de $n(t)$ :

$$
x\left(t_{i l}\right)=\frac{186,6 n\left(t_{i l}\right)^{2}-325,2}{22,1+8,5 n\left(t_{i l}\right)^{2}}
$$

que é a relação que envolve a porção degradada do MH-PPV com o índice de refração em $3,5 \mathrm{eV}$ em um dado $t_{i l}$

A Fig. 6.12 mostra a evolução do valor de $x\left(t_{i l}\right)$, obtido a partir da Eq. (6.3), e os valores da razão $\mathrm{A}_{1670} / \mathrm{A}_{1500}\left(t_{i l}\right)$, que representa a área das bandas de absorção referentes ao estiramento $\mathrm{C}=\mathrm{O}\left(1670 \mathrm{~cm}^{-1}\right)$, normalizadas pela banda de absorção do anel aromático $\left(1500 \mathrm{~cm}^{-1}\right) . \mathrm{A}_{1670} / \mathrm{A}_{1500}\left(t_{i l}\right)$ foi obtida a partir dos espectros do infravermelho mostrados na Fig. 6.3. A banda em $1670 \mathrm{~cm}^{-1}$ foi escolhida por representar, nos espectros de absorção, a carbonila proveniente de grupos cetona como representado na Fig. 6.10-(b). É importante destacar que as abscissas não são as mesmas devido ao uso de diferentes intensidades luminosas para as medidas de absorção no infravermelho e de elipsometria. Por esse motivo, denotamos $t_{i l}$ como o tempo de iluminação das medidas de elipsometria, e $t^{\prime}{ }_{i l}$ 
como o tempo de iluminação das medidas de absorção no infravermelho. Como pode ser observado na Fig. 6.12, o comportamento de $x\left(t_{i l}\right)$ e $\mathrm{A}_{1670} / \mathrm{A}_{1500}\left(t^{\prime}{ }_{i l}\right)$ obedecem à mesma dependência com o tempo de iluminação. Como resultado, a Fig. 6.13 mostra a curva $x$ vs. $n$ obtidas a partir da Eq. (6.3) e da Fig. 6.7.

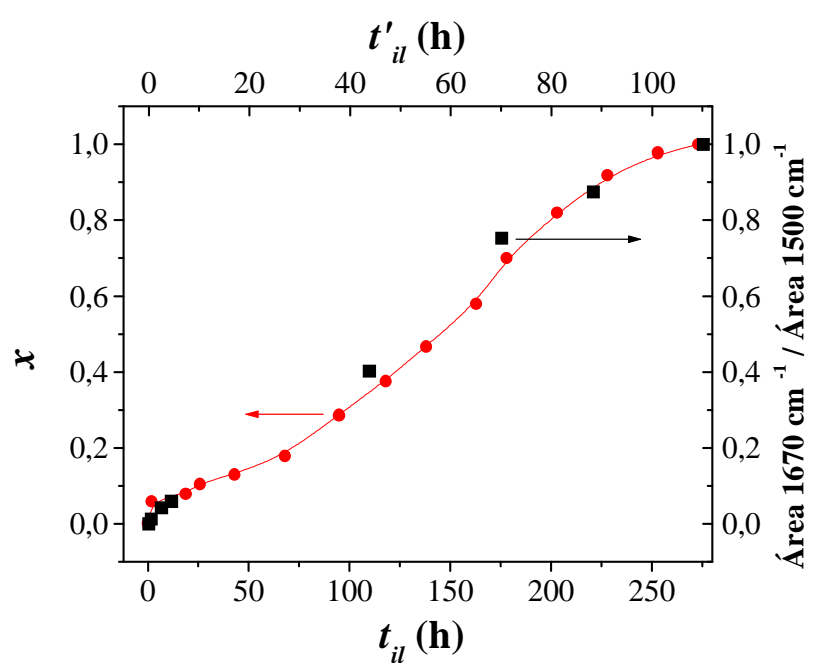

Figura 6.12: Evolução de $x$ e da razão $A_{1670} / A_{1500}$ como função do tempo de iluminação. $t_{i l}$ foi o tempo de medida do índice de refração, e $t^{\prime}{ }_{i l}$ o tempo de iluminação para a medida da razão $\mathrm{A}_{1670} / \mathrm{A}_{1500}$.

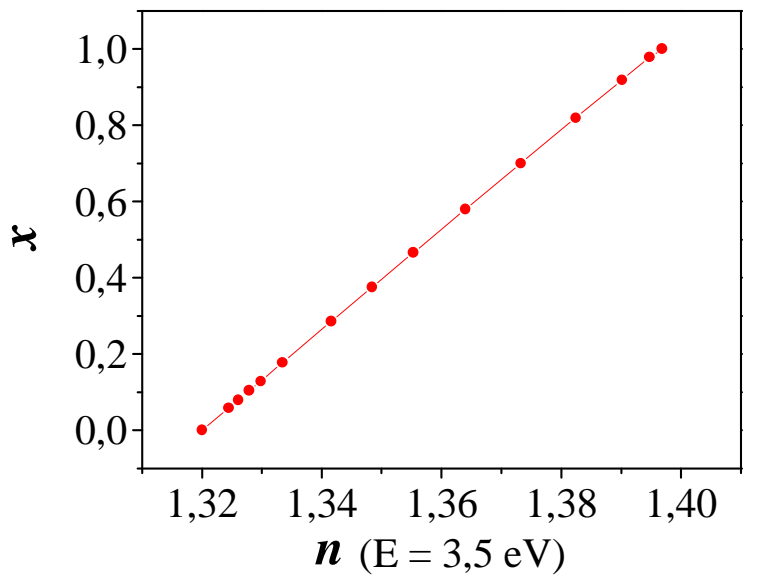

Figura 6.13: Índice de refração experimental vs. fração de unidades degradadas $x$ obtidos a partir da Eq. (6.3) e usando os valores de $n$ apresentados na Fig. 6.7.

A dependência $x$ vs. $n$ apresentada no gráfico da Fig. 6.13 é linear, para os valores de $n$ analisados, que do ponto de vista experimental torna-se útil para estimar a porção degradada do polímero se apenas o seu índice de refração for conhecido. A correlação entre $x$ e $n$ é inédita e mostra que a suposição realizada sobre a total substituição de ligações $\mathrm{C}=\mathrm{C}$ por $\mathrm{C}=\mathrm{O}$ pode ser usada, como uma primeira aproximação, para descrever o comportamento do índice de refração desse polímero na energia de $3,5 \mathrm{eV}^{[86]}$. 


\subsection{Discussão dos Resultados}

Nesse capítulo apresentamos a investigação do efeito de fotodegradação do $\mathrm{MH}$ PPV através de medidas de absorção e elipsometria. Esse efeito tem sido atualmente um importante objeto de estudo devido à sua importância científica e tecnológica.

Nas medidas de absorção UV-VIS foi observado que filmes de MH-PPV quando iluminados tinham seus máximos de absorção óptica UV-VIS reduzidos e deslocados para o azul rapidamente, quando exposto ao ar, e lentamente, quando exposto em $\mathrm{N}_{2}$. Entretanto, quando filmes eram armazenados no escuro e expostos ao ar por um longo período de tempo, nenhuma mudança nos espectros foi observada. Desses resultados ficou claro que a combinação luz e concentração de oxigênio exerce um papel importante no efeito de degradação do polímero. Resultados de absorção no infravermelho mostraram que as mudanças nos espectros de absorção óptica estão ligadas, principalmente, a substituição das ligações $\mathrm{C}=\mathrm{C}$ por $\mathrm{C}=\mathrm{O}$, reduzindo a conjugação efetiva da cadeia polimérica, e estando de acordo com os resultados da literatura ${ }^{[81]}$.

A degradação também foi acompanhada por medidas de elipsometria. Os resultados mostraram que a função pseudo-dielétrica do MH-PPV é alterada, irreversivelmente, quando o polímero é iluminado e exposto ao ar. Para explicar tal efeito, a evolução da função pseudo-dielétrica com o tempo de iluminação foi investigada através da equação do modelo de oscilador de Lorentz, que forneceu, dentre outros parâmetros, um aumento da energia de ressonância do oscilador $\left(E_{o}\right)$ e do parâmetro de amortecimento $(v)$. Nesse caso, $\mathrm{E}_{0}$ aumenta pois a conjugação efetiva da cadeia polimérica diminui. Já o aumento de $v$, por sua vez, pode estar associado ao aumento das ligações de hidrogênio entre as cadeias poliméricas adjacentes, oriundas do aumento das ligações $\mathrm{C}=\mathrm{O}$. Por último, um modelo baseado na equação de Lorenz-Lorentz, nas propriedades dos cromóforos do MH-PPV e na substituição das ligações $\mathrm{C}=\mathrm{C}$ por $\mathrm{C}=\mathrm{O}$ foi desenvolvido e usado, com relativo sucesso, para explicar o comportamento do índice de refração do polímero com o tempo de iluminação. Os resultados obtidos mostraram que o valor do índice de refração na energia de 3,5 eV acompanha a evolução das ligações carbonilas, apresentando uma forte correlação entre o seu valor e a fração degradada do polímero. O estudo da fotoxidação pela técnica de elipsometria e a utilização dos modelos do oscilador de Lorentz e LorenzLorentz são inéditos na literatura e, por esse motivo, tem especial destaque nesse trabalho. 


\section{Capítulo 7}

\section{Diodos Eletroluminescentes Poliméricos}

Nos últimos anos vários trabalhos têm mostrado que a eficiência de dispositivos eletroluminescentes poliméricos é influenciada pelas condições ambientes e pelos mecanismos de injeção e transporte dos portadores nesses sistemas. No capítulo anterior, investigamos como as condições ambientais modificam as propriedades ópticas de filmes de MH-PPV. Nesse capítulo estudaremos os mecanismos de transporte através do MHPPV e, principalmente, o efeito dos eletrodos no processo de injeção de portadores, nas duas interfaces, por meio de medidas isotermas de corrente vs. tensão e de impedância complexa em função da frequiência do campo elétrico. Para isso, as medidas foram realizadas com dispositivos ITO/MH-PPV/Al, que é a estrutura típica de um PLED, e também em estruturas tipo Au/MH-PPV/Au, ITO/MH-PPV/Au e ITO/PPV/Al. Como era de se esperar, as curvas $I$ vs. $V$ mostraram-se dependentes dos metais usados como eletrodos, da espessura do filme polimérico e da temperatura. Medidas de condutividade complexa realizadas em temperatura ambiente, por sua vez, mostraram que o comportamento dos componentes real e imaginário dependem dos metais, da espessura e da tensão de polarização da amostra. Para explicar tais efeitos, analisamos os resultados com o auxílio de um modelo de circuito equivalente que procurou separar os efeitos de volume dos de interface. O transporte através do volume foi em particular analisado considerando-se a estrutura desordenada do material polimérico através do modelo RFEB.

\subsection{Medidas Densidade de Corrente vs. Tensão (J vs. $V)$}

Nesse item apresentamos as medidas de densidade de corrente $v s$. tensão $(J v s . V)$ obtidas de dispositivos Au/MH-PPV/Au, ITO/MH-PPV/Au, ITO/MH-PPV/Al e ITO/PPV/Al. As amostras foram preparadas seguindo os procedimentos apresentados no item 3.2.2 utilizando, como substratos, lâminas de vidro/ITO ou lâminas de vidro recobertas com cromo/ouro. Todas as medidas foram realizadas no escuro e sob vácuo para 
minimizar o efeito da fotoxidação dos filmes poliméricos, e com intervalo entre aplicação de tensão e leitura de corrente (delay time) de $50 \mathrm{~ms}$. Foi adotado como padrão o ITO como eletrodo de potencial variável, $L$ a espessura do filme polimérico e $A r$ a área dos eletrodos metálicos. As funções trabalho dos materiais usados como eletrodos são apresentadas na Fig. 2.12.

A Fig 7.1 mostra curvas $J$ vs. $V$ obtidas com amostras Au/MH-PPV/Au, com $L=400 \mathrm{~nm}, L=1,1 \mu \mathrm{m}, L=14 \mu \mathrm{m}$ e $A r=0,03 \mathrm{~cm}^{2}$. Sendo a função trabalho do ouro próxima a energia HOMO do material, é de se esperar que a injeção de portadores positivos seja bem superior a de negativos, qualquer que seja a polaridade da tensão aplicada. Dessa forma, estruturas desse tipo podem ser usadas para estudar o mecanismo de condução de portadores positivos através do volume da camada polimérica. As medidas foram realizadas em temperatura ambiente, com umidade relativa de $10 \%$ e sob vácuo de $10^{-1}$ Torr. Para se evitar a degradação dos eletrodos pela ação do campo elétrico aplicado, limitamos o intervalo de tensão de -5 a $5 \mathrm{~V}$ e o máximo de corrente em $1 \mu \mathrm{A}$.
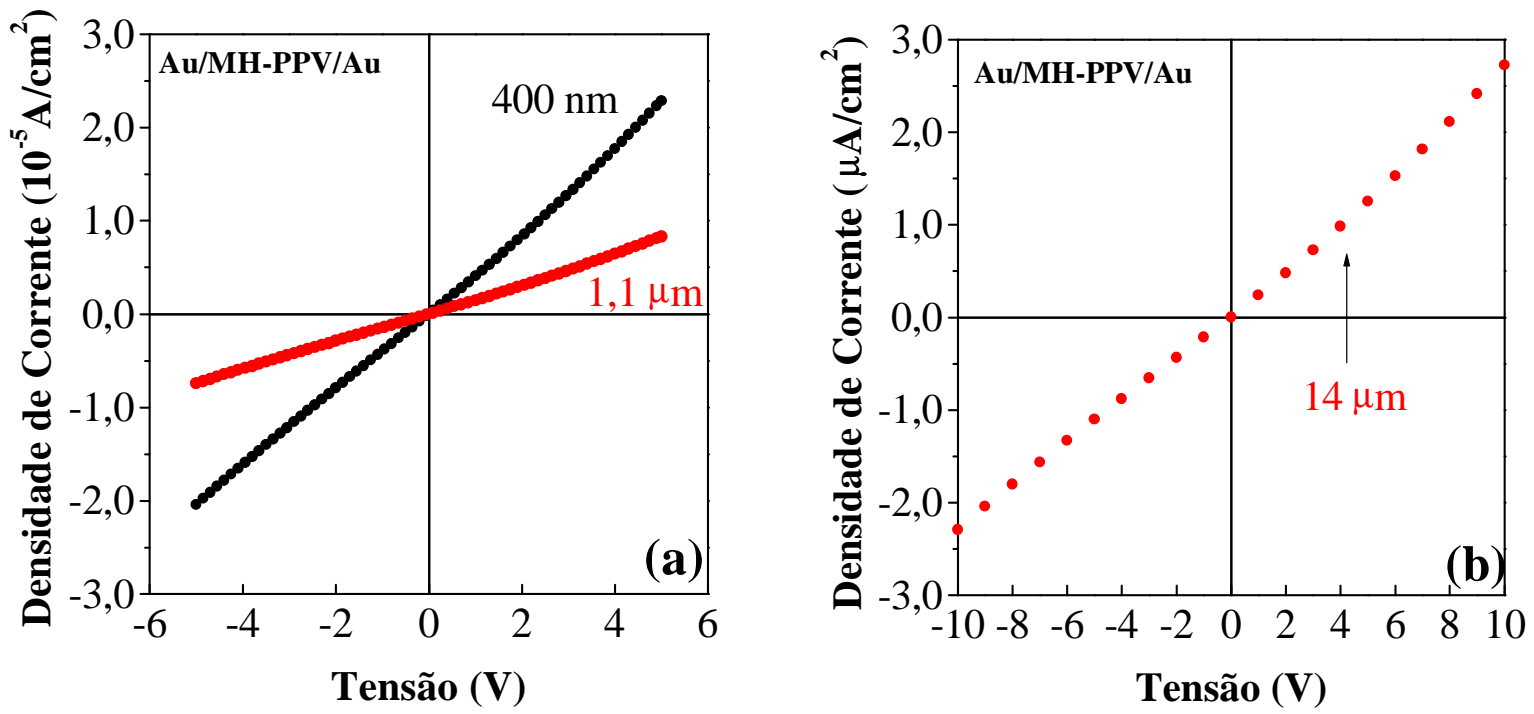

Figura 7.1: Curvas $J$ vs. $V$ de amostras Au/MH-PPV/Au, com (a) $L=400 \mathrm{~nm}$ e $L=1,1 \mu \mathrm{m}$, (b) $L=14 \mu \mathrm{m}$ e Ar $=0,03 \mathrm{~cm}^{2}$. Medidas realizadas no escuro, sob vácuo de $10^{-1}$ Torr, a $27{ }^{\circ} \mathrm{C}$ e com umidade relativa de $10 \%$.

Na Fig. 7.1 observamos que ambas as curvas obedecem a um comportamento ôhmico, tendo os três filmes o mesmo valor de resistividade $(\rho), c a .5,0 \times 10^{9} \Omega \mathrm{cm}$, em torno dos valores obtidos da literatura com o PPV ${ }^{[49]}$. Nesse caso, os portadores injetados por um eletrodo são transportados através do volume do material polimérico até o outro 
eletrodo, sendo a sua densidade de corrente limitada apenas pela resistividade do polímero. Eletrodos desse tipo são conhecidos como eletrodos neutros.

Para estudar a influência dos eletrodos nas características elétricas dos dispositivos, a Fig. 7.2 apresenta as curvas $J$ vs. $V$ obtidas com amostras ITO/MH-PPV/Au e ITO/MHPPV/Al, em escalas linear e mono-logarítmica, no intervalo de tensão de -5 a $5 \mathrm{~V}$, a temperatura ambiente, com umidade relativa de $10 \%$ e sob vácuo de $10^{-1}$ Torr. Ambas as amostras possuem $L=400 \mathrm{~nm}$ e $A r=0,3 \mathrm{~cm}^{2}$.
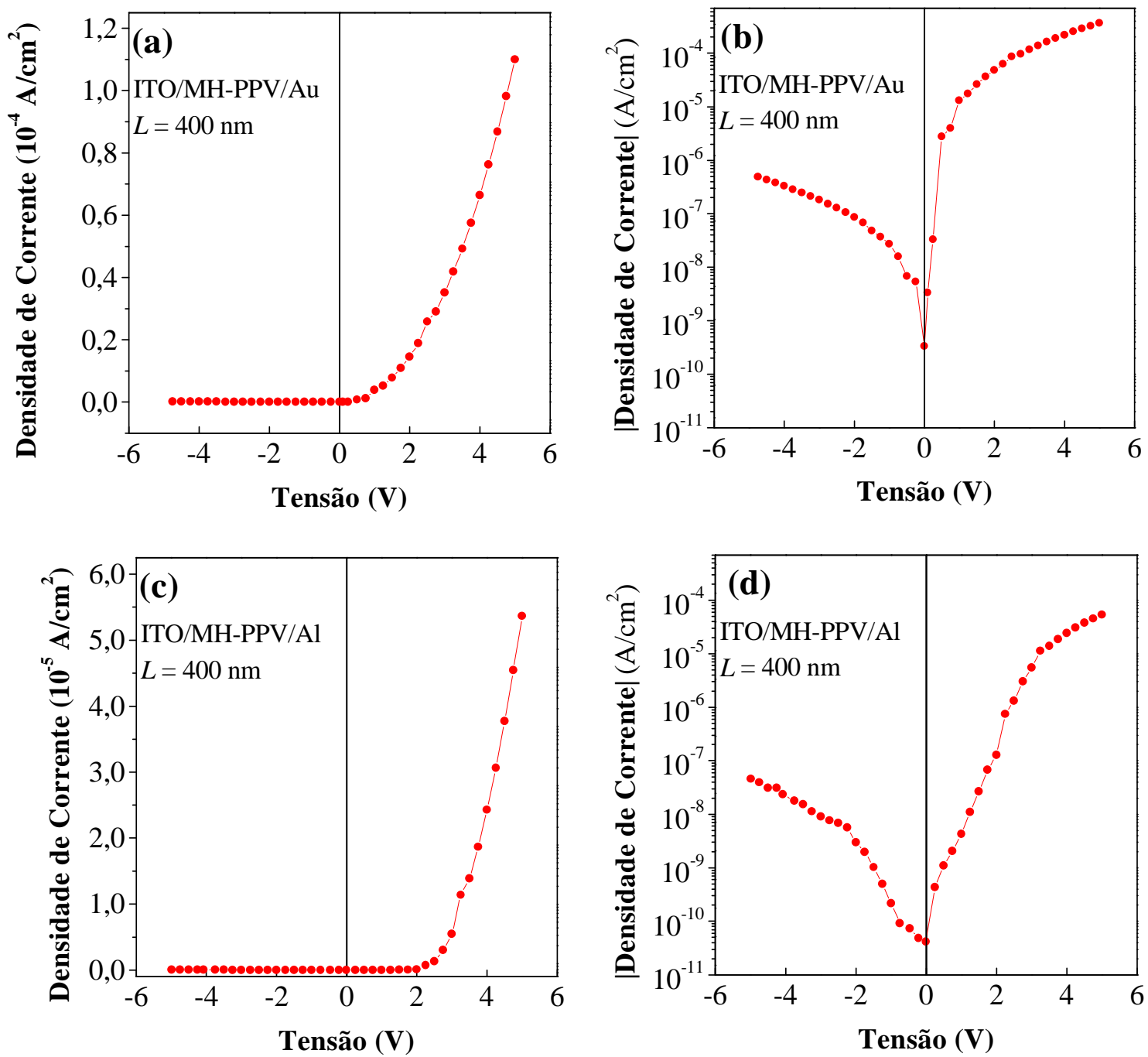

Figura 7.2: Curvas $J$ vs. $V$, em escalar linear e mono-log, obtidos com amostras: (a) e (b) ITO/MH-PPV/Au, e (c) e (d) ITO/MH-PPV/Al, ambas com L $=400 \mathrm{~nm}$ e $A r=0,3 \mathrm{~cm}^{2}$. Medidas realizadas em temperatura ambiente, sob vácuo de $10^{-1}$ Torr, no escuro e com umidade relativa de $10 \%$. 
A Fig. 7.2-(a) mostra que a densidade de corrente da amostra ITO/MH-PPV/Au apresenta um comportamento típico de diodos retificadores. Em escala mono-log, Fig. 7.2(b), é possível verificar que $J$, em modo reverso, cresce suavemente com a tensão aplicada, tendendo a um valor estacionário da ordem de $10^{-6} \mathrm{~A} / \mathrm{cm}^{2}$. Entre $0<\mathrm{V}<0,5 \mathrm{~V}$ se observa uma grande variação de corrente, cerca de 5 ordens de grandeza, e para $\mathrm{V}>0,5 \mathrm{~V}$, a corrente sobe suavemente com a tensão, tendendo a um valor em torno de $10^{-3} \mathrm{~A} / \mathrm{cm}^{2}$. Curvas similares foram obtidas com a amostra ITO/MH-PPV/Al, Figs. 7.2-(c) e (d). Nesse caso, $J$ apresenta sua maior variação no intervalo de tensão entre 0 e $2 \mathrm{~V}$. Em modo reverso ela tende a $10^{-7} \mathrm{~A} / \mathrm{cm}^{2}$, e em torno de $10^{-4} \mathrm{~A} / \mathrm{cm}^{2}$ com V > $5 \mathrm{~V}$. Das curvas obtidas fica claro que a corrente é maior quando o ITO é polarizado positivamente. Esta retificação é esperada quando o segundo eletrodo é de alumínio, mas, para a estrutura ITO/MH$\mathrm{PPV} / \mathrm{Au}$, era de se esperar uma fraca retificação, isto porque, teoricamente, o ouro é um bom injetor de portadores positivos para esse material. A função trabalho do ITO é igual a 4,8 eV, já para o ouro, são encontrados vários valores na literatura, variando-se entre 4,58 a $5,2 \mathrm{eV}{ }^{[28]}$. Além disso, pode ocorrer uma leve oxidação na superfície do ouro, que diminuiria ainda mais a função trabalho desse metal.

Para verificar a influência da temperatura nos dispositivos, a Fig. 7.3 mostra as curvas $J$ vs. $V$ obtidas com amostras ITO/MH-PPV/Al e ITO/PPV/Al em diferentes temperaturas e diferentes espessuras da camada polimérica. As Figs. 7.3-(a) e 7.3-(b) mostram os resultados obtidos com amostras ITO/MH-PPV/Al com $L=250 \mathrm{~nm}$ e $L=920$ $\mathrm{nm}$, a primeira variando-se a temperatura de -243 a $27{ }^{\circ} \mathrm{C}$, e a segunda de -143 a $27{ }^{\circ} \mathrm{C}$. A Fig. 7.3-(c) mostra os resultados obtidos com a amostra ITO/PPV/Al com $L=400 \mathrm{~nm}$ variando-se a temperatura de -235 a $47{ }^{\circ} \mathrm{C}$. Todas as medidas foram realizadas no vácuo, no escuro e em um amplo intervalo de tensão. 

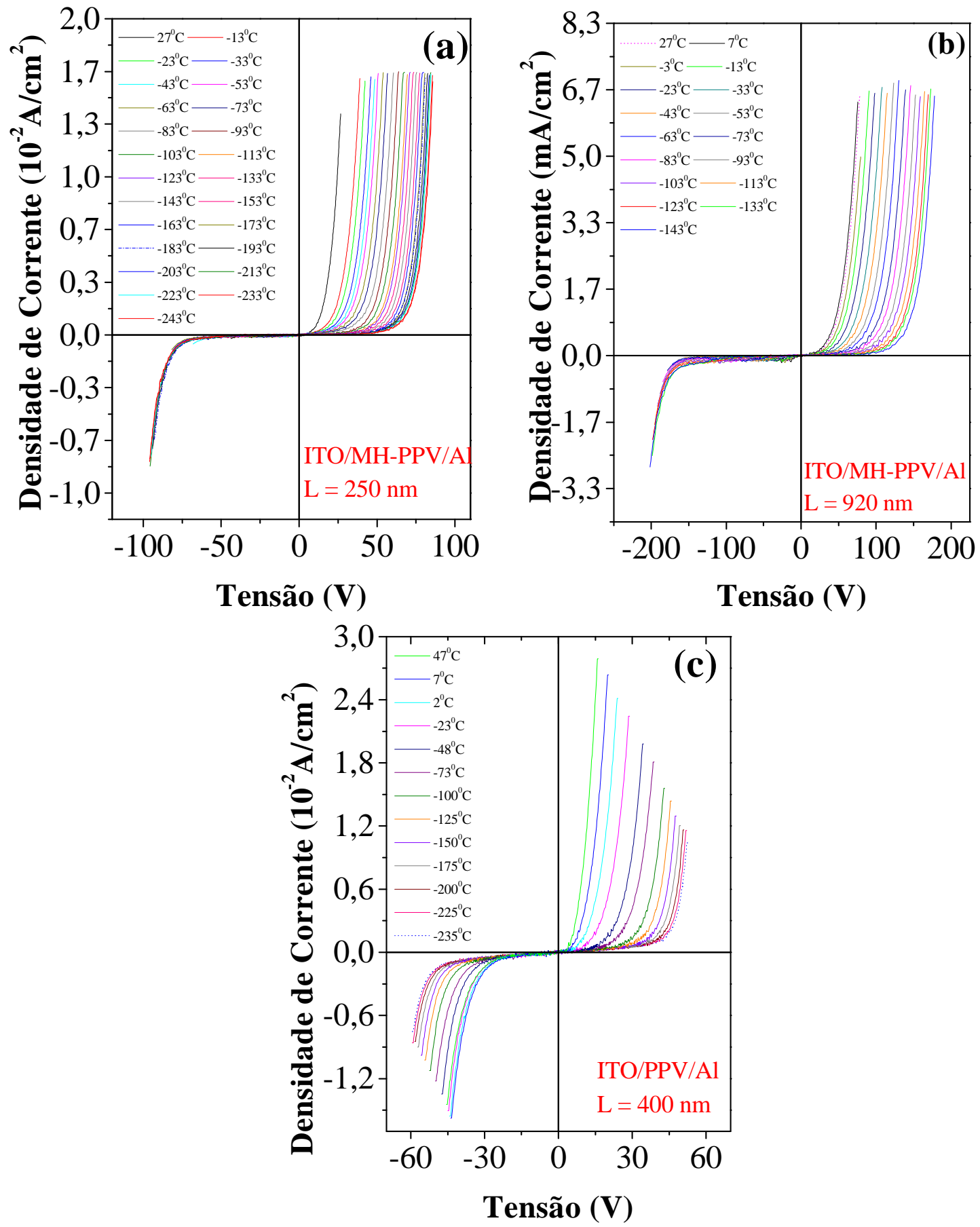

Figura 7.3: Gráficos da densidade de corrente vs. tensão ( $I$ vs. $V$ ) obtidos com as amostras (a) ITO/MH$\mathrm{PPV} / \mathrm{Al}$ com L $=250 \mathrm{~nm}$, (b) ITO/MH-PPV/Al com L $=920 \mathrm{~nm}$ e (c) ITO/PPV/AL com L $=400 \mathrm{~nm} \mathrm{em}$ diferentes temperaturas. As medidas realizadas sob vácuo e na ausência de luz.

As curvas das Figs 7.3 mostram perfeita retificação, sendo $V_{0}$ a tensão de limiar (threshold) do dispositivo. No modo direto observa-se que $V_{0}$ aumenta à medida que a temperatura diminui, concordando com o efeito de injeção controlado por barreira Schottky. Isso vale tanto para o MH-PPV como para o PPV. No modo reverso, semelhante dependência com a temperatura é verificada para o PPV, com a diferença de que a tensão 
limiar agora é bem superior, acima de 30 V. Já para o MH-PPV, verifica-se que a tensão limiar em modo reverso, que ocorre para campos superiores a $10^{6} \mathrm{~V} / \mathrm{cm}$, independe da temperatura. Numa primeira análise, conclui-se que, para o PPV a corrente reversa é dominada por injeção termiônica, enquanto para o MH-PPV ela só aparece quando há campo suficiente para iniciar o mecanismo de tunelamento.

\subsection{Modelo para $J$ vs $V$}

A estrutura morfológica altamente desordenada dos materiais poliméricos é incompatível com o modelo eletrônico de estrutura de bandas usualmente utilizado para explicar resultados de condução, fenômenos de injeção de portadores no polímero pelos eletrodos metálicos numa junção metal-polímero, e mesmo mecanismos de recombinação. No obstante essa incompatibilidade, muitos resultados experimentais têm sido explicados por essa teoria com relativo sucesso. Entretanto, alguns trabalhos ${ }^{[87,88]}$ vêm progredindo com a utilização de modelos mais elaborados, proporcionando uma descrição mais realista dos mecanismos eletrônicos envolvendo transporte e armazenamento de portadores em sistemas poliméricos. No caso específico de fenômenos que se dão nas interfaces metalpolímero, muitos resultados mostram a dificuldade que tem o modelo de injeção termoiônica (Richardson-Schottky) e de tunelamento (Fowler-Nordheim) em bem explicar as curvas $J$ vs $V$ em diodos de polímeros conjugados.

Para explicar nossos resultados de curvas $J v s V$ lançamos mão dos estudos recentes de Conwell e Arkhipov ${ }^{[87,88]}$ que consideram a injeção de portadores do nível de Fermi do metal a estados localizados na superfície do polímero que distam $x_{\mathrm{o}}$ da interface. É considerada uma distribuição de estados localizados na superfície do polímero, cuja densidade de estados obedece a uma distribuição gaussiana $g\left(E^{\prime}\right)$ de energia centrada em $E^{\prime}=0$, com uma variância $\sigma$. O nível de Fermi do metal é assumido estar à uma energia $\Delta$ abaixo do centro da distribuição $g\left(E^{\prime}\right)$. O potencial eletrostático a ser vencido pelo portador é dado por:

$$
U\left(x, E^{\prime}\right)=\Delta-\frac{e^{2}}{16 \pi \varepsilon x}-e F_{o} x+E^{\prime}
$$


onde $F_{o}$ é a intensidade do campo elétrico externo e $\varepsilon$ a permissividade do material polimérico. Sendo, então, $x_{\mathrm{o}}$ a distância medida a partir da interface até um determinado estado localizado no interior do polímero, a densidade de corrente no processo via-hopping fica definida por ${ }^{[88]}$ :

$$
J=e v_{o} \int_{a}^{\infty} d x_{o} \exp \left(-2 \gamma x_{o}\right) w_{e s c}\left(x_{o}\right) \int_{-\infty}^{\infty} d E^{\prime} B o l\left(E^{\prime}\right) g\left[U_{o}\left(x_{o}\right)-E^{\prime}\right]
$$

onde $a$ é o menor valor de $x_{0}, w_{e s c}$ é a probabilidade de um portador evitar a recombinação na superfície, $v_{\mathrm{o}}$ é freqüência de escape do portador no estado localizado, e $\gamma$ é o inverso do comprimento de localização do portador. A função $\operatorname{Bol}(E)$ é definida como:

$$
\operatorname{Bol}(E)=\left\{\begin{array}{l}
\exp \left(-\frac{E}{k T}\right) \text { para } E>0 \\
1 \text { para } E<0
\end{array}\right.
$$

Para determinar $w_{\text {esc }}{ }^{[88]}$ é usada a equação unidimensional de Fokker-Planck focalizada na densidade de portador $p(x)$ sob ação do potencial $U(x)$ :

$$
\frac{d}{d x}\left[-\frac{\mu(x) p(x)}{e} \frac{d U(x)}{d x}-e D \frac{d p(x)}{d x}\right]=e \delta\left(x-x_{o}\right)
$$

onde $\mu$ e D são, respectivamente, a mobilidade e o coeficiente de difusão do portador, e é assumida sua dependência pela relação de Einstein;

$$
\frac{\mu}{D}=\frac{e}{k T}
$$

Finalmente, envolvendo as equações acima num processo de cálculo de substituições e obedecendo a condição de contorno $p(x=a)=0$, se obtém a seguinte expressão para $J$ : 


$$
\begin{aligned}
& J=e v_{o}\left\{\int_{a}^{\infty} d x \exp \left[-\frac{e}{k T}\left(F_{o} x+\frac{e}{16 \pi \varepsilon x}\right)\right]\right\}^{-1} \times \\
& \int_{a}^{\infty} d x_{o}\left\{\exp \left(-2 \gamma x_{o}\right) \int_{a}^{x_{o}} d x \exp \left[-\frac{e}{k T}\left(F_{o} x+\frac{e}{16 \pi \varepsilon x}\right)\right]\right\}_{-\infty}^{\infty} d E^{\prime} B o l\left(E^{\prime}\right) g\left[U\left(x_{o}\right)-E^{\prime}\right]
\end{aligned}
$$

Essa expressão foi usada para ajustar a curva a $27^{\circ} \mathrm{C}$, em modo direto, mostrada na Fig. 7.3-(a). A Fig. 7.4 mostra esses ajustes, tendo como parâmetros os seguintes valores: $\sigma=0,08 \mathrm{eV}, \gamma=10^{8} \mathrm{~cm}^{-1}, \Delta=0,4 \mathrm{eV} \mathrm{e} \mathrm{K}=\varepsilon / \varepsilon_{0}=3$. Todos os parâmetros obtidos são compatíveis com as propriedades do material e próximos a muitos encontrados na literatura $^{[87-89]}$.

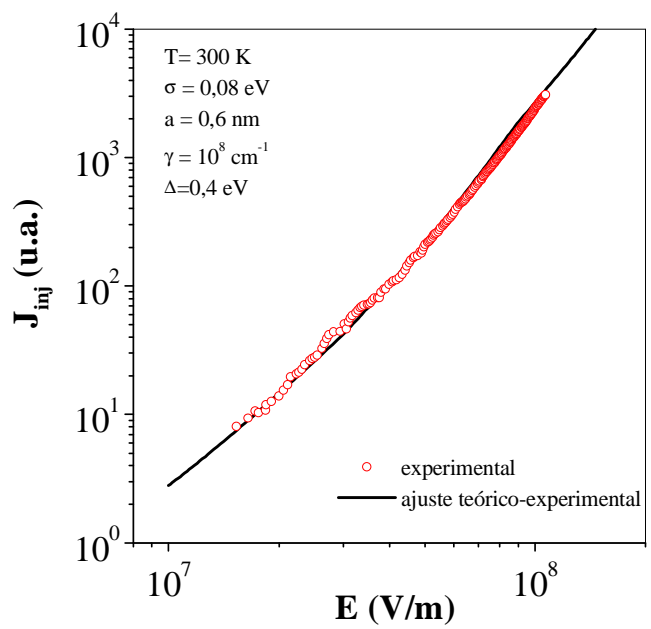

Figura 7.4: $J$ vs. $V$ da amostra ITO/MH-PPV/Al $\operatorname{com} L=250 \mathrm{~nm}$ em temperatura ambiente. A linha contínua é o resultado do ajuste pela Eq. (7.6).

\subsection{Espectros de Eletroluminescência}

Introduzimos esse tópico para apresentar os resultados de luminescência de nossos dispositivos, os quais estamos estudando do ponto de vista elétrico nesse capítulo.

A Fig. 7.5 mostra os espectros de eletroluminescência obtidos com PLEDs de ITO/MH-PPV/Al e ITO/PPV/Al. As amostras utilizadas foram às mesmas caracterizadas por medidas corrente vs. tensão, Figs. 7.3-(b) e (c). A espessura do filme de PPV é cerca de 2,5 vezes menor que a espessura do filme de MH-PPV, daí o motivo das tensões aplicadas no PLED de MH-PPV serem maiores que as aplicadas no PLED de PPV. As medidas foram realizadas em $0{ }^{\circ} \mathrm{C}$ com o MH-PPV, e em $27{ }^{\circ} \mathrm{C}$ com o PPV. 

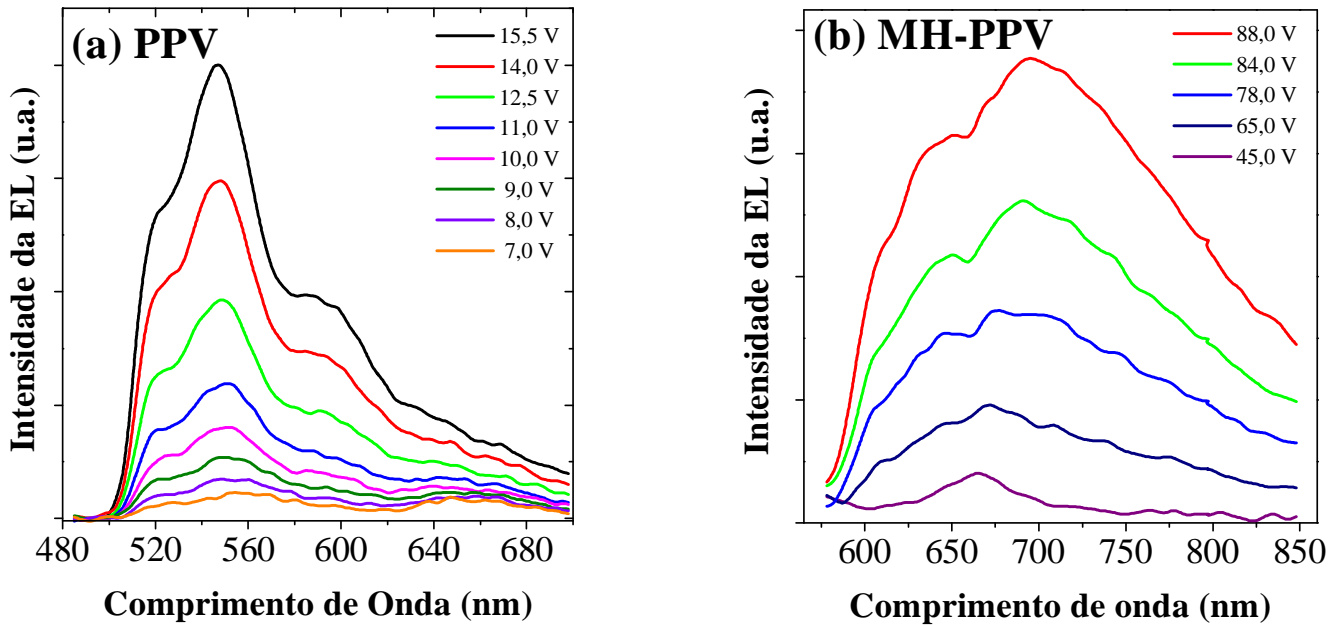

Figura 7.5: Espectros de Eletroluminescência obtidos com (a) ITO/PPV/Al $(L=400 \mathrm{~nm})$ e (b) ITO/MHPPV/Al $(L=920 \mathrm{~nm})$ com diferentes tensões. Medidas realizadas sob vácuo, a $27{ }^{\circ} \mathrm{C}$ para o $\mathrm{PPV}$ e $0{ }^{\circ} \mathrm{C}$ para o MH-PPV.

A Fig. 7.6 mostra que a intensidade total de emissão dos dispositivos é linearmente proporcional à corrente que o atravessa, mostrando, assim, uma relação direta entre a taxa de injeção de portadores com a recombinação responsável pela emissão de luz.
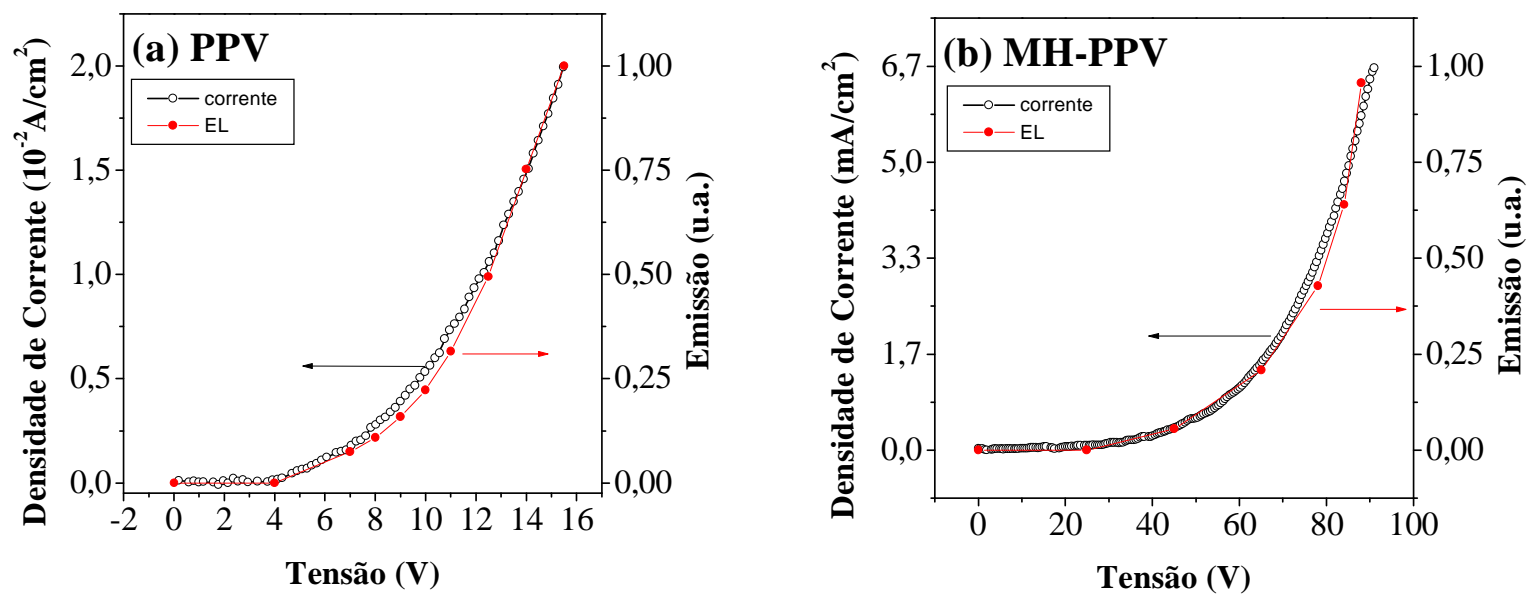

Figura 7.6: Curvas $J$ vs. $V$ e Emissão total vs. $V$ obtidas com os dispositivos (a) ITO/PPV/Al e (b) ITO/MHPPV/Al a partir dos gráficos das Figs. 7.3-(a), 7.3-(b) e 7.5.

\subsection{Medidas de Impedância Complexa}

Medidas de impedância complexa $\left(Z^{*}=Z^{\prime}-i Z^{\prime \prime}\right)$ foram realizadas nas amostras ITO/MH-PPV/Au e ITO/MH-PPV/Al caracterizadas por medidas $J$ vs. $V$, item 7.1. Também foram realizadas medidas em uma amostra Au/MH-PPV/Au auto-sustentável, 
preparada por casting. O objetivo dessas medidas é estudar o processo de transporte no dispositivo, levando-se em conta o efeito da espessura do filme polimérico, dos materiais usados como eletrodos e da polaridade da tensão aplicada. Foram realizadas medidas variando-se a amplitude da tensão elétrica oscilante $\left(V_{a c}\right)$ e a tensão de polarização $\left(V_{\text {bias }}\right)$ das amostras, em um intervalo de frequiência de 0,1 a 2,0 MHz. Todas as medidas foram realizadas a temperatura ambiente, no escuro, sob vácuo de $10^{-1}$ Torr e com umidade relativa de $10 \%$.

A Fig. 7.7 apresenta os resultados dos componentes $Z$ ' e $Z$ " obtidas com as amostras: (a) Au/MH-PPV/Au $(L=14 \mu \mathrm{m})$, (b) ITO/MH-PPV/Au $(L=400 \mathrm{~nm}),(\mathrm{c})$ ITO/MH-PPV/Al $(L=5 \mu \mathrm{m})$ e (d) ITO/PPV/Al $(L=400 \mathrm{~nm})$. As medidas foram realizadas com $V_{a c}=50 \mathrm{mV}$ e $V_{\text {bias }}=0 \mathrm{~V}$, em temperatura ambiente e com umidade relativa de $10 \%$.

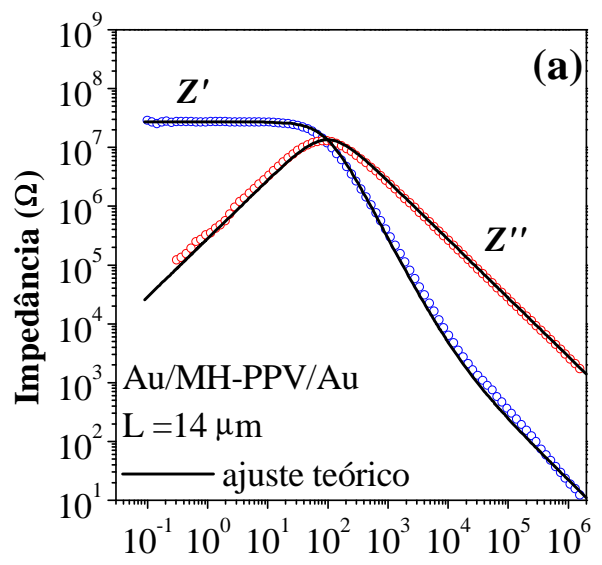

Freqüência $(\mathbf{H z})$

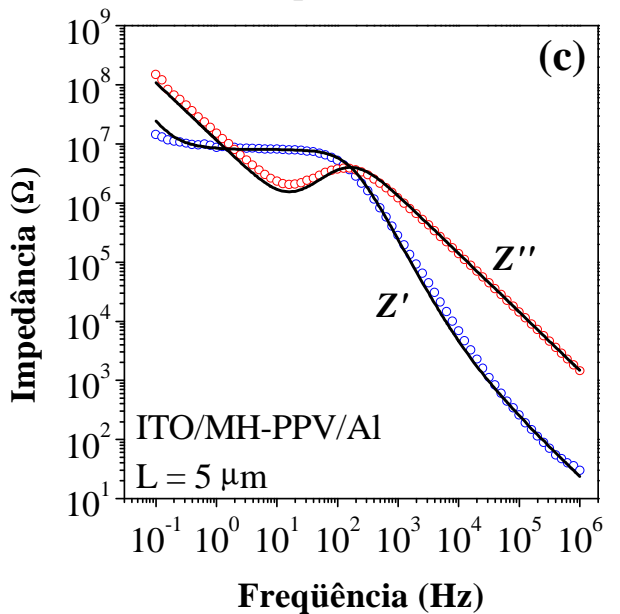

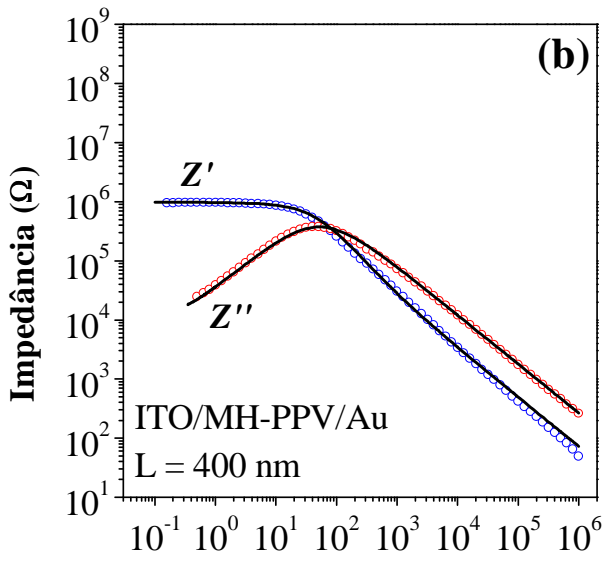

Freqüência $(\mathbf{H z})$

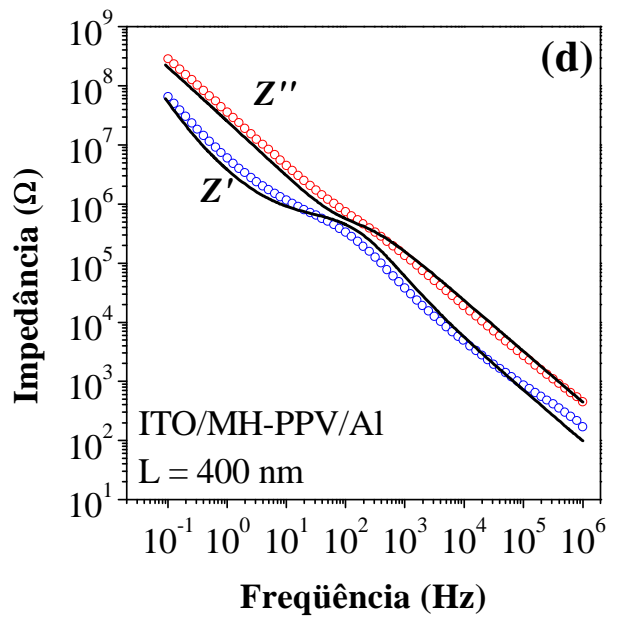

Figura 7.7: Gráficos $Z$ ' e $Z$ ' vs. $f$ das amostras: (a) Au/MH-PPV/Au $(L=14 \mu \mathrm{m}$ ), (b) ITO/MH-PPV/Au ( $L=400 \mathrm{~nm})$, (c) ITO/MH-PPV/Al $(L=5 \mu \mathrm{m})$ e (d) ITO/PPV/Al $(L=400 \mathrm{~nm})$. Medidas realizadas com $V_{a c}=50 \mathrm{mV}, V_{\text {bias }}=0 \mathrm{~V}$, no vácuo, com umidade relativa de $10 \%$ e no escuro. As linhas contínuas são os ajustes pela Eq. (7.10). 
Para a amostra Au/MH-PPV/Au, Fig. 7.7-(a), observamos que, para baixas frequiências, $Z$ ' permanece constante e próximo de $2 \times 10^{7} \Omega$, até atingir um valor crítico de freqüência $(f)$, em torno de $100 \mathrm{~Hz}$, quando passa a diminuir suavemente $\operatorname{com} f$. Já a componente imaginária apresenta um pico de máximo também em torno de $100 \mathrm{~Hz}$. Para facilitar a comparação dos resultados, denominaremos $Z_{0}$ como o valor da impedância real independente de $f$ na região de baixas freqüências, e $f_{c}$ como o valor da frequiência crítica a partir da qual $Z$ ' começa a decair com $f$, ou $Z$ ” apresenta um máximo. Para a amostra ITO/MH-PPV/Au com $L=400 \mathrm{~nm}$, Fig. 7.7-(b), observa-se que $Z$ ' e $Z$ " têm a mesma dependência com a freqüência daquela da amostra anterior, com $f_{c}$ em torno de $50 \mathrm{~Hz}$ e $Z_{0}$ em torno de $10^{6} \Omega$. Para a amostra ITO/MH-PPV/Al com $L=5 \mu \mathrm{m}$, Fig. 7.7-(c), observase que acima de $20 \mathrm{~Hz}, Z$ ' e $Z$ ” têm a mesma dependência com a freqüência observada da amostra Au/MH-PPV/Au, com valor de $f_{c}$ próximo de $200 \mathrm{~Hz}$ e $Z^{\prime} \approx 10^{7} \Omega$ em $20 \mathrm{~Hz}$. Entretanto, abaixo de $20 \mathrm{~Hz}, Z$ " passa a aumentar com $f$ e $Z$ ' repete o patamar, mas apresenta um ligeiro aumento abaixo de 0,2 Hz. Por último, as medidas de Z' e Z” obtidos com a amostra fina ITO/MH-PPV/Al, Fig. 7.7-(d), apresenta um comportamento quasilinear com a freqüência em todo intervalo medido, aparecendo em $Z^{\prime}$ um ponto de inflexão em torno de $100 \mathrm{~Hz}$.

De todos os resultados de impedanciometria fica claro que os metais usados como eletrodos, assim como a espessura das amostras, tem papel importante no comportamento de $Z$ ' e $Z$ ” com a freqüência. As medidas de $Z$ ' e $Z$ '” obtidas com as amostras com eletrodos de ouro, Figs. 7.7-(a) e 7.7-(b), apresentam o comportamento típico de sistemas sólidos desordenados ${ }^{[73]}$, onde $Z_{0}$ é independe da freqüência em baixos valores de $f$, e tendo resistividade calculada por $\rho=A Z_{0} / \mathrm{L}$ em torno de $6 \times 10^{9} \Omega \mathrm{cm}$, coincidente com o valor obtido a partir do gráfico $J$ vs. $V$, Fig. 7.1.

Para a amostra ITO/MH-PPV/Al espessa $(L=5 \mu \mathrm{m})$, Fig. 7.7-(c), a resistividade do material é obtida tomando-se $Z_{0}=2 \times 10^{7} \Omega$ em torno de $20 \mathrm{~Hz}$, o que forneceu $\rho=2,0 \times 10^{9} \Omega \mathrm{cm}$, também da ordem do valor obtido através da curva $J v s$. $V$, Fig. 7.1. Esse resultado mostra que os processos de volume em amostras espessas de MH-PPV com eletrodos de alumínio são observados acima de $20 \mathrm{~Hz}$, sendo que, abaixo desse valor de frequiência a resistência de contato MH-PPV/Al domina nos gráficos de impedância.

Para a amostra ITO/MH-PPV/Al fina $(L=400 \mathrm{~nm})$, Fig. 7.7-(d), tomando-se o valor da impedância real na frequiência do ponto de inflexão, obtemos $\rho=5,0 \times 10^{9} \Omega \mathrm{cm}$, que também coincide com os valores da resistividade do polímero. Esse resultado mostra 
que a resistividade da região de contato $\mathrm{MH}-\mathrm{PPV} / \mathrm{Al}$ é bastante influente nas curvas de impedância, isto porque a impedância real abaixo dessa frequiência (em torno de $100 \mathrm{~Hz}$ ) continua aumentando, chegando a duas ordens de grandeza superior em $f=0,1 \mathrm{~Hz}$, em comparação com as outras amostras, e sobrepondo-se sobre o efeito de volume próximo a $20 \mathrm{~Hz}$.

Portanto, podemos concluir que a partir de medidas de impedanciometria é possível separar os processo de condução de volume dos de interface. Acima de $20 \mathrm{~Hz}$ temos a curva governada pelo volume do polímero e, abaixo dessa freqüência, pela resistência da interface $\mathrm{MH}-\mathrm{PPV} / \mathrm{Al}$, que apresenta a maior resistividade. Amostras finas, por sua vez, ainda apresentam sobreposição desses dois processos em torno de $20 \mathrm{~Hz}$ e resistência de contato MH-PPV/Al maior do que a observada em amostras espessas.

Uma das alternativas usadas para identificar os tempos de relaxação associados a uma medida de impedância complexa é a visualização do gráfico Z' e Z” em diagramas de Argand $^{[90]}$, que consiste em representar esses componentes em gráficos do tipo $Z$ ' vs. $Z$ '. A Fig. 7.8 apresenta os resultados mostrados na Fig. 7.7 em gráficos desse tipo.
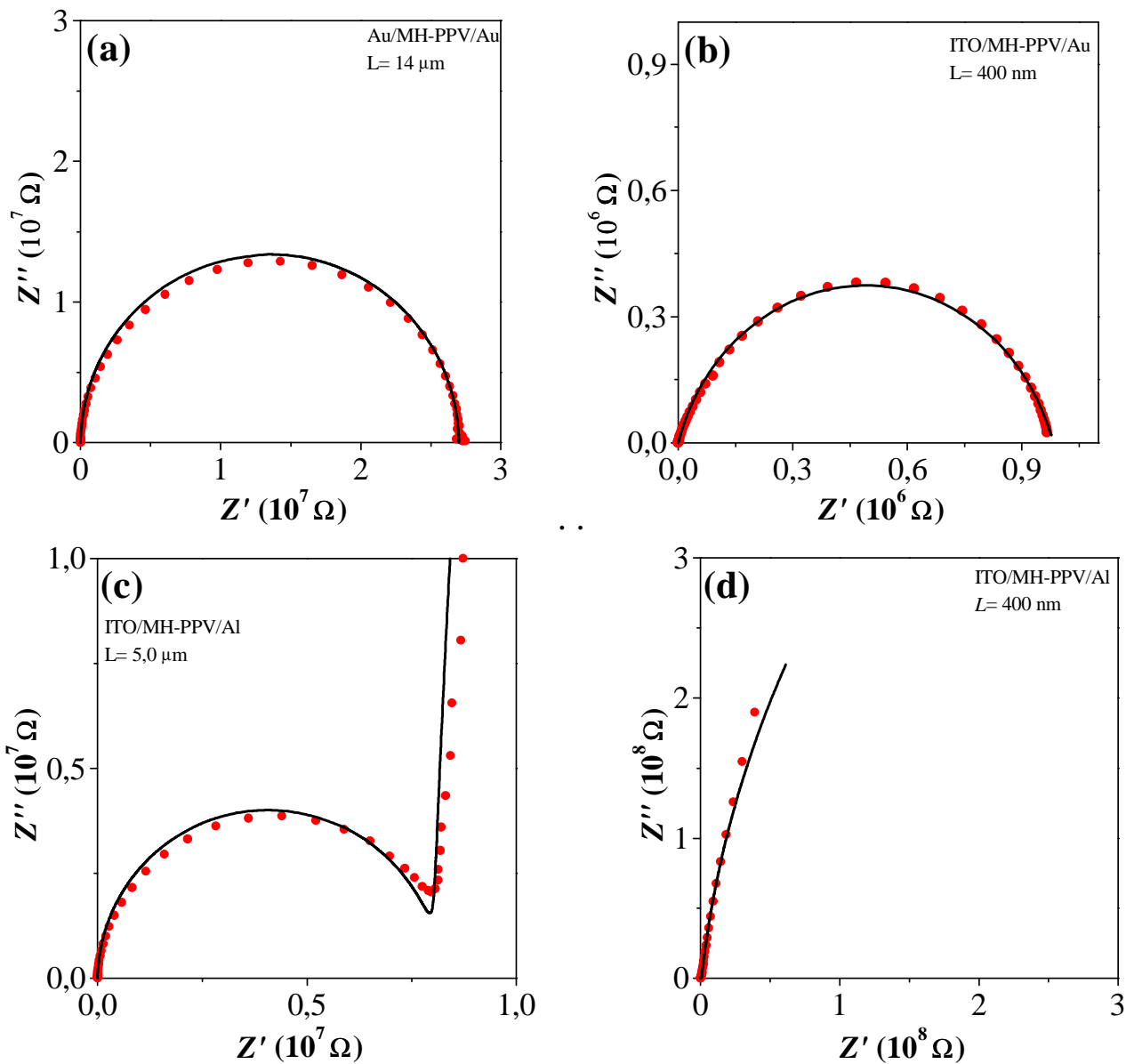

Figura 7.8: Gráficos Z’ vs. Z” das amostras apresentadas na Fig. 7.7. As linhas contínuas são os ajustes pela Eq. (7.10). 
Nas Figs. 7.8-(a) e (b), os componentes de Z" obtidos com as amostras $\mathrm{Au} / \mathrm{MH}-\mathrm{PPV} / \mathrm{Au}$ e ITO/MH-PPV/Au apresentam o comportamento de um semicírculo de diâmetro em torno de, respectivamente, $2,7 \times 10^{7} \Omega$ e $1,0 \times 10^{6} \Omega$, enquanto a amostra ITO/MH-PPV/Al ( $\mathrm{L}=5 \mu \mathrm{m})$, Fig. 7.8-( c) apresenta a tendência a um semicírculo, com diâmetro em torno de $9 \times 10^{6} \Omega$, seguido de um aumento quasi-linear de $Z$ ” com $Z$ ' na região de altas impedâncias reais (ou baixas freqüências). Desses resultados observamos que os valores dos diâmetros são coincidentes aos valores de $Z_{0}$. Como conclusão, gráficos desse tipo separam muito bem os efeitos de interface dos de volume: acima de $Z_{0}$ a curva é dominada pelos efeitos de interface e, abaixo, pelo de volume. Em especial a amostra ITO/MH-PPV/Al ( $L=400 \mathrm{~nm})$, Fig. 7.8-(d), sendo a resistência da interface MH-PPV/Al muito grande, o seu efeito se sobrepõe ao de volume em todo intervalo de impedância obtida, de modo que a identificação desse último processo não é verificada.

Já que a corrente varia muito nos dispositivos tendo ITO como um dos eletrodos quando polarizado positivamente, Fig. 7.2-(b), e que o comportamento da impedância apresentou dependência com a espessura e com o eletrodo de alumínio, repetimos os experimentos de impedanciometria sob diferentes tensões de polarização $\left(V_{\text {bias }}>0\right)$ na amostra ITO/MH-PPV/Al com L $=400 \mathrm{~nm}$. A título de comparações apresentamos curvas com $V_{\text {bias }}=0$ para diferentes amplitudes da tensão alternada $V_{a c}$, e também curvas com $V_{\text {bias }}$ em modo reverso $\left(V_{\text {bias }}<0\right)$.

Os gráficos da Fig. 7.9 apresentam os componentes $Z$ ' e $Z$ ' obtidos com a amostra ITO/MH-PPV/Al ( $L=400 \mathrm{~nm})$. As Figs. 7.9-(a.1) e 7.9-(a.2) mostram os resultados obtidos com $V_{\text {bias }}=0 \mathrm{~V}$ e $V_{a c}$ variando de $50 \mathrm{mV}$ a 3,0V. As Figs. 7.9-(b.1) e 7.9-(b.2) com $V_{a c}=50 \mathrm{mV}$ e $V_{\text {bias }}$ variando de 0 a $4 \mathrm{~V}$ e, por último, as Figs. 7.9-(c.1) e 7.9-(c.2) com $V_{a c}=50 \mathrm{mV}$ e $V_{\text {bias }}$ variando de $0 \mathrm{a}-4 \mathrm{~V}$. 


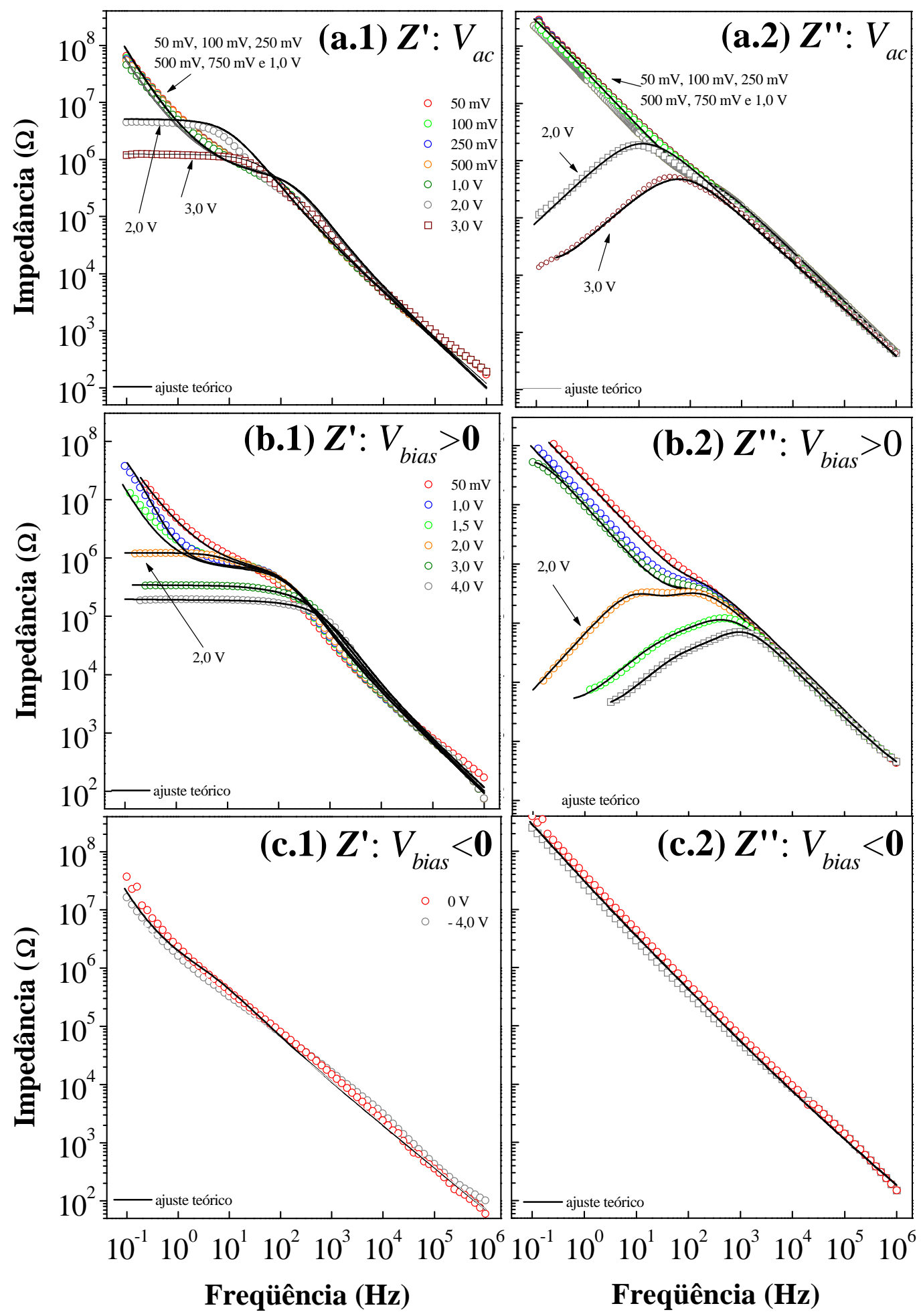

Figura 7.9: Z' e Z" vs. $f$ como função de $V_{a c}$ e $V_{\text {bias }}$ obtidos com a amostra ITO/MH-PPV/Al $(L=400 \mathrm{~nm})$ : (a.1) e (a.2) com $V_{a c}$ variando de $50 \mathrm{mV}$ a 3,0 V, (b.1) e (b.2) para $V_{\text {bias }}$ variando de 0 a $4 \mathrm{~V}$, e (c.1) e (c.2) para $V_{\text {bias }}$ igual a 0 e $-4 \mathrm{~V}$. As medidas foram obtidas no escuro, em temperatura ambiente e com umidade relativa controlada de $10 \%$. 
Nas curvas da Fig. 7.9, observa-se que a impedância real e imaginária independem de $V_{\text {bias }}$ ou $V_{a c}$ para tensões abaixo de $2 \mathrm{~V}$. Entretanto, acima dessa tensão, Z'e Z" passam a cair à medida que a $V_{\text {bias }}$ ou $V_{a c}$ aumentam. Por outro lado, quase nenhuma variação foi observada com $V_{\text {bias }}$ em modo reverso. É importante ressaltar que houve uma mudança significativa nos comportamentos das curvas Z' e Z" na transição de $V_{a c}$ e $V_{\text {bias }}$ entre 1,5 e $2 \mathrm{~V}$. Para tensões acima de $2 \mathrm{~V}$ o tradicional patamar em $Z^{\prime}$ em baixas freqüências é observado, com a freqüência crítica aumentando com o valor de $V_{b i a s}$ ou $V_{a c}$ aplicados, enquanto que a curva Z", que decrescia continuamente com o aumento da freqüência, passa a decair com um máximo em torno de $f_{c}$ ".

A Fig. 7.10 mostra diagramas de Argand, Z" vs. Z', obtidos a partir dos resultados apresentados nas Figs. 7.9. Na Fig. 7.10-(a) tem-se a variação de $V_{a c}$, na Fig. 7.10-(b) a variação de $V_{\text {bias }}$ positivamente, e na Fig. 7.10-(c) a variação de $V_{\text {bias }}$ negativamente.

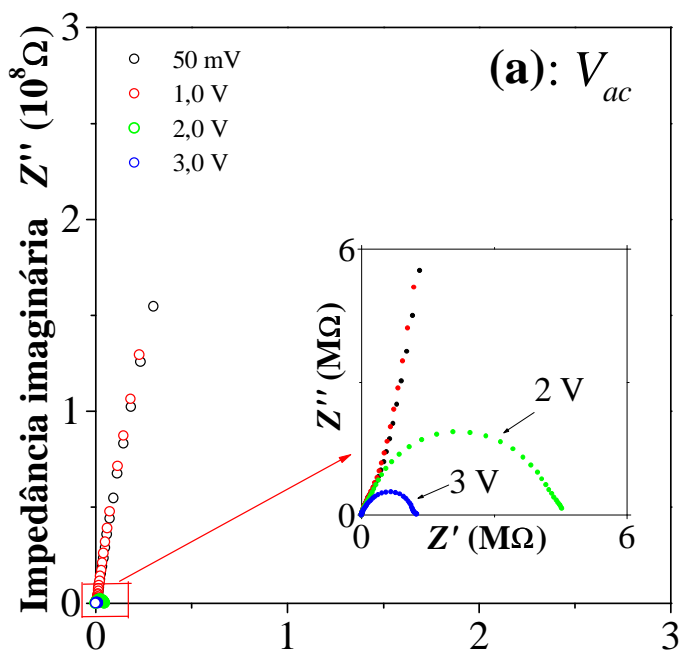

Impedância real $Z^{\prime}\left(10^{8} \Omega\right)$

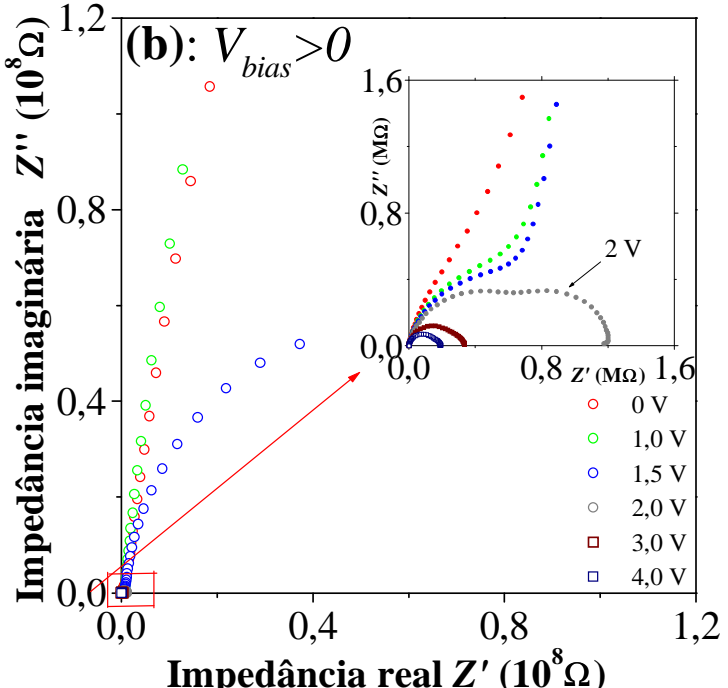

Impedância real $Z^{\prime}\left(10^{8} \Omega\right)$

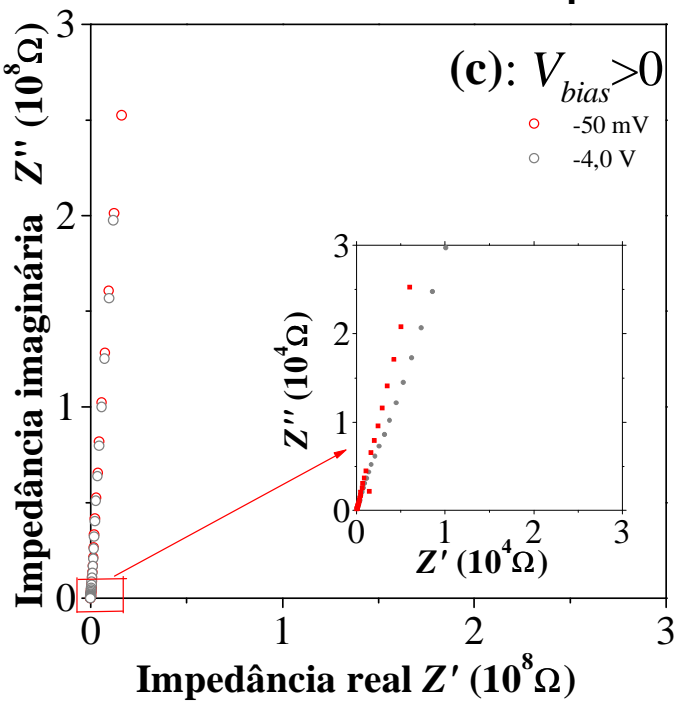

Figura 7.10: Gráficos $Z^{\prime \prime} v s$. $Z$ ' variando-se (a) $V_{a c}$, (b) $V_{\text {bias }}$ positivamente e (c) $V_{\text {bias }}$ negativamente com a amostra ITO/MH-PPV/Al $(\mathrm{L}=400 \mathrm{~nm})$. A Fig. 7.9 apresentou esses resultados em gráficos de Z' e Z' vs. $f$. 
Variando-se $V_{a c}$, Figs. 7.10-(a), a componente $Z$ ” aumenta quasi-linearmente com $\mathrm{Z}$ ', mas passa a se comportar como um semicirculo para tensões acima de $2 \mathrm{~V}$, diminuindo de diâmetro à medida que $V_{a c}$ aumenta. Resultados semelhantes foram obtidos variando-se $V_{\text {bias }}$ positivamente, Fig. 7.10-(b). Entretanto, para $V_{\text {bias }}=2 \mathrm{~V}$, a superposição de dois semicírculos é observada e, a medida que a tensão aumenta, Z' tende a semicírculos com diâmetros cada vez menores. Com $V_{\text {bias }}$ variando negativamente, Fig. 7.10-(c), o comportamento $Z$ ” praticamente não apresentou variação com a tensão aplicada.

Nas inserções nas Fig. 7.10-(a) e (b), observamos com clareza a grande redução que ocorre na impedância do dispositivo quando a tensão atinge $2 \mathrm{~V}$ ( $V_{a c}$ ou $V_{\text {bias }}$ direto). Esse fenômeno deve estar relacionado ao súbito aumento do processo de injeção pelo eletrodo de alumínio, provavelmente devido ao aparecimento do mecanismo de tunelamento. Aumentando-se ainda mais o valor da tensão, essa impedância tende a um valor de cerca de três ordens de grandeza menor do que o valor obtido com tensões menores que $2 \mathrm{~V}$.

\subsection{Modelo para a Impedância}

De um modo geral, o estudo do comportamento da impedância complexa por circuitos equivalentes é uma maneira simples e usual para descrever as características elétricas de uma amostra entre dois eletrodos em uma estrutura plana e paralela ${ }^{[91,92]}$. Capacitores e resistores associados de diversas maneiras têm sido usados como sistemas equivalentes na descrição do comportamento de condução e armazenamento de cargas em materiais não condutores. Resistores são usualmente utilizados para representar a resistividade de um dado material, ou a resistência da interface entre dois materiais à passagem de corrente. Capacitores, por sua vez, são usados para representar o acúmulo de cargas nessas interfaces, definindo tempos de relaxação característicos das estruturas estudadas. Entretanto, muitos podem ser os circuitos equivalentes para representar a impedância complexa de um dado sistema, porém, a simplicidade do circuito e a consistência dos elementos escolhidos com os processos físicos envolvidos devem sempre ser levados em consideração.

Considerando que os nossos sistemas metal/polímero/metal, nas faixas de tensões aplicadas, se comportam como diodos, onde um só portador é móvel, vamos representá-los por um circuito equivalente com uma série de dois RCs paralelos, simbolizando um o volume do material e o outro a interface que forma uma região com portadores 
aprisionados em armadilhas, definindo uma região de depleção. Além disso, há um resistor em série representando a resistência da outra interface, em geral MH-PPV/ITO. A Fig. 7.11 ilustra esse circuito.

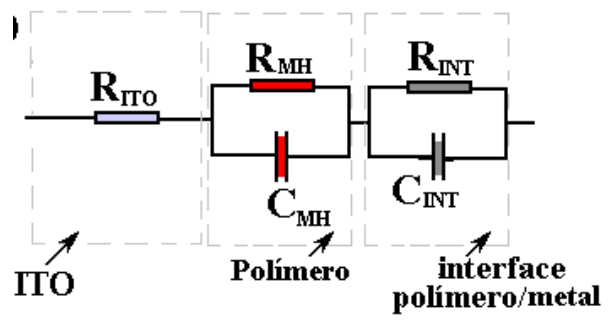

Figura 7.11: Representação do sistema ITO/MH-PPV/metal em termos de um circuito equivalente ${ }^{[91,92]}$.

Nessa representação simples, podemos escrever a expressão para a impedância complexa por:

$$
\mathrm{Z}^{*}=\frac{\mathrm{R}_{\mathrm{int}}}{1+\mathrm{i} \omega \mathrm{R}_{\mathrm{int}} \mathrm{C}_{\mathrm{int}}}+\frac{\mathrm{R}_{\mathrm{MH}}}{1+\mathrm{i} \omega \mathrm{R}_{\mathrm{MH}} \mathrm{C}_{\mathrm{MH}}}+\mathrm{R}_{\text {Iто }}
$$

onde $R_{I N T}$ e $C_{I N T}$ representam a resistência e a capacitância da interface polímero/metal, $R_{M H}$ e $C_{M H}$ a resistência e a capacitância do polímero, $R_{I T O}$ a resistência do ITO, e $\omega=2 \pi f$. Tomando-se $\tau=R C$ como o tempo de relaxação, característico de cada um dos circuitos equivalentes, reescrevemos a Eq. (7.7) como:

$$
\mathrm{Z}^{*}=\frac{\mathrm{R}_{\text {int }}}{1+\mathrm{i} \omega \tau_{\text {int }}}+\frac{\mathrm{R}_{\mathrm{MH}}}{1+\mathrm{i} \omega \tau_{M H}}+\mathrm{R}_{\text {Іто }}
$$

que decomposta em componentes real e imaginária resulta em:

$$
\mathrm{Z}^{*}=Z^{\prime}+\mathrm{i} Z^{\prime \prime}=\left(\frac{\mathrm{R}_{\mathrm{int}}}{1+\omega^{2} \tau_{\mathrm{int}}{ }^{2}}+\frac{\mathrm{R}_{\mathrm{MH}}}{1+\omega^{2} \tau_{M H}{ }^{2}}+\mathrm{R}_{\mathrm{ITO}}\right)-\mathrm{i}\left(\frac{\omega \tau_{\mathrm{int}}}{1+\omega^{2} \tau_{\mathrm{int}}{ }^{2}}+\frac{\omega \tau_{M H}}{1+\omega^{2} \tau_{M H}{ }^{2}}\right)
$$

Entretanto, o modelo não foi satisfatório no ajuste das curvas de impedância complexa mostradas nas Figs. 7.7 e 7.9. Na maioria dos casos a inclinação da componente Z' da expressão, em gráficos Z' vs. $f$, divergiu dos resultados experimentais. Para solucionar esse problema, fizemos uso de uma descrição empírica que leva em conta uma distribuição de tempos de relaxação dielétrica, em substituição ao modelo que considera um único $\tau$. Nesse caso, uma representação matemática equivalente se dá pela simples substituição do termo $i \omega \tau$ da Eq. (7.7) por um termo $(i \omega \tau)^{1-\alpha}$, com $0 \leq \alpha \leq 1^{[90]}$. Essa suposição, além de mais realista, fornece uma distribuição simétrica de tempos de 
relaxação, e facilita enormemente o desenvolvimento de modelos mais complexos. Utilizando esse novo termo, a Eq. (7.7) passa a ser reescrita como:

$$
Z^{*}=\frac{R_{i n t}}{1+\left(i \omega R_{i n t} C_{i n t}\right)^{1-\alpha_{i n t}}}+\frac{R_{M H}}{1+\left(i \omega R_{M H} C_{M H}\right)^{1-\alpha_{M H}}}+R_{I T O}
$$

que se reduz à própria Eq. (7.7) quando $\alpha_{\text {int }}$ e $\alpha_{\mathrm{MH}}$ são iguais a zero, e à $Z^{*}=Z^{\prime}=R_{i n t}+$ $R_{M H}+R_{\text {ITO }}$ quando $\omega \rightarrow 0$.

O modelo de circuitos equivalentes, embora simples, é de grande importância para se obter, em primeira análise, as características das interfaces, a constante dielétrica e a resistividade da camada polimérica, a partir de $\mathrm{C}_{\mathrm{MH}}$ e $\mathrm{R}_{\mathrm{MH}}$, respectivamente. Entretanto, quando $\alpha_{\mathrm{MH}} \neq 0$, uma descrição mais detalhada sobre os mecanismos microscópicos de condução de volume no polímero pode ser obtida substituindo-se o circuito $R C$ correspondente à camada polimérica pela expressão da condutividade do modelo RFEB apresentado no item 5.3.1, Eq. (5.11). Utilizando esse modelo, reescrevemos a Eq. (7.10) como:

$$
\sigma^{*}(\omega)=\frac{\ell}{A} \frac{1}{Z^{*}}=\frac{\ell}{A}\left[\frac{1}{\frac{\ell}{A} \frac{1}{\sigma_{M H}^{*}}+\frac{R_{\text {int }}}{1+\left(i \omega R_{\text {int }} C_{\text {int }}\right)^{1-\alpha_{\text {int }}}}+R_{\text {ITO }}}\right]
$$

que representa a condutividade de um diodo com a interface MH-PPV/metal descrita por um circuito RC paralelo e a condutividade do polímero pelo modelo RFEB.

Entretanto, essa equação também não foi satisfatória para os ajustes das curvas experimentais. Para solucionar esse problema alguns trabalhos sobre mecanismos de condução em sistemas sólidos têm mostrado que esses materiais podem apresentar uma função resposta dielétrica da forma $G(\omega)=\omega K \varepsilon_{0} i^{[93]}$, proveniente da polarização do sistema e com $K$ a constante dielétrica do material. Dessa forma, reescrevendo a Eq. (7.11) com esse novo termo, obtemos:

$$
\sigma^{*}(\omega)=\frac{\ell}{A} \frac{1}{Z^{*}}=\frac{\ell}{A}\left[\frac{1}{\frac{\ell}{A} \frac{1}{\sigma_{M H}^{*}+\omega K \varepsilon_{0} i}+\frac{R_{\text {int }}}{1+\left(i \omega R_{\text {int }} C_{\text {int }}\right)^{1-\alpha_{\text {int }}}}+R_{I T O}}\right]
$$


que passa a ser a equação que representa a condutividade do diodo com a condução na camada polimérica representada pelo modelo RFEB associado a uma resposta dielétrica $G(\omega)$.

\subsection{Resultados dos Ajustes}

Nesse item apresentamos uma série de resultados experimentais Z' $(f), Z^{\prime \prime}(f)$ e Z" $v s$. Z', ajustados pelas Eqs. (7.10) e (7.12).

No item 7.4, as Figs. 7.7 e 7.8 apresentam os ajustes dos componentes Z' $(f)$ e Z'” $(f)$ ajustados pela Eq. (7.10), além dos resultados experimentais obtidos com as amostras $\mathrm{Au} / \mathrm{MH}-\mathrm{PPV} / \mathrm{Au}, \mathrm{ITO} / \mathrm{MH}-\mathrm{PPV} / \mathrm{Au}$ e ITO/MH-PPV/Al. A Tabela 7.I apresenta os parâmetros obtidos. A tabela também apresenta os valores da resistividade e da constante dielétricas obtidas a partir de, respectivamente, $\mathrm{R}_{\mathrm{MH}}$ e $\mathrm{C}_{\mathrm{MH}}$.

Tabela 7.I: Parâmetros de ajustes dos componentes Z' e Z', através da Eq. (7.10), das amostras $\mathrm{Au} / \mathrm{MH}-\mathrm{PPV} / \mathrm{Au}(L=14 \mu \mathrm{m})$, ITO/MH-PPV/Au $(L=400 \mathrm{~nm})$, ITO/MH-PPV/Al espessa $(L=5 \mu \mathrm{m}) \mathrm{e}$ ITO/MH-PPV/Al $(L=400 \mathrm{~nm})$.

\begin{tabular}{||c|c|c|c|c||}
\hline Amostra & Au/MH-PPV/Au & ITO/MH-PPV/Au & ITO/MH-PPV/AI & ITO/MH-PPV/AI \\
\hline Espessura & $14 \mu \mathrm{m}$ & $400 \mathrm{~nm}$ & $5 \mu \mathrm{m}$ & $400 \mathrm{~nm}$ \\
\hline $\mathbf{R}_{\text {int }}(\Omega)$ & - & - & $9 \times 10^{8}$ & $1,5 \times 10^{9}$ \\
\hline $\mathbf{C}_{\mathbf{I N T}}(\mathbf{F})$ & - & - & $1,5 \times 10^{-8}$ & $8,5 \times 10^{-9}$ \\
\hline$\alpha_{\text {INT }}$ & - & - & 0,01 & 0,07 \\
\hline $\mathbf{R}_{\mathbf{M H}}(\Omega)$ & $2,8 \times 10^{7}$ & $9,5 \times 10^{5}$ & $8,0 \times 10^{6}$ & $6,5 \times 10^{5}$ \\
\hline $\mathbf{C}_{\mathbf{M H}}(\mathbf{F})$ & $6,0 \times 10^{-11}$ & $2,5 \times 10^{-9}$ & $1,2 \times 10^{-10}$ & $1,5 \times 10^{-9}$ \\
\hline$\alpha_{\mathbf{M H}}$ & 0,05 & 0,17 & 0,02 & 0,15 \\
\hline$\rho(\Omega \mathbf{c m})$ & $6,0 \times 10^{9}$ & $7,1 \times 10^{9}$ & $4,8 \times 10^{9}$ & $4,9 \times 10^{9}$ \\
\hline $\mathbf{K}$ & 3,2 & 3,7 & 2,3 & 2,3 \\
\hline
\end{tabular}

Da tabela 7.I observamos que nos ajustes obtidos das curvas da amostra Au/MH-PPV/Au e ITO/MH-PPV/Au, Fig. 7.7-(a) e (b) foi usado único circuito RC paralelo, isto é, com $\mathrm{R}_{\mathrm{ITO}}=\mathrm{R}_{\mathrm{INT}}=\mathrm{C}_{\mathrm{INT}}=0$. Já para as amostras com eletrodo de alumínio, Fig. 7.7-(c) e (d), foi necessário o uso do segundo circuito RC, que mostra a influência das interfaces MH-PPV/Al nesses dispositivos. Os valores da constante dielétrica de todas as amostras estão em torno de 3 , concordando com a literatura ${ }^{[89]}$, e a resistividade em torno 
de $5 \times 10^{9} \Omega \mathrm{cm}$, concordando com os resultados da curva $J v s$. I obtido da amostra Au/MHPPV/Au, Fig. 7.1.

A Fig. 7.12 mostra os ajustes obtidos com a amostra ITO/MH-PPV/Al com $V_{a c}$ e $V_{\text {bias }}$ iguais a 2,0 V, e com $V_{\text {bias }}=-2,0 \mathrm{~V}$ pela Eq. (7.10). A Fig. 7.9, item 7.4, apresenta os demais ajustes (linhas contínuas), e a Tabela 7.II, os parâmetros obtidos.
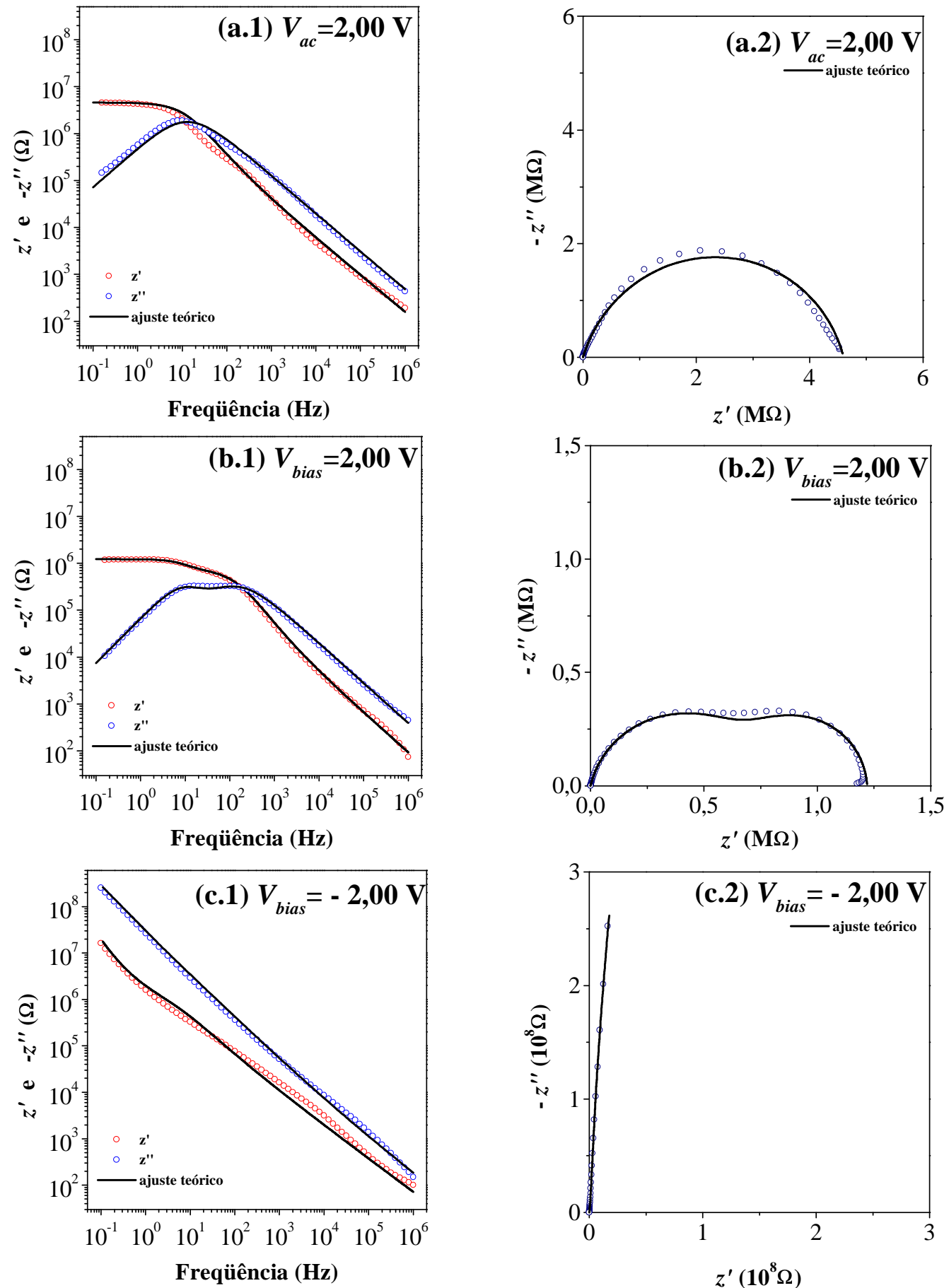

Figura 7.12: Z'e Z" vs. $f$ da amostra ITO/MH-PPV/Al $(L=400 \mathrm{~nm})$ com: (a.1) e (a.2) $V_{a c}=2,0 \mathrm{~V}$ e $V_{\text {bias }}=0$, (b.1) e (b.2) $V_{a c}=50 \mathrm{mV}$ e $V_{\text {bias }}=2,0 \mathrm{~V}$, e (c.1) e (c.2) $V_{a c}=50 \mathrm{mV}$ e $V_{\text {bias }}=-2,0 \mathrm{~V}$. As curvas cheias (一) mostram os ajustes dos resultados experimentais pela Eq. (7.10). 
Tabela 7.II: Parâmetros obtidos através dos ajustes dos componentes Z' e Z" apresentadas nas Fig. 7.9 e 7.12 através da Eq. (7.10) da amostra ITO/MH-PPV/Al $\left(L=400 \mathrm{~nm}\right.$ e $A r=0,5 \mathrm{~cm}^{2}$ variando-se $V_{a c}$, e $V_{b i a s}$ positiva e negativamente. Em todos os ajustes $\mathrm{R}_{\mathrm{ITO}}<<\mathrm{R}_{\mathrm{MH}}$.

\begin{tabular}{|c|c|c|c|c|c|c|}
\hline \multicolumn{7}{|l|}{$V_{a c}$} \\
\hline & $\mathbf{R}_{\text {int }}(\Omega)$ & $\mathrm{C}_{\text {int }}(\mathrm{F})$ & $\alpha_{\text {int }}$ & $\mathbf{R}_{\mathrm{MH}}(\Omega)$ & $\mathrm{C}_{\mathrm{MH}}(\mathbf{F})$ & $\alpha_{M H}$ \\
\hline $50 \mathrm{mV}$ & $1,5 \times 10^{9}$ & $8,5 \times 10^{-9}$ & 0,07 & $6,5 \times 10^{5}$ & $1,5 \times 10^{-9}$ & 0,15 \\
\hline $100 \mathrm{mV}$ & $1,5 \times 10^{9}$ & $8,5 \times 10^{-9}$ & 0,07 & $6,5 \times 10^{5}$ & $1,5 \times 10^{-9}$ & 0,15 \\
\hline $250 \mathrm{mV}$ & $1,5 \times 10^{9}$ & $8,5 \times 10^{-9}$ & 0,07 & $6,5 \times 10^{5}$ & $1,5 \times 10^{-9}$ & 0,15 \\
\hline $500 \mathrm{mV}$ & $1,5 \times 10^{9}$ & $8,5 \times 10^{-9}$ & 0,07 & $6,5 \times 10^{5}$ & $1,5 \times 10^{-9}$ & 0,15 \\
\hline $1,0 \mathrm{~V}$ & $1,4 \times 10^{9}$ & $9,0 \times 10^{-9}$ & 0,06 & $6,5 \times 10^{5}$ & $1,5 \times 10^{-9}$ & 0,15 \\
\hline $2,0 \mathrm{~V}$ & $9 \times 10^{7}$ & $8,0 \times 10^{-9}$ & 0,15 & $6,5 \times 10^{5}$ & $3,5 \times 10^{-9}$ & 0,15 \\
\hline $3,0 \mathrm{~V}$ & $1,0 \times 10^{6}$ & $3,0 \times 10^{-9}$ & 0,20 & $2,5 \times 10^{5}$ & $2,0 \times 10^{-9}$ & 0,15 \\
\hline \multicolumn{7}{|l|}{$V_{\text {bias }}>0$} \\
\hline & $\mathbf{R}_{\text {int }}(\Omega)$ & $C_{\text {int }}(\mathbf{F})$ & $\alpha_{\text {int }}$ & $\mathbf{R}_{\mathrm{MH}}(\Omega)$ & $\mathrm{C}_{\mathrm{MH}}(\mathrm{F})$ & $\alpha_{\text {MH }}$ \\
\hline $0 \mathrm{~V}$ & $1,5 \times 10^{9}$ & $8,5 \times 10^{-9}$ & 0,08 & $6,0 \times 10^{5}$ & $1,5 \times 10^{-9}$ & 0,15 \\
\hline $100 \mathrm{mV}$ & $1,2 \times 10^{9}$ & $7,5 \times 10^{-9}$ & 0,04 & $6,5 \times 10^{5}$ & $1,5 \times 10^{-9}$ & 0,15 \\
\hline $250 \mathrm{mV}$ & $1,0 \times 10^{9}$ & $9,5 \times 10^{-9}$ & 0,04 & $6,5 \times 10^{5}$ & $1,5 \times 10^{-9}$ & 0,15 \\
\hline $500 \mathrm{mV}$ & $1,0 \times 10^{9}$ & $1,2 \times 10^{-8}$ & 0,04 & $6,5 \times 10^{5}$ & $1,5 \times 10^{-9}$ & 0,15 \\
\hline $750 \mathrm{mV}$ & $9,0 \times 10^{8}$ & $1,5 \times 10^{-8}$ & 0,04 & $6,5 \times 10^{5}$ & $1,5 \times 10^{-9}$ & 0,15 \\
\hline $1,0 \mathrm{~V}$ & $9,0 \times 10^{8}$ & $1,9 \times 10^{-8}$ & 0,04 & $6,5 \times 10^{5}$ & $1,5 \times 10^{-9}$ & 0,15 \\
\hline $1,5 \mathrm{~V}$ & $1,1 \times 10^{8}$ & $1,7 \times 10^{-8}$ & 0,02 & $7,2 \times 10^{5}$ & $1,5 \times 10^{-9}$ & 0,15 \\
\hline $2,0 \mathrm{~V}$ & $5,0 \times 10^{5}$ & $3,5 \times 10^{-8}$ & 0,02 & $7,2 \times 10^{5}$ & $1,5 \times 10^{-9}$ & 0,15 \\
\hline $3,0 \mathrm{~V}$ & $8,0 \times 10^{4}$ & $4,0 \times 10^{-8}$ & 0,20 & $2,6 \times 10^{5}$ & $1,3 \times 10^{-9}$ & 0,15 \\
\hline $4,0 \mathrm{~V}$ & $3,0 \times 10^{4}$ & $4,0 \times 10^{-8}$ & 0,30 & $1,6 \times 10^{5}$ & $1,2 \times 10^{-9}$ & 0,15 \\
\hline \multicolumn{7}{|l|}{$V_{\text {bias }}<0$} \\
\hline & $\mathbf{R}_{\text {int }}(\Omega)$ & $\mathrm{C}_{\text {int }}(\mathrm{F})$ & $\alpha_{\text {int }}$ & $\mathbf{R}_{\mathrm{MH}}(\Omega)$ & $\mathrm{C}_{\mathrm{MH}}(\mathrm{F})$ & $\alpha_{\mathrm{MH}}$ \\
\hline $0 \mathrm{~V}$ & $9,5 \times 10^{9}$ & $6,0 \times 10^{-9}$ & 0,02 & $9,6 \times 10^{5}$ & $3,5 \times 10^{-8}$ & 0,29 \\
\hline$-4,0 \mathrm{~V}$ & $9,5 \times 10^{9}$ & $6,0 \times 10^{-9}$ & 0,02 & $9,6 \times 10^{5}$ & $3,5 \times 10^{-8}$ & 0,29 \\
\hline
\end{tabular}

Nessa tabela, os parâmetros obtidos são praticamente independentes da tensão para $\mathrm{V}$ menor que $2,0 \mathrm{~V}$. Entretanto, $\mathrm{R}_{\text {int }}$ passa a cair abruptamente a partir dessa tensão, enquanto $\mathrm{C}_{\mathrm{int}}, \mathrm{R}_{\mathrm{MH}}$, e $\mathrm{C}_{\mathrm{MH}}$ apresentam uma suave queda. Esse resultado corrobora a idéia que um súbito aumento do processo de injeção dos portadores pelo eletrodo de alumínio ocorre a partir de 2 V. Já dos resultados obtidos em baixas tensões, obtivemos os valores de $\rho=4,5 \times 10^{9} \Omega \mathrm{cm}$ e da constante dielétrica $\mathrm{K}=2,3$, que estão em boa concordância com os valores obtidos anteriormente.

Comparando-se os resultados obtidos variando-se $V_{a c}$ e $V_{\text {bias }}$ positivamente, vemos que os parâmetros obtidos são muito semelhantes. Porém, em modo reverso, não há 
variação dos parâmetros, mesmo com uma variação dessa tensão de $4 \mathrm{~V}$. Isso mostra que os processos responsáveis pelas características dos dispositivos ocorrem, preferencialmente, quando o ITO é polarizado positivamente e o alumínio negativamente.

Por último, os valores de $\alpha_{\mathrm{MH}}$ são diferentes de 0 . Esse resultado mostra que o mecanismo de condução do MH-PPV pode ser estudado através da Eq. (7.12). A figura a seguir apresenta as curvas de condutividade das amostras Au/MH-PPV/Au $(L=5 \mu \mathrm{m})$, ITO/MH-PPV/Au $(L=400 \mathrm{~nm})$ e ITO/MH-PPV/Al $(L=400 \mathrm{~nm}$ e $5 \mu \mathrm{m})$, ajustadas por essa equação. Todos os parâmetros obtidos pelos ajustes são apresentados Tabela 7.III
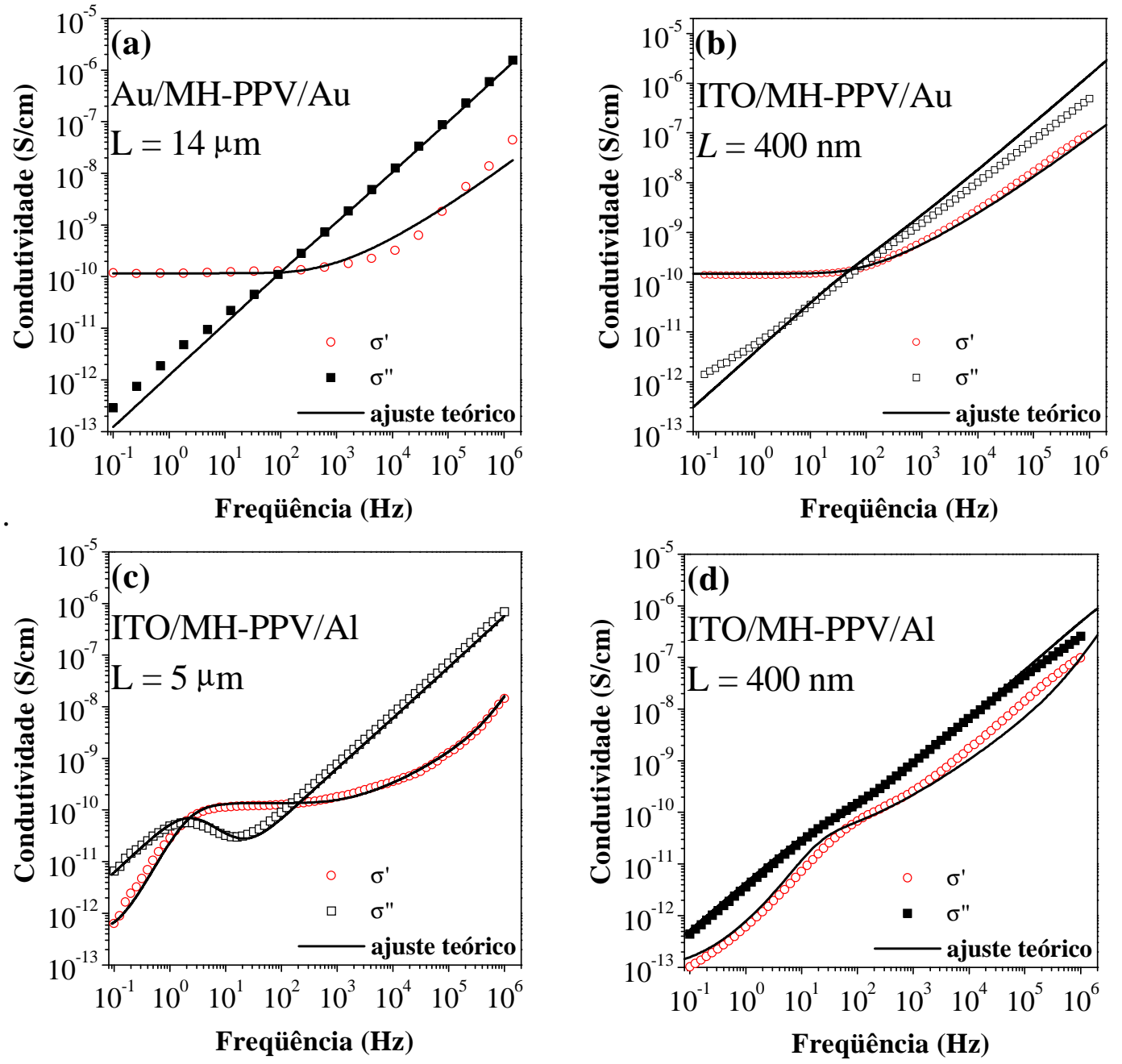

Figura 7.13: Gráficos $\sigma^{\prime}(f)$ e $\sigma^{\prime \prime}(f)$ vs. $f$ obtidos com as amostras (a) Au/MH-PPV/Au, (b) ITO/MH-PPV/Al espessa e (c) ITO/MH-PPV/Al fina pela Eq. (7.12). 
Tabela 7.III: Parâmetros de ajustes dos componentes $\sigma^{\prime}(f)$ e $\sigma^{\prime \prime}(f)$ das amostras Au/MH-PPV/Au $(L=14$ $\mu \mathrm{m})$, e ITO/MH-PPV/Al espessa $(L=5 \mu \mathrm{m})$ e ITO/MH-PPV/Al fina obtidas com a Eq. (7.12)

\begin{tabular}{||c|c|c|c|c|c|c|c||}
\hline \hline & $\boldsymbol{L}$ & $\sigma_{\mathbf{0}}(\mathbf{S} / \mathbf{c m})$ & $\gamma_{\min }(\mathbf{H z})$ & $\mathbf{R}_{\text {int }}(\Omega)$ & $\mathbf{C}_{\text {int }}(\mathbf{F})$ & $\alpha_{\text {int }}$ & $\mathbf{K}$ \\
\hline Au/MH-PPV/Au & $14 \mu \mathrm{m}$ & $1,2 \times 10^{-10}$ & 100 & - & - & - & 2,5 \\
\hline ITO/MH-PPV/Au & $400 \mathrm{~nm}$ & $1,4 \times 10^{-10}$ & 50 & - & - & - & 2,0 \\
\hline ITO/MH-PPV/AI & $5 \mu \mathrm{m}$ & $1,4 \times 10^{-10}$ & 200 & $2,5 \times 10^{9}$ & $1,3 \times 10^{-8}$ & 0,01 & 2,5 \\
\hline ITO/MH-PPV/AI & $400 \mathrm{~nm}$ & $1,4 \times 10^{-10}$ & 50 & $1,5 \times 10^{9}$ & $7,5 \times 10^{-9}$ & 0,08 & 2,5 \\
\hline
\end{tabular}

Da tabela 7.III observamos que os valores de $\sigma_{\mathrm{O}}$ independem da estrutura da amostra e são inversamente proporcionais à resistividade do polímero, obtida através da curva $J$ vs. $V . \gamma_{\min }$ é o valor da freqüência em torno de $f_{c}$, e $K$ é um valor próximo da permissividade do polímero obtido em itens anteriores. $R_{\text {int }}$ e $C_{\text {int }}$, por sua vez, são os mesmos valores obtidos através dos ajustes dessas curvas pela Eq. (7.10). É interessante notar que os valores de $\sigma_{0}$ e $K$ são praticamente os mesmos para todas as amostras, mostrando que esse modelo separa muito bem os efeitos de volume dos de interface. Além disso, essa expressão surge como uma alternativa viável para descrever o comportamento dos diodos poliméricos através de um modelo microscópico de condução de volume do polímero.

\subsection{Discussão dos Resultados}

Nesse capítulo mostramos que as características elétricas de dispositivos de MHPPV dependem da espessura da camada polimérica e dos materiais usados como eletrodos. Essas características foram estudadas através de medidas de corrente $v$. tensão e de impedância complexas, que forneceram a resistividade e a constante dielétrica do polímero, assim como a evolução da resistividade das interfaces metal/MH-PPV como função da tensão aplicada nos dispositivos.

Através de medidas $J$ vs. $V$ observamos que a amostra Au/MH-PPV/Au apresenta um comportamento ôhmico e resistividade em torno de $4,0 \times 10^{9} \Omega \mathrm{cm}$, independente da espessura da camada polimérica e em torno dos valores obtidos da literatura para filmes de PPV e de alguns de seus derivados $[49,91]$. Medidas $J$ vs. $V$ de dispositivos ITO/MH-PPV/Au e ITO/MH-PPV/Al, por sua vez, mostram que essas amostras apresentam uma retificação, com ganho de corrente quando o ITO é polarizado 
positivamente. Entretanto, a retificação observada com a amostra com eletrodo de ouro não era esperada, o que mostra que esse metal deve ter sofrido uma leve oxidação. Medidas de impedância nessas duas amostras mostraram, ainda, que a interface MH-PPV/Al é a mais resistiva de todas. Por último, comparando-se a intensidade de emissão total com as curvas $J$ vs. $V$ das amostras de ITO/MH-PPV e ITO/PPV/Al, foi observado uma relação direta entre essas duas medidas, o que indica que a taxa de injeção de portadores acompanha a sua recombinação.

Medidas de condutividade complexa obtidas com as amostras Au/MH-PPV/Au e ITO/MH-PPV/Au apresentaram um comportamento típico de sistemas sólidos desordenados, não havendo dependência com a espessura do filme de polímero, e fornecendo a resistividade do polímero em baixas freqüências semelhante ao resultado obtido pela curva $J$ vs. $V$. Amostras com eletrodos de alumínio, no entanto, apresentaram dois processos de relaxação distintos. Um de mais baixa resistência (na região de maior freqüência), e outro de alta (em baixas freqüências). Em amostras finas esses dois processos se sobrepõem, mas a identificação de um suave ponto de inflexão em torno de $100 \mathrm{~Hz}$ possibilitou a obtenção da resistividade do polímero e a separação do efeito de volume do de interface. Também foi observado que a resistividade da interface diminui com a tensão aplicada em modo direto, acompanhando a variação da resistividade obtida através da curva $J$ vs. $V$. Nas medidas de Z' e Z" na amostra ITO/MH-PPV/Al fina também foi observado uma descontinuidade no comportamento dos componentes das curvas quando a tensão aplicada é superior a 2,0 V. Nessa situação observa-se um grande aumento na condutividade de baixa freqüência, devido, muito provavelmente, ao início do fenômeno de tunelamento na interface.

Ajustando-se os componentes Z' e Z" das amostras Au/MH-PPV/Au pela expressão de um circuito equivalente de um único RC, obtivemos que o material apresenta uma distribuição de tempos de relaxação com largura muito pequena $(\alpha=0,05)$, mas o suficiente para caracterizar o MH-PPV com um material com uma distribuição de tempos de relaxação. A mesma expressão foi usada para ajustar as curvas da amostra ITO/MHPPV/Au. Os resultados dos ajustes mostraram que $\alpha$ é maior quando a espessura da camada polimérica é fina. Também foi obtido o valor da constante dielétrica em torno de 3 , em concordância com os resultados da literatura, e resistividade muito próxima ao obtido pela curva ôhmica $J$ vs. $V$ do dispositivo Au/MH-PPV/Au. Resultados semelhantes foram obtidos com as amostras ITO/MH-PPV/Al, mas utilizando-se dois circuitos equivalentes. 
Como $\alpha \neq 0$ o modelo RFEB foi usado para descrever o mecanismo de condução do filme polimérico. Entretanto, foi necessário associar a expressão da condutividade do polímero uma função resposta dielétrica, de acordo com as características dielétricas desse material. Como resultado dos ajustes a constante dielétrica obtida e o valor da resistividade do polímero foram semelhantes aos obtidos com o modelo de circuito equivalente. Dessa forma, concluímos que o modelo microscópico RFEB torna-se consistente com o modelo macroscópico de circuitos equivalentes.

Portanto, nesse capítulo mostramos como as propriedades elétricas dos dispositivos poliméricos podem ser estudadas através de medidas de corrente $v$ s. tensão e impedanciometria, e como esses resultados podem ser correlacionados para explicar o mecanismo de condução e os efeitos de interface desses sistemas. 


\section{Capítulo 8}

\section{Transistores de Efeito de Campo de POMA}

Dando continuidade ao estudo dos dispositivos eletrônicos poliméricos, nesse capítulo apresentamos as caracterizações elétricas de um transistor de efeito de campo utilizando a poli (o-metoxianilina) (POMA) como material ativo ${ }^{[46]}$. A motivação para esse estudo tem origem nas excelentes propriedades semicondutoras da POMA, sob dopagem adequada, da facilidade de processamento de filmes finos e do baixo custo de produção desse polímero ${ }^{[52]}$.

Nesse capítulo apresentamos curvas de corrente fonte-dreno $\left(I_{S D}\right) v s$. tensão fontedreno $\left(V_{S D}\right)$ modulada pela tensão de porta $\left(V_{G}\right)$ obtidas com um PFET utilizando a POMA como material ativo. As curvas mostraram uma forte dependência com o valor da tensão de porta aplicada $\left(V_{G}\right)$, sendo que, quanto maior o valor de $V_{G}$, menor a corrente de saturação do dispositivo. Para explicar os resultados experimentais, foi elaborado um modelo teórico baseado nas propriedades desordenadas da POMA, na dependência da mobilidade dos portadores com o potencial $V_{S D}$, e na variação da densidade de portadores com $V_{G}$ ao longo do eixo ortogonal às superfícies do polímero. Também foram caracterizados PFETs utilizando filmes de PPV, de MH-PPV, de MD-PPV e de PANI como materiais ativos, mas os resultados não foram muito promissores e, por esse motivo, não são apresentados nesse trabalho. Para o caso da PANI, a dificuldade em se obter filmes finos pelo método spin coating prejudicou a sua deposição sobre a estrutura do dispositivo. Para o PPV, a etapa de conversão a $200{ }^{\circ} \mathrm{C}$ oxidou os contatos dreno e fonte, prejudicando as medidas elétricas, e, por último, para o MH-PPV e o MD-PPV, as medidas obtidas não foram reprodutivas.

\subsection{O substrato $\mathrm{Al} / \mathrm{Si} / \mathrm{SiO}_{2} /($ eletrodos interdigitais)}

Para a confecção dos PFETs de POMA foram utilizados substratos de $\mathrm{Al} / \mathrm{Si} / \mathrm{SiO}_{2} /($ eletrodos interdigitais) com espessuras do óxido de $130 \mathrm{~nm}$, dos eletrodos de 
$50 \mathrm{~nm}$ e distâncias entre esses eletrodos de 10, 20 e $30 \mu \mathrm{m}$ (veja seção 3.3.2). A espessura da camada de $\mathrm{SiO}_{2}$ foi obtida por elipsometria, no intervalo de energia (E) de 2,2 a 5,3 eV, através do ajuste dos resultados experimentais de $\Delta(\mathrm{E})$ e $\Psi(\mathrm{E})$ por um modelo de dois filmes $\left(\mathrm{Si} / \mathrm{SiO}_{2}\right)^{[94]}$. Os eletrodos interdigitais foram preparados com a deposição de uma fina camada de cromo ( $20 \mathrm{~nm}$ ), sobre o $\mathrm{SiO}_{2}$, seguido da deposição de uma fina camada de ouro ( $30 \mathrm{~nm})$. A Fig. 8.1 mostra as imagens de microscopia óptica obtidas com esse substrato. Todos os procedimentos de preparação dos dispositivos, desde a limpeza das lâminas de silício até a confecção dos eletrodos interdigitais, foram apresentados no item 3.3 .

(a)

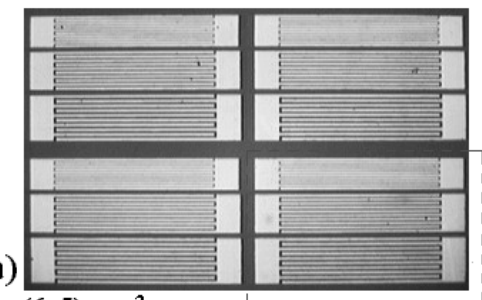

(6x5) $\mathrm{mm}^{2}$

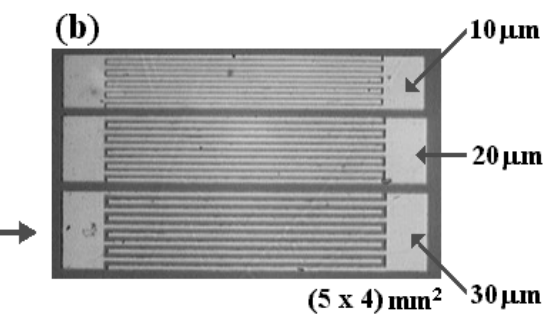

$(5 \times 4) \mathrm{mm}^{2} \backslash 30 \mu \mathrm{m}$

Figura 8.1: Imagens de microscopia óptica dos substratos $\mathrm{Al} / \mathrm{Si} / \mathrm{SiO}_{2} /($ eletrodos interdigitais). A figura mostra os eletrodos sobre a camada de $\mathrm{SiO}_{2}$ obtidos com uma fina deposição de $\mathrm{Cr}(20 \mathrm{~nm})$, seguido de uma fina deposição de $\mathrm{Au}(30 \mathrm{~nm})$ através dos processos de litografia apresentados no item 3.3.

Na Fig. 8.1-(a) temos quatro conjuntos idênticos de eletrodos interdigitais, cada qual composto de 3 sub-conjuntos com separação dos eletrodos dreno e fonte $(W)$ de $10 \mu \mathrm{m}, 20 \mu \mathrm{m}$ e $30 \mu \mathrm{m}$, como mostra a Fig. 8.1-(b). Sobre esses substratos, uma fina camada de POMA ( $50 \mathrm{~nm}$ ) foi depositada por spin coating (otimizado com velocidade de $3000 \mathrm{rpm}$ por $90 \mathrm{~s})$ utilizando uma solução do polímero em clorofórmio seco $(1 \mathrm{mg} / \mathrm{ml})$, seguindo os procedimentos apresentados no item 3.2.2. Após a deposição do polímero, o dispositivo foi levado a uma câmara a vácuo $\left(10^{-1}\right.$ Torr $)$, por 30 min., para eliminação de clorofórmio residual a temperatura de $50{ }^{\circ} \mathrm{C}$.

\subsection{Caracterização elétrica}

Para caracterizar as propriedades elétricas dos PFETs de POMA, medidas $I_{S D} v s$. $V_{S D}$ foram realizadas variando-se $V_{S D}$ de 0 a $2,5 \mathrm{~V}$, com $V_{G}$ variando de - 50 a $20 \mathrm{~V}$. Todas as medidas foram realizadas no escuro, em temperatura e atmosfera ambientes, com tempo entre aplicação de $V_{S D}$ e início da medida de $10 \mathrm{~s}$ (hold time), e intervalo entre a aplicação da tensão e leitura de corrente de $1 \mathrm{~s}$ (delay time). $\mathrm{O}$ intervalo de tensão $V_{S D}$ foi limitado de 
0 a 2,5 V, de modo que garantimos que não houvesse nenhuma degradação dos eletrodos e do óxido com a aplicação de $V_{S D}$, estando de acordo com os resultados apresentados no item 3.3.2.

A Fig. 8.2 mostra os resultados obtidos com um PFET com $W=10 \mu \mathrm{m}$. Para $V_{G}=-50 \mathrm{~V}$ a corrente $I_{S D}$ apresenta um patamar para valores de $V_{S D}$ menores que $0,25 \mathrm{~V}$, seguido de um aumento quasi-linear com $V_{S D}$. $I_{S D}$ ainda alcança um valor de saturação $\left(\boldsymbol{I}_{S}\right)$ próximo de $1,7 \times 10^{-8} \mathrm{~A}$ com $V_{S D}=2,0 \mathrm{~V}$. À medida que $V_{G}$ aumenta de $-50 \mathrm{~V}$ para $20 \mathrm{~V}$, $I_{S}$ diminui para $3,0 \times 10^{-10} \mathrm{~A}$, e $I_{S D}$ tende a uma dependência linear com $V_{S D}$ em todo intervalo de tensão medido. Para valores de $V_{G}$ menores que $-20 \mathrm{~V}$ (não mostrados nessa figura), os valores de $I_{S D}\left(V_{S D}\right)$ apresentam-se idênticos aos obtidos com $V_{G}=-20 \mathrm{~V}$. A POMA utilizada nesse dispositivo apresenta um baixo grau de dopagem química, proveniente da etapa de síntese química em meio ácido (item 3.1.2). Denominaremos esse dispositivo de PFET de POMA, para facilitar a sua identificação ao longo do texto.

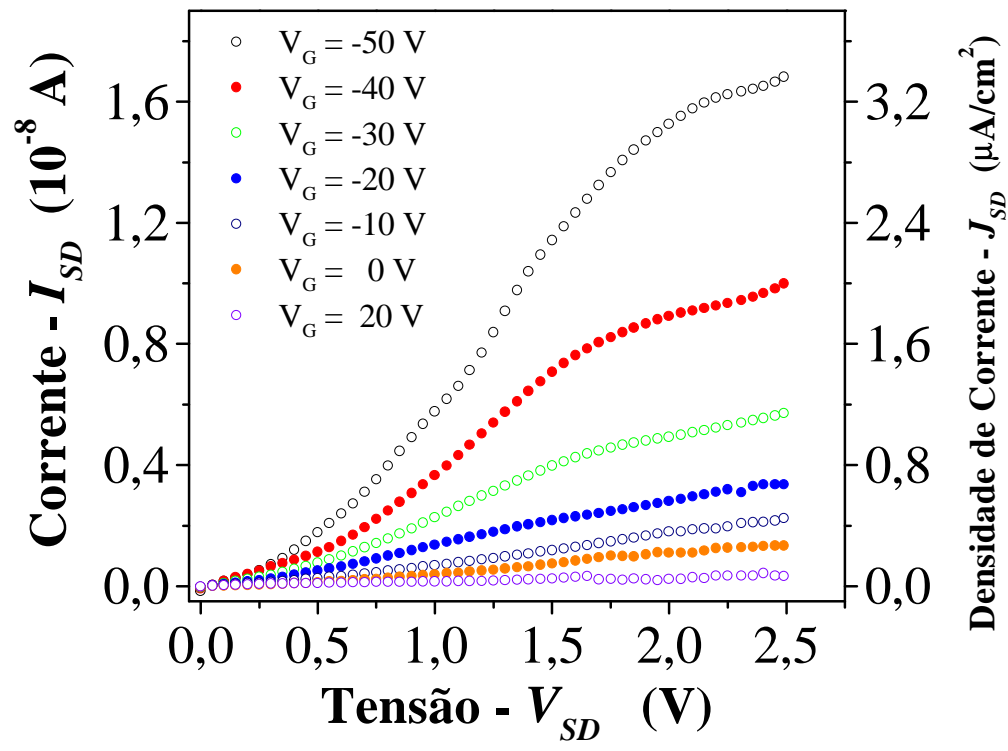

Figura 8.2: Medidas $I_{S D}$ vs. $V_{S D}$ obtidas com estruturas PFET de POMA com W $=10 \mu \mathrm{m}$ e $V_{G}$ variando de -50 a $20 \mathrm{~V}$.

A Fig. 8.3-(a) mostra as curvas $I_{S D}$ vs. $V_{S D}$ dos PFETs de POMA com valores de $W$ iguais a 10, 20 e $30 \mu \mathrm{m}$. Já a Fig. 8.3-(b) mostra as curvas obtidas com um dispositivo desse polímero com $W=10 \mu \mathrm{m}$, antes e depois da POMA ser dopada por imersão em soluções aquosas de ácido clorídrico. Primeiro foi realizado a medida com a amostra não dopada, e depois, sucessivamente, foram realizadas as medidas com a amostra dopada nas soluções $10^{-3} \mathrm{M}, 10^{-2} \mathrm{M}$ e $10^{-1} \mathrm{M}$ por 10 segundos. Entre uma dopagem e outra a amostra 
foi seca com jatos de nitrogênio e, só em seguida, caracterizada eletricamente. Todas as medidas foram realizadas com $V_{G}=0 \mathrm{~V}$.
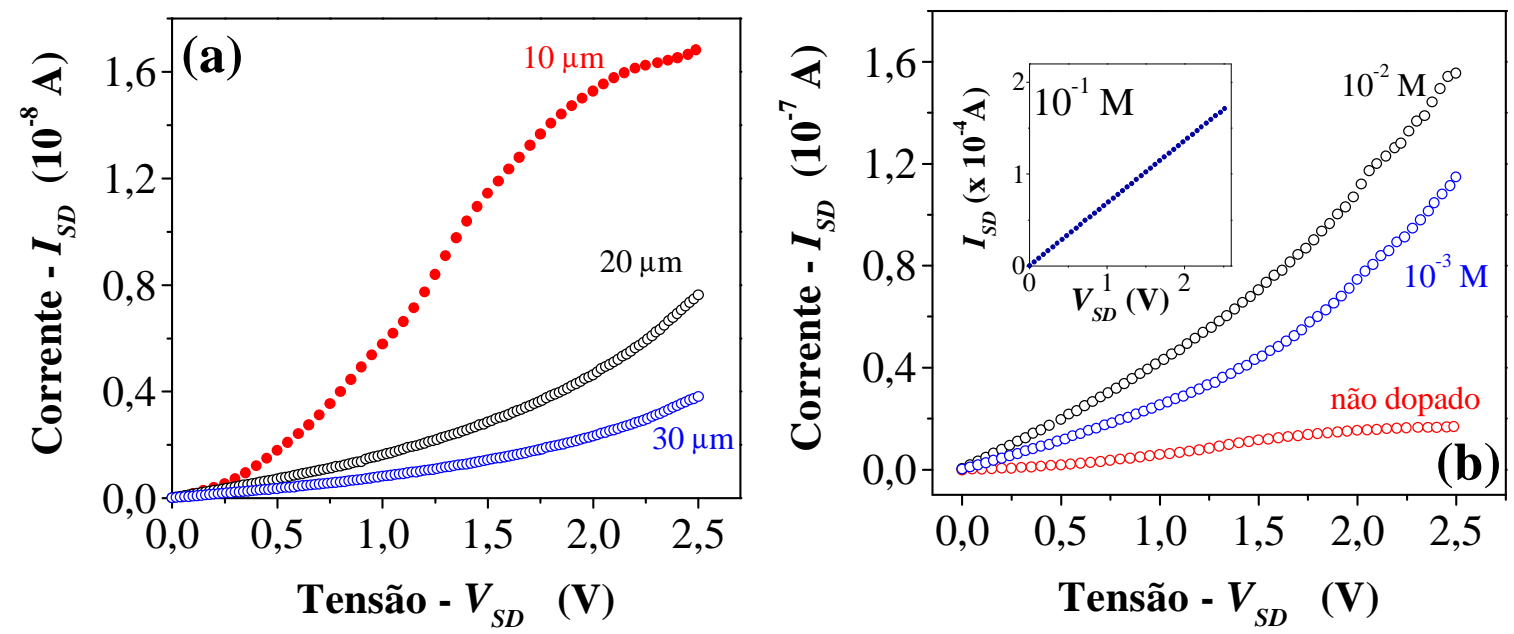

Figura 8.3: Medidas $I_{S D} v s . V_{S D}$ obtidas (a) com PFETs de POMA não dopada variando-se $\mathrm{W}$ de 10,20 e 30 $\mu \mathrm{m}$, e (b) com FETs de POMA ( $\mathrm{W}=10 \mu \mathrm{m}$ ) variando-se o grau de dopagem química do polímero em solução aquosa de ácido clorídrico $10^{-3}, 10^{-2}, 10^{-1} \mathrm{M}$.

As curvas apresentadas nos gráficos da Fig. 8.3 mostram que, quanto menor à distância entre os eletrodos e maior a concentração da solução ácida, maiores os valores de corrente $I_{S D}$ em 2,5 V. A amostra de PFET de POMA não dopada com W $=20$ e $30 \mu \mathrm{m}$ apresentou uma dependência linear de $I_{S D}$ com $V_{S D}$ até aproximadamente $2 \mathrm{~V}$, Fig. 8.3-(a). O mesmo ocorreu com a amostra de PFET de POMA dopada com as soluções $10^{-3} \mathrm{M}$ e $10^{-2} \mathrm{M}$ com $\mathrm{W}=10 \mu \mathrm{m}$, Fig. 8.3-(b). Já a amostra dopada em solução $10^{-1} \mathrm{M}$ apresentou um comportamento ôhmico em todo intervalo de tensão medido, inserção na Fig. 8.3-(b). Com todos os dispositivos foram realizadas medidas $I_{S D}$ vs. $V_{S D}$ variando-se $V_{G}$, mas nenhuma das curvas mostrou uma dependência, ou modulação, com a tensão de porta aplicada, exceto para o dispositivo de POMA não dopada e com $\mathrm{W}=10 \mu \mathrm{m}$, cujas curvas foram apresentadas na Fig. 8.2. Esses resultados indicam que o grau de dopagem do polímero e a distância entre os eletrodos têm papel importante nas características do dispositivo, sendo apenas modulado quando a dopagem do filme de POMA é muito baixa e com W igual a $10 \mu \mathrm{m}$. 


\subsection{Modelo Teórico}

Os conceitos de camada de inversão e de portadores minoritários utilizados para estudar as características dos transistores inorgânicos não são, em geral, aplicados aos PFETs ${ }^{[95]}$. Dessa forma, para explicar o comportamento das curvas apresentadas na Fig. 8.2, foi elaborado um modelo baseado nas características da POMA. Esse modelo leva em conta a dependência da mobilidade dos portadores com o campo elétrico, e gradientes da mobilidade e da densidade dos portadores ortogonais à superfície do filme polimérico.

Uma vez aplicada uma tensão $V_{S D}$, a corrente $I_{S D}$ que fluirá por esse material pode sofrer influência do tipo de contato ${ }^{[96]}$, bloqueante ou ôhmico, da densidade de armadilhas de portadores ${ }^{[31]}$, da sua estrutura desordenada e do campo elétrico aplicado ${ }^{[87,97]}$. Por outro lado, a superfície do polímero em contato com o ar está sujeita, se comparada à superfície em contato com o óxido, a uma maior influência das condições da atmosfera ambiente (oxigênio e umidade, por exemplo), o que deve gerar um aumento na densidade de armadilhas para os portadores de carga nessa superfície. Como resultado, a mobilidade dos portadores deve variar ao longo da direção perpendicular a essas duas superfícies, sendo maior próximo à camada de $\mathrm{SiO}_{2}$. Dependendo do valor de $V_{G}$ os portadores podem, ainda, se acumular próximo à superfície do óxido, ou próximo à superfície do polímero em contato com o ar. Para $V_{G}<0$, os portadores poderão se direcionar para a interface polímero-ar (caso sejam negativos), ou para a interface polímero-óxido (caso sejam positivos).

Para facilitar o acompanhamento do modelo desenvolvido, a Fig. 8.4 mostra o sistema de coordenadas cartesianas usado para representar as características geométricas do dispositivo. Na Fig. 8.4-(a) o eixo $x$ é definido pela direção perpendicular aos eletrodos dreno e fonte, o eixo y como a direção perpendicular às superfícies do polímero em contato com o óxido e com o ar, e o eixo $z$ como a direção ao longo do comprimento dos eletrodos. Na Fig. 8.4-(b) temos definida as distâncias $b, L$ e $W$, onde $b$ é espessura $(50 \mathrm{~nm}), L$ o comprimento $(1 \mathrm{~cm})$ e $W$ à distância $(10,20$ ou $30 \mu \mathrm{m})$ dos eletrodos interdigitais.
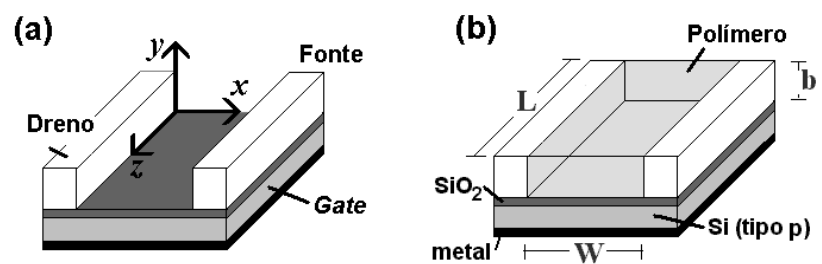

Figura 8.4: (a) Representação de um sistema cartesiano para o PFET e (b) descrição das variáveis utilizadas. 
A seguir descrevemos, em tópicos, as hipóteses usadas no desenvolvimento do modelo:

(i) usando a configuração mostrada na Fig. 8.4, ao aplicar uma tensão $V_{S D}$, a corrente $I_{S D}$ pode ser calculada a partir da diferencial de área no plano yz:

$$
d I_{S D}=J_{S D} d A=\rho v L d y
$$

onde $J_{S D}=\rho v$ é a densidade de corrente que flui pelo polímero, $v$ é a velocidade de arraste dos portadores de carga e $\rho$ a densidade de portadores de carga.

(ii) oxigênio, umidade e impurezas na superfície do polímero em contato com o ar são fontes de armadilhas para os portadores de carga e têm papel importante na limitação das suas mobilidades ${ }^{[31]}$. A superfície do polímero em contato com o óxido, devidamente limpa, está menos propensa ao ataque desses contaminantes. Como resultado, é de se esperar que a mobilidade dos portadores seja maior próximo à superfície do polímero em contato com o óxido, e menor na superfície em contato com o ar. Como uma primeira aproximação, a variação da mobilidade ao longo do eixo y pode ser escrita com uma dependência linear do tipo:

$$
\mu(\mathrm{y})=\mu^{\prime}\left(1-\frac{k}{b} \mathrm{y}\right),
$$

onde $0 \leq k \leq 1$ e $0 \leq y \leq b$, e $\mu$ ' é o valor da mobilidade dos portadores definida próxima a superfície do óxido $(\mathrm{y}=0)$.

É considerado que em sistemas sólidos desordenados a mobilidade $\mu^{\prime}$ dos portadores apresenta uma dependência com o campo elétrico aplicado $E\left(=V_{S D} / W\right)$ dada $\operatorname{por}^{[87,89,97] \text { : }}$

$$
\mu^{\prime} \equiv \mu(E)=\mu_{0} \mathrm{e}^{\alpha \sqrt{E}}
$$

onde $\alpha$ é uma constante definida como o parâmetro de desordem ${ }^{[87]}$, e $\mu_{0}$ um parâmetro para a mobilidade do material. A partir das Eqs. (8.2) e (8.3), a mobilidade dos portadores pode ser escrita como:

$$
\mu \equiv \mu(E, y)=\mu_{0} \mathrm{e}^{\alpha \sqrt{E}}\left(1-\frac{k}{b} y\right)
$$


(iii) a velocidade de arraste (v) deve variar com o campo elétrico aplicado, seja pelo fato dado pela Eq. (8.3), seja pelo efeito da retrodifusão térmica ${ }^{[98]}$. Nesse último caso, uma expressão para a velocidade de arraste dos portadores pode ser obtida calculando-se a diferença entre a densidade de corrente de injeção $\left(J_{0}\right)$ e a corrente de retrodifusão dos portadores $\left(J^{\prime}\right)^{[98]}$. Como resultado, $v$ apresenta a seguinte dependência com a mobilidade dos portadores e com o campo aplicado ${ }^{[98,99]}$ :

$$
v=\frac{\mu \mathrm{E}}{1+\frac{\mu \mathrm{E}}{v_{\mathrm{s}}}}
$$

onde $v_{\mathrm{s}}$ é a velocidade de saturação dos portadores e depende da densidade de armadilhas dos portadores no sistema. No caso de $v_{\mathrm{s}} \gg \mu \mathrm{E}, v$ tende a $v=\mu \mathrm{E}$, e no caso $v_{\mathrm{s}}<<\mu \mathrm{E}, v$ se reduz a $v_{\mathrm{s}}$.

(iv) a tensão $V_{G}$, conforme sua polaridade, concentra os portadores próximos à interface polímero-óxido ou a polímero-ar. É conhecido que a mobilidade dos portadores positivos da POMA é muito superior à dos negativos ${ }^{[100]}$. Nesse caso, com $V_{G}<0$, o acúmulo de cargas ocorre na interface polímero-óxido, onde a mobilidade deve ser bem maior que na interface polímero-ar e, para $V_{G}>0$, ocorre o oposto. Portanto, podemos expressar de maneira simplificada a densidade dos portadores ao longo de $y$, como:

$$
\rho(y)=c y+\rho_{0}\left(c, V_{G}\right)
$$

onde $c$ é um parâmetro de ajuste, $\rho_{0}$ o valor da densidade de portadores na interface polímero-óxido (y $=0)$ e ambos, $c$ e $\rho_{0}$, dependem de $V_{G}$.

Tomando-se a condição de conservação de carga como o vínculo entre $\rho_{0}$ e $c$ :

$$
\chi=\int_{0}^{b}\left(c y+\rho_{0}\right) d y=\text { constante }
$$

obtemos o valor da constante $c$ em termos de $\chi, \rho_{0}$ e $b$ :

$$
c=2 \frac{\chi-\rho_{0} b}{b^{2}}
$$

A partir das Eqs. (8.1), (8.5), (8.6) e (8.8), a corrente $I_{S D}$ para o PFET pode ser escrita como: 


$$
\mathrm{I}_{\mathrm{SD}}=\int_{0}^{b} \rho \nu L d y=\mathrm{L} \int_{0}^{\mathrm{b}}\left(c y+\rho_{0}\right) \mu E \frac{1}{1+\frac{\mu}{\mathrm{v}_{s}} E} \mathrm{dy}
$$

Desenvolvendo a integral da Eq. (8.9), com $\mu$ dado pela Eq. (8.4), obtemos a dependência de $I_{S D} \operatorname{com} V_{S D}$ :

$$
\mathrm{I}_{\mathrm{SD}}=\operatorname{Lb}\left[\mathrm{b}\left(\frac{1}{2}+\frac{k}{3}\right) \cdot\left(2 \frac{\chi-\rho_{o} \cdot b}{b^{2}}\right)+\rho_{0}\right]\left[\frac{\mu_{0} e^{\alpha \sqrt{\mathrm{E}}}}{1+\frac{\mu_{0} e^{\alpha \sqrt{\mathrm{E}}}}{v_{s}} \mathrm{E}}\right] \mathrm{E}
$$

que é a equação da corrente para um dispositivo tipo PFET utilizando as características descritas nos tópicos $(i)$ à $(i v)$.

A título de ilustração, a Fig. 8.5-(a) mostra as características físicas do PFET, a Fig. 8.5-(b) esquematiza a dependência da mobilidade dos portadores positivos ao longo do eixo y (a seta indica a variação crescente dessa grandeza), a Fig. 8.5-(c) mostra a influência de $V_{G}$ na densidade de portadores ao longo de y e, por último, a Fig. 8.5-(d) mostra a representação da densidade de corrente injetada pelos eletrodos no polímero $\left(J_{o}\right)$ e a corrente de retrodifusão ( $\left.J^{\prime}\right)$

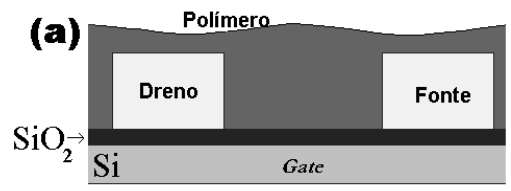

(b)
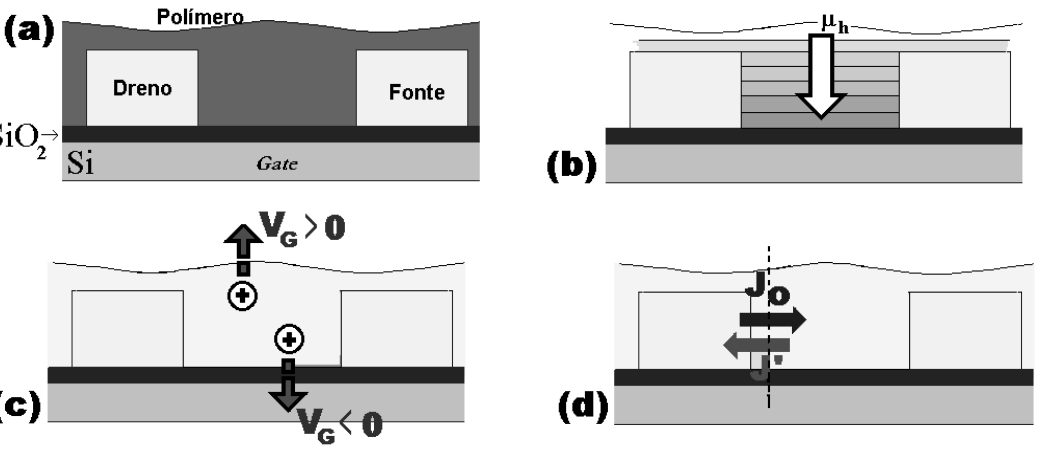

Figura 8.5: Esquema representativo das considerações usadas no modelo do PFET. (a) características físicas do dispositivo, e esquematização da: (b) variação da mobilidade ao longo de $y$, (c) variação da densidade de portadores ao longo de $y$ (no caso, portadores positivos) e (d) corrente de injeção ( $\mathrm{j}_{\mathrm{o}}$ ) e de retrodifusão (j').

A Fig. 8.6 reapresenta as curvas $I_{S D} v s$. $V_{S D}$ dos PFETs de POMA não dopada, mostradas na Fig. 8.2, com os ajustes obtidos através da Eq. (8.10). Os parâmetros de ajustes são mostrados na Tabela 8.I. Essa tabela também apresenta os valores da corrente de saturação $\left(I_{S}\right)$ desse dispositivo obtidos com $V_{S D}=2,5 \mathrm{~V}$. 


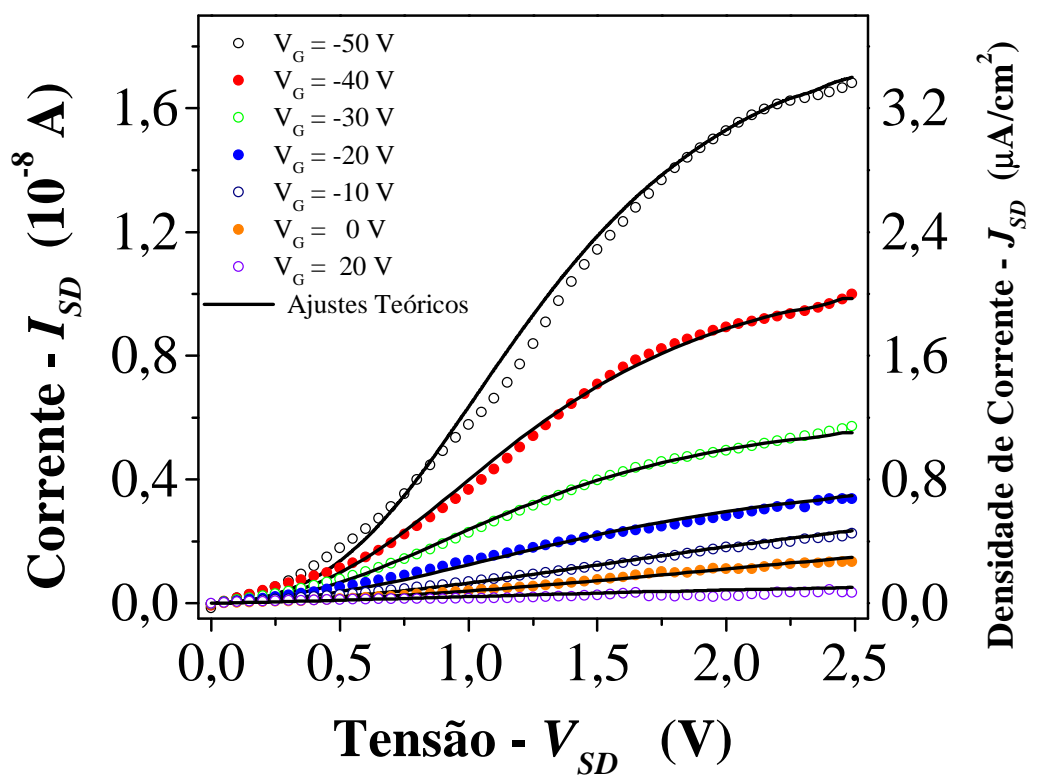

Figura 8.6: Medidas $I_{S D}$ vs. $V_{S D}$, ajustadas pela Eq. (8.10), curvas cheias (一), do PFET de POMA não dopada com $\mathrm{W}=10 \mu \mathrm{m}$ e diferentes valores de $V_{G}$.

Tabela 8.I: Parâmetros obtidos com o ajuste das curvas da Fig. 8.6 com a Eq. (8.10). Para todos os ajustes: $\mathrm{k}=0,5, \chi=1,5 \times 10^{-14} \mathrm{C}, \alpha=0,112(\mathrm{~cm} / \mathrm{V})^{1 / 2}$ e $\mu_{0}=7,0 \times 10^{-5} \mathrm{~cm}^{2} / \mathrm{Vs}$.

\begin{tabular}{||c|c|c|c|c||}
\hline $\boldsymbol{V}_{\boldsymbol{G}}(\mathbf{V})$ & $\rho_{\mathbf{0}}\left(\mathbf{C}_{\mathbf{c m}}\right)$ & $v_{\mathbf{S}}(\mathbf{c m} / \mathbf{s})$ & $\mathbf{c}\left(\mathbf{C}^{\mathbf{3}} \mathbf{c m}^{\mathbf{2}}\right)$ & $\boldsymbol{I}_{\boldsymbol{S}} \mathbf{( A )}$ \\
\hline $\mathbf{- 5 0}$ & $4,5 \times 10^{-4}$ & 10,50 & -168 & $1,7 \times 10^{-8}$ \\
\hline $\mathbf{- 4 0}$ & $3,3 \times 10^{-4}$ & 6,40 & -120 & $1,0 \times 10^{-8}$ \\
\hline $\mathbf{- 3 0}$ & $1,8 \times 10^{-4}$ & 3,70 & -60 & $5,7 \times 10^{-9}$ \\
\hline $\mathbf{- 2 0}$ & $4,5 \times 10^{-5}$ & 2,30 & -6 & $3,4 \times 10^{-9}$ \\
\hline $\mathbf{- 1 0}$ & $3,0 \times 10^{-5}$ & 1,00 & 0 & $2,3 \times 10^{-9}$ \\
\hline $\mathbf{0}$ & $1,0 \times 10^{-5}$ & 0,50 & 8 & $1,4 \times 10^{-9}$ \\
\hline $\mathbf{2 0}$ & $1,0 \times 10^{-5}$ & 0,20 & 12 & $5,1 \times 10^{-10}$ \\
\hline
\end{tabular}

Da Tabela 8.I observamos que os parâmetros $\rho_{0}$ e $v_{s}$ diminuem com $V_{G}$, enquanto que $c$ aumenta. Por outro lado, os parâmetros $\mathrm{k}, \chi, \mu_{0}$ e $\alpha$ são independentes do valor dessa tensão. É, também, de se esperar que $\rho_{0}$ diminua e o parâmetro $c$ aumente à medida que $V_{G}$ aumente, e que a velocidade de saturação dos portadores diminua à medida que $V_{G}$ aumente, corroborando ao fato da densidade de armadilhas próxima à interface polímero-ar ser maior do que na interface polímero-óxido. $\alpha$ é um parâmetro que depende da estrutura desordenada do filme polimérico, não devendo, em princípio, depender de $V_{G}$, e o valor de $\mu_{0}$ obtido (da ordem de $10^{-5} \mathrm{~cm}^{2} / \mathrm{Vs}$ ) é típico da mobilidade dos portadores encontrados em PFETs ${ }^{[43]}$. 
Para verificar a validade do modelo utilizado, a Fig. 8.7 apresenta duas curvas que representam duas situações distintas. (a) tomando-se $\mu$ independente do campo (curva a), e (b) tomando-se $v_{\mathrm{s}}<<\mu \mathrm{E}$ (curva b).

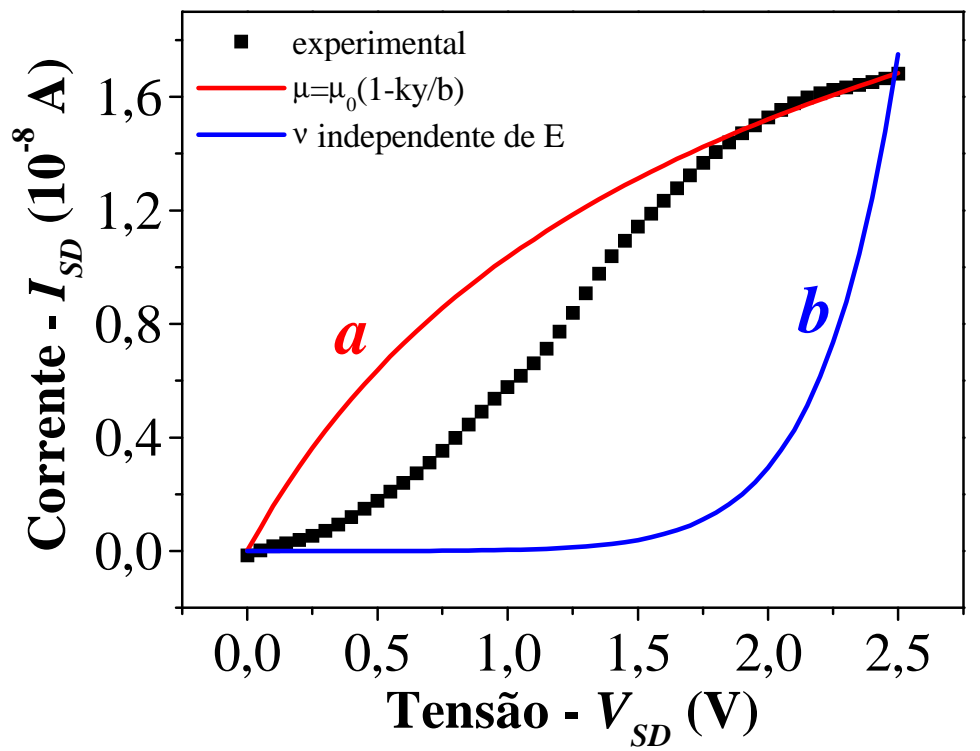

Figura 8.7: Medida $I_{S D}$ vs. $V_{S D}, V_{G}=-50$, do PFET de POMA não dopada com $\mathrm{W}=10 \mu \mathrm{m}$ e as curvas obtidas com o ajuste pela Eq. (7.8) levando-se em consideração $\mu \equiv \mu_{0}(1-\mathrm{ky} / b)$ (curva $a$ ) e $v_{=} v_{\mathrm{s}}$ (curva b).

Como pode ser observado, a curva $a$ é típica de transistores inorgânicos e a curva (b) é típica de um diodo, e ambas diferenciam, em muito, do resultado experimental. Esses dois comportamentos corroboram ao fato de que a mobilidade dos portadores deve variar tanto com o campo elétrico, quanto com a velocidade de saturação dos portadores de carga.

\subsection{Discussão dos Resultados}

Nesse capítulo apresentamos os resultados obtidos com transistores de efeito de campo de POMA. Para a confecção desses dispositivos, inúmeras etapas de caráter científico e tecnológico tiveram de ser vencidas e controladas durante o desenvolvimento desse projeto, dentre elas: (i) a confecção de filmes de dióxido de silício que apresentassem alta resistividade elétrica, procurando-se evitar correntes de fuga entre os eletrodos fonteporta e dreno-porta, (ii) o domínio das técnicas de litografia para a confecção dos eletrodos dreno e fonte, (iii) a escolha do polímero usado como elemento ativo, que apresentasse reprodutividade das medidas obtidas, (iv) a escolha dos parâmetros de medidas elétricas, 
tais como o delay time e o hold time, e (v) o desenvolvimento de um modelo teóricoexperimental que explicasse o comportamento dos dispositivos através das propriedades da POMA.

Vencidas as primeiras 4 etapas, os resultados obtidos com os dispositivos de POMA mostraram que as características elétricas desse dispositivo são fortemente influenciadas pela distância dos eletrodos dreno e fonte, e pelo grau de dopagem do polímero em solução aquosa de ácido clorídrico. Tanto para a POMA dopada, quanto para distâncias dreno-fonte maiores que $10 \mu \mathrm{m}$, o comportamento das curvas $I_{S D} v s . V_{S D}$ não foram modulados com $V_{G}$. Para distâncias maiores que $10 \mu \mathrm{m}$, supomos que os portadores alcancem a sua velocidade de saturação muito próxima ao eletrodo fonte, alcançando o comportamento ôhmico rapidamente. Com o aumento da dopagem a densidade de portadores deve ser grande o suficiente, de maneira que, a aplicação de $V_{G}$ não seja capaz de controlar o fluxo de portadores ao longo de y. Já quando a POMA está fracamente dopada, devido a protonação durante a sua síntese química, as curvas do dispositivo são moduladas por $V_{G}$, mas o ganho dos transistores ainda é muito baixo.

Para explicar o comportamento das curvas $I_{S D} v s$. $V_{S D}$ desse dispositivo, um modelo baseado nas propriedades da POMA, na variação da densidade de portadores ao longo do eixo $y$, na dependência da mobilidade com o campo elétrico, e na formação de contatos ôhmicos dos eletrodos dreno e fonte com o polímero foi desenvolvido e aplicado com relativo sucesso. Os resultados dos ajustes obtidos forneceram, entre outras características, que os portadores de carga da POMA são positivos quando dopadas em meio ácido, de acordo com medidas de fotocondução por tempo de vôo obtidas recentemente por S. Mergulhão et al. ${ }^{[100]}$. Também foi bastante razoável o valor da mobilidade encontrado em torno de $10^{-5} \mathrm{~cm}^{2} / \mathrm{Vs}$, que é o valor esperado para esses sistemas ${ }^{[43]}$.

Portanto os resultados desse capítulo mostram a viabilidade do uso de polímeros eletrônicos como materiais ativos em transistores, mas, para se alcançar valores maiores de corrente, e maior tempo de operação, é necessário ainda muito investimento no seu desenvolvimento tecnológico. Um fator limitante, e de difícil solução, é oriundo da baixa mobilidade eletrônica dos sistemas poliméricos, devido ao alto grau de desordem morfológica do material e, também, a grande concentração de armadilhas de portadores. 


\section{Capítulo 9}

\section{Conclusão}

Apesar de recente, a área de dispositivos eletrônicos e optoeletrônicos de polímeros tem alcançado enorme sucesso e desponta como uma área de grande interesse tecnológico. Isso se deve aos resultados animadores que vêm sendo obtidos, e pela real perspectiva de esses dispositivos se tornarem comerciais. Entretanto, essas pesquisas ainda estão em fase preliminar em se referenciando o aspecto de produção. Muitos problemas tecnológicos relacionados à eficiência e ao tempo de vida dos dispositivos ainda não estão vencidos, e demanda investigações sobre fenômenos de degradação da estrutura dos polímeros e sobre efeitos deletérios nas interfaces metal-polímero. Tem-se observado que em contínua operação os dispositivos, quando sob tensão aplicada e em contato com a umidade, a luz e a atmosfera ambiente, se degradam. A luz combinada com o oxigênio causa um efeito de foto-degradação na estrutura do polímero conjugado e o campo elétrico estimula processos físico-químicos na(s) interface(s) metal-polímero, ambos os efeitos levando à falência as propriedades elétricas e/ou ópticas dos dispositivos e, conseqüentemente, à sua inoperância.

O presente trabalho pretendeu contribuir para a área de dispositivos poliméricos e para o entendimento de alguns efeitos prejudiciais ao seu desempenho. Foram abordados dois tipos de dispositivos: um transistor por efeito de campo (PFET) e diodos emissores de luz (PLEDs). Os polímeros estudados foram: a polianilina e seu derivado, a poli(ometoxianilina) (POMA), e o poli( $p$-fenilenovinileno) (PPV) e seu derivado poli[(2metóxi,5-hexilóxi)-p-fenilenovinileno] (MH-PPV). Uma das contribuições originais desta tese foi o estudo do PLED de MH-PPV, mais um material luminescente pertencente à família do PPV. O trabalho de pesquisa desta tese pode ser dividido em duas partes. A primeira relacionada ao estudo de propriedades dos polímeros PANI e dos PPVs, e os efeitos de fotoxidação de sua estrutura. A segunda na confecção, análise e estudo das propriedades dos dispositivos (PFET e PLEDs). Esses estudos usaram muitas técnicas experimentais; técnicas necessárias à fabricação do elemento ativo polimérico, como as rotas de síntese e as de fabricação de filmes finos, métodos usados em sua caracterização, e 
técnicas de estudo de propriedades elétricas e ópticas tanto dos filmes poliméricos, como dos dispositivos já montados, e finalmente várias técnicas usadas, e adaptadas, na fabricação dos dispositivos. Essa riqueza e variedade de métodos científicos mostram o caráter multidisciplinar (física, química e engenharia) que envolve a pesquisa na área de dispositivos poliméricos. Além disso, o trabalho de modelagem, e ajuste, dos resultados experimentais obtidos nos estudos de foto-degradação do MH-PPV, de mecanismos de condução nos polímeros eletrônicos e nos de caracterização de dispositivos, proporcionaram um entendimento mais pormenorizado do funcionamento dos dispositivos, abrindo perspectivas de melhora em seu desempenho e indicando meios de solucionar efeitos nocivos responsáveis pela queda de eficiência e de tempo de vida.

Podemos sumarizar as contribuições desta tese com os seguintes itens:

a) Síntese e preparação de filmes dos polímeros;

b) Caracterização óptica dos filmes (elipsometria, absorção óptica e fotoluminescência);

c) Estudos de propriedades elétricas dos filmes da PANI;

d) Estudos de foto-degradação do MH-PPV;

e) Confecção dos dispositivos;

f) Estudo e caracterização dos dispositivos;

g) Modelagem física das propriedades elétricas e ópticas de filmes poliméricos e elétrica dos dispositivos PFETs e PLEDs.

Como resultado desta tese, até o momento já foi publicado um trabalho em revista indexada, outros dois foram enviados à publicação e um está em fase de preparação.

A título de ilustração, a Fig. 9.1mostra alguns padrões de ITO obtidos pelo processo de decapagem, utilizado durante este trabalho, com a geometria necessária para a confecção de displays de matriz passiva. A Fig. 9.1-(a) mostra 3 eletrodos de ITO com largura de 1,4 mm, e comprimento em torno de $6 \mathrm{~mm}$, separados por 1,0 mm. Já a Fig. 9.1-(b) apresenta 14 pares de eletrodos interdigitais com largura e separação de $0,1 \mathrm{~mm}$. 

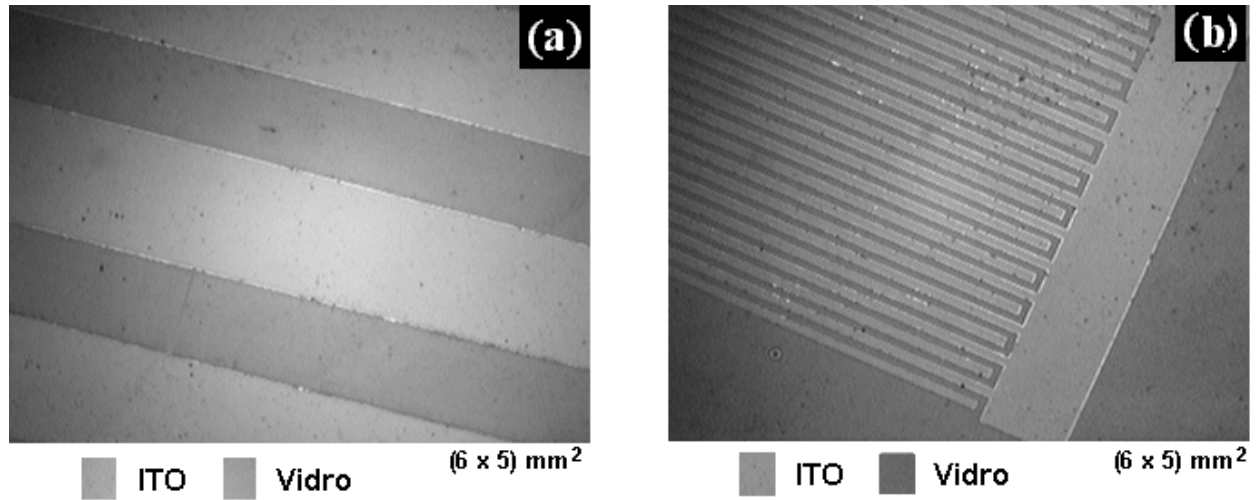

Figura 9.1: Imagens de microscopia óptica de padrões de ITO obtidos pelo processo de litografia lift off e de decapagem com $\mathrm{HCl}+\mathrm{Zn}$. A figura (a) apresenta 3 eletrodos de ITO com largura de 1,4 mm e com separação de 1,0 mm. A Figura (b) apresenta 15 pares de eletrodos com largura e separação de $0,1 \mathrm{~mm}$.

A Fig. 9.2 mostra a foto do primeiro PLED ITO/PPV/Al preparado durante o desenvolvimento desse trabalho. O dispositivo ficou em operação por cerca de 10 horas em condições ambientais.

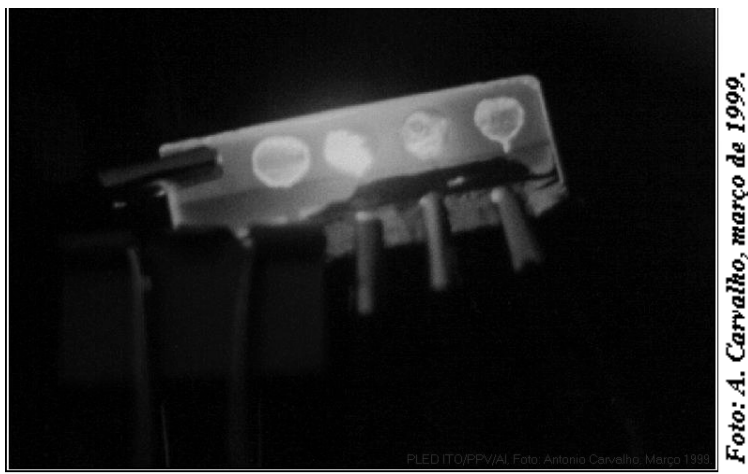

Figura 9.2: PLED ITO/PPV/Al em operação no Grupo de Polímero Bernhard Gross.

Para trabalhos futuros sugerimos a continuidade das medidas elétricas com os dispositivos PFET e PLEDs em diferentes temperaturas, procurando uma melhor compreensão nos mecanismos microscópicos de transporte no volume do material polimérico e nos de injeção de portadores pelos eletrodos. Essa tese deu início a essas propostas, apresentando resultados significativos de curvas $J$ vs $V$ de diodos em diferentes temperaturas (para LEDs com PPV e MH-PPV), e a inclusão de primeiras análises de condução pelo modelo Random Free Energy Barrier e de injeção que considerou não um mecanismo clássico termo-iônico (Richardson-Schottky) ou de tunelamento (FowlerNordheim), mas um processo via saltos (hopping) (ou tunelamento assistido por fônons) 
dos elétrons do nível de Fermi do metal para estados localizados próximos à superfície do polímero. Outra linha muito importante na continuidade do presente trabalho, e de meta com desdobramentos de interesse tecnológico, é o estudo de novos materiais de eletrodo, ou processos, que envolvem a injeção de portadores negativos nos dispositivos LEDs, e também na investigação de materiais e processos envolvidos com o encapsulamento dos dispositivos. Esse último tópico é de vital importância para o prolongamento do tempo de operação dos dispositivos, evitando, principalmente, efeitos de oxidação e de fotooxidação de suas camadas ativas. 


\section{Referências}

[1] SESSLER, G.M., Topics in Applied Physics 33, Ch 5 e 7, $2^{\text {nd }}$ Ed., Springer-Verlag (1987).

[2] SESSLER, G.M., Topics in Applied Physics 33, Ch 2, 5, e 7, $2^{\text {nd }}$ Ed., Springer-Verlag (1987).

[3] CHIANG C.K.; FINGER C.R.; PARK Y.W.; HEEGER A.J; SHIRAKAWA H.; LOUIS E.J.; GRAU S.C. \& MACDIARMID A.G., Electrical conductivity in doped polyacetylene, Phys. Rev. Let. 39, 1098 (1977).

[4] SKOTHEIN T.A., Handbook of conducting polymers Vol I, ${ }^{\text {st }}$ Ed., Marcel Dekker Inc. (1986).

[5] NALWA H.S., Organic conductive molecules and polymers, $1^{\text {st }}$ Ed., John Wiley \& Sons (1997).

[6] BURROUGHES J.H., JONES C.A., FRIEND R.H., New semiconductor device physics in polymer diodes and transistors, Nature 335, 8, 137 (1988).

[7] TANG C.W., VAN SLYKE S.A., Organic electroluminescent diodes, Appl. Phys. Let. 51, 913 (1987).

[8] BURROUGHES J.H., BRADLEY D.D.C., BROWN A.R., MARKS R.N., MACKAY K., FRIEND R.H., BURNS P.L., HOLMES A.B., Light-emitting diodes based on conjugated polymers, Nature 347, 539 (1990).

[9] GREENHAM N.C., FRIEND R.H., Semiconductor device physics of conjugated polymers, Sol. Stat. Phys. 49, 1 ( 1995).

[10] GUSTAFSSON G., CAO Y., TREACY G.M., KLAVETTER F., COLANERI N., HEEGER A.H., Flexible light-emitting diodes made from soluble conducting polymers, Nature 357, 477 (1992).

[11] BAIGENT D.R., GREENHAM N.C., GRÜNER N.C., MARKS R.N., FRIEND R.H., MORATTI S.C., HOLMES A.B., Light-emitting diodes fabricated with conjugated polymers - recent progress, Synth. Met. 67, 3 (1994).

[12] POPE M., SWENBERG C.E., Electronic process in organic crystals and polymers, Clarenfon press, $2^{\text {nd }}$ Ed., Oxford Press (1999).

[13] KRAFT A., GRIMSDALE A.C., HOLMES A.B., Electroluminescence conjugated polymers - seeing polymers in a new light, Nangew. Chem. Int. Ed., 37, 402 (1998).

[14] ARBIZZANI C., MASTROGOSTINO M., SCROSATI B., Conducting polymers for batteries, supercapacitors and optical devices, in Organic Conductive Molecules and Polymers, Ch 5, 595, Ed. by Nalwa H. S, John Wiley \& Sons (1997).

[15] FRIEND R.H., GYMER R.W., HOLMES A.B., BURROUGHES J.H., MARKS R.N., TALIANI C., BRADLEY D.D.C., DOS SANTOS D.A., BRÉDAS J.L., LÖGDLUND M., SALANECK R., Electroluminescence in conjugated polymers, Nature 397, 121 (1999).

[16] FRIEND R., BURROUGHES J., SHIMODA T., Polymer diodes, Phys. Word 12, 6, 35 (1999).

[17] Uniax, página da internet, em www.uniax.com.

[18] CDT, página da internet, em www.cdtltd.co.uk.seiko.htm.

[19] Philips, página da internet, em www.philips.com.

[20] SHEATS J.R., ANTONIADIS H., HUESCHEN M., LEONARD W., MILLER J., MOON R., ROITMAN D., STOCKING A., Organic electroluminescent devices, Science 27, 5277, 884 (1996).

[21] CUMPSTON B.H., JENSEN K.L., Photo-oxidation of electroluminescent polymers, TRIP 4, 5, 151 (1996).

[22] PARKER I.D., CAO Y., YANG C.Y., Lifetime and degradation effects in polymer light-emitting diodes, J. Appl. Phys. 85, 4, 2441 (1999). 
[23] MANCA J, BIJNENS W, KIEBOOMS R, D'HAEN J, D'OLIESLAEGER M, WU TD, DE CEUNINCK W, DE SCHEPPER L, VANDERZANDE D, GELAN J, STALS L, Effect of oxygen on the electrical characteristics of PPV-LEDs, OPT. Mater. 9, 1, 134 (1998).

[24] ATREYA M., LI S., KANG E.T., NEOH K.G., MA Z.H., TAN K.L., HUANG W., Stabilty studies of Poly(2-methoxy-5-(2'-ethyl hexyloxy)-p-(phenylenevinylene)) [MEH-PPV], Polym. Degrad. Stab. 65, 287 (1999).

[25] GELINCK G.H., WARMAN J.M., The effect of photo-oxidation on the photo-conductivity of isolated polyphenylenevinylene chains, Chem. Phys. Let. 277, 361 (1997).

[26] MORGADO J., FRIEND R.H., CACCIALI F., Environmental aging of poly(p-phenylenvinylene) based light-emitting diodes, Synt. Met. 114, 189 (2000).

[27] DAVIDS P.S., CAMPBELL I.H., SMITH D.L., Device model for single carrier organic diodes, J. Appl. Phys. 82, 12 , 6319 (1997).

[28] PARKER I.D., Carrier tunneling and device characteristics in polymer light-emitting diodes, J. Appl. Phys. 75, 3, 1656 (1994).

[29] HÜMMELGEN I. A., ROMAN L.S., NART F.C., PÉRES L.O., SÁ E.L., Polymer and polymer/metal interface characterization via Fowler-Nordheim tunneling measurements, App. Phys. Let. 28, 22, 3194 (1996).

[30] SCHER H., LAX M., Stochastic transport in a disordered solid. I. Theory, Phys. Rev. B 7, 10, 4491 (1973).

[31] BRÜTTING W., BERLEB S., MÜCKL A.G., Device physics of organic light-emitting diodes based on molecular materials, Organic Elec. 2, 1 (2001).

[32] MORGADO J., THOMAS D.S., FRIEND R.H., CACIALLI F., Role of indium chloride on the luminescence properties of PPV, Synt. Met. 111-112, 549 (2000).

[33] SCOTT J.C., KAUFMAN J.H., BROCK P.J., DIPIETRO R., SALEM J., GOITIA J.S., Degradation and failure of MEH-PPV light-emitting diodes, J. Appl. Phys. J 75, 5, 2745 (1996).

[34] CORNIL J., BELJONNE D., CALBERT J.P., BRÈDAS J.L., Interchain interaction in organic $\pi$ conjugated materials: impact on electronic structures, optical response and charge transport, Adv. Mat. 14, 13, 1053 (2001).

[35] SKOTHEIN T.A., Handbook of conducting polymers Vol I, Ch. 21, 22 e 24, $1^{\text {st }}$ Ed., Marcel Dekker Inc. (1986).

[36] FRIEND R.H., Electronic properties of conjugated polymers, Phys. Chem. Elec. Ions in Cond. Mat., 625 (1984).

[37] PEIERLS R.E., Quantum theory of solids, Clar. Press, Oxford (1995).

[38] HOLMES A.B., BRADLEY D.D.C., BROWN A.R., BURN P.L., BURROUGHES J.H., FRIEND R.H., GREENHAM N.C., GYMER R.W., HALLIDAY D.A., JACKSON R.W., KRAFT A., MARTENS J.H.F., PICHLER K. SAMUEL I.D.W., Photoluminescence and electroluminescence in conjugated polymeric systems, Synt. Met. 55-57, 4031 (1993).

[39] KRASOVITSKII B.M., BOLOTIN B.M., Organic luminecent materials, VCH Pub. (1998).

[40] GARNIER F., HAJLAOUI R., YASSAR A., SRIVASTAVA P., All-polymer field-effect transistor realized by printing techniques, Science 265, 1684 (1994).

[41] SCOTT C., Electronics put in on plastics, Phys. World, Oct (1998).

[42] DRURY C.J., MUTSAERS C.M.J., HART C.M., MATTERS M., LEEUW D.M., Low-cost all-polymers integrated circuits, App. Phys. Let. 73, 1, 108 (1998).

[43] PALOHEINO J., PUNKKA E., STUBB H., KUIVALAINEM P., Lower-dimensional systems and molecular electronics, E. R.M. Metzer et. Al, Plenum Press, NY, 635 (1991).

[44] KUO C.T., CHIOU W.H., Field-effect transistor with polyaniline thin film as semiconductor, Synt. Met. 88, 23 (1997).

[45] SIRRINGHAUS H., TESSLER N., FRIEND R.H., Integrated optoeletronic devices based on conjugated polymers, Science 280, 1741 (1998). 
[46] BIANCHI R.F., ONMORI R.K., GONÇALVES D., ANDRADE A.M., FARIA R.M, IRENE E.A., An electrical study of a thin film poly(o-methoxyaniline) field-effect transistor, Synt. Met. 121, 1687 (2001).

[47] WESSLING R.A. \& ZIMMERMAN R. G., Polyelectrolytes from bis sulfonium salts, U.S.P.O. 3.401.152, September (1968).

[48] MASSARDIER V., GUYOT A. \& TRAN V.H.; Direct conversion of sulfonium precursors into poly(pphenylenevinylene) by acids, Polymer 35, 7, 1591 (1994).

[49] BRADLEY D.D.C.; Precursor-route poly(p-phenylenevinylene): polymer characterization and control of electronic properties, J. Phys. D: Appl. Phys 20, 1389 (1987).

[50] WUDL F., SRDANOV G.; Conducting polymer formed of poly(2-methoxy,5-2'-ethyl-hexyloxy)pphenylenevinylene), U.S.P.O. 5.189.136, Feb. (1993).

[51] BRÉCLES J. L., Conjugated olygomers, polymer, and dendrimers: from polyacetyilene to DNA, Proc. of the Fourth Fran. Coll., Oct., Brussels (1998).

[52] MATTOSO L.H.C., in Síntese, Caracterização e Processamento de Polianilinas e seus Derivados, Tese de Doutorado, UFSCar, DEMA (1993).

[53] GENIES E.M., BOYLE A., LAPKOWSKI M., TSINITAVIS C., Polyaniline: a historical survey, Synt. Met. 36, 139 (1990).

[54] BIANCHI R.F., Aplicações do modelo de distribuição aleatória de barreiras de energia livre em mecanismos de condução iônico ou eletrônico em sistemas desordenados: polianilinas, ormolytes $e$ perovskitas tipo $\mathrm{SrTi}_{(1-x)} R u_{x} \mathrm{O}_{3}$, Dissertação de Mestrado, IFSC (1997).

[55] HALLIDAY D.A., BURN P.L., FRIEND R.H., BRADLEY D.D.C., HOLMES A.B., Determination of the average molecular weight of poly(p-phenylenevinylene), Synth. Met. 55-57, 902 (1993).

[56] KERN W., Purifying Si and $\mathrm{SiO}_{2}$ surfaces with hydrogen peroxide, Semiconductor International 94, Ap. (1984).

[57] KIM J.S., GRANATRRÖM M., FRIEND R.H., JOHANSSON N., SALANECK W.R., DAIK R., FEAST J., CACIALLI F., Indium-tin oxide treatments for single-and double layer polymeric lightemitting diodes: The relation between the anode physical, chemical, and morphological properties and the device performance, J. Appl. Phys. 84, 12, 6859 (1998).

[58] SASSAKI C.A.,Estudo de filmes finos de $\mathrm{In}_{2} \mathrm{O}_{3}$ :Sn por evaporação reativa, Dissertação de Mestrado, Escola Politécnica/USP (1989).

[59] ETTEDGUI E., DAVIS G.T., HU B., KARASZ F.E., Degradation of polymer-based light-emitting diodes during operation, Synt. Met. 90, 73 (1997).

[60] SHEATS J.R., ROITMAN D.B., Failure modes in polymer-based light-emitting diodes, Synt. Met. 95, 79 (1998).

[61] FUNG M.K., GAU Z.Q., LEE C.S. LEE S.T., Inhibition of dark spots growth in organic electroluminescen devices, Chem. Phys. Lett. 333, 432 (2001).

[62] TOMPKINS H.G. An user's guide to ellipsometry, Acad. Press Inc. (1993).

[63] WALL J.F., BRUMFIELD J.C., MURRAY R.W., IRENE E.A., Spectroscopic ellipsometry and microscopy of polyphenylene oxide-films, J. Elec. Soc. 141, 1, 306 (1994).

[64] COLLINS R.W., IRENE E.A., Ellipsometric fundamentals and applications, Mat. Res. Soc. Meeting, Short Course, San Francisco (1995).

[65] SAAH H.V., ARBUCKLE G.A., A comprehensive analysis of thermal elimination reaction in a poly( $p$ phenylene vinylene) precursor, Macromolecules 32, 1413 (1999).

[66] MORGADO J., CACIALLI F., GRÜNER J., GREENHAM N.C., FRIEND R.H., Luminescent properties of poly(p-phenylenevinylene): role of the convertion temperature on the photoluminescence and electroluminescence efficiences, J. Appl. Phys. 85, 13, 1784 (1999).

[67] SEOUL C., KANG J.I., MAH S., LEE C.H., Preparation of light-emitting devices with poly(pphenylenevinylene): effects of thermal elimination conditions and polymer layer thickness on device performance, Synt. Met. 99, 35 (1999). 
[68] MARCONI F.M., Dissertação de mestrado, IFSC, em andamento.

[69] SANTOS L.F., MARCONI F., BIANCHI R.F., MARLETTA A., NUNES L.A.O., FARIA R.M., BALOGH D.T., Line shape analysis of photoluminescence spectra on solutions of MD-PPV, Mat. Res. Soc. Bulletin, aceito à publicação.

[70] ARWIN H., JANSSON R., Line Shape analysis of ellipsometric spectra on thin conducting polymer films, Electr. Acta 39, 2, 211 (1994).

[71] FRANTA D., OHLÍDAL I., MUNZAR D., Parametrization of the model of dispersion dependences of solid state optical constants, Acta Phys. Slov. 48, 4, 451 (1998).

[72] DRAKE G.W.F., Atomic molecular \& optical physics handbook: light-matter interaction, 765, AIP Press (1996).

[73] DYRE J.C., SCHRODER T.B., Universality of AC conduction in disordered solids, Rev. Mod. Phys. 72, 3,873 (2000).

[74] BIANCHI R.F., LEAL FERREIRA G.F., LEPIENSKI C.M, FARIA R.M., Alternating conductivity of polyaniline, J. Chem. Phys. 110, 9, 4602 (1999).

[75] JEON, D.; KIM, J.; GALLAGHER, M.C., WILLIS, R.F., Scanning tunneling spectroscopic evidence for granular metallic conductivity in conducting polymeric polyaniline, Science 256, 19 (1992).

[76] LEPIENSKI C.M.; FARIA R.M., LEAL FERREIRA G.F., AC conductivity in doped and undoped Poly(o-methoxyaniline); Appl. Phys. Let 70, 14, 1 (1997).

[77] ODAGAKI T., LAX M., Coherent-medium approximation in the stochastic transport theory of random media; Phys. Rev. B 24, 5284 (1981).

[78] ASPNES D.E., Optical properties of thin-films, Thin Sol. Films 89, 3, 249 (1982).

[79] CUMPSTON B.H., JENSEN K.F., Photo-oxidation of polymers used in electroluminescent devices, Synt. Met. 73, 195 (1995).

[80] CUMPSTON B.H., PARKER I.D., JENSEN K.F., In situ characterization of the oxidative degradation of a polymeric light emitting, J. App. Phys. 81, 8 (1997),

[81] CUMPSTON B.H., JENSEN K.F., Photooxidative stability of substituted poly(phenylene vinylene) (PPV) and poly(phenylene acetylene) (PPA), J. Appl. Pol. Sci. 69, 2451 (1998).

[82] BIANCHI R.F., BALOGH D.T., GONÇALVES D., FARIA R.M. IRENE E.A., Characterization of $M H-P P V$ films - photoxidative process using refractive index measurements, Mol. Cryst. Liq. Cryst. 374, 457 (2002).

[83] GROH W., ZIMMERMANN A., What is the lowest refractive-index of an organic polymer, Macromolecules 24, 25, 6660 (1991).

[84] VAN KREVELEN D.W., Properties of Polymers, $3^{\text {rd }}$ Ed., Elsevier Scie. Pub. (1990).

[85] YANG C.J., JENEKLE S.A., Group contribution to molar refraction and refractive index of conjugated polymers, Chem. Mater. 7, 1276 (1995).

[86] BIANCHI R.F., BALOGH D.T., TINANI M., FARIA R.M. IRENE E.A., Ellipsometry studied of the photo-oxidation of a PPV derivative, Polymer (submetido à publicação).

[87] CONWELL E.M., WU W., Current-voltage characteristics of polymer light-emitting diodes, Appl. Phys. Lett. 70, 1867 (1977).

[88] ARKIPOV V.I., EMMELLANOVA E.V., TAK Y.H., BÄSSLER H., Charge injection into light-emittng diodes: theory and experiment, J. Appl. Phys. 84, 2, 848 (1998).

[89] DAVIDS P.S., CAMPBELL I.H., SMITH D.L., Device model for single carrier organic diodes, J. Appl. Phys. 82, 12, 6319 (1997). 
[90] BÖTTCHER C.J.F, BORDEWIJ K., Theory of electric polarization - Vol II, Elsevier Scient. Pub. Comp., The Netherlands (1978).

[91] MEIER M., KARG S., RIESS W., Light-emitting diodes based on poly-p-phenylenevinilene: II. Impedance spectroscopy, J. Appl. Phys. 82, 4, 1961 (1997).

[92] HARRISON M.G., GRÜNER J., SPENCER G.C.W., Investigations of organic electroluminescent diodes by impedance spectroscopy, photo-impedance spectroscopy and modulated photovoltage spectroscopy, Synt. Met. 76, 71 (1996).

[93] RAMOS R.J., BIANCHI R.F., BALOGH D.T., FARIA R.M., Conductivity of carbon black-PE composites as a function of temperature and UV aging, IEEE Trans. Diel. and EI 7, 855 (2000).

[94] IRENE E.A., Applications of spectroscopic ellipsometry to microelectronics, Thin Sol. Films 233, 1-2, $96(1993)$

[95] ONMORI R.K., Fabricação, caracterização e modelamento de um dispositivo de efeito de campo a base de poli(o-metoxianilina), Tese de Doutoramento, Escola Politécnica/USP (1997).

[96] KAO K.C., HWANG W., Electrical transport in solids, Pergamon Press, Germany (1981).

[97] RAKHMANOVA S.V., CONWELL E.M., Electric-field dependence of mobility in conjugated polymer films, Appl. Phys. Let. 72, 25, 3822 (2000).

[98] BADAREU E., POPESCU I., in Gaz ionisès décharges électriques dans les gaz, Ed. Techinica (1965).

[99] SZE S.M., in Physics of semiconductor devices, pag. 325, $2^{\text {nd }}$ Ed., John Wiley \& Sons, (1981).

[100] MERGULHÃO S., FARIA R.M., LEAL FERREIRA G.F., SWRAKOWSKI J., Transport of holes in uniformly and non-uniformly protonated poly(o-methoxyaniline), Chem. Phys. Let. 269, 489 (1997). 


\section{Apêndice}

\section{A. Princípios da Técnica de Elipsometria}

Em geral, quando uma luz polarizada e monocromática é refletida pela superfície de um material, mudanças na sua fase $(\Delta)$ e amplitude $(\Psi)$ são, facilmente, detectadas ${ }^{[62,94]}$. Essas grandezas descrevem as propriedades ópticas dos materiais e são bastante afetadas com a presença de regiões heterogêneas microestruturais (1 à $\left.10^{3} \mathrm{~nm}\right)$, como os contornos de grãos, regiões desordenadas, voids, fases distintas, etc. ${ }^{[64,78]}$. Desse modo, a função dielétrica de um material depende de todas essas características e, por esse motivo, ela é usualmente definida como função pseudo-dielétrica $-\langle\varepsilon\rangle$. Assim, como $\langle\varepsilon\rangle$ depende das composições químicas, formas, tamanhos e das cargas de blindagem de cada uma dessas regiões, uma diferença entre os campos elétricos local e externo é originada em cada ponto no interior de um material. Além disso, tomando-se a definição de $\langle\varepsilon\rangle$ como momento de dipolo elétrico por unidade de volume, a magnitude dessa grandeza dependerá, fortemente, das contribuições de cada uma dessas regiões e, conseqüentemente, influenciará as propriedades ópticas finais dos materiais estudados. Variando-se a energia do feixe incidente e comparando os espectros obtidos com os espectros das regiões microestruturais isoladas, parâmetros como as frações volumétricas e as formas dessas regiões podem ser obtidas, ajudando a compreender as propriedades ópticas de um determinado material ${ }^{[64,94]}$.

Para estudar o comportamento de $\langle\varepsilon\rangle$ como função da energia de um feixe incidente, o intervalo entre o visível e o ultravioleta próximo, embora seja um intervalo mínimo, é usualmente utilizado por conter a maioria das informações sobre as ligações eletrônicas dos materiais e ser facilmente coberto pelos elipsômetros convencionais. Além disso, as respostas dielétricas das regiões individuais, quando convenientemente combinadas por modelos apropriados, podem reproduzir fielmente a resposta da função pseudo-dielétrica dos filmes em termos de parâmetros independentes da energia do feixe 
(como a espessura e as frações volumétricas das suas composições), com um mínimo erro quadrático médio (RMSE) ${ }^{[94]}$.

\section{A.1 $O$ cálculo de $(\Delta)$ e da amplitude $(\Psi)$}

A Fig. A1-(a) mostra a representação de uma amostra composta de um substrato coberto por múltiplos filmes de um ou mais materiais. Já a Fig. A1.(b) apresenta o esquema geométrico de um feixe de luz propagando-se da esquerda (direção $\vec{r}$ ) para a direita (direção $\vec{r}^{\prime}$ ), cujos componentes dos vetores elétricos iniciais são $\vec{E}_{x}$ e $\vec{E}_{y}$ e finais, $\vec{E}_{x}^{\prime}$ e $\vec{E}_{y}^{\prime}$. Nessa figura, $\vec{E}_{x}$ e $\vec{E}_{y}$ encontram-se, respectivamente, no plano de incidência e perpendicular a esse plano, enquanto $\vec{E}_{x}^{\prime}$ e $\vec{E}_{y}^{\prime}$ são elipticamente polarizados. $\vec{N}$ é o vetor normal ao filme e está contido no plano de incidência ${ }^{[62]}$.

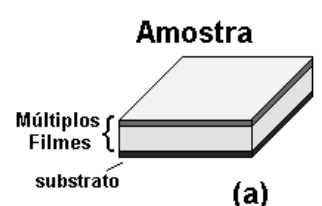

(b)

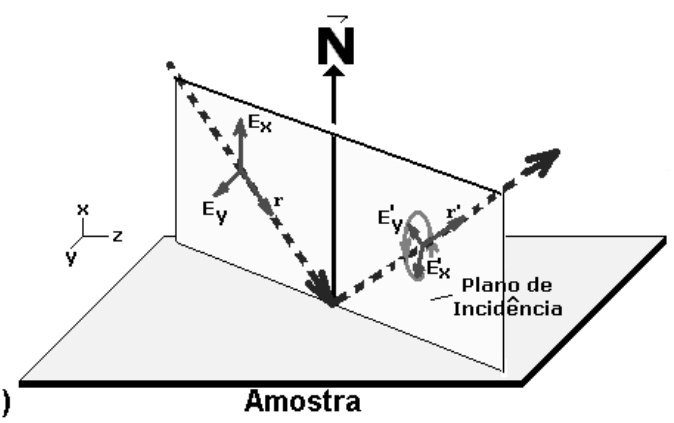

FIGURA A1: (a) Representação de uma amostra com múltiplos filmes sobre um substrato e (b) aspectos e geometrias básicas utilizados pela técnica de elipsometria.

Assim, definindo-se as diferenças de fase entre os componentes paralelas e perpendiculares do feixe incidente por $\delta_{1}(\lambda)$ e do feixe refletido por $\delta_{2}(\lambda), \Delta(\lambda)$ é obtido segundo:

$$
\Delta=\delta_{1}-\delta_{2}
$$

Além disso, a mudança nas amplitudes $\Psi(\lambda)$ é definida como o ângulo na qual a tangente é igual a razão entre as magnitudes dos coeficientes de reflexão de Fresnel, $\mathrm{R}^{\mathrm{X}} \mathrm{e}$ $\mathrm{R}^{\mathrm{y}[62]}$. A Eq. (A.2) mostra a relação entre $\Psi, \mathrm{R}^{\mathrm{x}}$ e $\mathrm{R}^{\mathrm{y}}$.

$$
\tan \Psi=\frac{\left|R^{x}\right|}{\left|R^{y}\right|}
$$

onde as quantidades $\mathrm{R}^{\mathrm{X}}$ e $\mathrm{R}^{\mathrm{y}}$ são definidas como: 


$$
R^{x}=\frac{E_{r}^{x}}{E_{i}^{x}} \quad e \quad R^{y}=\frac{E_{r}^{y}}{E_{i}^{y}}
$$

Assim, o coeficiente de reflexão complexo $\rho(\Delta, \Psi)$ é definido por:

$$
\rho=\frac{R^{x}}{R^{y}}
$$

e, conseqüentemente, a equação fundamental da elipsometria é obtida como:

$$
\rho=\tan \Psi e^{i \Delta}=\frac{R^{y}}{R^{x}}
$$

onde as quantidades $\Delta$ e $\Psi$ são obtidas, diretamente, pelos elipsômetros.

Em geral, $\rho$ depende das espessuras $\left(\ell_{\mathrm{i}}\right)$ dos filmes, do ângulo de incidência do feixe $\left(\phi_{0}\right)$ e do índice de refração dos diversos constituintes da amostra $\left(n_{i}\right)$. Para o caso de um único filme $\left(\ell_{1}\right.$ e $\left.n_{l}\right)$ sobre um determinado substrato $\left(n_{0}\right)$ e exposto ao ar $\left(n_{a r}\right), \rho$ pode ser escrito como ${ }^{[62,94]}$ :

$$
\rho=\tan \Psi e^{i \Delta}=\rho\left(n_{0}, n_{1}, n_{a r}, \ell_{1}, \phi_{0}, \lambda\right)
$$

onde $\lambda$ é o comprimento de onda do feixe incidente e os parâmetros $\Delta, \Psi, \lambda, \phi_{0}, n_{a r}$ e $n_{0}$ são, usualmente, conhecidos, o que reduz o número de parâmetros desconhecidos a, apenas, $\mathrm{n}_{1}$ e $\ell_{1}$. Portanto, utilizando modelos que envolvem médias efetivas entre dois ou mais meios, formação de filmes, de ilhas, de nucleação ${ }^{[64,78]}$, ou modelos que envolvendo teorias semiclássicas sobre as interações dos elétrons com um núcleo ${ }^{[70-72]}$, é possível obter $\rho$ com um mínimo erro quadrático médio e, em seguida, obter propriedades ópticas importantes dos materiais estudados,

\section{A.2 Usando $\rho(\Delta, \Psi)$ para determinar as propriedades ópticas}

A partir da obtenção de $\rho(\lambda)$ é possível determinar algumas propriedades físicas importantes sobre um dado material. A Eq. (A.7) mostra a expressão que relaciona $\rho(\lambda)$ $\operatorname{com}\langle\varepsilon(\lambda)\rangle$, ou simplesmente, $\langle\varepsilon\rangle$

$$
\langle\varepsilon\rangle=\langle\varepsilon(\lambda)\rangle=\varepsilon_{1}+i \varepsilon_{2}=\operatorname{sen}^{2} \phi_{0}\left[1+\tan ^{2} \phi_{0}\left(\frac{1-\rho}{1+\rho}\right)^{2}\right]
$$


onde $\varepsilon_{1}$ e $\varepsilon_{2}$ são os componentes real e imaginária de $\langle\varepsilon\rangle$. Desse modo, de acordo com Aspen ${ }^{[78]}$, tomando-se o exemplo de um filme fino exposto ao ar e sobre um substrato, a função pseudo-dielétrica desse sistema é obtida como:

$$
\langle\varepsilon\rangle=\varepsilon_{0}+\frac{4 \pi i \ell n_{a r}}{\lambda} \frac{\varepsilon_{0}\left(\varepsilon_{0}-\varepsilon\right)\left(\varepsilon_{0}-\varepsilon_{a r}\right)}{\varepsilon\left(\varepsilon_{s}-\varepsilon_{a r}\right)}\left(\frac{\varepsilon_{0}}{\varepsilon_{a r}}-\operatorname{sen}^{2} \phi_{0}\right)^{1 / 2}
$$

onde, $\ell$ e $\varepsilon$ são, respectivamente a espessura e a função dielétrica do filme, $\varepsilon_{0}$ a função dielétrica do substrato, $\varepsilon_{\mathrm{ar}}$ a função dielétrica do ar e $\phi_{0}$ e $\lambda$, respectivamente, o ângulo e o comprimento de onda do feixe incidente. Portanto, obtendo-se $\rho$, através da Eq. (A.5), é possível obter $\langle\varepsilon\rangle$ pela Eq. (A.7) e encontrar os valores de $\ell$ e $\varepsilon$ que satisfaçam a Eq. (A.8). Em seguida, o índice de refração complexo $\left(\mathrm{N}^{*}=\mathrm{n}+\mathrm{ik}\right)$ desse sistema pode ser calculado por:

$$
N^{*}=\sqrt{\langle\varepsilon\rangle}=n+i k=\sqrt{\operatorname{sen}^{2} \phi_{0}\left[1+\tan ^{2} \phi_{0}\left(\frac{1-\rho}{1+\rho}\right)^{2}\right]}
$$

onde $n$ e $k$ são os componentes real e imaginária de $\mathrm{N}^{*}$, e $k$ é denominado de coeficiente de extinção estando, diretamente, relacionado a constante de absorção $(\alpha)$ e ao comprimento de onda da luz no vácuo $\left(\lambda_{0}\right)$ :

$$
\alpha=\frac{4 \pi k}{\lambda_{0}}
$$

Desse modo, a partir da obtenção de $\Delta(\lambda)$ e $\Psi(\lambda)$, e utilizando modelos apropriados, é possível determinar as contribuições das regiões microestruturais no volume de um dado material. Entretanto, quando um material puro e desconhecido é analisado, algumas considerações importantes devem ser realizadas. A primeira delas é a eliminação da interação do substrato com o material. Para isso, um filme espesso dever ser preparado e medidas de $\Delta(\lambda)$ e $\Psi(\lambda)$ realizadas. Nesse caso, descontando o efeito do substrato, o espectro obtido servirá como uma base de dados do material puro, o qual servirá para obter o seu índice de refração e a função dielétrica como função do comprimento de onda do feixe incidente. Assim, quando um filme fino for analisado, será possível utilizar a base de dados desse material e obter a espessura e/ou as contribuições das regiões microestruturais em seu volume, através das Eqs. (A.7) e (A.8). 


\section{B. Modelo do Oscilador Harmônico de Lorentz}

Na teoria clássica, o modelo do átomo de Lorentz ${ }^{[70-72]}$ é um dos modelos mais simples utilizados para estudar o comportamento da função pseudo-dielétrica complexa, $\langle\varepsilon\rangle$, de alguns polímeros e semicondutores na presença de um campo eletromagnético não perturbativo, cuja freqüência de oscilação está próxima a uma situação de ressonância do material. Nesse modelo, os átomos de um material são definidos como um átomo de um único elétron oscilando, como uma nuvem eletrônica, em torno de um núcleo positivo fixo (próton) e com uma energia de oscilação proporcional a energia do feixe incidente. Lorentz representou o sistema elétron-núcleo como um oscilador harmônico e, a partir da resolução da equação de movimento de Newton, Eq. (B.1), obteve uma expressão para $\langle\varepsilon\rangle$, Eq. (B.6), representando, satisfatoriamente, o seu comportamento experimental como função da energia do fóton incidente (E), do parâmetro de amortecimento (v) e da amplitude (A) de oscilação, da energia de ressonância $\left(\mathrm{E}_{\mathrm{o}}\right)$ e do valor de $\langle\varepsilon\rangle$ abaixo do intervalo de energia medido, $\varepsilon_{\infty}$. Para isso, ele negligenciou os efeitos magnéticos e assumiu que o centro de massa do átomo não é afetado pelo campo externo, que as interações entre o elétron-núcleo são do tipo massa-mola e as interações dos elétrons com os átomos vizinhos são do tipo dissipativas. Ele calculou o vetor deslocamento da nuvem eletrônica $(\vec{r})$, seguido da polarização induzida, $\vec{P}$, das oscilações da nuvem eletrônica com relação ao núcleo de um átomo e de $\langle\varepsilon\rangle$. A seguir são apresentados os passos para a obtenção da Equação do átomo de Lorentz.

A Eq. (B.1) apresenta a equação do movimento da nuvem eletrônica com relação ao núcleo fixo. Nessa equação, $m$ e $e$ são, respectivamente, a massa e a carga do elétron, $\vec{r}$ o vetor deslocamento do centro de cargas da nuvem em relação ao núcleo, $\kappa$ a constante de mola (lei de Hooke) dada por $\kappa=m\left(\omega_{0}\right)^{2}$, onde $\omega_{0}$ é a frequiência de ressonância eletrônica, $v$ é a constante de amortecimento relacionada as interações da nuvem eletrônica com os seus átomos vizinhos e $\vec{E}_{L o c}=\vec{E}_{0} e^{-i \omega t}$ é o campo óptico local obtido, teoricamente, removendo-se o átomo e colocando-se uma carga de prova no espaço vazio.

$$
m \frac{d^{2} \vec{r}}{d t^{2}}=-e \vec{E}_{l o c}-\kappa \vec{r}-m v \frac{d \vec{r}}{d t}
$$

Assim, a partir da Eq. (B.1), o vetor deslocamento $\vec{r}$ pode ser obtido como: 


$$
\overrightarrow{\mathrm{r}}=\frac{\mathrm{e}}{\mathrm{m}} \overrightarrow{\mathrm{E}}_{\mathrm{Loc}}\left\{\frac{1}{\left(\omega_{0}^{2}-\omega^{2}\right)-\mathrm{i} \nu \omega}\right\}
$$

Assumindo que a nuvem eletrônica oscila com a freqüência do campo $\mathrm{E}$ (um sistema linear), a polarização $\vec{P}$, pode ser determinada por:

$$
\vec{P}=\varepsilon_{0}\left(\varepsilon^{*}-1\right) \vec{E}=N_{a} \vec{p}=-N_{a} e \vec{r}=N_{a} \frac{e^{2}}{m} \vec{E}_{L o c}\left\{\frac{1}{\left(\omega_{0}^{2}-\omega^{2}\right)-i v \omega}\right\}
$$

onde $\mathrm{N}_{\mathrm{a}}$ é a concentração de átomos, $\vec{p}$ o momento de dipolo de cada um desses átomos e $\overrightarrow{\mathrm{E}}$ o campo elétrico macroscópico. Assumindo $\vec{E}=\vec{E}_{L o c}$ na Eq. (B.3), a função dielétrica $\langle\varepsilon\rangle$ é obtida como:

$$
\langle\varepsilon\rangle=1+N_{a} \frac{e^{2}}{m \varepsilon_{0}}\left\{\frac{1}{\left(\omega_{0}^{2}-\omega^{2}\right)-i v \omega}\right\}
$$

Incluindo-se a contribuição de $\langle\varepsilon\rangle$, fora da situação de ressonância e abaixo do intervalo de freqüência medido $\left(\varepsilon_{\infty}\right)$, podemos reescrever a Eq. (B.4) como:

$$
\langle\varepsilon\rangle=\varepsilon_{\infty}\left[1+\frac{N_{a} e^{2}}{m \varepsilon_{0} \varepsilon_{\infty}} \frac{1}{\left(\omega_{0}^{2}-\omega^{2}\right)-i v \omega}\right]
$$

Assim, escrevendo a Eq. (B.5) como função da energia do feixe (E) e de uma constante $A^{2}=\frac{N_{a} \hbar e^{2}}{m \varepsilon_{0} \varepsilon_{\infty}}$, obtemos:

$$
\langle\varepsilon\rangle=\varepsilon_{\infty}\left[1+\frac{A^{2}}{E_{0}^{2}-E(E-i \nu)}\right]
$$

que é a expressão para $\langle\varepsilon\rangle$ do modelo do átomo de Lorentz, onde $A^{2}$ é definida como a amplitude do oscilador $(\mathrm{em} \mathrm{eV}), \mathrm{E}_{0}$ a energia na ressonância, ou energia central do oscilador, e $v$ o parâmetro de amortecimento.

Para ilustrar o comportamento da Eq. (B.6), A Fig. B.1 mostra os componentes real e imaginária da função pseudo-dielétrica obtida com $\mathrm{E}_{0}=3 \mathrm{eV}, A=3,0 \mathrm{eV}, \mathrm{v}=1,2 \mathrm{eV}$ e $\varepsilon_{\infty}=3,6$. 


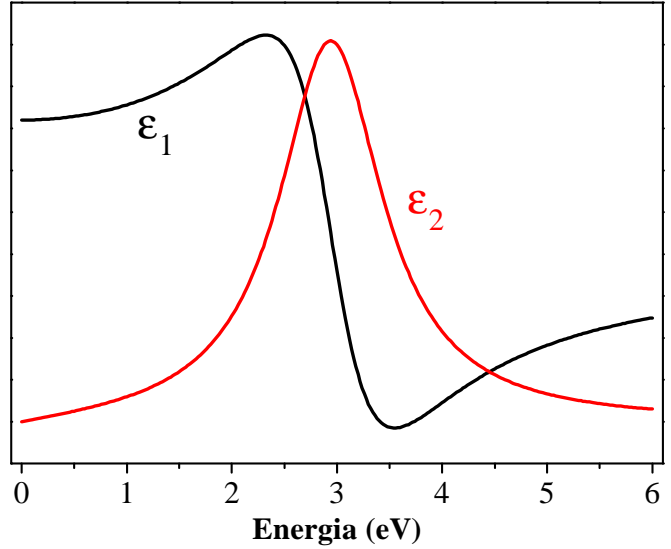

FIGURA B.1: Componentes real e imaginária da função pseudo-dielétrica obtidas com a Eq. (B.6) com $\mathrm{E}_{0}=3 \mathrm{eV}, A=3,0 \mathrm{eV}, \nu=1,2 \mathrm{eV}$ e $\varepsilon_{\infty}=3,6$.

A Fig. B.2 mostra o comportamento dos componentes real e imaginária para o caso em que o valor de $v$ variou de 0,1 a 2, mantendo-se os outros parâmetros fixos. A Fig. A.3 mostra o comportamento das mesmos componentes para o caso do parâmetro $A$ variar de 0,1 a 2, com os outros parâmetros fixos.
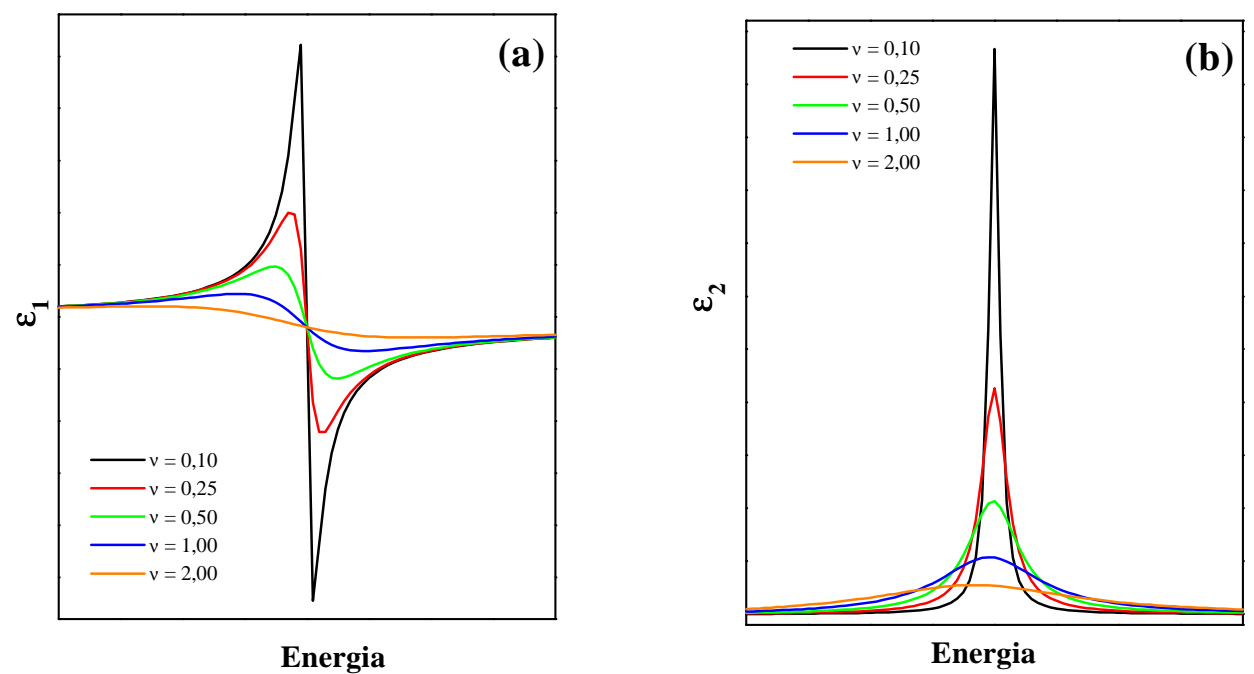

FIGURA B.2: Componentes real e imaginária da função pseudo-dielétrica obtidas com a Eq. (B.6) mantendo-se $\mathrm{E}_{0}=3 \mathrm{eV}, \mathrm{A}=3,0 \mathrm{eV}$ e $\varepsilon_{\infty}=3,6$ fixos e variando-se $v$ de $0,1 \mathrm{a} 2 \mathrm{eV}$. 


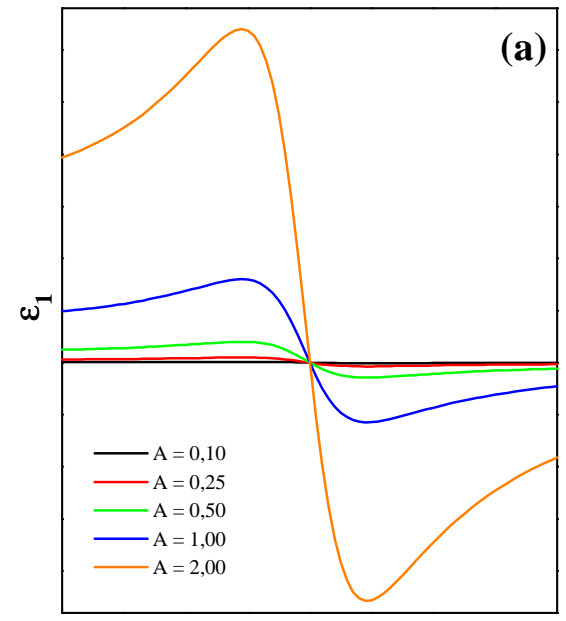

Energia

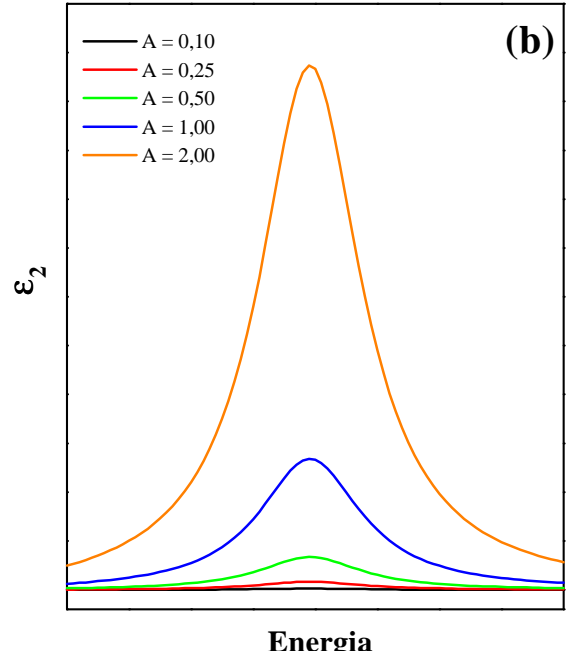

Energia

FIGURA B.3: Componentes real e imaginária da função pseudo-dielétrica obtidas com a Eq. (B.6) mantendo-se $\mathrm{E}_{0}=3 \mathrm{eV}, \varepsilon_{\infty}=3,6 \mathrm{e} v=0,10 \mathrm{eV}$ fixos e variando-se $A$ de $0,1 \mathrm{a} 2 \mathrm{eV}$.

Observe na Fig. B.2 que o aumento de $v$ diminui o valor máximo de $\varepsilon_{1}$ e $\varepsilon_{2}$, enquanto, na Fig. B.3, o aumento de $A$ aumenta esses valores. 


\section{CONSIDERAÇÕES FINAIS}

Agradeço a todos que me ajudaram, direta ou indiretamente, na elaboração deste trabalfio. Muito Obrigado !!! Rodrigo F. Bianchi

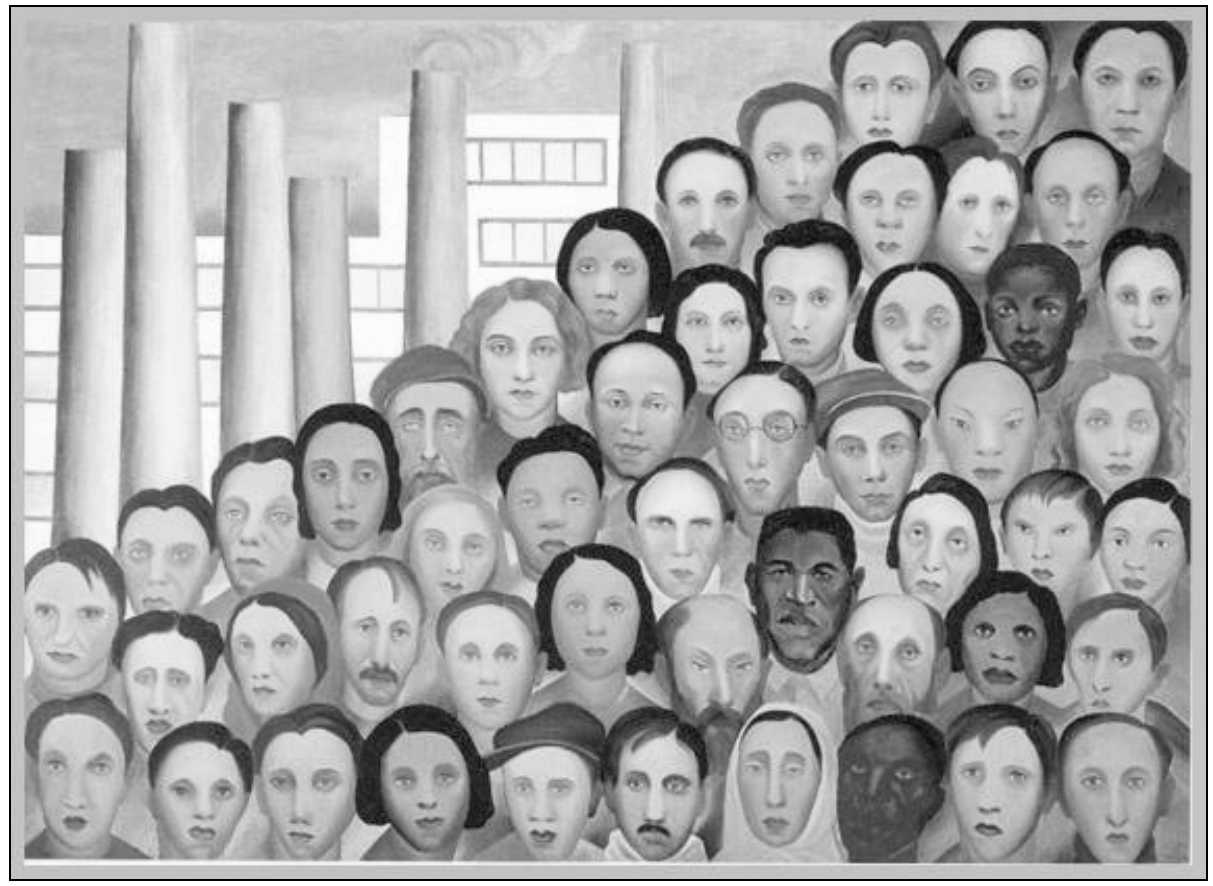

Tela Operários, Tarsila do Amaral (1933). 